\title{
CEZAR SAYÃO
}

\section{FATORES CRÍTICOS DE SUCESSO PARA FERRAMENTAS DE BUSINESS ANALYTICS}

SÃO PAULO

2017 


\section{CEZAR SAYÃO}

\section{FATORES CRÍTICOS DE SUCESSO PARA FERRAMENTAS DE BUSINESS ANALYTICS}

Dissertação apresentada à Universidade de São Paulo para obtenção do título de mestre em ciências

Área de concentração:

Engenharia de produção

Orientador:

Prof. Dr. Renato de Oliveira Moraes 
Este exemplar foi revisado e corrigido em relação à versăo original, sob responsabilidade única do autor e com a anuência de seu orientador.

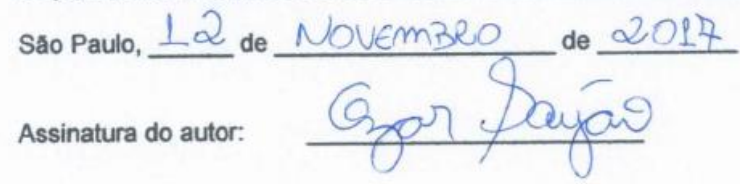

Assinatura do orientador:

\section{Catalogaçăo-na-publicaçăo}

\section{Sayão, Cezar}

FATORES CRITICOS DE SUCESSO PARA FERRAMENTAS DE BUSINESS ANALYTICS / C. Sayăo - versăo corr. -- Săo Paulo, 2017.

$152 \mathrm{p}$.

Dissertaçăo (Mestrado) - Escola Politécnica da Universidade de Săo Paulo. Departamento de Engenharia de Produçăo.

1.Business Analytics 2.Business Intelligence 3.Big Data 4.Processo de tomada de decisâo 5.Modelagem de equaç̋̋es estruturais I.Universidade de São

Paulo. Escola Politécnica. Departamento de Engenharia de Produçăo II.t. 
Dedico esse trabalho a minha família pelo suporte ao longo deste caminho... 


\section{RESUMO}

Atualmente vivemos em uma sociedade com a maior quantidade de dados já disponíveis em toda a história, e ao mesmo tempo que ocorre o crescimento desta vasta quantidade de informações dispersas, os ambientes empresariais tornaram-se cada vez mais complexos e competitivos. Nos quais gestores necessitam detectar e, se possível, prever tendências para estruturar planos de ação através de análises simples e/ou, por vezes, extremamente complexas dos dados.

Dessa forma, o potencial impacto nas organizações referentes à utilização dessas informações em sua gestão tem chamado a atenção tanto de executivos com de pesquisadores

Esta pesquisa buscou identificar os fatores de sucesso de sistemas de Business Analytics (BA) e avaliar empiricamente suas relações de causalidade, sendo utilizada a metodologia de pesquisa científica de Levantamento tipo Survey e a técnica estatística de Modelagem de Equações Estruturais.

Além de contribuir com a expansão do conhecimento relacionado a área de Business Analytics, esta dissertação apresentou uma discussão e proposta de delimitação do conceito de BA frente demais termos relacionados a literatura de sistemas de suporte a decisão (i.e. BI, Big Data e Inteligência Competitiva) e a estruturação de uma ferramenta de mensuração de sucesso de SI de BA baseado no modelo apresentado por Delone e McLean.

Após a delimitação do conceito de BA, foi discutido os fatores críticos de sucesso (FCS) presentes na literatura e suas particularidades frente a sistemas transacionais (e.g. Enterprise Resource Planning). Os quais foram estruturados em 3 dimensões e 4 construtos: Tecnologia (Qualidade dos dados), Cultura organizacional (Gestão Baseada em Fatos e Engajamento dos executivos) e Pessoas (Qualidade da Equipe).

Nesta análise, a Cultura Organizacional apresentou a maior relevância no sucesso de SI (i.e. Uso da Informação e Impacto Individual) dentre as 3 dimensões. Como alta impacto tanto do engajamento dos executivos, como da Cultura organizacional de gestão baseada em fatos.

Palavras-Chave: Business Analytics, Big Data, Business Intelligence, Modelagem de equações estruturais e Processo de tomada de decisão. 


\begin{abstract}
We have never lived in a society with such amount of data available where, at the same time of this dispersed information growth, managers and decision makers are facing the most challenging and competitive business environment they have ever seen. Being necessary to detect and, if it is possible, predict trends based on simple and/or complex data analysis in order to structure action plans.

In this context, the potential impact of data based management on organizations has increased and have been drawing attention of scholars and executives.

This research focused on identify critical success factors of Business Analytics (BA) systems and analyze their causal relationship. It was conducted by survey methodology and the statistical technique selected was structural equation modeling (Partial Least Square).

Besides the contribution to the body of knowledge of Business Analytics field, this dissertation presents a theoretical discussion about BA definition, its relationship with order support decision systems terms often present on literature (i.e. Business Intelligence, Big Data and Competitive Intelligence), and a search tool for information system success based on DeLone and McLean model.

The proposition of critical success factors of Business Analytics systems were based on a comprehensive literature review and were classified into 3 groups and 4 constructs: Technology (Data Quality), Organizational culture (Fact-based management and Executive engagement) and People (Team knowledge and skill).

Organizational Culture showed more relevance on Business Analytics system success (i.e. Information Use and Individual Impact) them Technology and People, with high impact of both constructs (Fact-based management and Executive engagement).
\end{abstract}

Key-words: Business Analytics, Big Data, Business Intelligence, Structural Equation Modeling and Decision making process. 


\section{LISTA DE ABREVIATURAS E SÍLABAS}

AVE AVERAGE VARIANCE EXTRACTED

BA BUSINESS ANALYTICS

BI BUSINESS INTELLIGENCE

BI\&A BUSINESS INTELLIGENCE \& ANALYTICS

BPM BUSINESS PROCESS MANAGEMENT

BPO BUSINESS PROCESS ORIENTATION

CIO CHIEF INFORMATION OFFICER

CEO CHIEF EXECUTIVE OFFICER

COGB CULTURA ORGANIZACIONAL DE GESTÃO BASEADA EM FATOS

DBMS DATA BASE MANAGEMENT SYSTEM

DSS DECISION SUPPORT SYSTEMS

ETL EXTRACTION, TRANSFORMATION AND LOAD

FCS FATORES CRÍTICOS DE SUCESSO

HTMT HETEROTRAIT-MONOTRAIT RATIO

IC INTELIGÊNCIA COMPETITIVA

IE INTELIGÊNCIA ECONÔMICA

OLAP ONLINE ANALYTICAL PROCESSING

OM OPERATIONS MANAGEMENT

P\&D PESQUISA E DESENVOLVIMENTO

RBV RESOURCE-BASED VIEW

RDMS RELATIONAL DATABASE MANAGEMENT SYSTEMS 
SI SISTEMAS DE INFORMAÇÃO

SEM STRUCTURED EQUATION MODEL

TI TECNOLOGIA DA INFORMAÇÃO

VIF VARIANCE INFLATION FACTOR 


\section{LISTA DE FIGURAS}

Figura 1 - Evolução de publicações sobre Business Analytics - Agosto/2016................... 18

Figura 2 - Evolução das publicações Web of Science e Scopus ......................................23

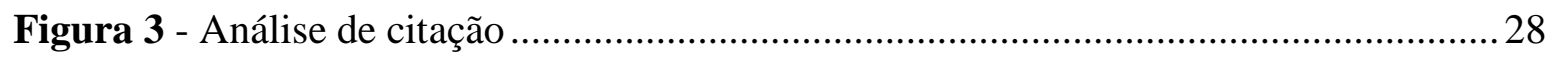

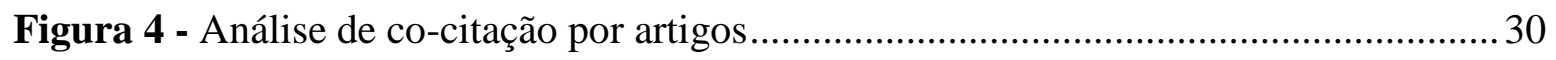

Figura 5 - Rede de citações de palavras chave ................................................... 31

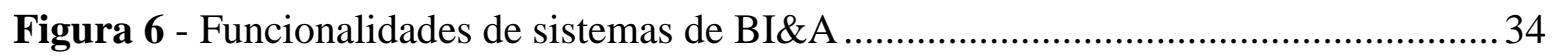

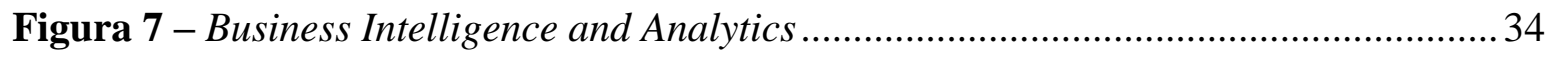

Figura 8 - Business Analytics Framework ............................................................... 40

Figura 9 - Áreas de conhecimento do Business Analytics ......................................... 41

Figura 10 - Hierarquia entre BI, BA e Big Data.................................................... 47

Figura 11 - Processo de Inteligência Competitiva.......................................................... 48

Figura 12 - Modelo de Inteligência Competitiva....................................................50

Figura 13 - Categorias Sistemas de Informação.......................................................58

Figura 14 - Modelo de sucesso de SI ................................................................59

Figura 15 - Áreas de conhecimento relacionadas à engenharia de produção .................... 68

Figura 16 - Etapas de execução de um levantamento tipo survey explanatória ................. 73

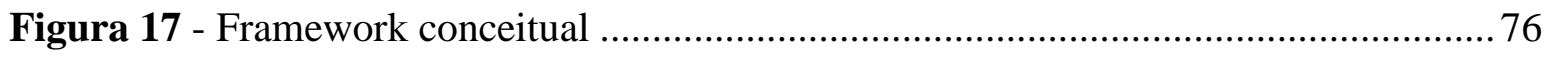

Figura 18 - Cálculo do tamanho da amostra no software G*Power............................... 86

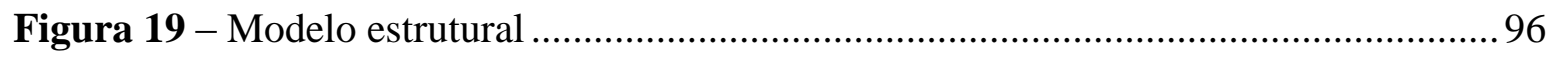

Figura 20 - Evolução das respostas .................................................................... 97

Figura 21 - Funcionalidades presentes no sistema.............................................. 101

Figura 22- Características pessoais dos respondentes ........................................... 102 
Figura 23 - Características profissionais dos respondentes ...................................... 103

Figura 24 - Interação dos respondentes com o sistema ............................................ 104

Figura 25 - Significância, Relevância e Coeficiente de determinação .............................. 109

Figura 26 - Framework conceitual (Confirmação de hipóteses) ................................... 117 


\section{LISTA DE TABELAS}

Tabela 1 - Palavras-Chave utilizadas na pesquisa de artigos .........................................22

Tabela 2 - Ranking de revistas científicas .............................................................. 24

Tabela 3 - Autores com maior número de artigos .................................................... 25

Tabela 4 - Artigos com maior volume de citações ...................................................... 27

Tabela 5 - Autores com maior relevância na rede de co-citações .................................... 29

Tabela 6 - Artigos com maior relevância na rede de co-citações ................................... 30

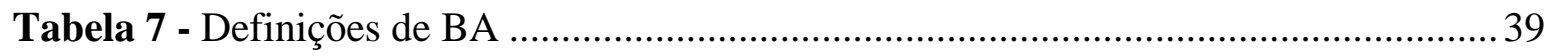

Tabela 8 - Correntes teóricas Business Analytics...................................................... 44

Tabela 9 - Terminologia para o uso e a análise de dados ...............................................46

Tabela 10 - Diferenças entre Big Data e Analytics ...................................................... 46

Tabela 11 - Revisão bibliográfica sobre FCS de BI ...............................................52

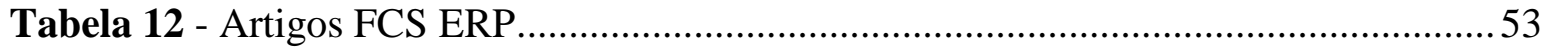

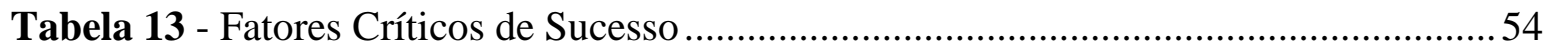

Tabela 14 - Fatores Críticos de Sucesso Implantação ERP ..........................................55

Tabela 15- Comparação entre FCS de sistemas ERP e BA ...........................................56

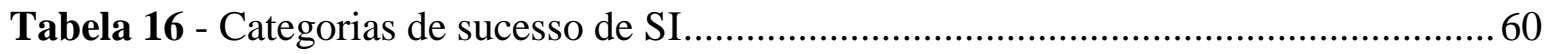

Tabela 17- Classificação metodológica da dissertação ..................................................73

Tabela 18 - Ferramenta de operacionalização da Qualidade do sistema ..........................78

Tabela 19 - Ferramenta de operacionalização do construto da Qualidade da informação .. 79

Tabela 20 - Ferramenta de operacionalização do construto Uso da informação .................80

Tabela 21 - Ferramenta de operacionalização do construto Satisfação do usuário .............80

Tabela 22 - Ferramenta de operacionalização do construto Impacto Individual................81 
Tabela 23 - Ferramenta de operacionalização do construto da Qualidade dos dados 82

Tabela 24 - Ferramenta de operacionalização do construto Engajamento dos executivos.. 83

Tabela 25 - Ferramenta de operacionalização do construto Cultura Organizacional ..........83

Tabela 26 - Ferramenta de operacionalização do construto Cultura Organizacional ..........84

Tabela 27 - Análises Multivariada de Dados............................................................. 88

Tabela 28 - Código dos construtos .................................................................... 94

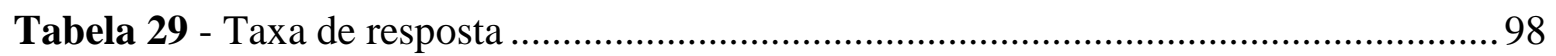

Tabela 30 - Questionários incompletos............................................................ 98

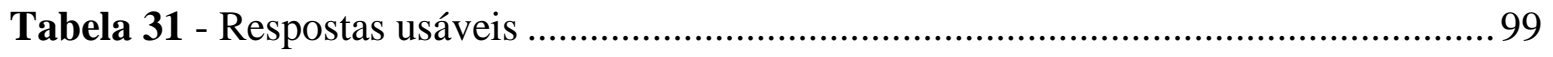

Tabela 32 - Resultados modelo de mensuração (Rodada 1) ......................................... 106

Tabela 33 - Resultados modelo de mensuração (Rodada 2) ........................................... 107

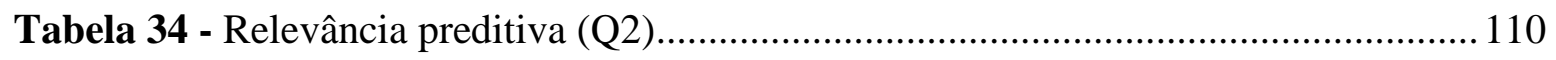

Tabela 35 - Análise de significância e relevância (Qualidade dos dados) ....................... 111

Tabela 36- Análise de significância e relevância (Qualidade do Sistema)........................ 112

Tabela 37 - Análise de significância e relevância (Qualidade da Informação) ................. 113

Tabela 38 - Análise de significância e relevância (Cultura Organizacional) .................... 114

Tabela 39 - Análise de significância e relevância (Uso da Informação) .......................... 115

Tabela 40 - Análise de significância e relevância (Satisfação do usuário)....................... 115

Tabela 41 - Análise de significância e relevância (Impacto Individual) .......................... 116

Tabela 42 - Análise de Cross-Loadings (Rodada 1) .................................................. 142

Tabela 43 - Análise de Fornell-Lacker (Rodada 1) .................................................... 143

Tabela 44 - Análise de HTMT .......................................................................... 144

Tabela 45 - Análise de significância HTMT (Rodada 1) ............................................ 145

Tabela 46 - Análise de Cross-Loadings (Rodada 2) ................................................... 146 
Tabela 47 - Análise de Fornell-Lacker (Rodada 2) ................................................. 147

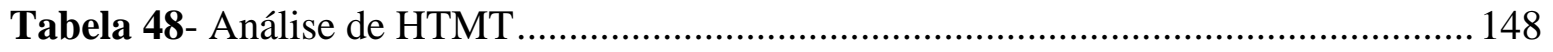

Tabela 49 - Análise de significância HTMT (Rodada 2) ............................................. 149

Tabela 50 - Análise de colinearidade......................................................................... 150

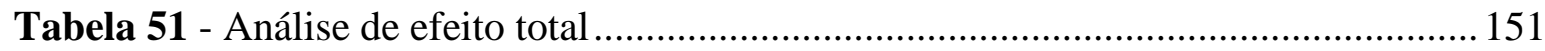

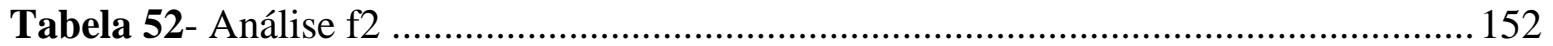




\section{SUMÁRIO}

1 Introdução ............................................................................................................................. 17

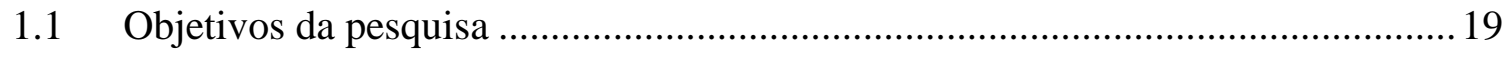

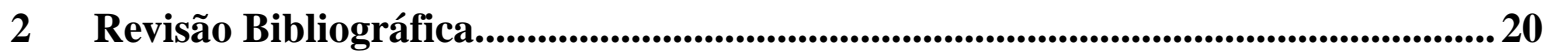

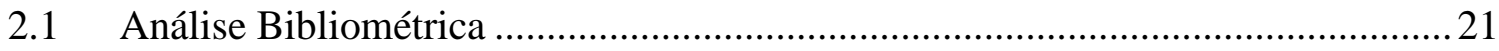

2.1.1 Dados das publicações ..............................................................................22

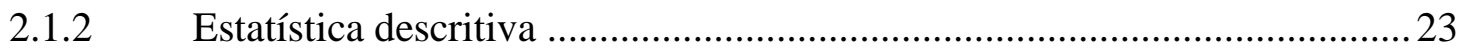

2.1.3 Análise de citação e co-citação ………………………………………......28

2.2 Revisão da literatura .................................................................................... 32

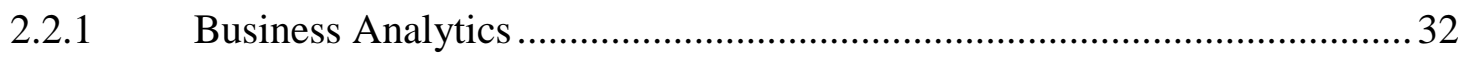

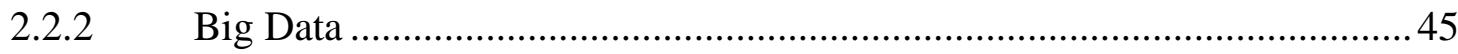

2.2.3 Inteligência Competitiva ........................................................................ 47

2.2.4 Fatores Críticos de Sucesso ……………………...................................

2.2.4.1 Comparação entre FCS de sistemas ERP e BI ........................................52

2.2.5 Modelos de sucessos de sistemas de informação...........................................57

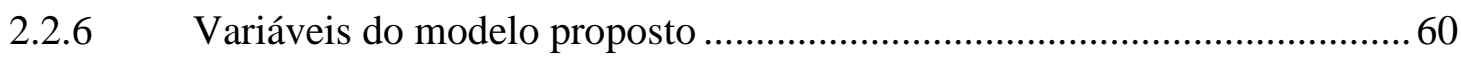

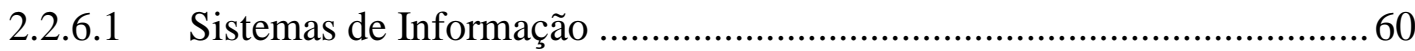

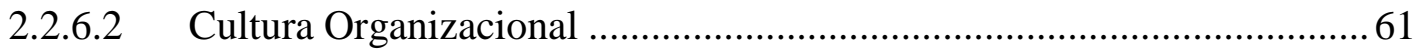

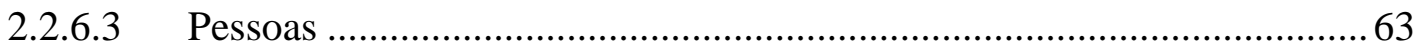

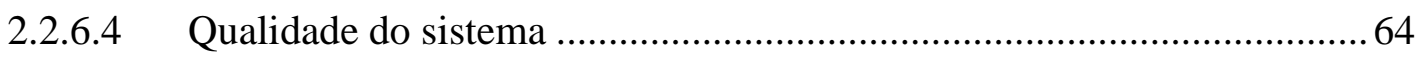

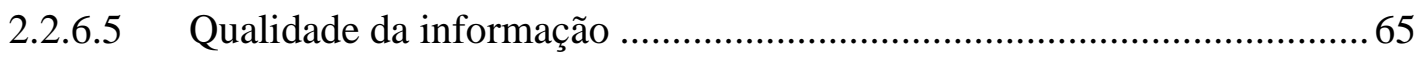

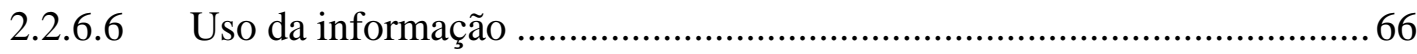

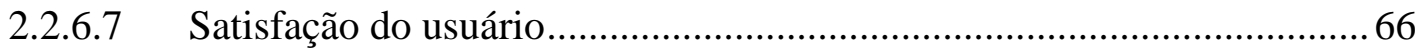

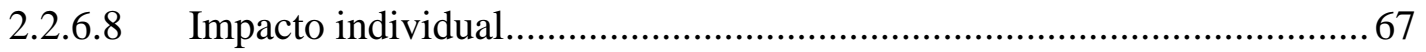

3 Metodologia.............................................................................................................................. 68

3.1 Levantamento tipo Survey .......................................................................... 71

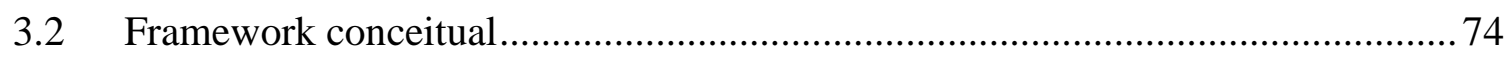

3.2.1 Operacionalização dos construtos .............................................................. 77

3.2.1.1 Modelo de sucesso de Sistemas de Informação .......................................... 77

3.2.1.1.1 Qualidade do sistema ......................................................................... 77

3.2.1.1.2 Qualidade da informação .................................................................. 78

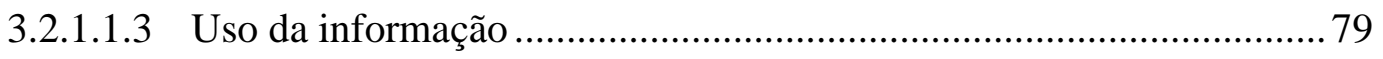

3.2.1.1.4 Satisfação do usuário ........................................................................... 80 


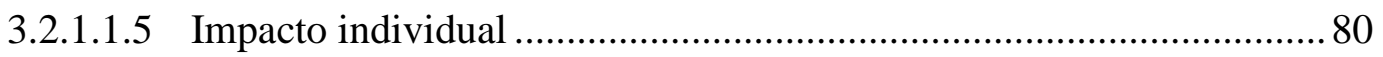

3.2.1.2 Construtos para Fatores críticos de sucesso de BA.................................... 81

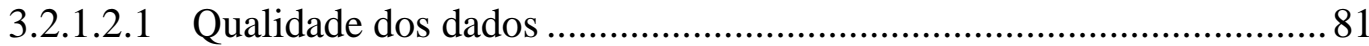

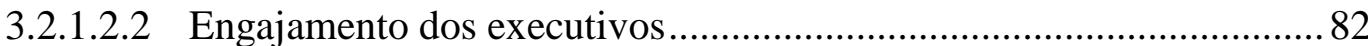

3.2.1.2.3 Cultura Organizacional de Gestão Baseada em Fatos ............................ 83

3.2.1.2.4 Qualidade da equipe de BA .............................................................. 83

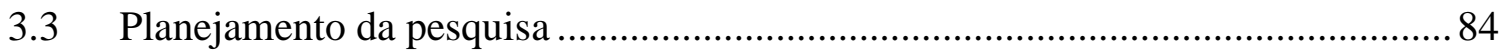

3.3.1 Definição da população e amostra ................................................................ 84

3.3.2 Método de coleta de dados......................................................................... 86

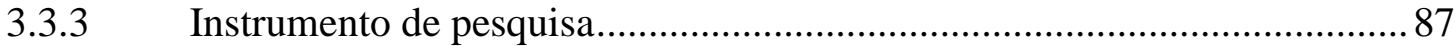

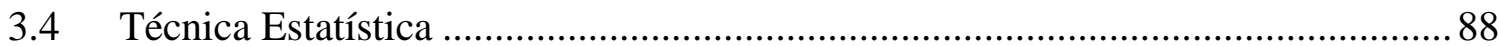

3.4.1 Análise multivariada de dados: SEM-PLS …............................................. 88

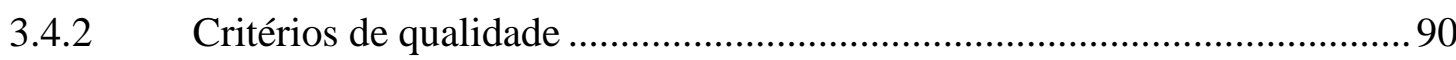

3.4.2.1 Modelo de mensuração............................................................................90

3.4.2.1.1 Consistência interna .........................................................................99

3.4.2.1.2 Validação de convergência ................................................................ 91

3.4.2.1.3 Validação discriminatória ...................................................................91

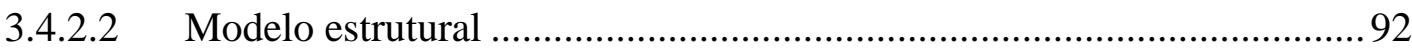

3.4.2.2.1 Análise de colinearidade .................................................................92

3.4.2.2.2 Significância e Relevância das relações estruturais..............................92

3.4.2.2.3 Avaliação do coeficiente de determinação $\left(\mathrm{R}^{2}\right)$...................................93

3.4.2.2.4 Avaliação do efeito do tamanho no coeficiente de determinação $\left(\mathrm{f}^{2}\right) 93$

3.4.2.2.5 Análise de relevância preditiva (Q2) ...................................................93

3.5 Estruturação do modelo em estudo .......................................................................94

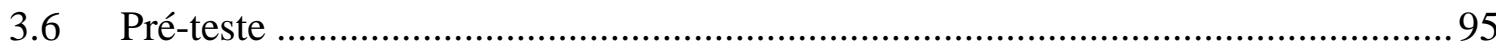

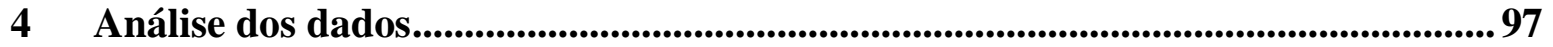

4.1 Caracterização da amostra ..................................................................................97

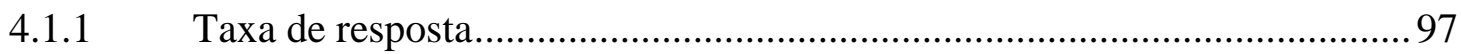

4.1.1.1 Questionários incompletos ...............................................................98

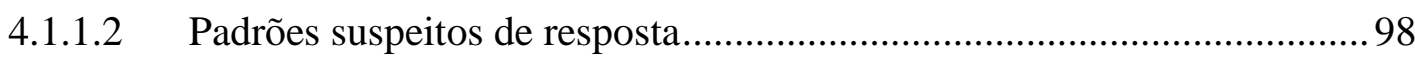

4.1.1.3 Restrição de público alvo .......................................................................99

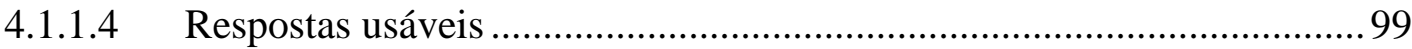

4.1.2 Caracterização dos respondentes ...............................................................99 


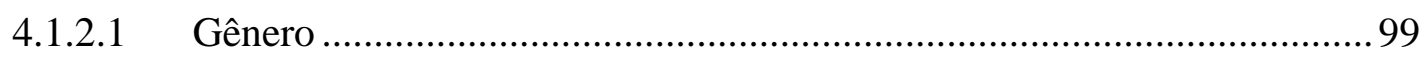

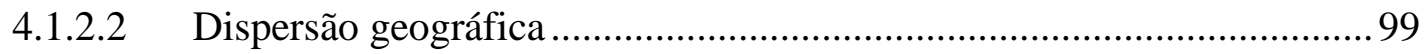

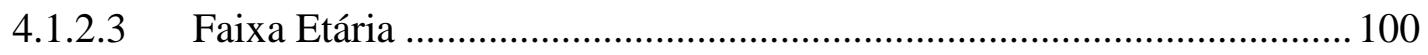

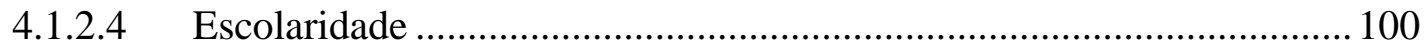

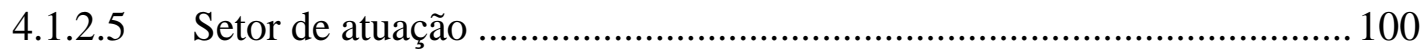

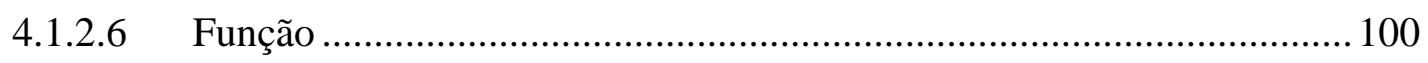

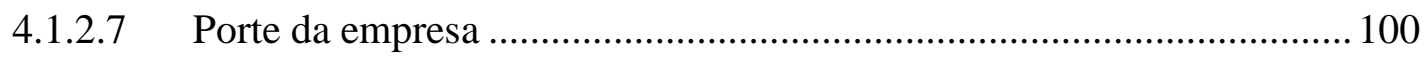

4.1.2.8 Interação com o sistema ...................................................................... 100

4.1.2.9 Funcionalidades do sistema............................................................. 100

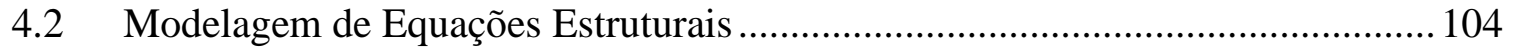

4.2.1 Análise do modelo de mensuração ……………………………………..... 104

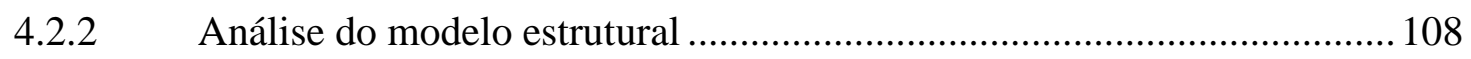

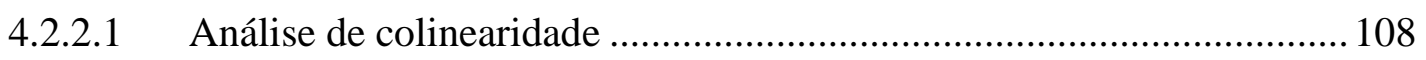

4.2.2.2 Significância e Relevância dos coeficientes de caminho ......................... 108

4.2.2.3 Avaliação do coeficiente de determinação $\left(\mathrm{R}^{2}\right)$.................................... 109

4.2.2.4 Avaliação do efeito do tamanho no coeficiente de determinação $\left(\mathrm{f}^{2}\right) \ldots 109$

4.2.2.5 Análise de relevância preditiva $\left(\mathrm{Q}^{2}\right)$.................................................... 110

4.2.3 Análise do framework conceitual proposto ………….............................110

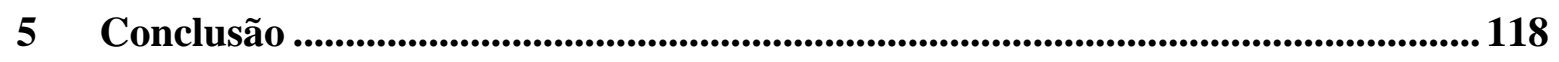

5.1 Limitações e oportunidades de pesquisa......................................................... 119

5.2 Considerações finais ....................................................................................... 120

6 Referência bibliográfica................................................................................................ 121

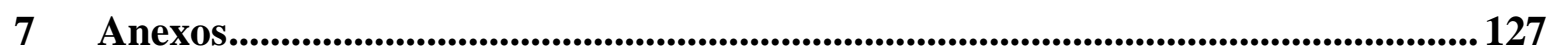

7.1 E-mail de solicitação de participação .................................................................. 127

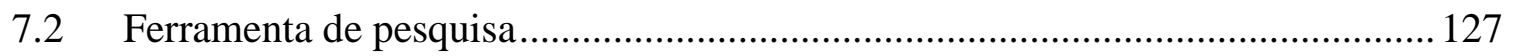

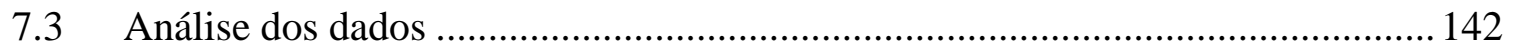




\section{Introdução}

Atualmente vivemos em uma sociedade com a maior quantidade de dados já disponíveis em toda a história, na qual estima-se que existam 2,7 Zettabytes de dados no mundo. Valor equivalente ao armazenamento de 200 bilhões de filmes HD (O`HAIR; BERTSIMAS, 2015).

Sistemas computacionais atualmente geram 15 Petabytes de novas informações todos os dias, o que representa oito vezes mais informação que todas as bibliotecas dos Estados Unidos (CHIANG et al., 2012).

Ao mesmo tempo que ocorre o crescimento desta vasta quantidade de informações dispersas, os ambientes empresariais tornaram-se cada vez mais complexos e competitivos, nos quais os gestores necessitam detectar e, se possível, prever tendências para estruturar planos de ação (VIAENE; BUNDER, 2011), através de análises simples e, por vezes, extremamente complexas dos dados (BARTLETT, 2013)

O potencial impacto na empresa, e em sua forma de condução, referentes à utilização dessas informações na gestão das empresas tem chamado a atenção tanto de executivos com de pesquisadores (VIAENE; BUNDER, 2011; DAVENPORT, 2014; CHEN; STOREY; CHIANG, 2012).

Dessa forma, os autores Davenport e Harris (2007) definem o termo Business Analytics (BA) como sendo:

"A utilização extensiva de dados, estatística e análises quantitativas, em modelos exploratórios e preditivos e na gestão baseada em fatos para o direcionamento de ações e decisões. O Analytics pode ser input para as decisões humanas ou direcionar decisões completamente automatizadas"

Segundo Damiani (2004), todas as organizações ao longo da história têm como característica inerente à sua atividade a geração de dados. Porém, o grande diferencial entre as instituições do passado para as atuais está no crescimento cada vez mais acelerado dessa capacidade.

A relevância do tema nas organizações também é enfatizada na pesquisa realizada por Heudecker e Kart (2014), na qual mais de $73 \%$ das organizações consultadas realizaram ou pretendem realizar investimentos na área de Business Analytics (BA) no horizonte de 2 anos. Sendo esse um dos temas mais relevantes na visão dos CIO de grandes empresas (HOLSAPPLE; LEE-POST; PAKATH, 2014; VIAENE; BUNDER, 2011), e uma das principais tendências em tecnologia da informação na atualidade (HOWARD et al., 2012).

$\mathrm{Na}$ academia, sua importância pode ser constatada pela popularização de cursos referentes a BA nas universidades e pelo crescente número de publicações ano longos dos últimos anos, porém ainda em volume restrito (HOLSAPPLE et al.; 2014; MORTENSON et al., 2015; CHEN et al., 2012).

A relevância do tema nas universidades e a necessidade da formação de profissionais é materializada no depoimento de Hal Varian, professor da universidade da Califórnia (Berkley) e executivo da Google (DUBNER; STEVEN, 2008):

"O que está se tornando ubíquo e barato? Dados. E o que é complementar aos dados? Análises. Portanto, minha recomendação é fazer vários cursos 
sobre como manipular e analisar dados: Banco de dados, aprendizado de máquina, econometria, estatística, visualização, dentre outros".

A Figura 1 apresenta a evolução de publicações sobre o tema Business Analytics (BA) ao longo da última década. Para essa análise, foi utilizada a base da coleção principal do ISI Web of Knowledge, da Thomson Reuters, na qual foram selecionados artigos com a palavrachave "Business Analytics" ou "Analytics". E restringido as áreas de conhecimento de Operations Research Management Science e Business Economics.

\section{Evolução de publicação de artigos}

\section{Business Analytics}

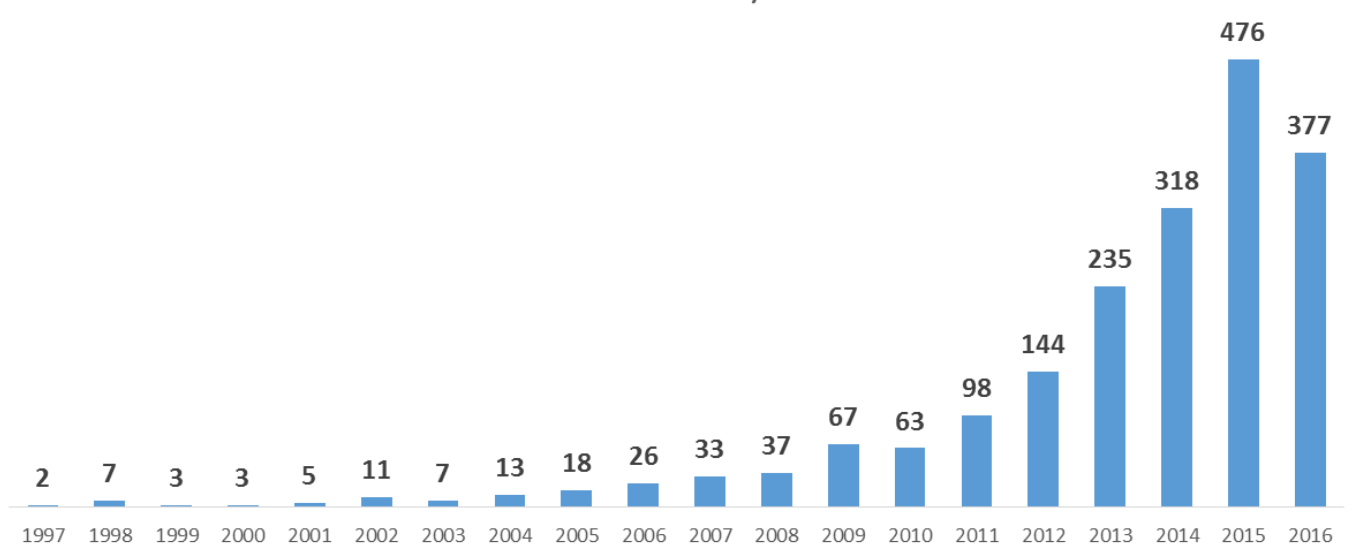

Figura 1 - Evolução de publicações sobre Business Analytics - Agosto/2016

Fonte: ISI Web of Science

A partir dessa análise é possível observar o crescimento expressivo de publicações nos últimos 5 anos, o que reforça a tendência de crescimento de pesquisas nessa área do conhecimento.

Apesar do crescente volume de publicações ainda há um restrito número de artigos, em especial na área de gestão de operações (Operations Management), frente a relevância do tema (MORTENSON et al., 2015).

Dentre as obras analisadas, também é possível constatar uma concentração em temas referentes a técnicas matemáticas e computacionais para a estruturação de ferramentas de BA, o que forma uma lacuna de estudos sobre os desafios de execução e sucesso de sistemas de Business Analytics sob a ótica de gestão e utilização das informações no processo decisório dos executivos. Visão essa alinhada com Viaene e Bunder (2011), os quais afirmam que o BA é uma área relativamente nova na qual as empresas ainda apresentam deficiências na sua incorporação aos processos atuais de gestão.

Conforme apresentado por Mortenson et al. (2015) em sua pesquisa bibliográfica, BA é um tema multidisciplinar e composto por distintas áreas de conhecimento. Os autores Trkman et al. (2010) também corroboram com essa visão afirmando que BA não é apenas uma tecnologia, mas sim um conjunto de abordagens, procedimentos operacionais e ferramentas.

Portanto, a análise sobre os fatores críticos de sucesso de ferramentas de Business Analytics deve apresentar uma abordagem multidisciplinar, cobrindo os desafios das áreas de conhecimento envolvidas no processo. 
Conforme apontado por Mortenson et al. (2015), também não há consenso sobre a definição de BA. Dessa forma a presente pesquisa tem como objetivo delimitar os conceitos de BA e analisar os fatores determinantes de sucesso (abordados neste trabalho como fatores críticos de sucesso - FCS) para a implantação de ferramentas dessa categoria.

O mapeamento destes fatores foi conduzido através da revisão bibliográfica sobre Business Analytics para o entendimento das peculiaridades deste tipo de ferramenta, e da análise de modelos existentes de mensuração de sucesso de sistemas de informação.

Com base nestas duas frentes teóricas e nos respectivos fatores críticos mapeados, foi estruturado um modelo de causalidade e uma ferramenta de mensuração de sucesso de SI de BA baseado no modelo de sucesso de sistemas de informação de Delone e McLean (1992).

Dessa forma, além de expandir o conhecimento relacionado a área de Business Analytics e validar os fatores de causalidade, o trabalho também apresenta como contribuição a estruturação de uma ferramenta de mensuração de sucesso para esse tipo de sistema.

\subsection{Objetivos da pesquisa}

Conforme discussão apresentada anteriormente, este trabalho busca responder a seguinte pergunta de pesquisa:

"Quais os fatores críticos de sucesso de sistemas de Business Analytics?"

Na sequência são apresentados como desdobramento da pergunta pesquisa os objetivos gerais e específicos desta dissertação.

\section{Objetivo geral}

\section{Avaliar os fatores críticos de sucesso de sistemas de Business Analytics}

Como parte do desdobramento do objetivo geral de pesquisa, foram propostos os seguintes objetivos específicos:

Adotar uma definição de BA, bem com seu posicionamento frente outros conceitos correlatos (e.g. Business Intelligence, Big Data e Inteligência Competitiva)

Adotar definições para os construtos Qualidade de dados, Engajamento dos executivos, Cultura organizacional e Qualidade da equipe para o contexto de sistemas de Business Analytics;

Adotar definições dos construtos Qualidade da informação, Qualidade do sistema, Uso da informação, Satisfação do Usuário e Impacto Individual referentes ao modelo de análise de sucesso de SI apresentados por DeLone e McLean (1992) para o contexto de sistemas de Business Analytics;

Estruturar instrumento para mensuração de sucesso de sistemas de Business Analytics;

Analisar a relação entre os construtos apresentados anteriormente;

Na sequência será apresentada uma análise bibliométrica e uma revisão bibliográfica sobre Business Analytics no capítulo 2 - Revisão Bibliográfica, o qual será utilizado como fundamentação teórica para a proposição no capítulo 3 - Metodologia dos fatores críticos de sucesso de sistemas BA, bem como as hipóteses de causalidade entre os construtos. 


\section{Revisão Bibliográfica}

Segundo Boote e Beile (2005), a revisão bibliográfica é a base para a estruturação de um trabalho científico e afirmam que um pesquisador não pode realizar um trabalho relevante sem primeiramente entender o conhecimento (teoria) previamente existente do campo de estudo. Esse ponto também é reforçado por Randolph (2009) e Miguel (2007), que apontam a relevância dessa etapa da pesquisa na condução do trabalho.

Para Lakatos e Marconi (2003), teoria é um conjunto de princípios fundamentais que constituem um instrumento científico apropriado na procura e principalmente na explicação dos fatos. Dessa forma, sob o aspecto científico a teoria se refere as relações e a ordenação significativa desses fatos, consistindo em conceitos, classificações, correlações, generalizações, princípios, leis, regras, teoremas, axiomas etc.

De forma similar, Sutton e Staw (2007) afirmam que a teoria aborda as conexões entre o fenômeno, uma história sobre a razão de atos, eventos, estruturas e pensamentos. Ela realça a natureza das relações causais, identificando temporalmente a ocorrência dos eventos. Os mesmos autores sinalizam a falta de consenso na academia sobre a definição de teoria, e elencam o que não pode ser considerado, por si só, teoria: Referências bibliográficas, Dados, Variáveis, Diagramas e Hipóteses.

Miguel et al. (2012) destacam os principais papéis da teoria nas pesquisas científicas, sendo eles:

- Orientar os objetivos e restringir a amplitude dos fatos a serem estudados;

- Servir como sistema de conceptualização e de classificação dos fatos;

- Resumir o conhecimento sobre o objeto de estudo por meio de generalizações empíricas e das inter-relações entre afirmações comprovadas;

- Prever novos fatos e indicar lacunas de conhecimento;

Nesse capítulo serão explorados os conceitos apresentados na literatura sobre Business Analytics, bem como as características e fatores críticos de sucesso na implantação de sistemas de informação (SI) dessa natureza.

A revisão bibliográfica foi estruturada inicialmente através de uma pesquisa bibliométrica, que tem o intuito de analisar as principais referências e linhas de pesquisa sobre Business Analytics. Após esse mapeamento inicial, as obras e conceitos relevantes para esse estudo foram exploradas com o intuito de mapear as áreas de conhecimento envolvidas e os fatores críticos de sucesso na implementação de ferramentas de BA presentes na bibliografia atual.

Também será apresenta uma discussão sobre o posicionamento dos termos Business Intelligence, Big data e Inteligência Competitiva frente ao Business Analytics, de forma a delimitar o conceito de BA para este estudo.

Para a elaboração do instrumento de pesquisa será explorado o tema de modelos de mensuração de sistemas de informação, o qual será utilizado como direcionador para a estruturação do framework e instrumento de pesquisa. 


\subsection{Análise Bibliométrica}

A bibliometria é uma técnica quantitativa e estatística de medição dos índices de produção e disseminação do conhecimento científico que surgiu no início do século 20 como sintoma da necessidade do estudo e da avaliação das atividades de produção e comunicação científica (ARAÚJO, 2006). Ela permite estudar de forma exaustiva um domino ou campo do conhecimento mediante a identificação das principais correntes de estudo e sua evolução no tempo, assim como os vazios existentes e oportunidades de pesquisa futuras.

Em seu trabalho, Macias-Chapula (1998) define a bibliométrica como:

“(...) o estudo dos aspectos quantitativos da produção, disseminação e uso da informação registrada. Usada pela primeira vez por Pritchardo em 1969, a bibliometria desenvolve padrões e modelos matemáticos para medir esses processos, usando seus resultados para elaborar previsões $e$ apoiar tomadas de decisão"

Sua estrutura possui três leis fundamentais (ARAÚJO, 2006; NEVES et. al., 2011), sendo a primeira delas relacionada a produtividade científica dos autores (Lei de Lotka -1926), a qual afirma que grande parte da publicação científica é produzida por um restrito número de autores.

A segunda lei, sendo ela conhecida como lei da dispersão (Lei de Bradford - 1934), está relacionada com a produtividade dos periódicos e permite mediante a medição da produtividade das revistas identificar o núcleo e as áreas de dispersão sobre um determinado assunto em um mesmo conjunto de revistas. Dessa forma, é possível encontrar em um pequeno núcleo de periódicos uma grande quantidade de artigos referentes a um específico tema, e ao afastar-se desse núcleo a representatividade de artigos relacionados a essa área de pesquisa diminui.

O autor Araújo (2006) descreve a lei da dispersão da seguinte forma:

“...se dispormos periódicos em ordem decrescente de produtividade de artigos sobre um determinado tema, pode-se distinguir um núcleo de periódicos mais particularmente devotados a tema e vários grupos ou zonas que incluem o mesmo número de artigos que o núcleo, sempre que o número de periódicos existentes no núcleo e nas zonas sucessivas seja de ordem de 1: n: $n 2$ n3..."

A terceira das leis bibliométricas clássicas é a lei do menor esforço (Lei de Zipf - 1949), a qual define que existe uma tendência de economia do uso de palavras pelos autores e, dessa forma as palavras mais usadas indicam o assunto do documento.

Araújo (2006) destaca alguns indicadores populares na análise de publicação científica, dentre eles:

- Número de trabalhos: Quantidade de produtos científicos (e.g. livros, artigos, publicações científicas, relatórios, etc) estratificado por tipos de documentos. A 
dinâmica da pesquisa em um determinado país pode ser monitorada e sua tendência traçada ao longo do tempo;

- Número de citações: Quantidade de citações referentes a uma produção científica. Reflete o impacto dos artigos ou assuntos citados;

- Co-autoria: Grau de colaboração entre cientistas no desenvolvimento de suas produções acadêmicas;

Neves et al. (2011) destaca duas técnicas frequentemente utilizadas em análises bibliométricas, sendo elas a análise de citação e de cocitação.

"A análise de citação baseia-se na premissa de que autores citam artigos que consideram importantes no desenvolvimento de suas pesquisas. Já a análise de cocitação de artigos registra o número de artigos que citaram qualquer par de documentos e é entendida como uma similaridade do conteúdo desses dois registros."

A utilização dessas análises e indicadores para o entendimento da área de conhecimento de Business Analytics serão explorados no tópico 2.1.3 Análise de citação e co-citação.

\subsubsection{Dados das publicações}

Para a análise foram utilizadas as bases de dados ISI Web of Knowledge da Thomson Reuters e Scopus da Elsevier. Sendo selecionadas por sua abrangente coleção de trabalhos científicos, a qual consolida publicações dos principais jornais da área de Operations Management.

Conforme apresentado anteriormente, não há consenso na academia sobre o conceito de Business Analytics. Dessa forma esta pesquisa bibliográfica foi estruturada de forma abrangente considerando os conceitos de Business Analytics, Big Data, Business Intelligence e Inteligência competitiva no levantamento inicial das publicações, os quais posteriormente foram classificados de acordo com sua aderência ao conceito de BA apresentado por Davenport e Harris exposto no capítulo 1- Introdução. A comparação e posicionamento sobre estes conceitos será explorada no capítulo 2.2 - Revisão da literatura.

As pesquisas nas bases de dados (ISI Web of Knowledge e Scopus) foram realizadas através da busca por título, nas quais os resultados apresentam todos os registros que contenham o termo pesquisado (palavra-chave) em seu referente título (REUTERS, 2014). As palavraschave utilizadas estão apresentadas na Tabela 1, sendo a procura realizada pela expressão exata e não foram consideradas distinções entre letras maiúsculas e minúsculas entre os tópicos de busca.

Tabela 1 - Palavras-Chave utilizadas na pesquisa de artigos Fonte: Elaborado pelo autor

\begin{tabular}{|l|}
\hline Palavras-chave \\
\hline Business Analytics \\
\hline Analytics \\
\hline Big Data \\
\hline Competitive Intelligence \\
\hline Business Intelligence \\
\hline
\end{tabular}


Os resultados iniciais das pesquisas foram restritos para textos do tipo artigo em idioma inglês, e posteriormente limitados as áreas de pesquisa referentes à administração e gestão de operações (i.e. Scopus - Business, Management and Accountin e Decision Science; ISI Web of Knowledge - Business Economics e Operations Research Management Science). Sendo estes selecionados pelo objetivo do trabalho apresentado anteriormente, o qual tem o intuito de delimitar os conceitos de BA e analisar os fatores críticos de sucesso para a implantação de ferramentas desta natureza.

A partir desta lista de trabalhos, a seleção dos artigos foi refinada com base na aderência de seu tema com o objetivo da pesquisa. Esta seleção ocorreu através da leitura de seus títulos e, se necessário, dos resumos dos trabalhos. Ao total, foram selecionados 567 artigos entre as duas bases de dados.

\subsubsection{Estatística descritiva}

A Figura 2 apresenta a distribuição temporal referente a data de publicação dos artigos selecionados na base. O resultado é similar ao apresentado capítulo 1- Introdução, no qual há uma clara tendência de crescimento ao longo dos últimos 5 anos, o que reforça a relevância do tema de pesquisa.

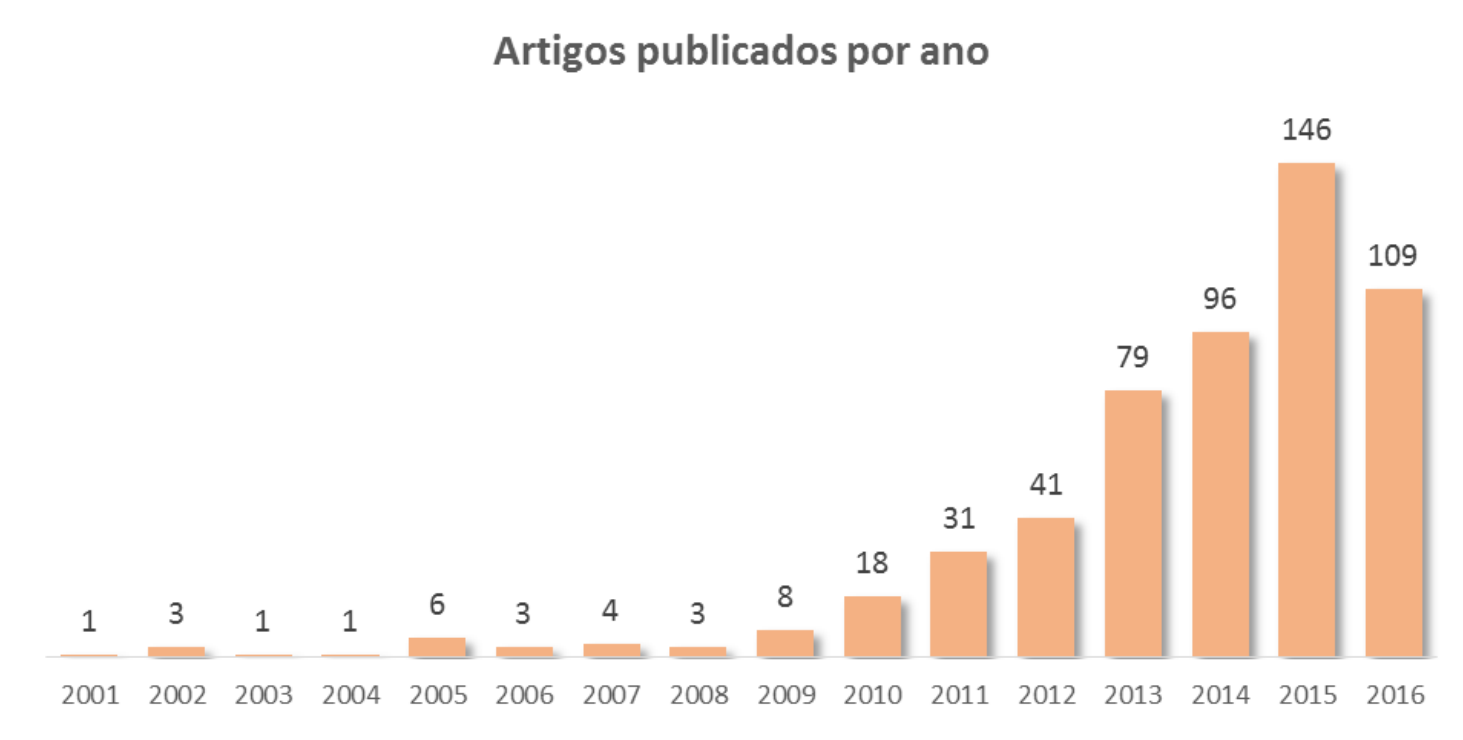

Figura 2 - Evolução das publicações Web of Science e Scopus Fonte: Elaborado pelo autor

Dentre as revistas científicas com maior número de publicações da base de dados selecionada, destaca-se IBM Data Management Magazine pela sua representatividade de 7\% dos artigos selecionados. Este jornal internacional apresenta artigos publicados de diversas áreas de conhecimento como: Big Data, Data Warehousing e Business Analytics. A Tabela 2 apresenta um resumo das revistas com maior número de publicação e sua respectiva representatividade na base de dados. 
Tabela 2 - Ranking de revistas científicas

Fonte: Elaborado pelo autor

\begin{tabular}{clrc} 
& \multicolumn{1}{c}{ Revista Científica } & Ocorrências & $\%$ \\
\hline 1 & IBM Data Management Magazine & 40 & $7 \%$ \\
\hline 2 & Expert Systems wiith Applications & 19 & $3 \%$ \\
\hline 3 & Decision Support Systems & 18 & $3 \%$ \\
\hline 4 & Interfaces & 16 & $3 \%$ \\
\hline 5 & Journal of Decision Systems & 15 & $3 \%$ \\
\hline 6 & MIT SLOAN Management Review & 15 & $3 \%$ \\
\hline 7 & Harvard Business Review & 13 & $2 \%$ \\
\hline 8 & Accounting Horizons & 9 & $2 \%$ \\
\hline 9 & International Journal of Production Economics & 9 & $2 \%$ \\
\hline 10 & Big Data Research & 8 & $1 \%$ \\
\hline
\end{tabular}

Analisando os autores com maior quantidade de publicações selecionadas, conforme Tabela 3, destaca-se Thomas H. Davenport com 9 publicações. Este autor é co-fundador do International Institute for Analytics e leciona matérias relacionadas a Analytics e Big Data em Babson, Harvard Business School, MIT Sloan School e Boston University.

Dentre suas obras, destaca-se o artigo Competing on Analytics publicado pela Harvard Business Review em 2006 e predecessor de seu renomado livro Competing on analytics (DAVENPORT; HARRIS, 2007), o qual analisa as características e melhores práticas realizadas por organizações voltadas a gestão baseada em fatos (fact-based analytics), e ressalta a importância no alinhamento da cultura organizacional e suporte da alta gerência. Na continuação de sua obra, Analytics at Work: Smarter Decision, Better Results (DAVENPORT; HARRIS; MORISON, 2010), os autores apresentam um framework (DELTA) para a implementação de ferramentas de analytics nas empresas. A obra dos autores será discutida em maior detalhe no 2.2.1 Business Analytics.

Outro autor que se sobressai através desta análise é o pesquisador e professor da Universidade de Arizona Hsinchun Chen, o qual atua nas áreas de conhecimento referentes a Business Intelligence, Data mining, Text mining, Web mining, Gestão do conhecimento, dentre outros.

Seu relevante artigo Business Intelligence and Analytics: From big data to big impact publicado em 2012 no MIS Quarterly: Management Information Systems apresenta 584 citações na base de dados SCOPUS e 281 na base de dados Web of Science.

Neste artigo os autores apresentam o conceito de Business Intelligence e Analytics e analisam e classificam as ferramentas e três grupos (BI\&A 1.0, 2.0 e 3.0) de acordo com o perfil de dados utilizados (i.e. estruturados e não estruturados) e sua capacidade de análise, e também apresentam uma discussão sobre aplicação e áreas de pesquisa emergentes em Analytics.

O terceiro autor com o maior número de publicações é o pesquisador Bongsug Chae. Este autor é professor da escola de administração da Universidade do Kansas, e atua nas áreas de pesquisa da aplicação de técnicas e métodos de Big Data e Analytics em inovação digital, Supply Chain Management, Marketing, dentre outros.

Entre seus artigos selecionados, destaca-se sua linha de pesquisa de aplicações de Analytics em Supply Chain Management sob o prisma da teoria de Visão Baseada em Recursos (Resource Based View). 
Seu artigo Business analytics for supply chain: a dynamic-capabilities framework analisa o impacto de Analytics (Supply Chain Analytics) na performance do planejamento da cadeia (Supply Chain Planning) através de uma pesquisa tipo Survey com 537 plantas de manufatura, na qual a qualidade e gestão de dados é fator crítico para a utilização de ferramentas Supply Chain Analytics.

Tabela 3 - Autores com maior número de artigos Fonte: Elaborado pelo autor

\begin{tabular}{clc}
\multicolumn{2}{c}{ Autores } & Artigos \\
\hline 1 & Davenport, TH & 9 \\
\hline 2 & Chen, H & 7 \\
\hline 3 & Chae, B & 5 \\
\hline 4 & Soares, S & 4 \\
\hline 5 & Shockley, R & 4 \\
\hline 6 & Kiron, D & 4 \\
\hline 7 & Kobielus, J & 4 \\
\hline 8 & Court, D & 4 \\
\hline 9 & Deutsch, T & 4 \\
\hline 10 & Sun, J & 3 \\
\hline
\end{tabular}

A Tabela 4 apresenta a lista com os artigos mais citados nas bases de dados Scopus e Web of Science, nas quais é possível notar uma convergência entre 4 artigos das bases de dados: Business Intelligence and Analytics:

- Business Intelligence and Analytics: From Big Data to Big Impact (CHEN; STOREY; CHIANG, 2012);

- Competing on Analytics (DAVENPORT, 2006);

- Big Data: The management revolution (MCAFEE; BRYNJOLFSSON, 2012);

- Leveraging the capabilities of service-oriented decision support systems: Putting analytics and big data in cloud (DEMIRKAN; DELEN, 2013);

- The impact of business analytics on supply chain performance (TRKMAN et al., 2010);

As obras Business Intelligence and Analytics: From Big Data to Big Impact e Competing on Analytics foram apresentadas brevemente neste capítulo e serão abordadas no tópico 2.2 Revisão da literatura.

O texto Big Data: The management revolution de Mcafee e Brynjolfsson (2012) publicado na Harvard Business Review ressalta o potencial benefício da utilização do grande volume de dados atualmente disponível para as empresas e seus respectivos desafios de gestão.

Segundo os autores, tanto o Big Data como Analytics tem como objetivo extrair informações e insight dos dados para gerar vantagens competitivas para as empresas, porém diferenciamse pelos 3V's: Volume de dados, Velocidade de processamento e Variedade de tipos e fontes de dados). 
Em parceria com o MIT (Massachusetts Institute of Technology) e a consultoria McKinsey, os autores realizam 330 entrevistas com executivos de empresas públicas americanas e coletaram informações da performance financeira das respectivas instituições.

Em sua análise, os pesquisadores constataram que as empresas autocaracterizadas como direcionadas à uma gestão baseada em dados (data-driven) apresentaram melhor performance em indicadores de resultado financeiro e operacional.

Mcafee e Brynjolfsson também sinalziam a necessidade de transformações na organização com relação a sua gestão, cultura (decision-making culture), postura e direcionamento da liderança, Tecnologia e Habilidades dos colaboradores.

A publicação de Demirkan e Delen (2013) analisa os desafios e oportunidades na estruturação de ferramentas de Analytics utilizando arquitetura SOA (Service-Oriented Architecture). Os autores ressaltam que mecanismos tradicionais de análise de performance (i.e. Tempo e Custo) não são suficientes sendo necessário incluir parâmetros de qualidade e nível de serviço. E também sinalizam que a arquitetura SOA viabiliza redução de custos, aumento de escopo da ferramenta (serviços e análises providas pela ferramenta) e redução do tempo de implementação.

Em seu trabalho, Trkman et al. (2010) estudam a relação entre a capacidade analítica na área de supply chain (planejamento, compras, produção e entrega) das empresas considerando como moderadores o suporte de sistemas de informação de BA e a orientação da empresa para gestão por processos (Business Process Orientation - BPO), opondo-se a visão tradicional departamental.

Os autores afirmam que a implantação de sistemas de apoio a decisão (DSS) pode prover diferenciais competitivos impactando positivamente a performance da cadeia de suprimento e apresentam possíveis aplicações de ferramentas de BA em supply chain:

- Planejamento: Análise de dados para previsão de tendências de mercado em produtos e serviços;

- Compras: Utilização em sistema de simulação de compra (agente-based) para melhor seleção de fornecedores, negociação de preços e avaliação de fornecedores;

- Produção: Produção correta de cada item do inventário considerando prazo (just in time) e lote de produção;

- Entrega: Aplicações referentes à gestão logística, porém menos frequente nas empresas possivelmente pela frequente terceirização desse processo;

Os autores apontam que uma das maiores dificuldades para o sucesso em projetos de Business Analytics está na utilização dos dados no processo decisório. Sendo necessário, por vezes, a revisão dos processos empresariais e aplicação de técnicas de gestão da mudança para a implantação de uma cultura organizacional de tomada de decisão baseada em fatos.

Através da aplicação de uma pesquisa tipo Survey com várias empresas os pesquisadores constataram efeito positivo com relação ao moderador suporte de sistemas de informação. Porém não foram encontradas correlações sobre a orientação à processos (BPO), possivelmente pelo alto grau de maturidade nesse quesito de todas as empresas selecionadas na amostra. 
Tabela 4 - Artigos com maior volume de citações Fonte: Elaborado pelo autor

Web of Science

\begin{tabular}{|c|c|c|c|}
\hline Autor & Título & Ano & Citações \\
\hline $\begin{array}{l}\text { Chen, Hsinchun; Chiang, } \\
\text { Roger H. L.; Storey, Veda } \\
\text { C. }\end{array}$ & $\begin{array}{l}\text { Business Intelligence and Analytics: From } \\
\text { Big Data to Big Impact }\end{array}$ & 2012 & 281 \\
\hline $\begin{array}{l}\text { McAfee, Andrew; } \\
\text { Brynjolfsson, Erik }\end{array}$ & Big data: the management revolution. & 2012 & 147 \\
\hline $\begin{array}{l}\text { Lavalle, Steve; Lesser, } \\
\text { Eric; Shockley, Rebecca; } \\
\text { et al. }\end{array}$ & $\begin{array}{l}\text { Big Data, Analytics and the Path From } \\
\text { Insights to Value }\end{array}$ & 2011 & 83 \\
\hline Davenport, TH & Competing on analytics & 2006 & 75 \\
\hline $\begin{array}{l}\text { Chung, W; Chen, } \mathrm{H} \text {; } \\
\text { Nunamaker, JF }\end{array}$ & $\begin{array}{l}\text { A visual framework for knowledge } \\
\text { discovery on the Web: An empirical study } \\
\text { of business intelligence exploration }\end{array}$ & 2005 & 60 \\
\hline $\begin{array}{l}\text { Demirkan, Haluk; Delen, } \\
\text { Dursun }\end{array}$ & $\begin{array}{l}\text { Leveraging the capabilities of service- } \\
\text { oriented decision support systems: Putting } \\
\text { analytics and big data in cloud }\end{array}$ & 2013 & 53 \\
\hline $\begin{array}{l}\text { Chen, HC; Chau, M; } \\
\text { Zeng, D }\end{array}$ & $\begin{array}{l}\mathrm{Cl} \text { Spider: a tool for competitive } \\
\text { intelligence on the Web }\end{array}$ & 2002 & 53 \\
\hline $\begin{array}{l}\text { Shmueli, Galit; Koppius, } \\
\text { Otto R. }\end{array}$ & $\begin{array}{l}\text { Predictive Analytics in Information Systems } \\
\text { Research }\end{array}$ & 2011 & 50 \\
\hline $\begin{array}{l}\text { Shi, Y; Peng, Y; Kou, G; et } \\
\text { al. }\end{array}$ & $\begin{array}{l}\text { Classifying credit card accounts for } \\
\text { business intelligence and decision making: } \\
\text { A multiple-criteria quadratic programming } \\
\text { approach }\end{array}$ & 2005 & 50 \\
\hline $\begin{array}{l}\text { Trkman, P.; McCormack, } \\
\text { K; et al. }\end{array}$ & $\begin{array}{l}\text { The impact of business analytics on supply } \\
\text { chain performance }\end{array}$ & 2010 & 47 \\
\hline
\end{tabular}

Scopus

\begin{tabular}{|c|c|c|c|}
\hline Autor & Título & Ano & Citações \\
\hline $\begin{array}{l}\text { Chen, Hsinchun; Chiang, } \\
\text { Roger H. L.; Storey, Veda } \\
\text { C. }\end{array}$ & $\begin{array}{l}\text { Business Intelligence and Analytics: From } \\
\text { Big Data to Big Impact }\end{array}$ & 2012 & 584 \\
\hline $\begin{array}{l}\text { McAfee, Andrew; } \\
\text { Brynjolfsson, Erik }\end{array}$ & Big data: the management revolution. & 2012 & 388 \\
\hline Davenport, TH & Competing on analytics & 2006 & 192 \\
\hline $\begin{array}{l}\text { Philip Chen, C.L., Zhang, } \\
\text { C.-Y. }\end{array}$ & $\begin{array}{l}\text { Data-intensive applications, challenges, } \\
\text { techniques and technologies: A survey on } \\
\text { Big Data }\end{array}$ & 2014 & 177 \\
\hline $\begin{array}{l}\text { Demirkan, Haluk; Delen, } \\
\text { Dursun }\end{array}$ & $\begin{array}{l}\text { Leveraging the capabilities of service- } \\
\text { oriented decision support systems: Putting } \\
\text { analytics and big data in cloud }\end{array}$ & 2013 & 98 \\
\hline $\begin{array}{l}\text { Trkman, P.; McCormack, } \\
\text { K; et al. }\end{array}$ & $\begin{array}{l}\text { The impact of business analytics on supply } \\
\text { chain performance }\end{array}$ & 2010 & 85 \\
\hline $\begin{array}{l}\text { Bijmolt, T.H.A., Leeflang, } \\
\text { P.S.H., Block, F., (...), } \\
\text { Lemmens, A., Saffert, P. } \\
\end{array}$ & Analytics for customer engagement & 2010 & 74 \\
\hline $\begin{array}{l}\text { Crampton, J.W., Graham, } \\
\text { M., et al, }\end{array}$ & $\begin{array}{l}\text { Beyond the geotag: Situating 'big data' and } \\
\text { leveraging the potential of the geoweb }\end{array}$ & 2013 & 67 \\
\hline $\begin{array}{l}\text { Davenport, T.H., Barth, P., } \\
\text { Bean, R. }\end{array}$ & How 'big data' is different & 2012 & 65 \\
\hline $\begin{array}{l}\text { Waller, M.A., Fawcett, } \\
\text { S.E. }\end{array}$ & $\begin{array}{l}\text { Data science, predictive analytics, and big } \\
\text { data: A revolution that will transform } \\
\text { supply chain design and management }\end{array}$ & 2013 & 62 \\
\hline
\end{tabular}




\subsubsection{Análise de citação e co-citação}

Essa técnica realiza o cruzamento entre obras referenciadas por cada artigo selecionado e estrutura uma rede de citações e co-citações. Essa análise permite visualizar a estrutura do domínio de conhecimento da área pesquisada e também identificar por meio das redes de citações os trabalhos com maior contribuição para o embasamento teórico da amostra analisada.

Neste tipo de representação gráfica os nós apresentam obras citadas e as linhas as co-citações. Quanto mais espessa a linha, maior a frequência na qual essas obras foram citadas simultaneamente nos trabalhos selecionados.

Para a estruturação desse estudo foi utilizada a ferramenta CiteSpace, sendo essa desenvolvida para análise e entendimento da evolução de áreas de conhecimento por intermédio de suas respectivas bibliografias (CHEN, 2014).

O sistema foi parametrizado para considerar os artigos publicados de 2000 à 2016 e apresentar por ano as 25 obras mais citadas dessa seleção.

A Figura 3 apresenta a rede estruturada pelo sistema, na qual cada nó da estrutura representa um autor referenciado entre os artigos selecionados. As cores dos nós e linhas referenciam as datas de publicação de suas obras, variando de azul (2000) à vermelho (2016).

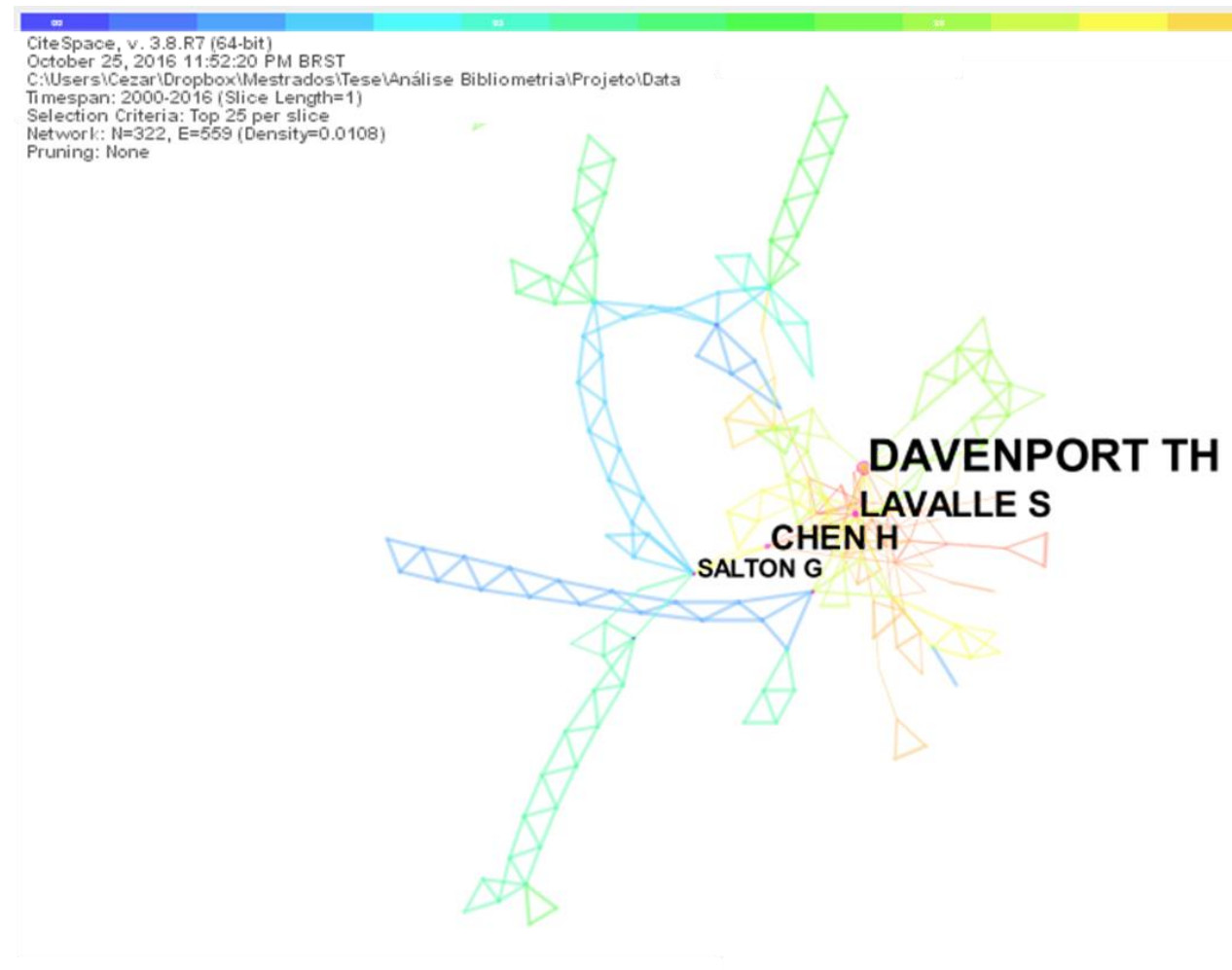

Figura 3 - Análise de citação

Fonte: Software CiteSpace (CHEN, 2014)

Os autores sinalizados na rede de co-citações apresentados na figura anterior destacam-se por sua quantidade de citações e grau de centralidade, conforme a Tabela 5. 
Tabela 5 - Autores com maior relevância na rede de co-citações

Fonte: Elaborado pelo autor

\begin{tabular}{lcc} 
Autor & Citações & Centralidade \\
\hline LaValle, Steve & 42 & 0.32 \\
Salton, Gerard & 13 & 0.20 \\
Chen, Hsingun & 37 & 0.18 \\
Davenport, Thomas & 140 & 0.14
\end{tabular}

De acordo com Chen (2014) a centralidade dos nós varia entre 0 e 1 , nos quais pontos com elevado valor geralmente conectam grandes grupos e podem sinalizar elos de conexão entre distintas linhas de pesquisa e/ou marcos teóricos, o que ressalta a relevância destas obras.

Steve LaValle é professor do departamento de Ciências da Computação da universidade de Illinois e atua em pesquisas voltadas para as áreas de conhecimento de Inteligência artificial, Realidade Virtual e Interfaces gráficas (Human-Computer Interaction) (ILLINOIS, 2016). Dentre suas publicações destaca-se Big Data, Analytics and the Path From Insights to Value, publicada em 2011 no MIT Sloan Management Review na qual foi conduzida uma pesquisa com aproximadamente 3.000 executivos, gestores e analistas distribuídos em mais de 30 segmentos industriais nos quais constatou-se que as empresas de alta performance utilizavam aproximadamente 5 vezes mais ferramentas de Analytics (LAVALLE et al., 2011).

Gerald Salton, falecido em 1995, foi professor e co-fundador do departamento de Ciências da Computação da Cornell University, e renomado pesquisador na área de recuperação e indexação de informações. Seus conceitos desenvolvidos serviram como base para os mecanismos atuais de pesquisa como o sistema SMART - System for the Manipulation and Retrieval of Text (CORNELL, 1999). Este autor foi citado 13 vezes na base de dados selecionada por suas obras:

- Introduction to modern information retrieval

- Automatic Text Processing: The Transformation, Analysis, and Retrieval of;

- Another look at automatic text-retrieval systems

- A theory of term importance in automatic text analysis

- A vector space model for automatic indexing;

- Term-weighting approaches in automatic text retrieval

Os autores Thomas Davenport e Hsingun Chen foram analisados brevemente no tópico 2.1.2 Estatística descritiva, e suas obras serão exploradas de forma mais detalhada em 2.2 Revisão da literatura.

A Figura 4 apresenta a análise de citações e co-citações sob o prisma de obras referenciadas, na qual cada nó da estrutura refere-se a um artigo citado. Essa análise foi realizada com o auxílio do software CiteSpace, e utilizou os mesmos parâmetros discutidos anteriormente. 


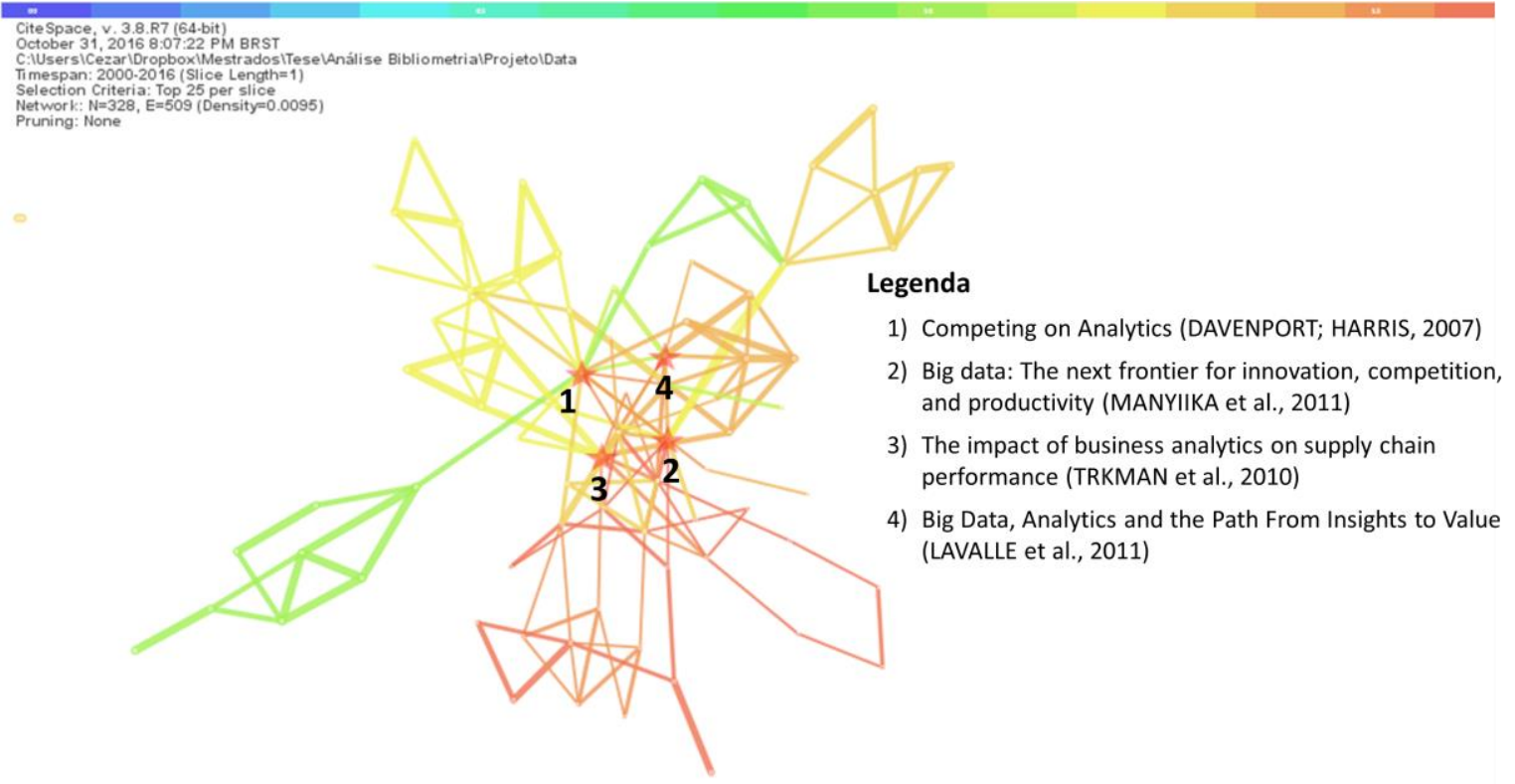

Figura 4 - Análise de co-citação por artigos Fonte: Elaborado pelo autor

Conforme apresentado na Tabela 6, a obra com maior centralidade é o livro publicado por Davenport e Harris em 2007. Esta análise reforça a relevância desta obra e dos autores já constatada na análise de estatística descritiva e de co-citações de autores.

Big data: The next frontier for innovation, competition, and productivity (MANYIKA et al., 2011) é uma publicação da consultoria McKinsey que apresenta técnicas e tecnologias de Big Data bem como seus impactos nas organizações e seus respectivos desafios de gestão.

De forma similar a Competing on Analytics (DAVENPORT, 2006), as obras The impact of business analytics on supply chain performance (TRKMAN et al., 2010) e Big Data, Analytics and the Path From Insights to Value (LAVALLE et al., 2011) foram exploradas anteriormente neste capítulo.

Tabela 6 - Artigos com maior relevância na rede de co-citações Fonte: Elaborado pelo autor

\begin{tabular}{|c|c|c|c|}
\hline Autor & Título & Citações & Centralidade \\
\hline $\begin{array}{l}\text { Davenport, T.; Harris, } \\
\text { J.G.; }\end{array}$ & Competing on Analytics & 41 & 0.06 \\
\hline Manyiika, J.; et al. & $\begin{array}{l}\text { Big data: The next frontier for innovation, } \\
\text { competition, and productivity }\end{array}$ & 36 & 0.04 \\
\hline $\begin{array}{l}\text { Trkman, P.; McCormack, } \\
\text { K.; De Oliveira, M. P. V.; }\end{array}$ & $\begin{array}{l}\text { The impact of business analytics on supply } \\
\text { chain performance }\end{array}$ & 18 & 0.02 \\
\hline LaValle, S.; et al. & $\begin{array}{l}\text { Big Data, Analytics and the Path From } \\
\text { Insights to Value }\end{array}$ & 17 & 0.02 \\
\hline
\end{tabular}

Também foi analisada as palavras chave definidas pelos autores, Figura 5 apresenta a rede de relacionamento construída com auxílio do software CiteSpace. De forma similar à análise de co-citações o sistema foi parametrizado para considerar os artigos publicados de 2000 a 2016, porém apresentando por ano as 5 palavras chave mais citadas dessa seleção. O tamanho da fonte é proporcional à quantidade de ocorrências de cada uma das palavras chave. 


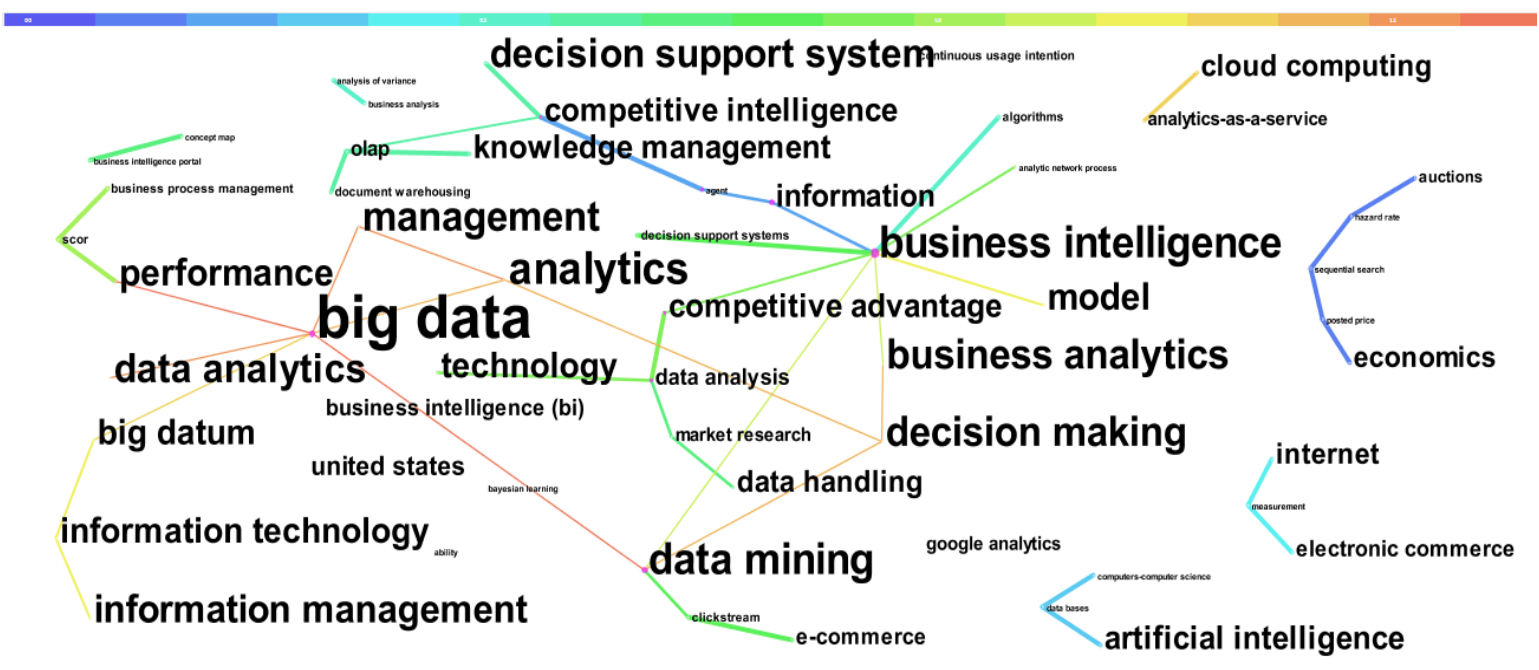

Figura 5 - Rede de citações de palavras chave

Fonte: Elaborado pelo autor 


\subsection{Revisão da literatura}

Neste tópico será apresentada uma revisão da literatura e discutido inicialmente a evolução histórica do termo Business Analytics e as principais obras desse campo de pesquisa, e posteriormente uma discussão sobre as definições, áreas envolvidas e fatores críticos de sucesso através da revisão dos trabalhos mapeados na análise bibliométrica apresentada anteriormente. Também será abordado na revisão modelos de sucesso de SI para a estruturação do framework conceitual discutido no tópico 3. Metodologia.

\subsubsection{Business Analytics}

Conforme apontado por Mortenson et al. (2015), não há um consenso na academia sobre a definição de Business Analytics e como este termo se diferencia de conceitos correlatos (como, por exemplo, Business Intelligence e Big data).

Chen et. al. (2012) adotam uma definição unificada dos dois conceitos, utilizando a nomenclatura Business Intelligence \& Analytics (BI\&A). Segundo os autores o termo Business Intelligence tornou-se popular entre os profissionais de TI e gestão na década de 1990 e a expressão Analytics no final da década passada (2000), sendo esse termo introduzido para representar os componentes analíticos de ferramentas de BI. Posteriormente os termos Big Data e Big Data Analytics foram adotados para descrever técnicas analíticas aplicadas em grandes e complexos (desestruturados e de distintas origens) volumes de dados, as quais demandam métodos e tecnologias avançadas de armazenagem, gestão, análise e visualização.

Segundo os autores, BI\&A tem sua origem na área de gestão de dados e apresentam a seguinte definição para o termo:

“...é geralmente atribuido a técnicas, tecnologias, sistemas, práticas, metodologias, e aplicações que analisam dados críticos no negócio para auxiliar as organizações em um melhor entendimento seu mercado, negócio e em decisões mais rápidas..."

A evolução das ferramentas e aplicações de BI\&A são classificadas em 3 grupos (CHEN et. al., 2012):

- BI\&A 1.0 - Apresentam em sua essência a gestão e armazenagem de dados, sendo esses geralmente estruturados e coletados pelas indústrias de seus sistemas legados e armazenados em banco de dados relacionais (Relational Database Management Systems - RDMS). Dentre as principais funcionalidades dessas ferramentas estão: Geração de relatórios e Dashboards, Online Analytical Processing - OLAP, visualizações interativas, scorecards, modelos preditivos e data mining.

- BI\&A 2.0 - Voltado para análise de dados provenientes da internet (os quais são geralmente não estruturados), esse grupo de ferramentas permite às empresas um maior entendimento das necessidades de seus clientes e descoberta de novas oportunidades de negócio através da análise de dados de navegadores, informações de fóruns, blogs e redes sociais através da aplicação de técnicas de text mining, web mining, web analytics, social media analytics e social netwrok analysis.

- BI\&A 3.0 - Baseado na tecnologia mobile e sensor-based (Internet of Things), essa evolução das ferramentas possibilita novos tipos de analytics, como location-aware 
analysis, person-centered analysis e context-relevant analysis. Além de apresentarem desafios na visualização e interface via mobile.

De forma similar, Chiang et al. (2012) utilizam o termo BI\&A e classificam analytics em três categorias de análises para tomada de decisão: Descritiva, Preditiva e Prescritiva. Os autores apresentam a seguinte definição para seu trabalho:

"Nós utilizamos BI\&A como um termo unificado para descrever conceitos e métodos de utilização intensiva de informações para melhor a tomada de decisão das empresas. BI\&A inclui a arquitetura subjacente, ferramentas analíticas, sistemas de gestão de banco de dados, técnicas de mineração de dados (data/text/web mining), aplicações, e metodologias. "

E também afirmam que BI\&A é uma área interdisciplinar que integra gestão de dados, sistemas de banco de dados, data warehousing, mineração de dados, text mining, network analysis, otimização e análises estatísticas. Sendo necessário aos profissionais dessa área além dos conhecimentos técnicos (TI) e analíticos/estatísticos, também noções de gestão e administração para o entendimento das necessidades do negócio e habilidades de comunicação para transmitir os insights e resultados das análises aos tomadores de decisão.

Alinhado com essa corrente de pensamento, Chen e Chen (2013) apontam que tradicionalmente o termo Business Intelligence tem sido empregado de forma genérica (umbrella term) para descrever conceitos e métodos utilizados para melhorar o processo de tomada de decisão através da utilização de sistemas de informação (fact-based support systems), os quais viabilizam o acesso interativo e fácil aos diversos tipos de dados da empresa de forma a habilitar sua manipulação e transformação em informações e insights úteis aos gestores e tomadores de decisão.

O BI está fundamentalmente baseado em diversas tecnologias avançadas de coleta, extração, armazenagem e análise de dados (e.g. Data warehousing, Data marts, ETL-Extraction, Transformation and Load, Database query, OLAP, Dashboards, Scorecards, text mining, database segmentation and clustering, anomaly detection e análises preditivas). Sendo esse último ponto coletivamente conhecido como Business Analytics.

Devido à alta dependência dos modernos sistemas de BI as técnicas avançadas de análise de dados (BA), Chen e Chen (2013) abordam de forma unificada os termos e apresentam a seguinte definição para Business Intelligence and Analytics (BIA):

"BIA é referente à: (1) as tecnologias, sistemas, práticas, e aplicações que (2) analisam dados críticos das empresas para (3) auxiliar as organizações em um melhor entendimento de seu mercado e negócio"

O modelo apresentado por Hill (2014) ilustra o encadeamento de funcionalidades de sistemas de BI\&A conforme Figura 6, na qual o valor e potencial diferencial competitivo gerado às companhias aumenta conforme a sofisticação das análises empregas. 


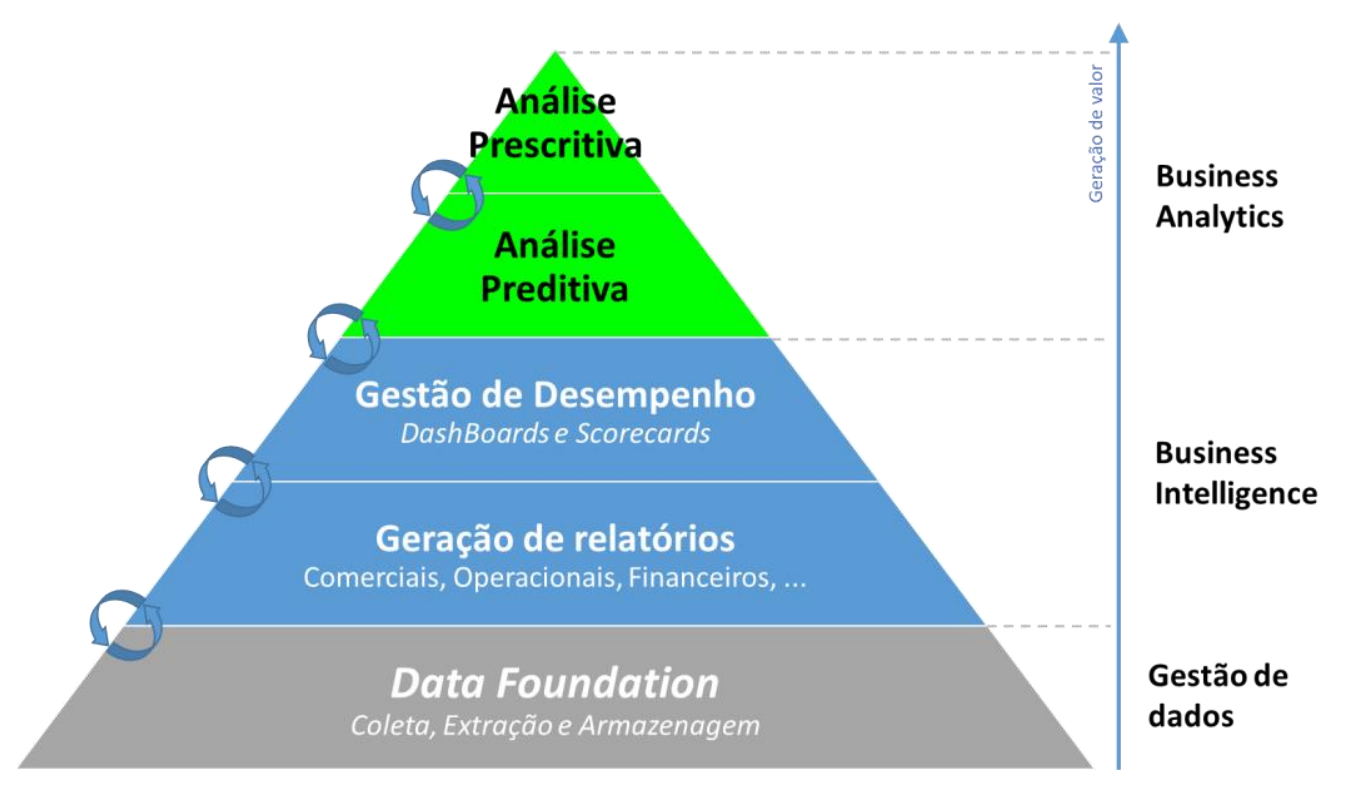

Figura 6 - Funcionalidades de sistemas de BI\&A

Fonte: Adaptado pelo autor (HILL, 2014)

Porém, Davenport e Harris (2007) em seu trabalho definem analytics como um subconjunto do BI, sendo esse um grupo de tecnologias e processos que utilizam dados para o entendimento e análise da performance empresarial. Dessa forma, BI inclui tanto o acesso e visualização (relatórios), como as análises dos dados. E, quanto maior o grau de inteligência empregada nas análises, maior o valor gerado para as empresas. A Figura 7 relaciona o grau de sofisticação das análises, o valor gerado e os questionamentos referentes as atividades da empresa abordados em casa uma das etapas.

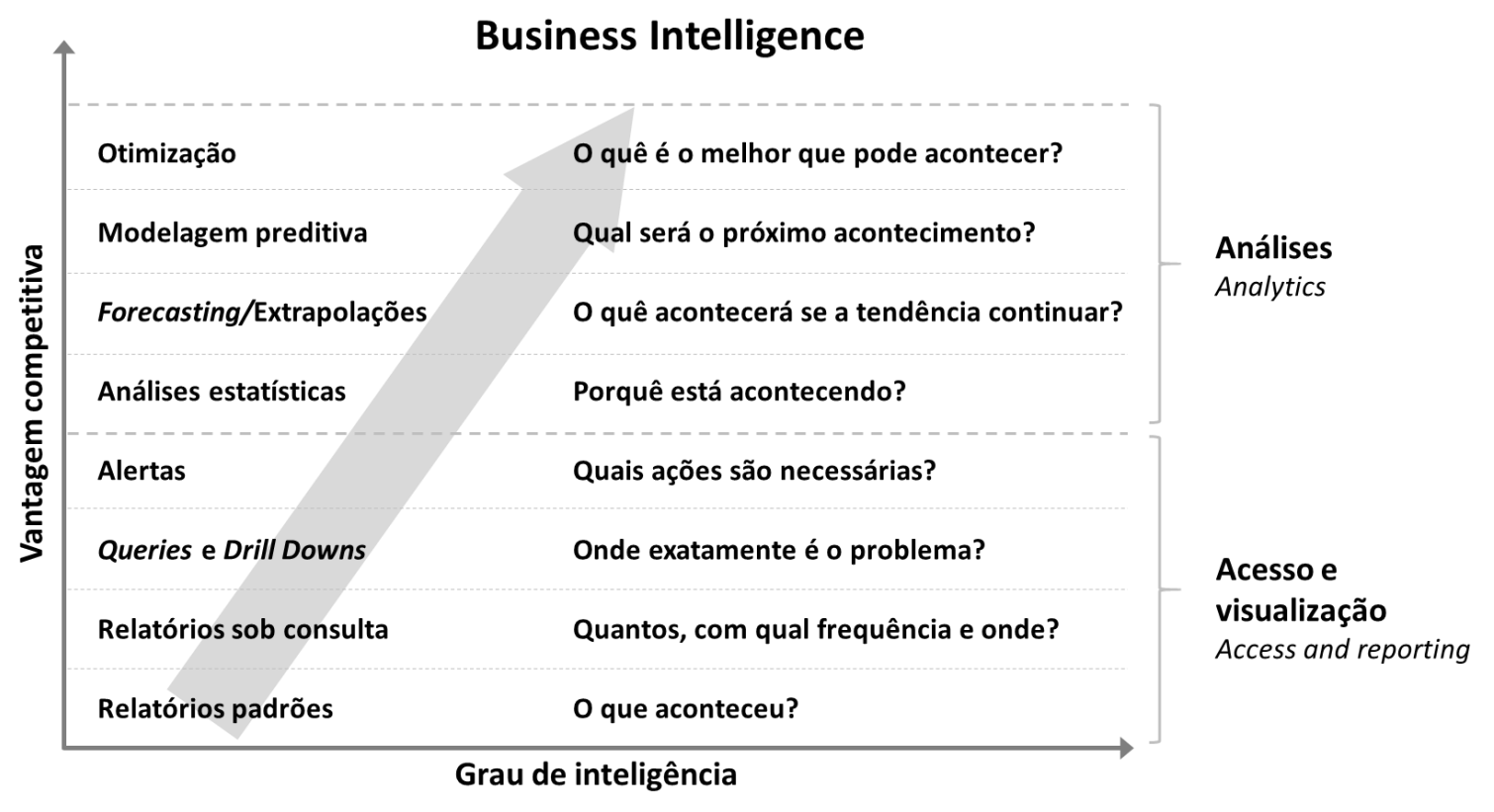

Figura 7 - Business Intelligence and Analytics

Fonte: Adaptado pelo autor (DAVENPORT; HARRIS, 2007) 
Dessa forma, os autores utilizam a seguinte definição para Business Analytics e Business Intelligence:

"Utilização extensiva de dados e métodos quantitativos e estatísticos, modelos explanatórios e preditivos, e gestão baseada em fatos para o direcionamento de ações e decisões. $O$ Analytics pode ser input para decisões humanas ou direcionar decisões completamente automatizadas. Sendo esse um subconjunto do Business Intelligence: Conjunto de tecnologias e processos que utilizam dados para o entendimento e análise da performance organizacional”

Dessa forma, BI incorpora a coleta, gestão e relatório dos dados referentes à tomada de decisão, bem como técnicas analíticas e computacionais empregadas em sua manipulação.

Os autores destacam que Analytics não necessariamente precisaria de um sistema para sua realização, porém devido à grande quantidade de dados e ao extensivo volume de trabalho desprendido para a análise faz-se necessário a utilização de ferramentas de tecnologia da informação.

Davenport (2006) realiza um estudo de caso com 32 empresas que utilizam análises quantitativas (fact-based analysis), dentre as quais 11 apresentam elevado grau de maturidade nesse quesito, para a análise das características e melhores práticas realizadas por essas organizações de forma a estruturar quais as mudanças sob as quais as empresas devem ser submetidas para atingirem elevado grau de maturidade na utilização de analytics como diferencial competitivo.

Dentre as transformações identificadas pelo autor estão: Investimentos em tecnologia, armazenagem de grandes massas de dados, formulação de uma estratégia e processos para a utilização das informações e alteração na cultura organização para decisões baseadas em fatos (fact-based decisions).

Dentre as características em analytics (Analytics Competitors) dessas empresas foram identificados os seguintes pontos:

- Vasta aplicação de modelagens estatísticas e de otimização, utilizando tanto dados internos como externos da empresa.

- Gestão centralizada dos dados (enquanto empresas tradicionais apresentam a gestão departamental), garantindo integridade das informações e indicadores da empresa;

- Implantação e valorização de uma cultura de gestão baseada em fatos (fact-based decision) através de testes e mensuração de evidências quantitativas;

- Suporte da alta liderança da empresa (preferencialmente o CEO) para a transformação tanto cultural como dos processos da empresa;

- Definição de uma estratégia e foco na seleção dos processos e atividades à serem empregados as ferramentas de BA;

- Entendimento da liderança da empresa sobre o modelo matemático utilizado e suas limitações; 
- Busca/contratação de colaboradores analíticos e com habilidades tanto para expressar ideias complexas de forma simples como de relacionamento interpessoal para interagir de forma adequada com os tomadores de decisão;

- Inovação e constante busca por novos algoritmos estatísticos e tecnologias;

Bartlett (2013) considera Business Analytics como um subconjunto do Business Intelligence. Sendo BI composto pela união dos termos Tecnologia da Informação e Business Analytics (Business Intelligence $=$ Information Technology + Business Analytics $)$.

Para o autor, tanto TI como BA envolvem a utilização de dados por profissionais para criação de insights ao negócio e, portanto, facilitando as tomadas de decisão. Sendo os conceitos complementares e sinérgicos, definidos da seguinte forma:

"Tecnologia da informação - Consolidação e gestão de dados para a criação de data warehouse, viabilizando o fornecimento de relatórios $e$ dashboards. (Trazendo os dados para o negócio)"

"Business analytics - Catalisação da análise de dados e o do conhecimento do negócio para a realização de decisões baseadas em dados (Trazendo os questionamentos do negócio para os dados)."

Bartlett (2013) destaca que TI está relacionada à coleta, segurança e armazenagem de dados. Auxiliando no suporte à decisão através da geração de relatórios e Dashboards, atuando de forma incisiva no acompanhamento da performance da empresa e direcionando as atividades de planejamento. Já o Business Analytics tem como foco a análise detalhada dos dados para o suporte a tomada de decisão conectando os problemas e desafios do negócio à análise de dados (analytics). BA envolve a geração de relatórios, análises exploratórias e complexas de dados através de ferramentas e algoritmos matemáticos e estatísticas.

Apesar de tanto TI como BA apresentarem a geração de relatórios, o primeiro tem como foco a eficiência e padronização na geração de relatórios que abordam indicadores de performance previamente definidos. Enquanto o segundo gera relatórios baseados em técnicas estatísticas e inteligência de negócio (Business Savvy), sendo mais apropriado para a definição e revisão dos indicadores da empresa.

Os conhecimentos necessários e posicionamento na estrutura organizacional também diferem entre os termos. TI está diretamente relacionado à ciências da computação, e geralmente sua equipe reporta para o CIO da empresa. Já BA está relacionado à análise de dados e tomada de decisão, e geralmente está posicionado nas áreas de negócio próximo aos tomadores de decisão.

Segundo Bartlett (2013) as análises realizadas no contexto do negócio devem atender os seguintes objetivos: Expectativa do cliente, acuracidade, confiabilidade, custos e prazo. E, para a operacionalização, são utilizadas ferramentas matemáticas (deduções numéricas e análise de dados completos e exatos), estatísticas (inferências numéricas e análise de dados geralmente inexatos e completos) e algoritmos (operacionalização das soluções e otimização).

Holsapple et al. (2014) em seu trabalho abordam os conceitos de Business Intelligence e Business Analytics de formas distintas. Segundo os autores, BI tem suas origens e tecnologias baseadas em sistemas de apoio a decisão (DSS - Decision Support Systems), sendo esses 
centrados em grandes massas de dados armazenados de forma estruturada em bancos de dados do tipo data warehouses e data marts. Os softwares de BI permitem várias formas de operacionalização dados como: geração de relatórios, visualizações consolidadas e desagregadas dos dados (drill down e bottom up), ad hoc queries e dashboards. Além de facilidades como data mining, business performance management e business activity monitoring (acesso em tempo real aos indicadores de performance críticos). Recentemente, também há uma tendência de aplicações de BI em gigantescos volumes de dados não estruturados como áudio, vídeo e textos. Sendo necessária novas técnicas de processamento e armazenagem de dados para essas aplicações (e.g. Hadoop, MapReduce).

Apesar do BA ter suas funcionalidades de suporte a decisão disponibilizadas por sistemas de BI, seu conceito não está restrito apenas a parte tecnológica e tem suas origens de forma distinta, por exemplo na pesquisa operacional e na estatística aplicada, as quais são as bases de conhecimento para os modelos e análises quantitativas. Além dos métodos qualitativos empregados para suporte a tomada de decisão, os quais tem sua relevância destacada pelos autores tendo em vista a recorrente falta de dados numéricos e a natureza não estruturada dos problemas encontrados nas empresas.

Os autores sinalizam que o BA permite o atingimento de quatro tipos de objetivos, para os quais utilizam a sigla SPED, e os definem da seguinte forma: entender uma situação (make Sense of a situation), realizar previsões (make Predictions), realizar avaliações (make $\boldsymbol{E}$ valuations) e tomar decisões (make Decisions). E classifica as análises como preditivas, descritivas e prescritivas.

Os autores reforçam a falta de consenso sobre a definição de BA na academia e apresentam uma tabela resumo das definições levantadas (Tabela 7), e destacam o recorrente aparecimento das palavras fact-based e decision (ou decision making) nas definições mapeadas. Estas definições são classificadas em 6 grupos, conforme descrição abaixo:

- Movimento: BA é um movimento no qual a mentalidade de gestão baseada em evidências (evidence based management) permeia e direciona a estratégia, operação e tática da empresa. Sendo essencial a adequação da filosofia e cultura da empresa para a implementação do movimento BA;

- Conjunto de práticas e tecnologias: BA é um conjunto de práticas e tecnologias que pode existir sem necessariamente um movimento, apesar de sua implantação e utilização poder ser menos efetiva;

- Processo de transformação: BA é um processo de transformação de evidência em insights ou ações operacionalizado por um conjunto de práticas e tecnologias e influenciado por uma cultura organizacional. Nessa perspectiva de processo, o foco está no direcionamento, coordenação, controle e indicadores da transformação;

- Conjunto de competências (capability set): BA está relacionado a um conjunto de competências da organização na identificação e solução de problemas baseados em evidências como:

○ Utilizar técnicas quantitativas, qualitativas e suas combinações;

○ Utilizar técnicas estatísticas; 
○ Empregar de forma efetiva modelos descritivos/exploratórios, preditivos e prescritivos;

- Trabalhar efetivamente com evidências (e.g. banco de dados, click-streams, documentos, sensores e mapas)

- Conjunto de atividades específicas: Nessa visão BA é analisado como um conjunto específico de atividades para a operacionalização de evidências para a obtenção de insights ou decisões. Sendo elas: acesso, avaliação, agregação e análise de evidências;

- Paradigma da decisão: Nesse caso BA é definido como uma abordagem de tomada de decisão, sendo essa definição a mais ampla e contendo todas as demais categorias anteriormente descritas;

Para seu trabalho, os autores adotam uma definição mais abrangente de BA incluindo os conceitos de evidence-based management e problem recognition and solving.

"Nós adotamos uma caracterização central de business analytics como a identificação e resolução de problemas baseado em evidências, os quais ocorrem no contexto de negócios"

De acordo com os autores evidence-based management é mais abrangente que os termos fact based e data based, e se refere à adoção de uma cultura e filosofia organizacional na qual as solicitações de mudança ocorrem pautadas em evidências de sua necessidade e eficácia, com clara descrição da lógica envolvida e da origem das informações. Neste contexto evidências incluem fatos concretos, medições confiáveis, estimativas justificadas, aproximações racionais, observações não tendenciosas, conselhos/recomendações de autoridades, dentre outros.

De acordo com o conceito dos objetivos do BA apresentados anteriormente pelos autores (SPED), eles afirmam que o BA pode atuar tanto na identificação como na solução de problemas, sendo esses conceitos mais amplos que apenas o suporte a tomada de decisão. O que justifica a utilização o termo problem recognition and solving em sua definição. 
Tabela 7 - Definições de BA

Fonte: Adaptado pelo autor Holsapple et al. (2014)

\begin{tabular}{|c|c|c|}
\hline Classificação & Definição de BA & Referência \\
\hline \multirow{3}{*}{ Movimento } & "...cultura, onde a tomada de decisão baseada em fatos é encorajada e recompensada" & $\begin{array}{l}\text { Ramamurthy, K. et al. } \\
\text { (2008) }\end{array}$ \\
\hline & $\begin{array}{l}\text { " "filosofia de gestão" através da qual insights podem ser obtidos e decisões melhoradas } \\
\text { com base em "ricas bases de dados" " }\end{array}$ & $\begin{array}{l}\text { Larsson, T.; Lundgren, } \\
\text { R. (2009) }\end{array}$ \\
\hline & $\begin{array}{l}\text { "movimento...direcionado por executivos tecnicamente competentes que realizam: } \\
\text { decisões baseadas em fatos, disponibilizam bons dados, gerenciam a empresa de forma } \\
\text { orientada à processos, e aprimoram softwares para a captura, processamento e análise de } \\
\text { dados." }\end{array}$ & $\begin{array}{l}\text { Liberatore, M.; Luo, W. } \\
\text { (2010) }\end{array}$ \\
\hline \multirow{3}{*}{$\begin{array}{l}\text { Conjunto de } \\
\text { práticas e } \\
\text { tecnologias }\end{array}$} & $\begin{array}{l}\text { "um subconjunto do que tem sido chamado de Business Intelligence: conjunto de } \\
\text { tecnologias e processos que utilizam dados para o entendimento e análise do negócio." }\end{array}$ & $\begin{array}{l}\text { Davenport, T; Harros, } \\
\text { J. G. (2007) }\end{array}$ \\
\hline & $\begin{array}{l}\text { "grupo de ferramentas, as quais são utilizadas e combinadas entre si, para gerar } \\
\text { informação, analisar informação e prever resultados." }\end{array}$ & Bose, R. (2009) \\
\hline & $\begin{array}{l}\text { "um grande grupo de tecnicas e tecnologias que facilitam a extração de valor e significado } \\
\text { dos dados." }\end{array}$ & Taylor, J. (2010) \\
\hline \multirow{3}{*}{$\begin{array}{l}\text { Processo de } \\
\text { transformação }\end{array}$} & $\begin{array}{l}\text { "mais do que apenas metodologias analíticas ou técnicas utilizadas em análises lógicas. É } \\
\text { um processo de transformação de dados em ações através de análises e insights no } \\
\text { contexto de tomadas de decisão e solução de problemas organizacionais." }\end{array}$ & $\begin{array}{l}\text { Liberatore, M.; Luo, W. } \\
(2010)\end{array}$ \\
\hline & $\begin{array}{l}\text { "processo de transformação de dados em ações através de análises e insights no contexto } \\
\text { de tomadas de decisão e solução de problemas organizacionais." }\end{array}$ & $\begin{array}{l}\text { Liberatore, M.; Luo, W. } \\
\text { (2011) }\end{array}$ \\
\hline & $\begin{array}{l}\text { "o processo cientifico de transformação de dados em insights para a melhor tomada de } \\
\text { decisão" }\end{array}$ & $\begin{array}{l}\text { INFORMS Online } \\
(2012)\end{array}$ \\
\hline \multirow[b]{3}{*}{$\begin{array}{l}\text { Conjunto de } \\
\text { capacidades }\end{array}$} & $\begin{array}{l}\text { "utilização extensiva de dados, análises estatísticas e quantitativas, modelos descritivos e } \\
\text { preditivos, e gestão baseada em fatos para o direcionamento das ações e decisões." }\end{array}$ & $\begin{array}{l}\text { Davenport, T; Harros, } \\
\text { J. G. (2007) }\end{array}$ \\
\hline & $\begin{array}{l}\text { "o uso de análises, dados e pensamento sistêmico para tomada de decisão... a maioria das } \\
\text { empresas e gestores analiticos utilizam uma combinação de técnicas tanto quantitativas } \\
\text { como qualitativas" }\end{array}$ & $\begin{array}{l}\text { Davenport, T. et al. } \\
\text { (2010) }\end{array}$ \\
\hline & $\begin{array}{l}\text { "a utilização por empresas de banco de dados, modelos descritivos e preditivos e gestão } \\
\text { baseada em fatos para o direcionamento de ações e decisões" }\end{array}$ & $\begin{array}{l}\text { O’Dwyer, J. Renner, R. } \\
\text { (2011) }\end{array}$ \\
\hline
\end{tabular}

"A utilização de dados e insights obtidos através da aplicação de disciplinas analitica (e.g. modelos estatísticos, preditivos, cognitivos, dentre outros) para o direcionamento do planejamento, tomada de decisão, execução, gestão, mensuração e aprendizagem. Analytics ponde ser descritivo, preditivo ou prescritivo."

"disciplina de aplicação de métodos analíticos avançados abrangendo desde modelagens descritivas, preditivas, e até prescritivas."

Teece, D. (1997)

"acessando, consolidando, e analisando grandes volumes de dados de diversas fontes para

\begin{tabular}{|c|c|}
\hline \multirow{2}{*}{$\begin{array}{l}\text { Conjunto de } \\
\text { atividades } \\
\text { específicas }\end{array}$} & $\begin{array}{l}\text { o entendimento da performance histórica ou comportamento ou para prever - ou gerir - } \\
\text { resultados/consequências." }\end{array}$ \\
\hline & "análise e manipulação de dados para o direcionamento de ações da empresa" \\
\hline \multirow[b]{2}{*}{$\begin{array}{l}\text { Paradigma de } \\
\text { decisão }\end{array}$} & $\begin{array}{l}\text { "a "parte da gestão de decisões" que envolve "análises lógicas baseadas em dados para a } \\
\text { melhor tomada de decisão"" }\end{array}$ \\
\hline & $\begin{array}{l}\text { " "tomada de decisão direcionadas por dados" ao invés de "ignorar as evidênicas e tomar } \\
\text { nossas decisões estratégicas com base em anedotas e advinhações...simplismente porque } \\
\text { colher os dados corretos para informar nossas decisões é mais complexo do que pode } \\
\text { parecem no primeiro momento". }\end{array}$ \\
\hline
\end{tabular}

Tyagi, S. (2003)

TWDI (2013)

Rosenberger, L.F.; Nash, J. (2009)

Ravishanker, G. (2011) 
Neste trabalho também é apresentado um framework conceitual que abrange e unifica as definições de BA apresentadas anteriormente, conforme a Figura 8.

Na base do modelo temos o movimento (e.g. implementação de uma estratégia ou atingimento de um objetivo) catalisado por uma filosofia e cultura organizacional de gestão baseada em evidências, o qual demanda um conjunto de competências que viabilize a utilização e interpretação de evidências tanto quantitativas e qualitativas para sua implementação.

No processo de transformação, as evidências tornam-se insights ou decisões através do emprego das competências em BA em atividades específicas respaldadas por um conjunto de práticas e tecnologias. Esses conjuntos de elementos formam o paradigma de decisão, sendo esse termo a definição ampla conforme apresentado anteriormente.

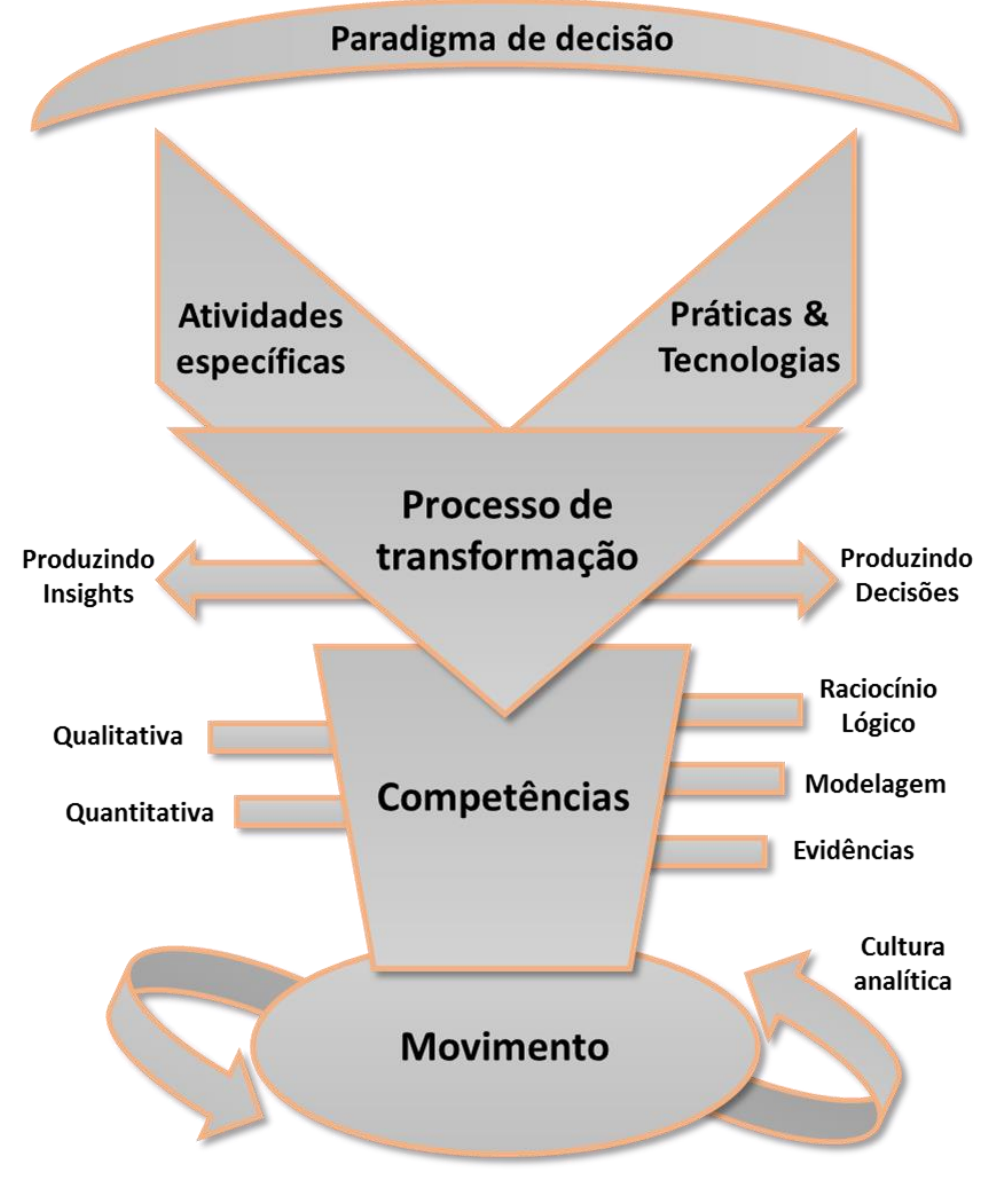

Figura 8 - Business Analytics Framework

Fonte: Adaptado pelo autor Holsapple et al. (2014)

Mortenson et al. (2015) ressaltam a falta de consenso na academia sobre a definição de BA e sua semelhança com os conceitos de Business Intelligence e Pesquisa Operacional, o que dificulta a delineação dos limites entre estes conceitos. Esta similaridade ocorre principalmente devido ao fato de fundamentalmente buscarem objetivos similares: Melhorar a operação das empresas e tomadas de decisão através da utilização de informações, análises quantitativas e/ou tecnologias. Sendo eles componentes de um movimento maior do qual se baseia na ideologia de Science Management desenvolvida na segunda revolução industrial 
por Frederick Taylor, a qual defende a aplicação de abordagens científicas e análises estatísticas nos processos empresariais e de gestão de pessoas.

Dessa forma os autores adotam um termo unificado para os conceitos de BI, BA e Pesquisa Operacional chamado de dianoetic management paradigm, e o definem como:

"O desenvolvimento da gestão baseada em lógica e evidências ao invés de intuições"

Mortenson et al. (2015) ressaltam a multidisciplinaridade do tema e classificam os conhecimentos necessários em 3 grupos, conforme descrição abaixo:

- Tecnologia: Incorpora diversas ferramentas utilizadas para viabilizar de forma eficiente o processamento dos dados (e.g. Hardware, Software, Redes de computadores)

- Métodos quantitativos: Aplicação de abordagens quantitativas para análise de dados das empresas (e.g. Estatística, Inteligência Artificial, Econometria e Pesquisa Operacional)

- Tomada de decisão: Representa as ferramentas, teorias e práticas utilizadas para o entendimento e suporte ao processo de tomada de decisão. Fundamentando-se tanto em áreas clássicas de conhecimento como psicologia e ciência comportamental (behavioural science), como em outras disciplinas menos tradicionais (e.g. Interface gráfica do usuário e visualização de informações em sistemas e métodos de estruturação de problemas de pesquisa operacional).

A Figura 9 sumariza os conhecimentos, seus relacionamento e intersecções:

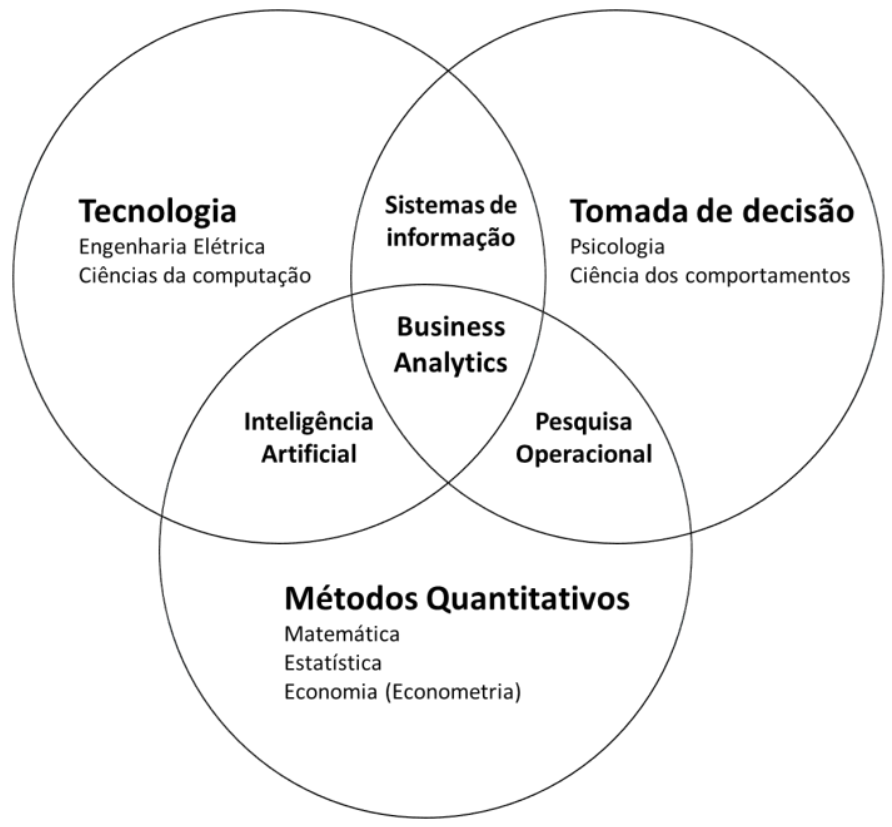

Figura 9 - Áreas de conhecimento do Business Analytics Fonte: Adaptado pelo autor Mortenson et al. (2015)

Outro trabalho que se destaca para o presente estudo é o artigo dos autores Viaene e Bunder (2011), que sinaliza que projetos de Business Analytics apresentam alto grau de incerteza, alteração de requisitos e, consequentemente, elevado risco. $\mathrm{O}$ estudo apresentado pelos 
autores teve como intuito mapear as principais características de experientes gerentes de projetos dessa área e quais as melhores práticas empregadas pelos mesmos.

Dentre os principais pontos de destaque estão o foco em resultado e a flexibilidade no planejamento das atividades. Sendo esse ponto consequência da premissa adotada por eles de que o plano inicial sofrerá alterações devido ao alto grau de incerteza dos projetos e alterações de requisitos. Dessa forma, foi identificado maior aderência a aplicações de metodologias de gestão ágil de projetos por esses profissionais. As quais priorizam a geração de valor através da prototipação rápida, iteração com usuários e entregas contínuas ao longo do projeto (iterative feature-based delivery).

Os gerentes ressaltam também a necessidade do engajamento e compreensão dos usuários ao modelo proposto, e também seu respectivo alinhamento aos processos da empresa. Sendo esses pontos fatores críticos para a ferramenta não entrar em desuso ou ser aplicada de forma errada.

Os autores por fim ressaltam a necessidade do entendimento do negócio por parte da equipe do projeto e a necessidade de estímulos por parte do gerente do projeto na mudança da cultura organizacional da empresa.

Bose (2009) investiga a utilização e fatores críticos de implementação e gestão de tecnologias de analytics.

Segundo o autor, a diferenciação das empresas no atual disputado e competitivo mercado está em sua habilidade de realizar decisões de forma precisa, rápida e efetiva em todos os níveis (Operacional, Tático e Estratégico), de forma a endereçar as preferências e prioridades dos clientes. Dessa forma, a incorporação de técnicas analíticas (advanced analytics) em sua operação atua como relevante viabilizador para o atingimento dos objetivos do negócio.

Os autores apresentam a seguinte definição para o termo Advanced Analytics:

“Advanced analytics é um termo generalista, o qual significa a aplicação de várias técnicas analíticas em dados para responder perguntas $e$ resolver problemas. Não é apenas uma tecnologia, mas sim um grupo de ferramentas, as quais são utilizadas e combinadas entre si, para gerar informação, analisar informação e prever resultados."

E também ressaltam a relevância das técnicas de integração e mineração de dados para o levantamento das informações e a utilização de métodos estatísticos para identificação de tendências e padrões nas informações. Além de outras técnicas utilizadas para manipulação de dados como a lógica fuzzy para o manejo de dados incompletos e ambíguos, e as redes neurais para a antecipação de decisões e auxílio em análises preditivas.

Em seu texto, os autores também exploram possíveis utilizações para as tecnologias de data mining, text mining e web mining.

Empresas com forte foco no consumidor tem grande potencial para a utilização de ferramentas de data mining, como exemplo: melhora na efetividade de campanhas de marketing, maximização da performance comercial através de cross-selling e up-selling e melhora na taxa de inadimplência através da utilização das tecnologias em análise de crédito, monitoramento do nível de satisfação dos clientes. 
Com relação a aplicações de text mining, o autor apresenta 3 vantagens frente à análise tradicional de textos:

1. Agilidade no processamento de grandes volumes de texto, em comparação à velocidade humana de leitura;

2. A objetividade e possibilidade de customização do processo - i.e. os resultados são dependentes apenas dos algoritmos e análises estatísticas disponibilizados pela tecnologia de text mining;

3. A possibilidade de automatização de atividades e rotinas trabalhosas realizadas por humanos;

A tecnologia pode ser empregada principalmente na extração de informações, classificação, organização e visualização de documentos de acordo com seu conteúdo.

Web mining é caracterizado pela utilização de ferramentas de mineração e análise para o acompanhamento dos padrões de navegações dos usuários para o refinamento da estrutura e layout de websites. Outra relevante área de aplicação e objeto de estudo são os sistemas de recomendação (recommender systems), os quais através da análise de padrões de comportamento dos usuários realizam sugestões de acordo com suas potenciais preferências.

Os autores também apresentam os principais desafios para a implantação e utilização bem sucedidas de Business Analytics, e apontam os seguintes pontos:

- Engajamento da companhia na utilização e no processo de implantação é um fator crítico de sucesso. O qual pode ser alcançado através do envolvimento de uma equipe multifuncional (sendo essa liderada por um executivo da área de negócios) no projeto, no cumprimento de todas as atividades necessárias (e programadas no cronograma) para a correta implantação e no reconhecimento e motivação da equipe ao longo da implantação;

- Devido ao elevado custo inicial e significativas alterações nos processos organizacionais, estratégias de implementação incrementais são mais apropriadas que as disruptivas (big bang), e preferencialmente em áreas com elevado impacto potencial, de forma a dar visibilidade na empresa do valor gerado ao negócio;

- Adequação às políticas e regulamentações de privacidade de informações de clientes;

- Capacitação da equipe para a utilização da ferramenta e interpretação das análises;

- Facilidade de acesso e qualidade dos dados disponíveis na organização, além de seu compartilhamento por todas as áreas da empresa;

Etapas da utilização do analytics:

1. Desenvolver o entendimento do escopo e dos objetivos do processo de BA;

2. Captar e selecionar um grupo de dados alvo;

3. Integrar e verificar os dados;

4. Limpar, pré-processar e transformar os dados;

5. Desenvolver os modelos de análise preditiva (e.g. árvores de decisão, regressões e redes neurais) e as hipóteses do problema; 
6. Selecionar os algoritmos apropriados de data mining, text mining ou web mining;

7. Interpretar e visualizar os resultados;

8. Testar e verificar os resultados;

9. Utilizar e manter a descoberta do conhecimento;

Apesar das variações entre as definições apresentadas anteriormente e suas correlações com o termo Business Intelligence, é possível notar uma convergência entre os autores sobre a aplicação de metodologias e técnicas de análise de dados organizacionais com o intuito de suportar a tomada de decisão de forma mais assertiva, na qual há uma corrente de autores que o definem como subconjunto de BI, outra como algo mais amplo e uma terceira linha de pesquisa que define o termo de forma complementar - BI\&A. Conforme apresentado na Tabela 8 .

Tabela 8 - Correntes teóricas Business Analytics

Fonte: Elaborado pelo autor

\begin{tabular}{|c|c|c|}
\hline $\begin{array}{l}\text { Posicionamento } \\
\text { Teórico }\end{array}$ & Autores & Definição de Business Analytics \\
\hline \multirow{2}{*}{$\begin{array}{l}\text { Business Analytics } \\
\text { como subconjunto } \\
\text { de Business } \\
\text { Inteligence }\end{array}$} & $\begin{array}{l}\text { Davenport e } \\
\text { Harris (2007) }\end{array}$ & $\begin{array}{l}\text { "Utilização extensiva de dados e métodos quantitativos e estatísticos, modelos } \\
\text { explanatórios e preditivos, e gestão baseada em fatos para o direcionamento de } \\
\text { ações e decisões. O Analytics pode ser input para decisões humanas ou direcionar } \\
\text { decisões completamente automatizadas. Sendo esse um subconjunto do Business } \\
\text { Intelligence: Conjunto de tecnologias e processos que utilizam dados para o } \\
\text { entendimento e análise da performance organizacional" }\end{array}$ \\
\hline & Bartlett (2013) & $\begin{array}{l}\text { Business Intelligence = Information Technology + Business Analytics } \\
\text { "Tecnologia da informação - Consolidação e gestão de dados para a criação de data } \\
\text { warehouse, viabilizando o fornecimento de relatórios e dashboards. (Trazendo os } \\
\text { dados para o negócio)" } \\
\text { "Business analytics - Catalisação da análise de dados e o do conhecimento do } \\
\text { negócio para a realização de decisões baseadas em dados (Trazendo os } \\
\text { questionamentos do negócio para os dados)." }\end{array}$ \\
\hline \multirow{3}{*}{$\begin{array}{l}\text { Business Inteligence } \\
\& \text { Analytics como um } \\
\text { conceito único }\end{array}$} & & $\begin{array}{l}\text { “...é geralmente atribuído a técnicas, tecnologias, sistemas, práticas, metodologias, } \\
\text { e aplicações que analisam dados críticos no negócio para auxiliar as organizações em } \\
\text { um melhor entendimento seu mercado, negócio e em decisões mais rápidas..." }\end{array}$ \\
\hline & Chen et al. 2012 & $\begin{array}{l}\text { "Termo unificado para descrever conceitos e métodos de utilização intensiva de } \\
\text { informações para melhor a tomada de decisão das empresas. BI\&A inclui a } \\
\text { arquitetura subjacente, ferramentas analíticas, sistemas de gestão de banco de } \\
\text { dados, técnicas de mineração de dados (data/text/web mining), aplicações, e } \\
\text { metodologias." }\end{array}$ \\
\hline & $\begin{array}{l}\text { Chen e Chen } \\
\text { (2013) }\end{array}$ & $\begin{array}{l}\text { "BIA é referente à: (1) as tecnologias, sistemas, práticas, e aplicações que (2) } \\
\text { analisam dados críticos das empresas para (3) auxiliar as organizações em um } \\
\text { melhor entendimento de seu mercado e negócio" }\end{array}$ \\
\hline \multirow{2}{*}{$\begin{array}{l}\text { Business Inteligence } \\
\text { como subconjunto } \\
\text { de Business } \\
\text { Analytics }\end{array}$} & $\begin{array}{l}\text { Holsapple et al. } \\
\text { (2014) }\end{array}$ & $\begin{array}{l}\text { "Nós adotamos uma caracterização central de business analytics como a } \\
\text { identificação e resolução de problemas baseado em evidências, os quais ocorrem } \\
\text { no contexto de negócios" }\end{array}$ \\
\hline & Bose (2009) & $\begin{array}{l}\text { "Advanced analytics é um termo generalista, o qual significa a aplicação de várias } \\
\text { técnicas analíticas em dados para responder perguntas e resolver problemas. Não é } \\
\text { apenas uma tecnologia, mas sim um grupo de ferramentas, as quais são utilizadas e } \\
\text { combinadas entre si, para gerar informação, analisar informação e prever } \\
\text { resultados." }\end{array}$ \\
\hline
\end{tabular}


O presente trabalho tem como intuito analisar os fatores críticos de sucesso na implantação de sistemas que utilizam técnicas estatísticas e modelagens matemáticas para o suporte à tomada de decisão. Dessa forma o posicionamento teórico de BA como um subconjunto de BI e a definição de Davenport e Harris (2007) apresenta-se mais adequada para esse estudo por restringir seu escopo a este tipo de aplicação, além de sua relevância tanto na academia como na indústria conforme apresentado em 2.1.3 Análise de citação e co-citação.

Isto posto, será adotada a seguinte definição de Business Analytics para este trabalho:

"Utilização extensiva de dados e métodos quantitativos e estatísticos, modelos explanatórios e preditivos, e gestão baseada em fatos para o direcionamento de ações e decisões. O Analytics pode ser input para decisões humanas ou direcionar decisões completamente automatizadas. Sendo esse um subconjunto do Business Intelligence: Conjunto de tecnologias e processos que utilizam dados para o entendimento e análise da performance organizacional"

Para estruturação do modelo referência e ferramenta de mensuração, os fatores críticos de sucesso específicos de ferramentas de Business Analytics foram agrupados em 3 dimensões: Tecnologia (Sistemas de Informação), Cultura Organizacional (Fact-Based Management) e Pessoas. Seu detalhamento e desdobramento em hipóteses será detalhado em 2.2.4 - Fatores Críticos de Sucesso.

\subsubsection{Big Data}

Chen et al. (2012) apresentam a evolução histórica dos termos BI, BA e Big Data. Segundo os autores, Business Intelligence (BI) é um termo que se popularizou na década de 90 entre os profissionais de TI e negócios. No final dos anos 2000 o termo Business Analytics (BA) foi introduzido para referenciar ao componente de técnicas analíticas implementadas em sistemas de BI. Já o Big Data ou Big Data Analytics são termos utilizados para descrever técnicas analíticas aplicadas em volumes de dados extremamente extensos (de terabytes à exabytes) e complexos (de sensores à social media), os quais requerem avançadas e únicas tecnologias de armazenagem, gestão, análise e visualização de dados.

Mcafee e Brynjolfsson (2012) apontam que de forma similar ao conceito de Business Analytics, Big Data tem como objetivo expandir o conhecimento das empresas através da análise dos dados, porém apresenta 3 principais diferenças (3V's): Volume de informações, Velocidade de armazenagem e interpretação de dados e Variedade dos tipos e origens das informações (e.g. textos, áudio, imagem, sensores, etc).

De forma similar aos autores debatidos anteriormente, Manyika et al. (2011) apresentam Big Data com conjunto de dados cujo seu tamanho é superior a capacidade de ferramentas de bancos de dados convencionais capturar, gerenciar e analisar.

Davenport (2014) afirma que apesar de suas particularidades, a noção que fundamenta o termo Big Data não é particularmente nova. Pois a ideia de analisar dados para o melhor entendimento dos negócios já é utilizada pelas corporações desde 1954 através da criação de um grupo de Analytics pela UPS (empresa logística americana). A evolução dos termos relativos à utilização de dados para suporte a decisão é apresentada pelo autor, conforme Tabela 9. 
Tabela 9 - Terminologia para o uso e a análise de dados

Fonte: Davenport (2014)

\begin{tabular}{lll} 
Termo & Período & Significado específico \\
\hline $\begin{array}{l}\text { Suporte à decisão } \\
\text { Suporte aos executivos }\end{array}$ & 1970 - 1985 & $\begin{array}{l}\text { Uso da análise de dados para dar suporte à } \\
\text { tomada de decisão }\end{array}$ \\
\hline Processamento analítico 1990 & $\begin{array}{l}\text { Foco na análise de dados para dar suporte ao } \\
\text { processo decisório dos altos executivos }\end{array}$ \\
on-line (OLAP) & $1990-2000$ & $\begin{array}{l}\text { Software para a análise de tabelas de dados } \\
\text { multidimensionais }\end{array}$ \\
\hline Business Intelligence & $1989-2005$ & $\begin{array}{l}\text { Ferramentas para dar suporte a decisões } \\
\text { orientadas por dados, com ênfase em relatórios }\end{array}$ \\
\hline Analytics & $2005-2010$ & $\begin{array}{l}\text { Foco em análises estatíticas e matemáticas para } \\
\text { a tomada de decisões }\end{array}$ \\
\hline Big Data & 2010 - atualmente & $\begin{array}{l}\text { Foco em grande volume de dados não } \\
\text { estruturados e em rápido movimento }\end{array}$ \\
\hline
\end{tabular}

O autor aponta os principais desafios para o Big Data sendo: estruturar os dados, analisá-los e extrair valor deles. E apresenta a seguinte definição para o termo:

"Big data é um termo genérico para dados que não podem ser contidos nos repositórios usuais; refere-se a dados volumosos demais para caber em um único servidor; não estruturados demais para se adequar a um banco de dados organizado em linhas e colunas; ou fluidos demais para serem armazenados em um data warehouse estático. Embora o termo enfatize seu tamanho, o aspecto mais complicado do big data, na verdade, envolve sua falta de estrutura." (DAVENPORT, 2014)

Nessa mesma obra, Davenport (2014) diferencia o termo de Analytics conforme Tabela 10:

Tabela 10 - Diferenças entre Big Data e Analytics Fonte: Davenport (2014)

\begin{tabular}{lll}
\hline & Big Data & Analytics tradicional \\
\hline Tipo de dados & Formatos não estruturados & $\begin{array}{l}\text { Dados formatados em } \\
\text { linhas e colunas }\end{array}$ \\
\hline Volume de dados & 100 terabytes a petabytes & $\begin{array}{l}\text { Dezenas de terabytes ou } \\
\text { menos }\end{array}$ \\
\hline Fluxo de dados & Fluxo constante de dados & Pool estático de dados \\
\hline Métodos de análise & Aprendizado de máquina & Baseados em hipóteses \\
\hline Objetivo principal & $\begin{array}{l}\text { Produtos baseados em } \\
\text { dados }\end{array}$ & $\begin{array}{l}\text { Suporte ao processo } \\
\text { decisório interno }\end{array}$ \\
\hline
\end{tabular}

Devido ao elevado volume de dados processados pelas ferramentas de Big Data, por vezes modelagens matemáticas para análises preditivas ou prescritivas (baseadas na lógica indutiva) não são necessárias tendo em vista o processamento de toda a população de dados, mitigando a relevância de conceitos como significância estatística ou probabilidade (DAVENPORT, 2014). Nestes casos, relatórios simples de análises de frequência, gráficos 
de dispersão e de representatividade (e.g. gráficos de pizza) são suficientes para o auxílio na tomada de decisão.

Conforme mencionado anteriormente no capítulo 2.2.1 Business Analytics, neste trabalho o conceito de Business Intelligence (BI) será adotado de forma mais ampla que o termo Business Analytics (BA), e Big data será considerado como um sub conjunto de BA no qual são utilizadas técnicas e análises quantitativas em grandes massas de dados para o suporte a tomada de decisão.

Utilizando como variáveis o grau de sofisticação de modelagem de matemática, a complexidade dos dados analisados e as funcionalidades se sistemas de BI apresentadas por Davenport e Harris (2007), a Figura 10 ilustra o relacionamento entre os 3 termos.

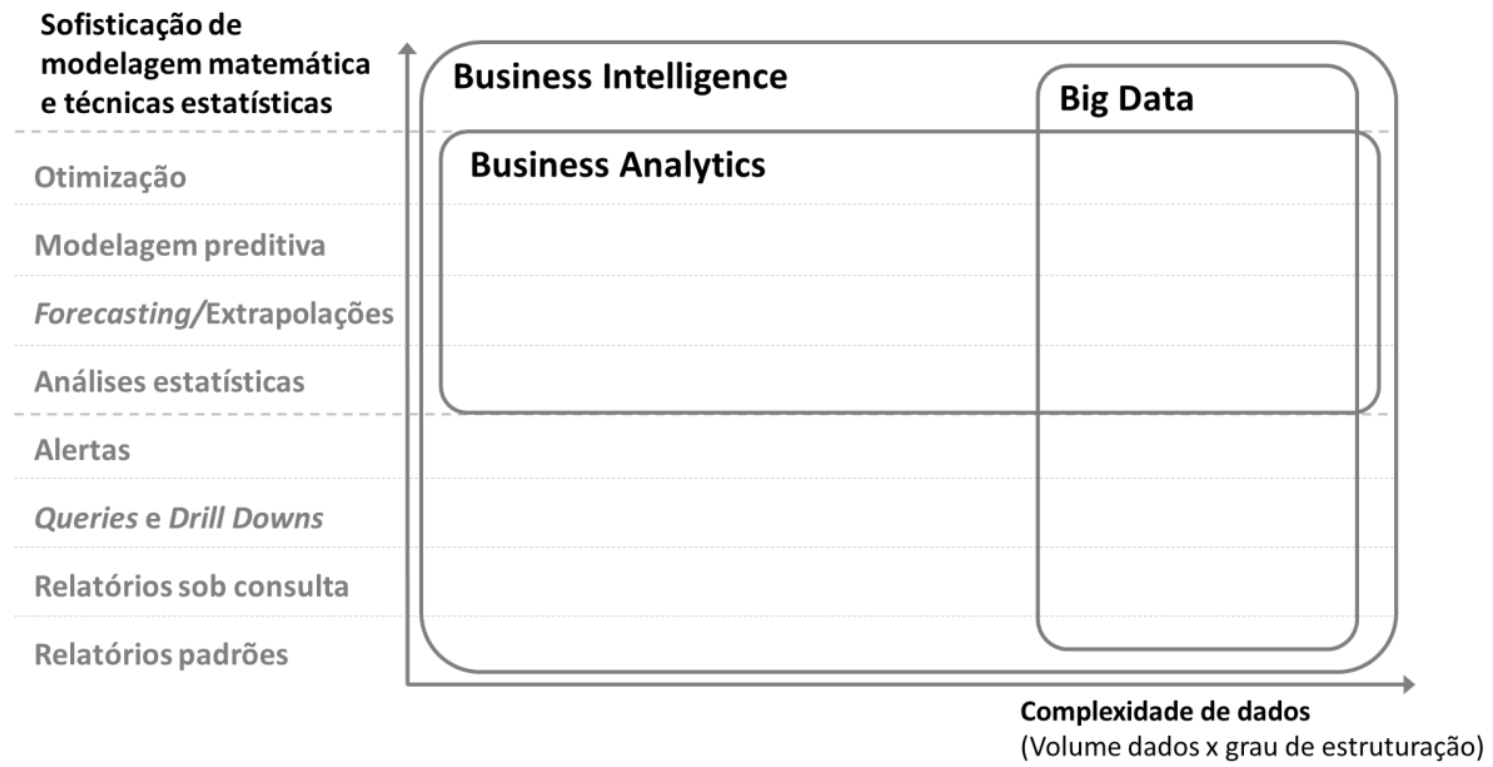

Figura 10 - Hierarquia entre BI, BA e Big Data

Fonte: Elaborado pelo autor

\subsubsection{Inteligência Competitiva}

Embora alguns autores tentem delimitar os conceitos de Business Intelligence e Inteligência Competitiva (IC), ainda não há consenso na academia e por vezes os termos são utilizados de forma equivalente (ARISTIZABAL, 2014; NETTO, 2011). Sendo esse ocasionado possivelmente pela similaridade no objetivo (captura e análise de informações para a ampliação do conhecimento das organizações) e na pluralidade de conhecimentos envolvidos de ambos os conceitos.

O conceito de inteligência no ambiente das organizações pode ser compreendido como proposições que permitem tomar decisões. Sendo o argumento central para a defesa dessa definição a afirmação de que é a inteligência, e não a informação, que auxilia o administrador a tomar decisões corretas no ambiente corporativo (CAPUANO et al., 2009).

Segundo Kahaner (1997), o processo de transformação de informações em inteligência é chamada de Inteligência Competitiva (IC), sendo esse adaptado de técnicas utilizadas na política e agências de inteligência militar durante a época da guerra fria. O qual é composto 
por um processo formado por 4 macro atividades, conforme Figura 11, e apresenta a seguinte define Inteligência Competitiva da seguinte forma:

"Inteligência Competitiva é um método sistemático de coleta e armazenagem de informação sobre as atividades dos competidores $e$ tendências gerais do negócio para o atingimento dos objetivos da companhia. "(KAHANER, 1997)

Conforme mencionado anteriormente o autor define IC como processo formado pelas seguintes etapas:

- Planejamento e Direcionamento: Etapa na qual gestores são envolvidos na decisão nos requerimentos de conhecimento (Inteligência necessária);

- Coleta de dados: Esta etapa é referente à coleta de informações de acordo com o conhecimento a ser produzido. Essa etapa também envolve o processamento e armazenamento das informações em formato eletrônico. De forma à ser manipulada e analisada posteriormente;

- Análise: Essa é geralmente a etapa considerada de maior grau de dificuldade no processo, pois exige habilidades e conhecimentos do mercado necessários para interpretar as informações, observar padrões e gerar cenários;

- Disseminação: A última etapa é responsável pela entrega da inteligência (conhecimento) aos requisitantes (gestores) para a estruturação de possíveis planos de ação e, posteriormente, disseminação para o restante da companhia;

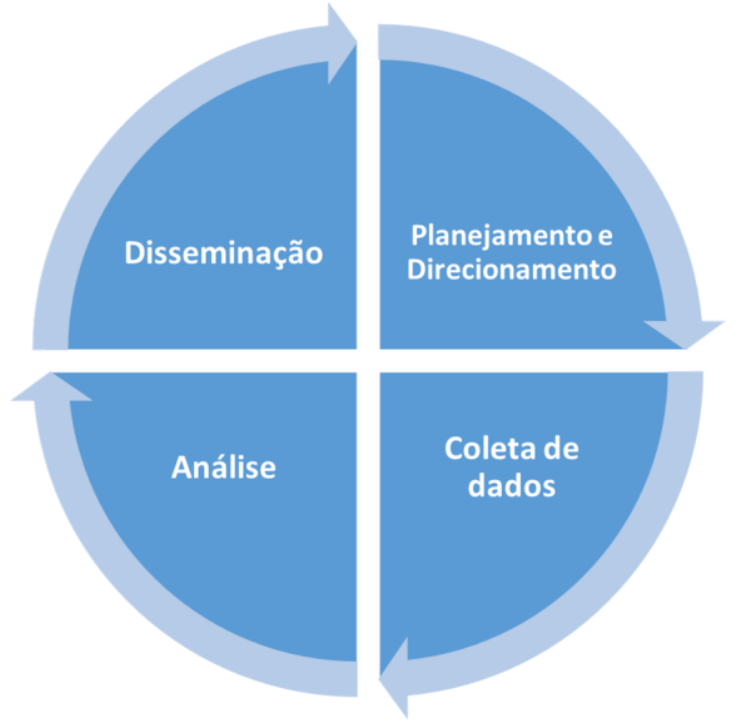

Figura 11 - Processo de Inteligência Competitiva Fonte: Adaptado Kahaner (1997)

De forma similar, Vriens (2004) apresenta a seguinte definição para o termo Inteligência Competitiva:

"Inteligência Competitiva pode ser descrita como a produção e o processamento de informações sobre o ambiente de uma organização para fins estratégicos. Para (re)formular sua estratégia, organizações precisam 
coletar e processar informações sobre seu ambiente - sobre, por exemplo, competidores, clientes, fornecedores, governos, tendências tecnológicas ou desenvolvimentos ecológicos. "(VRIENS, 2004)

IBICT (2006) discute sobre a evolução da inteligência competitiva nas organizações, no qual inicialmente o processo de adoção da inteligência nas organizações teve como marco contextual a percepção da instabilidade e da incerteza na ambiência, obtida por meio da atividade de monitoramento ambiental, que mostrou características de imprecisão e ambiguidade em relação aos fatores externos, tanto no ambiente nacional quanto no internacional. Esses fatos induziram economistas e administradores a adotar a inteligência econômica (IE) para que organizações e até países pudessem se antecipar ao se depararem com esses fatores. Sendo IE definida como o conjunto de ações coordenadas de busca, tratamento, distribuição e proteção de informação útil aos atores econômicos e obtida legalmente. Tendo como objetivo fornecer aos gestores e tomadores de decisão tanto do governo como do setor privado, os conhecimentos necessários para a compreensão de seu meio ambiente e de forma a ajustar suas estratégias individuais ou coletivas.

$\mathrm{Na}$ interpretação das organizações e empresas, a inteligência econômica tornou-se inteligência de negócios e, posteriormente, inteligência competitiva. Sendo essa definida da seguinte forma:

"A inteligência competitiva pode se definir como um processo de aprendizado motivado pela competição, fundado sobre a informação, permitindo esta última a otimização da estratégia corporativa em curto e em longo prazo" (IBICT, 2006)

Os benefícios organizacionais da prática de inteligência competitiva estão principalmente voltados ao suporte às decisões estratégicas, por exemplo: antecipação a movimentos da concorrência; detecção antecipada de tecnologias emergentes e de alto impacto estrutural; redução de custos com o aprimoramento do desempenho operacional; subsídios para estratégias de fusão e aquisição; melhoria da eficiência das ações de marketing; reavaliação constante das estratégias com a criação de cenários; desenvolvimento de fornecedores mais estratégicos e competitivos em custo; penetração em novos mercados (CAPUANO et al., 2009).

A multidisciplinaridade da inteligência competitiva é reconhecida por Marcial (2007), a qual apresenta as seguintes as áreas do conhecimento científico que suportam os processos e atividades de IC são: administração, ciência da informação, ciência da computação, comunicação, psicologia, filosofia, matemática, lógica e estatística.

Netto (2011) também ressalta esse ponto, afirmando que esse é um campo de estudo que envolve o conhecimento de diferentes áreas de pesquisa com foco sobre a utilização de tecnologias computacionais aplicadas a administração de negócios.

Em seu trabalho o autor utiliza a definição apresentada por Valentim, conforme descrição abaixo:

“A inteligência competitiva é o processo que investiga o ambiente onde a empresa está inserida, com o propósito de descobrir oportunidades e reduzir os riscos, bem como diagnostica o ambiente interno 
organizacional, visando o estabelecimento de estratégias de ação a curto, médio e longo prazo" (VALENTIM, 2003 apud CABRAL NETTO, 2011)

Segundo o autor, a Inteligência Competitiva tem interface com os conceitos de Gestão do Conhecimento, Decisão, Monitoramento Ambiental, Estratégia e Business Intelligence (BI). Sendo esse último termo relacionado às ferramentas de TI que viabilizam a Inteligência Competitiva. Conforme apresentado na Figura 12.

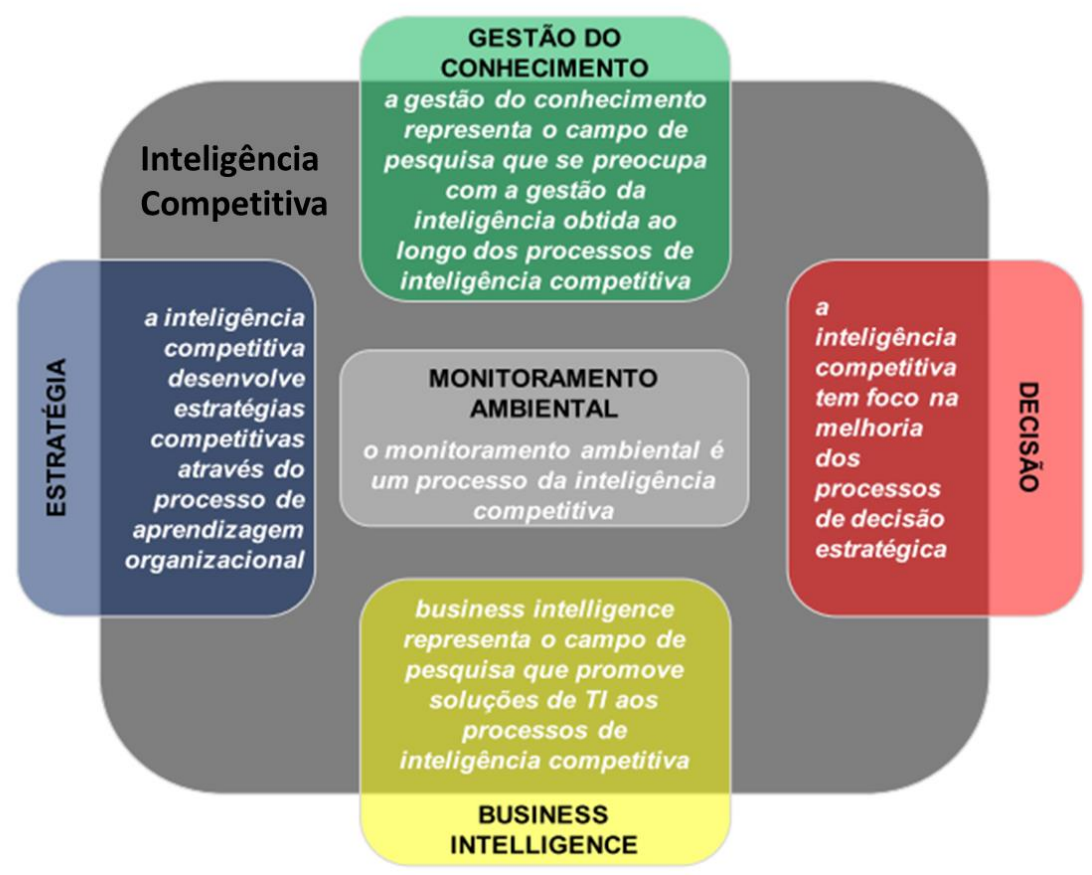

Figura 12 - Modelo de Inteligência Competitiva

Fonte: Cabral Netto (2011)

É possível observar nas definições apresentadas anteriormente a relação do conceito de IC com o monitoramento do mercado (i.e. Comportamento dos consumidores, concorrentes, tendências tecnológicas, etc) para o auxílio na definição estratégica das empresas e posicionamento de mercado.

Conforme apresentado por Capuano et al. (2009), tal monitoramento pode ser realizado de distintas formas (e.g. entrevistas, relatórios anuais, discursos, relatórios financeiros) sendo uma delas a utilização de ferramentas BI para a captura (e.g. data mining e text mining) e análise das informações.

Em contrapartida, Business Intelligence tem como essência em seu conceito o suporte a tomada de decisão seja ela voltada tanto para a estratégia e posicionamento de mercado da empresa como para a otimização interna de sua operação. Sendo passível de utilização tanto em decisões operacionais, táticas como estratégicas.

Dessa forma para este trabalho a Inteligência Competitiva será considerado como um campo correlato, porém distinto de Business Intelligence e, consequentemente, de Business Analytics e Big Data (conforme capítulo 2.2.1 Business Analytics e 2.2.2 Big Data). 


\subsubsection{Fatores Críticos de Sucesso}

O conceito de identificação de fatores de sucesso foi abordado pela primeira vez por Donald Daniel em seu artigo Management Information Crisis de 1961 (SANTOS, 2014). O qual enfoca a questão da crise no gerenciamento da informação e indica a necessidade de uma administração estratégica deste recurso.

Rockart (1979) em sua obra Chief Executives Define Their Own Data Needs apresenta um método para a identificação das necessidades de informação dos executivos e seus respectivos fatores críticos de sucesso (FCS), e apresenta a seguinte definição para esse termo:

"Fatores críticos de sucesso são, para qualquer negócio, um número limitado de áreas nas quais o resultado, se satisfatório, irá garantir uma performance competitiva bem-sucedida da organização"

Na literatura há diversas definições para Fatores Críticos de Sucesso (AMBERG et al., 2005), e na conjuntura de sistemas de BI, Olszak e Ziemba (2012) apresentam a seguinte definição:

"No contexto de sistemas de Business Intelligence, FCS podem ser compreendidos como um conjunto de tarefas e procedimentos que devem ser endereçados para garantir o sucesso de sistemas de BI. Estas tarefas e procedimentos devem ser fomentados caso já tenham sido realizados, ou fomentados caso sejam inexistentes"

Para este trabalho o termo Fatores Críticos de Sucesso (FCS) será utilizado no contexto de variáveis determinantes para o sucesso de sistemas de Business Analytics e desta forma será adotada a definição apresentada por Olszak e Ziemba (2012), a qual pode diferir do conceito inicial de FCS apresentado por Rockart (1979).

Conforme a discussão apresentada anteriormente e ilustrada na Figura 10, sistemas de Business Analytics podem ser compreendidos como um tipo de Business Intelligence, o que viabiliza a adoção desta definição para este trabalho.

A Tabela 11 apresenta uma consolidação sobre trabalhos referentes à CFS de sistemas de Business Intelligence apresentada por Hawking (2013). 
Tabela 11 - Revisão bibliográfica sobre FCS de BI

Fonte: Adaptado Hawking (2013)

\begin{tabular}{|c|c|c|}
\hline Autor & Método de & Fatores críticos de sucesso \\
\hline Farley (1998) & Conceitual & $\begin{array}{l}\text { Velocidade de implementação, Flexibilidade de ajuste para necessidades do } \\
\text { negócio, Utilidade da informação, Facilidade de navegação }\end{array}$ \\
\hline $\begin{array}{l}\text { Watson e Haley } \\
(1997)\end{array}$ & Survey & $\begin{array}{l}\text { Suporte dos gestores, Adequação dos recursos, Gestão da mudança, } \\
\text { Gerenciamento de metadados }\end{array}$ \\
\hline Chen et al (2000) & Survey & Satisfação do usuário \\
\hline $\begin{array}{l}\text { Sammon e } \\
\text { Finnegan (2000) }\end{array}$ & $\begin{array}{l}\text { Estudo de } \\
\text { caso }\end{array}$ & $\begin{array}{l}\text { Abordagem focada no negócio, Suporte dos gestores, Adequação dos recursos } \\
\text { (incluindo o orçamentário e habilidades), Qualidade de dados, Flexibilidade do } \\
\text { modelo de negócio, Administração de dados, Integração do Data warehouse com } \\
\text { os demais sistemas, Estratégia de automação nos métodos/ferramentas de } \\
\text { extração de dados }\end{array}$ \\
\hline $\begin{array}{l}\text { Little e Gibson } \\
(2003)\end{array}$ & Survey & $\begin{array}{l}\text { Suporte dos gestores, Abordagem do negócio (Enterprise aproach, Prototipagem } \\
\text { da utilização do DW, Metadados, Metodologia de implementação, Suporte } \\
\text { externo (consultoria) }\end{array}$ \\
\hline $\begin{array}{l}\text { Mukherjee e } \\
\text { D'Souza (2003) }\end{array}$ & Conceitual & $\begin{array}{l}\text { Qualidade de dados, Adequação da tecnologia (Technology fit), Suporte dos } \\
\text { gestores, Definição dos objetivos de negócio, Envolvimento dos usuários, Gestão } \\
\text { da Mudança }\end{array}$ \\
\hline Rudra e Yeo (2000) & Survey & Fatores técnicos (Qualidade de dados, Consistência de dados, etc.) \\
\hline $\begin{array}{l}\text { Joshi e Curtis } \\
\text { (1999) }\end{array}$ & Conceitual & $\begin{array}{l}\text { Fatores relacionados ao projeto (aderência do planejamento do projeto às } \\
\text { necessidades do negócio), fatores técnicos (Seleção de DBMS, Carga de dados, } \\
\text { Eficiência de acesso de dados, etc.) }\end{array}$ \\
\hline $\begin{array}{l}\text { Wixom e Watson } \\
(2001)\end{array}$ & Survey & $\begin{array}{l}\text { Qualidade do sistema, Suporte dos gestores, Adequação dos recursos, } \\
\text { Participação do usuário, Habilidades do time de projeto }\end{array}$ \\
\hline $\begin{array}{l}\text { Chenweth et al } \\
(2006)\end{array}$ & $\begin{array}{l}\text { Estudo de } \\
\text { caso }\end{array}$ & $\begin{array}{l}\text { Suporte dos gestores, defensor, Arquitetura do sistema (data marts), Adequação } \\
\text { da organização(Organizational fit) /Aceitação do usuário }\end{array}$ \\
\hline $\begin{array}{l}\text { Yeoh e Koronios } \\
(2010)\end{array}$ & $\begin{array}{l}\text { Estudo de } \\
\text { caso }\end{array}$ & $\begin{array}{l}\text { Suporte dos gestores, Visão clara do negócio, Gestão de projetos, Gestão de } \\
\text { mudança, Qualidade de dados e Infraestrutura }\end{array}$ \\
\hline
\end{tabular}

\subsubsection{Comparação entre FCS de sistemas ERP e BI}

A análise de fatores críticos de sucesso na implantação de ferramentas de TI é um assunto recorrente em pesquisas na área de Gestão de Tecnologia da Informação, no qual destaca-se o final da década de 90 e início dos anos 2000 pelo volume de publicações impulsionado pelos recorrentes projetos de implantação de ferramentas de ERP (Enterprise Resource Planning) em curso nas organizações neste período (AKKERMANS; VAN HELDEN, 2002).

Devido a maturidade do tema e volume de publicações destes tipos de sistema, este tópico apresenta um resumo sobre os FCS de sistemas ERP e posteriormente exibe uma discussão entre os pontos de convergência e dispersão relativos à FCS de ferramentas de suporte a decisão (i.e. Business Intelligence).

Sistemas ERP são softwares integrados que automatizam e conectam atividades centrais da empresa de distintos departamentos como produção, recursos humanos, financeiro e logística (Supply Chain Management) (HOLLAND; LIGHT, 1999).

Para este trabalho, utilizaremos a definição apresentada por Hawking e Sellitto (2009): 
"Sistemas ERP podem ser definidos como sitemas de informação que são: integrados, modulares, abrangem um amplo escopo de funcionalidades e são responsáveis pelo processo de transações em tempo real"

De acordo com Holland e Light (1999), apesar do crescente mercado destas plataformas estimava-se nesta época que $90 \%$ dos projetos de implantação de ERP atrasavam ou apresentavam custo superior ao orçado e $40 \%$ dos projetos falhavam completamente (o sistema não foi implementado ou era inutilizável).

A Tabela 12 apresenta os artigos mapeados com base em uma pesquisa bibliográfica sobre Fatores Críticos de Sucesso (FCS) em projetos/implantações de ferramentas ERP (Enterprise Resource Planning). Para essa análise, foi utilizada a base da coleção principal do ISI Web of Knowledge, da Thomson Reuters, na qual foram selecionados artigos que contenham no título a palavra-chave "Critical Success Factors" das áreas de conhecimento de Operations Research Management Science, Business Economics, Information Science Library Science e Computer Science.

Tabela 12 - Artigos FCS ERP

Fonte: Elaborado pelo autor

\begin{tabular}{|c|c|c|}
\hline Citações & Autor & Título \\
\hline 331 & Umble et. al 2003 & Enterprise resource planning: Implementation procedures and critical success factors \\
\hline 277 & Hong e Kim 2002 & The critical success factors for ERP implementation: an organizational fit perspective \\
\hline 243 & Holland Light 1999 & A critical success factors model for ERP implementation \\
\hline 190 & Akkermans e Helden 2002 & $\begin{array}{l}\text { Vicious and virtuous cycles in ERP implementation: a case } \\
\text { study of interrelations between critical success factors }\end{array}$ \\
\hline 90 & Ngai et al. 2008 & Examining the critical success factors in the adoption of enterprise resource planning \\
\hline 86 & Nah et al. 2003 & ERP implementation: Chief Information Officers' perceptions of critical success factors \\
\hline 59 & Nah e Delgado 2006 & Critical success factors for enterprise resource planning implementation and upgrade \\
\hline 53 & Sun et al. 2005 & $\begin{array}{l}\text { Achievement assessment for enterprise resource planning (ERP) system } \\
\text { implementations based on critical success factors (CSFs) }\end{array}$ \\
\hline 32 & Olson e Zhao 2007 & CIOs' perspectives of critical success factors in ERP upgrade projects \\
\hline 24 & Plant e Willcocks 2007 & Critical Success Factors in International ERP Implementations: A Case Research Approach \\
\hline 21 & Ram et al. 2014 & $\begin{array}{l}\text { Implementation critical success factors (CSFs) for ERP: Do they contribute to } \\
\text { implementation success and post-implementation performance? }\end{array}$ \\
\hline 12 & Koh et al. 2011 & $\begin{array}{l}\text { Drivers, barriers and critical success factors for ERPII implementation in supply chains: A } \\
\text { critical analysis }\end{array}$ \\
\hline 8 & Liu 2011 & $\begin{array}{l}\text { Empirical study on influence of critical success factors on ERP knowledge management } \\
\text { on management performance in high-tech industries in Taiwan }\end{array}$ \\
\hline 7 & Ehie e Madsen 2004 & Identifying critical issues in enterprise resource planning ERP implementation \\
\hline 5 & Ahmad e Cuenca 2012 & Critical successfactorsforERPimplementationinSMEs \\
\hline 3 & Shaul e Tauber 2013 & $\begin{array}{l}\text { Critical Success Factors in Enterprise Resource Planning Systems: } \\
\text { Review of the Last Decade }\end{array}$ \\
\hline 2 & Gajic et. Al 2014 & $\begin{array}{l}\text { Method of evaluating the impact of ERP implementation critical success factors - a case } \\
\text { study in oil and gas industries }\end{array}$ \\
\hline 0 & Bansal e Agarwal 2015 & Enterprise resource planning: identifying relationships among critical success factors \\
\hline 0 & Sowan e Tahboub 2015 & Erp Systems Critical Success Factors ICT Perspective \\
\hline
\end{tabular}

Entre os artigos mapeados, destacam-se as pesquisas de Umble et al. (2003), Hong e Kim (2002), Holland e Light (1999) e Akkermans e Van Helden (2002) pela sua relevância acadêmica conforme sinalizado pelo volume de citações, os quais serão explorados abaixo.

Para Holland e Light (1999) o conceito de software integrado do ERP torna sua implementação complexa, e ressaltam a necessidade da reengenharia dos principais 
processos da empresa e consequentemente do consenso entre as áreas da instituição de como estes novos processos devem ocorrer. Desta forma, a empresa deve optar entre duas estratégias para o projeto: Implantação do pacote padrão da ferramenta (standard) e adequação de seus processos ou customização do ERP para adequação a organização.

Os autores agrupam os fatores críticos de sucesso, sendo estes os fatores que precisam ser considerados e geridos para garantir o sucesso do projeto, como estratégicos e táticos, conforme a Tabela 13 .

Tabela 13 - Fatores Críticos de Sucesso

Fonte: Adaptado Holland e Light (1999)

\begin{tabular}{|c|c|c|}
\hline Dimensão & FCS & Descrição \\
\hline \multirow{5}{*}{ Estratégico } & $\begin{array}{l}\text { Visão do negócio } \\
\text { (Business Vision) }\end{array}$ & Clara visão sobre o modelo de gestão da organização, metas e objetivos; \\
\hline & $\begin{array}{l}\text { Suporte da diretoria } \\
\text { (Top management support) }\end{array}$ & $\begin{array}{l}\text { Grau de comprometimento da diretoria em termos de seu próprio } \\
\text { envolvimento e/ou alocação de recursos no projeto; }\end{array}$ \\
\hline & $\begin{array}{l}\text { Cronograma do projeto } \\
\text { (Project schedule/plans) }\end{array}$ & Definição formal do projeto com relação escopo, caminho crítico e milestones \\
\hline & $\begin{array}{l}\text { Sistema legado } \\
\text { (Legacy System) }\end{array}$ & $\begin{array}{l}\text { Determina o grau de alterações na organização que será necessário para a } \\
\text { implantação do sistema de ERP (e.g. work flow e processos); }\end{array}$ \\
\hline & $\begin{array}{l}\text { Estratégia de } \\
\text { implementação } \\
\text { (ERP Strategy) }\end{array}$ & $\begin{array}{l}\text { Estratégia de implementação do sistema (e.g. Grau de customização do } \\
\text { sistema, migração em fases ou completa do sistema, etc); }\end{array}$ \\
\hline \multirow{6}{*}{ Tático } & $\begin{array}{l}\text { Envolvimento do usuário } \\
\text { (Client Consultation) }\end{array}$ & $\begin{array}{l}\text { Envolvimento dos usuários no desenho, implementação e treinamento sobre } \\
\text { os novos processos; }\end{array}$ \\
\hline & $\begin{array}{l}\text { Aceitação do usuário } \\
\text { (Client acceptance) }\end{array}$ & Apoio dos usuários chave dos processos; \\
\hline & $\begin{array}{l}\text { Monitoramento e captura } \\
\text { de opiniões } \\
\text { (Monitoring and feedback) }\end{array}$ & $\begin{array}{l}\text { Troca de informações entre membros da equipe de projetos e análise das } \\
\text { opiniões (feedbacks) dos usuários da organização; }\end{array}$ \\
\hline & $\begin{array}{l}\text { Comunicação } \\
\text { (Communication) }\end{array}$ & $\begin{array}{l}\text { Visibilidade e divulgação formal da equipe de projeto sobre sua evolução } \\
\text { para o restante da organização; }\end{array}$ \\
\hline & $\begin{array}{l}\text { Resolução de problemas } \\
\text { (Troubleshooting) }\end{array}$ & Habilidade de gerir crises e desvios do plano; \\
\hline & $\begin{array}{l}\text { Mudanças em processos e } \\
\text { configuração do sistema } \\
\text { (Business Process Change and } \\
\text { Software Configuration) }\end{array}$ & Alinhamento entre os processos da empresa e o sistema ERP; \\
\hline
\end{tabular}

Hong e Kim (2002) apontam em seu trabalho que a implantação de inovações tecnológicas é vista como um processo dinâmico de adaptação mútua entre a tecnologia (sistema) e a organização. E desta forma ressaltam a importância da aderência do ERP à organização (Organization fit), de forma a minimizar customizações nos processos da empresa, no sistema ou em ambos.

Os autores estruturam o construto Aderência do ERP à organização (Organization fit) em 3 dimensões (Data fit, Process fit e User fit) e analisam sua correlação com o sucesso na implantação de sistemas ERP utilizando como variáveis moderadoras o grau de customização do sistema, dos processos organizacionais e a resistência a mudança da organização. Constatando tanto a correlação da Aderência do ERP à organização como a interferência do grau de customização do Sistema e dos Processos no sucesso dos projetos.

Akkermans e Van Helden (2002) analisam a relevância e a correlação dos FCS destacados por Somers e Nelson (2001), os quais o mapeamento foi realizado através de uma revisão 
bibliográfica sobre fatores críticos de sucesso em 110 projetos/implementações de sistemas de ERP, o qual foi consolidado através de uma lista de 22 FCS referentes ao tema. Após este mapeamento, os autores realizaram um levantamento tipo survey com executivos de TI de empresas com sistemas de ERP implementados para a identificação do grau de relevância de cada FCS no projeto, a qual está sumarizada na Tabela 14.

Tabela 14 - Fatores Críticos de Sucesso Implantação ERP

Fonte: Adaptado Akkermans e Van Helden (2002)

\begin{tabular}{ll}
\multicolumn{2}{l}{ Fatores Críticos de Sucesso } \\
\hline 1 & Engajamento dos executivos \\
\hline 2 & Competência da equipe de projetos \\
\hline 3 & Cooperação interdepartamental \\
\hline 4 & Clara definição de metas e objetivos \\
\hline 5 & Gestão de projetos \\
\hline 6 & Comunicação interdepartamental \\
\hline 7 & Gestão de expectativas \\
\hline 8 & $\begin{array}{l}\text { Sponsor do projeto } \\
\text { (Project Champion) }\end{array}$ \\
\hline 9 & Suporte do fornecedor \\
\hline 10 & Seleção criteriosa da ferramenta \\
\hline 11 & Qualidade de dados \\
\hline
\end{tabular}

\begin{tabular}{ll}
\hline Fatores Críticos de Sucesso \\
\hline 12 & Recursos dedicados (equipe) \\
\hline 13 & $\begin{array}{l}\text { Criação de um Comitê de Gestão } \\
\text { (Steering Committee) }\end{array}$ \\
\hline 14 & Capacitação dos usuários no sistema \\
\hline 15 & Capacitação da equipe sobre os novos process \\
\hline 16 & Reestruturação dos processos de negócio \\
\hline 17 & Mínima customização \\
\hline 18 & Seleção da arquitetura do sistema \\
\hline 19 & Gestão da mudança \\
\hline 20 & Parceria com fornecedores \\
\hline 21 & $\begin{array}{l}\text { Utilização de ferramentas de implantação } \\
\text { dos fornecedores (aceleradores) }\end{array}$ \\
\hline 22 & Utilização de consultores \\
\hline
\end{tabular}

Umble et al. (2003) sinalizam que apesar da complexidade e altos custos envolvidos nos projetos de implantação de sistemas ERP, este tipo de ferramenta apresenta benefícios que se distinguem de sistemas não integrados como uma visão unificada da organização que abrange todas as funções e departamentos, e um banco de dados único no qual todas as transações são carregadas, armazenadas, processadas, monitoradas e reportadas. E apresentam os seguintes fatores críticos de sucesso: Claro entendimento dos objetivos estratégicos da empresa, Comprometimento da Diretoria, Excelência na gestão de projetos, Gestão da mudança, Qualidade do time de implementação, Acuracidade dos dados, Treinamento e capacitação da equipe, Monitoramento de indicadores de performance do projeto e Gestão entre plantas (multi-site issues).

De forma similar à sistemas de BA, entre os FCS para sistemas ERP citados anteriormente pelos autores é possível notar uma convergência sobre aspectos referentes ao Sistema (e.g. Qualidade do sistema, Qualidade de dados e Aderência do sistema aos processos), Pessoas (e.g. Competência da equipe e Capacitação e treinamento) e Cultura Organizacional (e.g. Engajamento dos executivos, Sponsor do projeto e Visão do projeto). Esta convergência pode ser justificada pela complexidade do projeto desta natureza, bem como de gestão da mudança devido ao impacto gerado nos processos empresariais e, consequentemente, nas atividades dos colaboradores e possivelmente na própria estrutura organizacional da empresa.

Esta similaridade está alinhada com a visão de Olszak e Ziemba (2012), que sinalizam que projetos de implantação de BI apresentam características análogas ao ERP em que sua implementação não se restringe apenas à compra e integração entre software e hardware, sendo necessária alocação de distintos recursos por um longo período de tempo para alterações estruturais na organização.

Apesar da similaridade entre os pilares de FCS (Sistema, Pessoas e Cultura Organizacional) entre os dois tipos de sistema, há uma divergência entre seus objetivos e vocações devido à 
natureza das duas aplicações. Sistemas ERP possuem caráter transacional e integrado aos processos da empresa de forma praticamente indissociável, de forma que sua utilização do sistema por parte dos usuários é compulsória após a implementação. Em sistemas de apoio a decisão (e.g. BI e Big Data) o usuário possui maior flexibilidade em seu emprego tendo em vista que estas ferramentas não impedem processos operacionais críticos como entrada de pedidos, produção e faturamento.

Com base nas revisões bibliográficas apresentadas anteriormente, a Tabela 15 apresenta um resumo entre o objetivo e desafio de implantação do sistema, e exemplifica e diferença do foco de FCS mapeados entre os dois sistemas.

Outro ponto de destaque na diferenciação entre os FCS de sistemas BI (i.e. Business Analytics) frente ERPs está na cultura organizacional de gestão baseada em fatos, sendo esse FCS sinalizado como de elevada relevância por autores (e.g. Davenport e Harris (2007)), porém não apresentado pelos autores de FCS de ERP. Fato este alinhado com o objetivo primário de cada sistema.

Tabela 15- Comparação entre FCS de sistemas ERP e BA

Fonte: Desenvolvida pelo autor

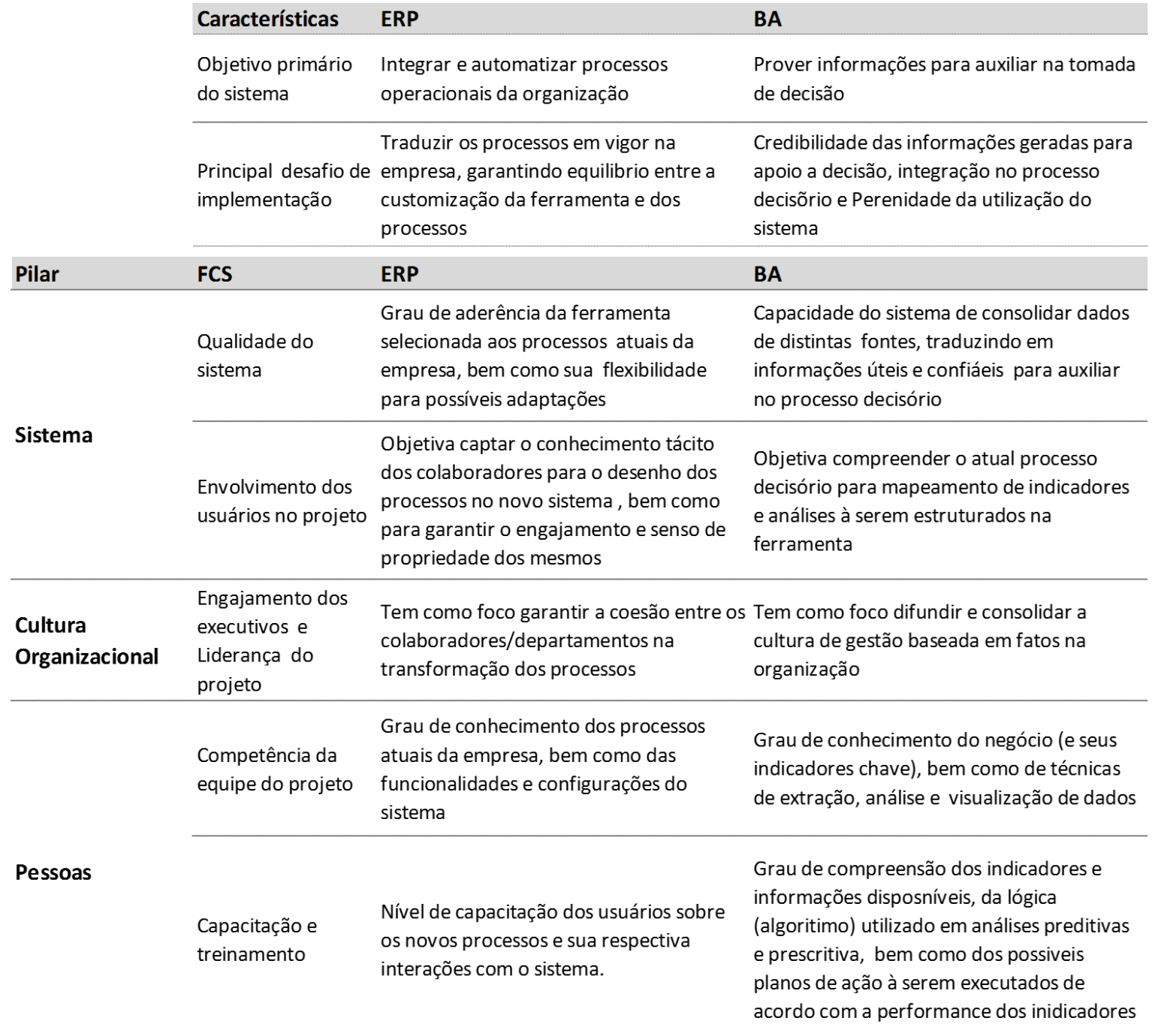


Conforme mencionado anteriormente, os fatores críticos de sucesso de ferramentas de Business Analytics foram agrupados em 3 dimensões: Tecnologia (Sistemas de Informação), Cultura Organizacional (Fact-Based Management) e Pessoas. Seu detalhamento e desdobramento em hipóteses será apresentado em 2.2.6 Variáveis do modelo proposto.

\subsubsection{Modelos de sucessos de sistemas de informação}

Apesar da avaliação de sistemas de Tecnologia da Informação (TI) ser um tema recorrente e de ampla produção academia, não existe consenso entre os pesquisadores sobre quais indicadores permitem avaliar de forma mais adequada o valor gerado pelas ferramentas de TI, sendo esse cenário ainda mais evidente no domínio de pesquisa de BI pela natureza de seu principal produto: informação para o suporte a tomada de decisão.

Segundo Balocco (2006), existem pelo menos 3 especificidades que tornam a análise de investimentos em TI de difícil operacionalização:

- A intangibilidade de muitos dos benefícios proporcionados pela TI, dificilmente conversíveis em medidas monetárias (como qualidade de produtos e serviços, aumento de flexibilidade, ampliação e aprendizado das competências ou satisfações dos usuários);

- A distribuição dos efeitos ao longo da empresa, de forma ampla e transversal, dificilmente isoláveis (e.g. mudanças em processos internos ou nas relações com demais empresas);

- Os efeitos da TI nos recursos e nas competências da empresa muitas vezes são perceptíveis somente ao longo prazo;

De acordo com Farbey et al. (1995), os sistemas de TI são utilizados de distintas maneiras e, consequentemente, com distintos objetos. O que resulta na necessidade de diferentes métodos de avaliação para cada perfil de aplicações. Para resolver esse problema, os autores estruturaram um modelo que apresenta uma classificação das aplicações de TI, dispostas em diversos "degraus", que denominaram "a Escada de Avaliação de Benefícios" (Benefits Evaluation Ladder). Nos primeiros degraus é possível uma precificação de custos e benefícios das aplicações de TI, porém a medida em que se "sobe a escada", como é o caso de sistemas de suporte à decisão (DDS), aumenta a extensão dos benefícios potenciais (e portanto, a eficácia), mas também a complexidade, os riscos, a incertezas do retorno gerado pelas aplicações.

Segundo os autores DSS devem ser avaliados pela sua capacidade em melhorar as decisões tomadas pela gerência da empresa e consequentemente pelo ganho de produtividade nesse processo. Eles também apontam as dificuldades em obter as informações necessárias para a execução da análise e também o extenso volume de pesquisas realizadas, porém não conclusivas.

Os modelos para mensuração do sucesso de sistemas de informação também são uma linha de pesquisa que tem evoluído nos últimos anos, objetivando identificar as variáveis que atuam como determinantes do sucesso dos sistemas de informação (RAI et al., 2002). Porém não há consenso tanto sobre as variáveis envolvidas e sua operacionalização, como na forma de mensurar o sucesso dos sistemas de informação. O que restringe a comparabilidade dos 
resultados obtidos em estudos e pesquisas, dificultando a construção e consolidação do conhecimento sobre o tema.

Diversos autores abordam o tema, como Bailey e Pearson (1983) e Kim (1989) em suas análises sobre satisfação do usuário, Smithson e Hirschheim (1998) com seu framework conceitual de avaliação de SI organizado pelas dimensões (zones) eficiência e Wixon e Watson (2001) na análise de FCS para sistemas de data warehouse.

Dentre as publicações, destaca-se a obra de DeLone e McLean (1992) por sua abordagem holística do construto Sucesso de SI e por sua relevância no tema, sendo essa evidenciada por mais de 1.800 citações na base de dados ISI Web of Science.

Segundo os autores, a correta mensuração dos resultados (outcomes) dos sistemas de informação são essenciais para sua gestão, na qual a falta de consenso na métrica do sucesso de SI pode ser ocasionada pelos distintos níveis de análise da informação resultante do SI, sendo esses: técnico (acuracidade e eficiência do sistema), semântico (sucesso na comunicação de seu significado) e de impacto ou efetividade (efeito causado pela informação no receptor).

Tais níveis são resultado da natureza serial da informação, de acordo com a teoria da comunicação, na qual o SI cria uma informação a qual é comunicada ao receptor que pode ou não ser influenciado. Dessa forma a informação flui por uma série de estágios (produção, consumo, e influência em indivíduos e organizações), sendo necessário indicadores distintos para a mensuração do sucesso de SI para cada um deles.

Os autores apresentam um conjunto de categorias ou aspectos do sucesso de SI (Figura 13) e realizam uma revisão bibliográfica para o mapeamento dos indicadores utilizados para mensuração do sucesso de SI em cada uma delas.

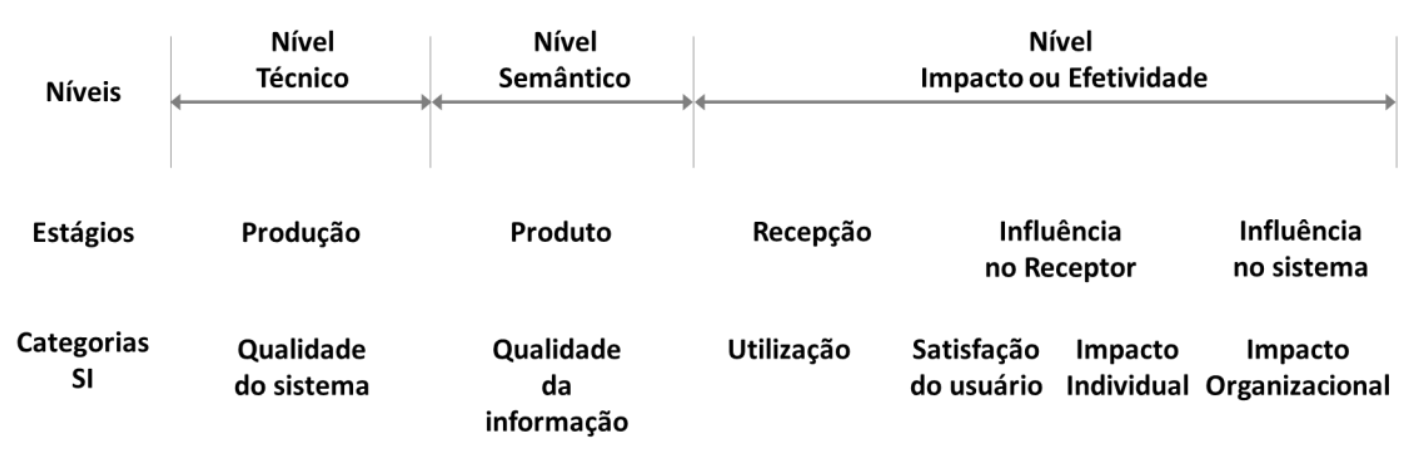

Figura 13 - Categorias Sistemas de Informação

Fonte: Adaptado DeLone e McLean (1992)

Segundo os autores o sucesso de SI é um construto multidimensional causal composto pelas categorias apresentadas anteriormente e, portanto, deve ser mensurada como tal (Figura 14). $\mathrm{E}$ afirmam que a seleção dos indicadores de sucesso de cada uma destas categorias deve considerar o objetivo do estudo, o contexto organizacional, os aspectos do SI em análise, as variáveis independentes do sucesso de SI utilizadas, o método de pesquisa e o nível de análise (i.e. individual, organizacional ou sociedade). 
A Tabela 16 sumariza os conceitos relacionados à cada categoria e também apresentam exemplos de indicadores mapeados na revisão bibliográfica.

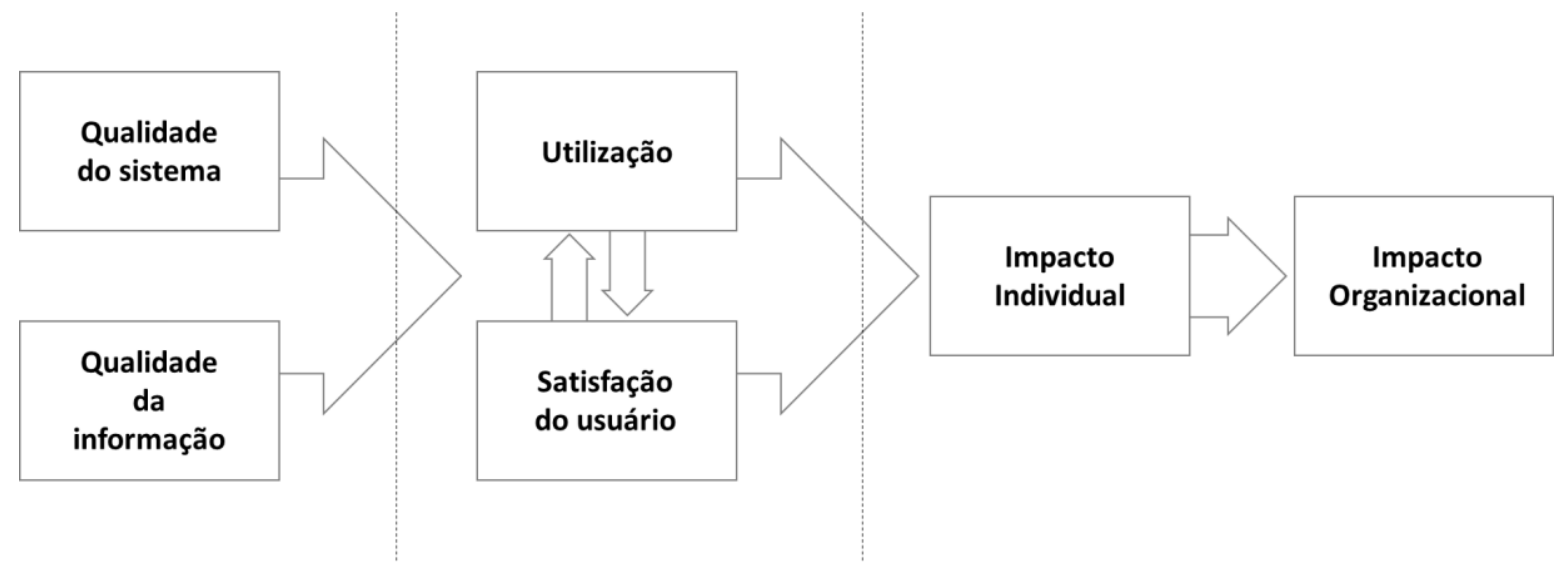

Figura 14 - Modelo de sucesso de SI

Fonte: Adaptado DeLone e McLean (1992)

Para a análise de sucesso de SI será utilizado como referência o modelo apresentado por DeLone e McLean (1992), no qual seu detalhamento e desdobramento em hipóteses será apresentado em 2.2.6 Variáveis do modelo proposto.

Outro ponto relevante sobre estes construtos é apresentado por DeLone e McLean (2003), que afiram que os pesos entre as categorias de sucesso Qualidade do sistema, Qualidade da informação e Qualidade do serviço variam de acordo com o nível da análise. Em estudos com foco em um único sistema, as categorias qualidade do sistema e qualidade da informação apresentam maior relevância, sendo qualidade do serviço mais representativo para o sucesso total de departamentos de TI. Dessa forma, para esta dissertação a análise de sucesso de sistema de BA será restrita as dimensões de Qualidade do sistema e Qualidade da informação. 
Tabela 16 - Categorias de sucesso de SI

Fonte: Adaptado DeLone e McLean (1992), DeLone e McLean (2003) e Petter et al. (2013)

\begin{tabular}{|c|c|c|}
\hline Categorias SI & Definição & Exemplos de indicadores \\
\hline $\begin{array}{l}\text { Qualidade do } \\
\text { Sistema }\end{array}$ & $\begin{array}{l}\text { Características desejáveis de um } \\
\text { sistema de informação }\end{array}$ & $\begin{array}{l}\text { Facilidade de uso, flexibilidade do sistema, } \\
\text { confiabilidade do sistema, facilidade de } \\
\text { aprendizado, intuitividade, sofisticação, } \\
\text { flexibilidade e tempo de resposta. }\end{array}$ \\
\hline $\begin{array}{l}\text { Qualidade da } \\
\text { Informação }\end{array}$ & $\begin{array}{l}\text { Características desejáveis dos } \\
\text { produtos do sistema (outputs) }\end{array}$ & $\begin{array}{l}\text { Relevância, compreensibilidade, precisão, } \\
\text { concisão, completude, atualidade, oportunidade } \\
\text { e usabilidade. }\end{array}$ \\
\hline Utilização & $\begin{array}{l}\text { Grau e forma de utilização das } \\
\text { capacidades dos sistemas por parte } \\
\text { dos usuários }\end{array}$ & $\begin{array}{l}\text { Quantidade de uso, frequência de uso, natureza } \\
\text { de uso, adequação do uso, alcance do uso e } \\
\text { proposito de uso. }\end{array}$ \\
\hline $\begin{array}{l}\text { Satisfação do } \\
\text { usuário }\end{array}$ & $\begin{array}{l}\text { Nível de satisfação do usuário com } \\
\text { o SI }\end{array}$ & $\begin{array}{l}\text { Item único para mensuração da satisfação do } \\
\text { usuário, escalas de diferença semântica para da } \\
\text { atitude dos usuários }\end{array}$ \\
\hline Impacto Individual & $\begin{array}{l}\text { Efeito causado pela informação } \\
\text { fornecida pelo SI no } \\
\text { comportamento do receptor }\end{array}$ & $\begin{array}{l}\text { Confiança do usuário, qualidade e eficiência na } \\
\text { tomada de decisão, tempo para realização de } \\
\text { atividades, habilidade na identificação e } \\
\text { resolução de problemas, produtividade dos } \\
\text { usuários }\end{array}$ \\
\hline $\begin{array}{l}\text { Impacto } \\
\text { Organizacional }\end{array}$ & $\begin{array}{l}\text { Efeito causado pelo SI na } \\
\text { performance organizacional }\end{array}$ & $\begin{array}{l}\text { Lucro, produtividade, rendimento sobre ativos } \\
\text { (return on assets), participação de mercado } \\
\text { (Market Share), inovação, valor de mercado } \\
\text { das ações (stock price) }\end{array}$ \\
\hline
\end{tabular}

\subsubsection{Variáveis do modelo proposto}

Este tópico apresenta uma discussão sobre as variáveis propostas no modelo referentes aos FCS de sistemas de BA e os construtos referentes ao modelo de sucesso de Sistemas de Informação, bem como suas respectivas hipóteses de causalidade do modelo proposto.

\subsubsection{Sistemas de Informação}

Conforme apresentado por Davenport e Harris (2007), BA poderia ser conceitualmente operacionalizado sem a utilização de sistemas de informação. Porém devido à grande quantidade de informações à serem processadas pelas empresas, sua execução torna-se inviável devido ao extensivo volume de trabalho necessário para sua realização. Sendo necessária a utilização de ferramentas de tecnologia da informação (SI) para viabilizar o processo.

De acordo com Bose (2009), dados são os principais elementos (building blocks) de sistemas focados em análises e modelagem matemática. Sendo que mesmo as mais sofisticadas ferramentas analíticas podem se tornar ineficientes caso os dados apropriados não estejam 
disponíveis ou tenham baixa qualidade. Entre as empresas líderes de mercado, é possível observar como boas práticas a consolidação das informações em repositórios únicos (bancos de dados) de forma a estarem prontos e disponíveis para análises quando necessário, além de disponibilização por toda a empresa (respeitando restrições de sigilo de acordo com as características das informações).

Sammon e Finnegan (2000) em seu estudo exploratório sobre fatores críticos de sucesso em projetos de Data Warehouse identificaram que nas 4 empresas nas quais foram realizados o estudo de caso a disponibilidade e qualidade dos dados foram subestimados no início do projeto, porém se revelaram com de alta criticidade.

De acordo com os autores a complexidade no tratamento e processamento dos dados, geralmente oriundos de diversos sistemas e em distintos formatos, torna-se evidente apenas após seu carregamento no BD e não deve ser subestimada. Como exemplo: Problemas de duplicidade, inflexibilidade, nomenclatura dos campos e fragmentação/granularidade.

Rudra e Yeo (2000) afirmam que a qualidade dos dados contidos no DW é um dos fatores críticos de sucesso para esse tipo de sistemas, pois a qualidade das informações fornecidas para a tomada de decisão estão diretamente relacionadas a qualidade de seus dados. Dessa forma, se os usuários tiverem a percepção que dos dados contidos no sistema são de baixa qualidade, o mesmo está fadado ao desuso.

A relevância da qualidade dos dados para as aplicações de Analytics também são destacadas por Davenport et al. (2010):

"Você não pode ser realmente analítico sem dados, e você não pode ser realmente bom em Analytics sem bons dados."

Para esse trabalho será adotado como FCS a Qualidade de dados e a seguinte hipótese de causalidade será analisada:

Qualidade dos dados: grau de relevância, precisão, utilidade, contextualidade, compreensividade e atualidade dos dados (RUDRA; YEO, 2000).

H1 - A Qualidade dos dados disponíveis (input para o BA) tem impacto positivo na qualidade da informação disponibilizada pelo SI

Com base na definição apresentada por Rudra e Yeo (2000), as seguintes hipóteses são estabelecidas em relação as dimensões do construto qualidade dos dados:

$H_{Q D} 1$ - Acuracidade é uma dimensão da qualidade dos dados

$H_{Q D} 2$ - Completude é uma dimensão da qualidade dos dados

$H_{Q D} 3-$ Atualidade é uma dimensão da qualidade dos dados

A operacionalização do construto será abordada posteriormente em 3.2.1 Operacionalização dos construtos.

\subsubsection{Cultura Organizacional}

Conforme a revisão bibliográfica apresentada anteriormente, a cultura organizacional voltada para a gestão baseada em evidências e o engajamento dos executivos são uns dos fatores críticos apontados com maior frequência na literatura de Business Analytics, sendo esse ponto também evidenciado anteriormente por pesquisadores de DSS. 
Liang (1986) aponta a relevância do engajamento dos executivos como sendo um dos fatores organizacionais internos (fatores sob controle da organização) determinantes para o sucesso de DSS. Lawrence e Courtney (1985) encontraram correlação positiva entre o suporte da alta gerência como variável dependente para o sucesso de sistemas de DSS em seu estudo quantitativo, resultado esse similar ao de Kaiser e Srinivasan (1980).

Segundo Sharma e Yetton (2003) o engajamento dos executivos é a variável relacionada ao sucesso de implantação de sistemas mais recorrente na literatura. Sendo esse construto nomeado como Management Support ou Top Management Support.

O engajamento dos executivos (Top management support) é definido por Croteau e Li (2003) como o grau de esforço empregado pelos executivos na implantação de sistemas de tecnologia da informação. Sendo especialmente importante em situações nas quais o redesenho de processos e papéis e responsabilidades tenham alta probabilidade de ocorrer.

Para esse trabalho será adotado como FCS o Engajamento dos executivos e a seguinte hipótese de causalidade será analisada:

Engajamento dos executivos: grau de esforço empregado pelos executivos na implantação de sistemas de tecnologia da informação (CROTEAU; LI, 2003).

H2 - O Engajamento dos executivos afeta positivamente o Uso das Informações disponibilizadas pelo sistema;

Apenas a implantação de sistemas de apoio a decisão não garante melhor performance nesse processo. Além do desenvolvimento de sistemas e do compartilhamento de suas informações, as empresas devem estabelecer um ambiente de utilização proativa das informações no qual a tomada de decisão é realizada de forma racional e pautada em ampla análise das informações (POPOVIČ et al., 2012).

Conforme a revisão bibliográfica apresentada por Holsapple et al. (2014), uma das perspectivas pela qual o conceito de Business Analytics pode ser analisado é o de um movimento no qual a identificação e solução de problemas baseados em evidências direciona a estratégia, tática e operação das organizações. Na qual a racionalidade na tomada de decisão sobrepõe dogmas, modismos e agendas pessoais e políticas. E as evidências não são selecionadas simplesmente para corroborar com preconceitos e descartadas caso se oponham aos modelos preconcebidos. Os autores ressaltam a criticidade do alinhamento da cultura organizacional com as diretrizes apresentadas anteriormente para a implantação do movimento BA.

Mortenson et al. (2015) também ressaltam a criticidade da sobreposição da lógica e racionalidade na gestão através da análise de evidências frente a intuição (gut-feeling), apesar de não reduzir sua relevância no processo decisório.

Davenport e Harris (2007) apontam que a adoção efetiva e ampla de BA nas empresas requer mudanças na cultura, processos, comportamento e habilidades de muitos colaboradores. Essa transformação deve ser liderada por uma diretoria envolvida e engajada por analytics e gestão baseada em fatos.

Para esse trabalho será adotado como FCS a Cultura Organizacional de Gestão Baseada em Fatos $(C O G B F)$ e as seguintes hipóteses de causalidade serão analisadas: 
Cultura Organizacional de Gestão Baseada em Fatos: ambiente de utilização proativa das informações no qual a tomada de decisão é realizada de forma racional e pautada em ampla análise das informações (POPOVIČ et al., 2012).

H3 - A Cultura organizacional de gestão baseada em fatos impacta positivamente o Uso das Informações disponibilizadas pelo sistema;

H4 - A Cultura organizacional de gestão baseada em fatos impacta positivamente o Engajamento dos executivos;

\subsubsection{Pessoas}

De acordo com Bose (2009), analytics não é um conceito ou tecnologia simples tanto para o entendimento dos usuários, como para sua utilização. Dessa forma, organizações podem dispor da tecnologia, porém não ter expertise para sua utilização efetiva e aproveitamento de todo seu potencial.

Davenport e Harris (2007) sinalizam analytics como um conceito que transcende a área de tecnologia da informação, sendo o aspecto humano e organizacional os mais impactantes no sucesso de BA.

Conforme mencionado anteriormente, Chiang et al. (2012) afirmam que BI\&A é uma área interdisciplinar que integra gestão de dados, sistemas de banco de dados, data warehousing, mineração de dados, text mining, network analysis, otimização e análises estatísticas. Sendo necessário aos profissionais dessa área além dos conhecimentos técnicos (TI) e analíticos/estatísticos, também noções de gestão e administração para o entendimento das necessidades do negócio e habilidades de comunicação para transmitir os insights e resultados das análises aos tomadores de decisão.

Em seu trabalho, Chen et al. (2012) também ressaltam que para suportar a cultura organizacional de gestão baseada em fatos (fact-based decision) os profissionais de BA devem ser capazes tanto de transformar dados brutos e informações (através de análises) em conhecimentos relevantes para a organização, como interagir e comunicar esse conhecimento para as áreas de negócio e tomadores de decisão.

Davenport et al. (2010) definem os principais conhecimentos e habilidades necessários dos profissionais de Business Analytics como:

- Habilidades técnicas e quantitativas: Proficiência em análises quantitativas e conhecimento em softwares para sua operacionalização. As técnicas utilizadas podem variar entre setores e empresas, como exemplo: simulação de cenários, construção e análise de dashboards, desenvolvimento de algoritmos e técnicas de mineração de dados e aprendizado de máquina;

- Conhecimentos de negócio: Familiaridade com disciplinas de gestão e com os processos aos quais o Analytics é aplicado. Os profissionais devem ser capazes de identificar oportunidades e desafios enfrentados pela companhia, os quais podem ser solucionados através de aplicações de BA;

- Habilidades de relacionamento e comunicação: Possibilita o trabalho efetivo em conjunto com as equipes das áreas de negócio na concepção, especificação, realização 
de pilotos e implementação de aplicações de Business Analytics. Além da capacidade de negociação, gestão de expectativas e aconselhamento, os analistas de BA devem ser capazes de comunicar de forma clara e compreensível o resultado de suas análises;

Para esse trabalho será adotado como FCS a Qualificação da equipe de BA e as seguintes hipóteses de causalidade serão analisadas:

Qualificação da equipe de BA: Habilidades técnicas e interpessoais da equipe (WIXOM; WATSON, 2001).

H5 - A Qualidade da equipe de BA tem impacto positivo na Qualidade da informação disponibilizada pelo SI;

\subsubsection{Qualidade do sistema}

Apesar de alguns trabalhos abordarem a qualidade do sistema e de sua informação resultante em um construto único, nesse estudo utilizaremos o conceito apresentado por DeLone et al. (2013) no qual o construto Qualidade do sistema considera aspectos técnicos do sistema. E a qualidade das informações disponibilizadas pelo sistema é abordada no construto Qualidade da informação.

Dessa forma, a seguinte definição será adotada para esse construto:

Qualidade do sistema: Características desejáveis de um sistema de informação (DELONE; MCLEAN, 1992).

E com base no modelo proposto por DeLone e McLean (1992), as seguintes hipóteses serão analisadas:

H6 - A Qualidade do sistema tem impacto positivo no Uso da informação;

H7 - A Qualidade do sistema tem impacto positivo no Satisfação do usuário;

A multidimensionalidade do construto Qualidade do sistema é recorrente entre vários autores como Wixon e Watson (2001), Iivari (2005) e Nelson et al. (2005).

Wixon e Watson (2001) estruturam o construto em seu estudo sobre sistemas de Data Warehouse nas dimensões Flexibilidade,o Versatilidade e Integração do sistema. Já Iivari (2005) estrutura o construto como as seguintes componentes: Flexibilidade, Integração, Tempo de resposta, Recuperação do sistema, Comodidade no acesso e Interação com o usuário.

Nelson et al. (2005) relaciona o construto Qualidade do sistema as percepções dos usuários referentes as suas interações com o sistema ao longo do tempo e, de forma similar a Iivari (2005), estruturam o construto através das dimensões: confiabilidade, flexibilidade, integração, acessibilidade e tempo de resposta.

Com base no trabalho apresentado por Nelson et al. (2005) as seguintes hipóteses são estabelecidas em relação as dimensões do construto Qualidade do sistema para BA:

$H_{Q S} 1$ - Confiabilidade é uma dimensão da Qualidade do sistema

$H_{Q S} 2$ - Flexibilidade é uma dimensão da Qualidade do sistema

$H_{Q S} 3$ - Integração é uma dimensão da Qualidade do sistema 


$$
\begin{aligned}
& H_{Q S} 4 \text { - Acessibilidade é uma dimensão da Qualidade do sistema } \\
& H_{Q S} 5 \text { - Tempo de Resposta é uma dimensão da Qualidade do sistema }
\end{aligned}
$$

\subsubsection{Qualidade da informação}

Sistemas de informação são concebidos para a geração de informações relevantes e precisas (DELONE et al., 2013). Dessa forma, a qualidade das informações geradas pelos sistemas são elementos decisivos na análise de sucesso de SI.

Tal relevância é evidenciada pelo estudo de Bailey e Pearson (1983) sobre a satisfação do usuário de SI, no qual 5 entre os 10 principais fatores relacionados ao tema (no total de 39) estão relacionados a qualidade da informação (i.e. acuracidade, completude, relevância, confiabilidade, precisão e grau de atualidade das informações - currency).

Apesar de não haver consenso sobre a definição de Qualidade da informação, há uma convergência entre os pesquisadores sobre o atendimento dos requerimentos e expectativas dos usuários (POPOVIČ et al., 2012).

Desta forma este construto aborda as características das informações providas pelo sistema, e apresenta a seguinte definição:

Qualidade da informação: Características desejáveis das informações disponibilizadas pelo sistema (outputs) (DELONE; MCLEAN, 1992).

E com base no modelo proposto por DeLone e McLean (1992), as seguintes hipóteses serão analisadas:

H8 - A Qualidade da informação tem impacto positivo no Uso da informação;

H9 - A Qualidade da informação tem impacto positivo na Satisfação do usuário;

De forma similar a Qualidade do sistema, é recorrente a estruturação da Qualidade da informação de forma multidimensional por pesquisadores da área.

Aristizabal (2016) apresenta uma revisão bibliográfica deste construto e expõe 19 dimensões distintas presentes na literatura para Qualidade da informação. Destaca-se pela frequência encontrada as dimensões: Atualidade, Completude, Precisão/Exatidão e Oportunidade.

Wixon e Watson (2001) apresentam as seguintes dimensões: Completude, Precisão, Acuracidade, Consistência, Atualidade e Formato. E Nelson et al. (2005) apresenta uma versão mais consolidada estruturando o construto em 4 dimensões: Acuracidade, Completude, Atualidade e Formato.

Com base no trabalho apresentado por Nelson et al. (2005) as seguintes hipóteses são estabelecidas em relação as dimensões do construto Qualidade da informação para BA:

$H_{Q I} 1$ - Completude é uma dimensão da Qualidade da informação

$H_{Q I} 2$ - Acuracidade é uma dimensão da Qualidade da informação

$H_{Q I} 3$ - Atualidade é uma dimensão da Qualidade da informação

$H_{Q I} 4$ - Formato é uma dimensão da Qualidade da informação 


\subsubsection{Uso da informação}

Segundo DeLone e McLean (1992), o nível de uso dos sistemas de informação é uma das dimensões de sucesso de SI mais usadas na literatura por ser uma medida objetiva e fácil de quantificar. Segundo os autores esta medida faz sentido unicamente quando o uso é voluntário, pois quando obrigatório o indicador torna-se uma medida menos útil tendo em vista as circunstâncias de sua utilização.

Diferentemente de sistemas transacionais (e.g. Enterprise Resource Planning), BA tem por natureza como objetivo o suporte a tomada de decisão, não sendo mandatória sua utilização para a execução dos processos empresarias no qual sua aplicação impacta.

Popovič et al. (2012) afirmam que a utilização da informação tem sido definida no âmbito de sistema de suporte a decisão como "a aplicação de informações adquiridas e transmitidas para o processo organizacional de tomada de decisão". Sendo empregadas no auxílio a gestão dos processos empresariais e toda a cadeia de suprimentos (Supply Chain).

Para o âmbito de sistemas de decisão, a seguinte definição será adotada para essa dissertação:

Utilização: Aplicação de informações adquiridas e transmitidas para o processo organizacional de tomada de decisão (POPOVIČ et al., 2012).

E com base no modelo proposto por DeLone e McLean (1992), as seguintes hipóteses serão analisadas:

H10 - Uso da informação tem impacto positivo na Satisfação do usuário;

H11 - Uso da informação tem impacto positivo no Impacto individual;

Este construto será abordado de forma unidimensional, e sua operacionalização será discutida em 3.2.1 - Operacionalização dos construtos e também

\subsubsection{Satisfação do usuário}

Satisfação em uma situação pode ser definida de forma genérica como o conjunto de sentimentos e atitudes direcionados por uma variedade de fatores, os quais afetam tal situação (BAILEY; PEARSON, 1983).

De acordo com DeLone e McLean (2003), os conceitos de Uso da informação e Satisfação do usuário estão inter-relacionadas. E do ponto de vista de processo o uso precede a satisfação do usuário pois uma utilização satisfatória da informação irá impactar positivamente na satisfação do usuário.

Dessa forma, por não ser mandatória a utilização de sistemas BA a dependência analisada neste modelo será o impacto do Uso da informação na Satisfação do usuário.

Para o âmbito de sistemas de decisão, a seguinte definição será adotada para essa dissertação:

Satisfação do usuário: Nível de satisfação do usuário com o SI (DELONE; MCLEAN, 1992).

E com base no modelo proposto por DeLone e McLean (1992), a seguinte hipótese será analisada:

H12 - Satisfação do usuário tem impacto positivo no Impacto individual; 
Este construto será abordado de forma unidimensional, e sua operacionalização será discutida em 3.2.1 - Operacionalização dos construtos e também

\subsubsection{Impacto individual}

Conforme a evolução dos SI, seus respectivos impactos transcenderam os usuários imediatos, atingindo grupos de trabalho, organizações, cadeias produtivas, setores da indústria, consumidores e a sociedade. O que demandou por parte dos pesquisadores uma maior amplitude de indicadores para sua mensuração. Porém, a escolha do nível de granularidade para a aferição do impacto do SI depende do sistema em estudo e seu respectivo propósito (DELONE; MCLEAN, 2003).

Os autores também ressaltam a complexidade em mensurar o impacto de SI na performance da organização pela dificuldade em isolar seus efeitos oriundos frente a demais possíveis contribuintes.

Dessa forma, para os objetivos do presente estudo a análise do impacto causado pelo SI será restrita ao nível individual. Sendo esse definido por DeLone e McLean (2003) como efeito causado pela informação fornecida pelo SI no comportamento do receptor. E Iivari (2005) ressalta que o Impacto Individual pode ser interpretado como benefícios individuais ocasionados pela utilização do sistema

Para o âmbito de sistemas de decisão, a seguinte definição será adotada para essa dissertação:

Impacto Individual: Efeito causado pela informação fornecida pelo SI no comportamento do receptor (DELONE; MCLEAN, 1992). 


\section{Metodologia}

A Engenharia de Produção ou Gestão de Operações (Operations Management) é um campo de conhecimento que tem como objetivo a seleção e gestão de processos de transformação que criam valores para a sociedade (LOVEJOY, 1998).

Miguel et al. (2012) apresentam a seguinte definição para o termo:

"A engenharia de produção trata do projeto, aperfeiçoamento e implantação de sistemas integrados de pessoas, materiais, informações, equipamentos e energia para a produção de bens e serviços, de maneira econômica, respeitando as condições sociais, culturais, éticas e ambientais. Tem como base os conhecimentos específicos e as habilidades associadas às ciências físicas, matemáticas e sociais, assim como os princípios e métodos de análise da engenharia de projeto para especificar, predizer e avaliar os resultados obtidos por tais sistemas."

De forma distinta às demais engenharias clássicas (i.e. Mecânica, Elétrica e Civil), as áreas de conhecimento que compõem a Engenharia de Produção transcendem as ciências exatas, sendo essa composta por conhecimentos oriundos tanto da Física, como da Filosofia e da Psicologia Social. Conforme a Figura 15:

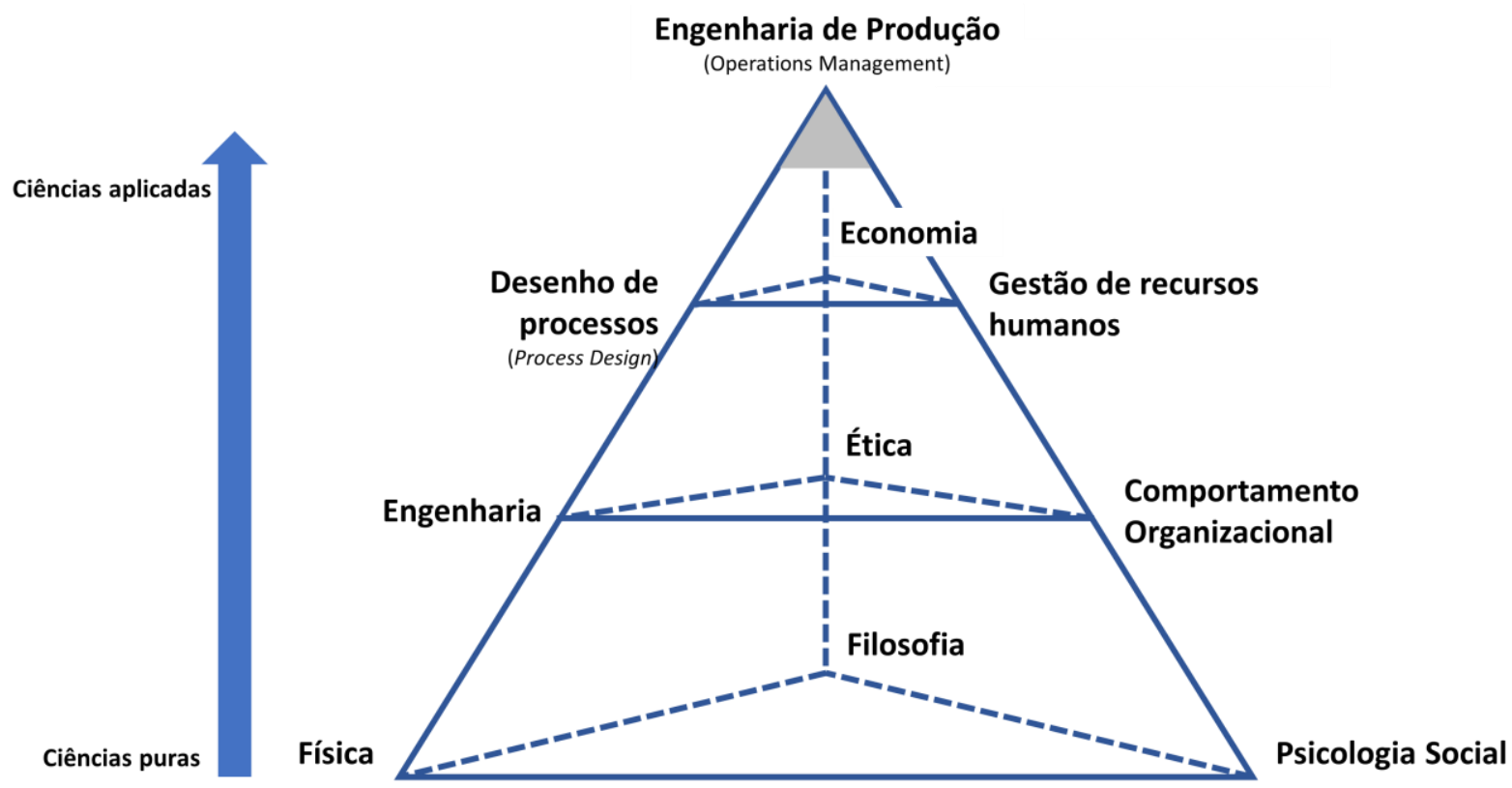

Figura 15 - Áreas de conhecimento relacionadas à engenharia de produção

Fonte: Adaptado Lovejoy (1998)

Devido a sua interdisciplinaridade, sendo esse um fator que amplifica a complexidade na realização de pesquisas científicas, é recorrente nessa área de pesquisa a preocupação com relação a abordagem metodológica utilizada no desenvolvimento de trabalhos científicos. O correto embasamento científico na condução das pesquisas é determinante para a realização de trabalhos estruturados, passíveis de replicação e aperfeiçoamento, e acima de tudo que contribuam para a extensão ou refinamento de teorias pré-existentes ou criação de novas teorias de forma a proporcionar a expansão do conhecimento pré-existente (TURRIONI; MELLO, 2012; MIGUEL et al., 2012). 
De acordo com Kauark et al. (2010), as pesquisas científicas podem ser classificadas de distintas formas, dependendo de sua natureza, do objetivo, de sua abordagem e de seus métodos.

A natureza da pesquisa pode ser classificada da seguinte forma:

- Pesquisa Básica: objetiva ampliar os conhecimentos para o avanço da ciência sem aplicação prática prevista. Envolve verdades e interesses universais, sendo recorrente em áreas de pesquisa de ciências puras (e.g. Matemática, Física e Biologia);

- Pesquisa Aplicada: objetiva gerar conhecimentos para aplicação prática, dirigida à solução de problemas específicos. Envolve verdades e interesses locais sendo recorrente em áreas de pesquisa de ciências aplicadas (e.g. Engenharia, Administração e Economia);

Do ponto de vista de seus objetivos, esta pode ser classificada como:

- Pesquisa Exploratória: objetiva a maior familiaridade com o problema

- Pesquisa Descritiva: visa descrever as características de determinada população ou fenômeno, ou analisar de relações entre variáveis.

- Pesquisa Explanatória ou Explicativa: visa identificar os fatores que determinam ou contribuem para a ocorrência dos fenômenos. Aprofunda o conhecimento da realidade porque explica a razão, o porquê das coisas. Quando realizada nas ciências naturais requer o uso do método experimental, e nas ciências sociais requer o uso do método observacional. Assume, em geral, as formas de Pesquisa Experimental e Pesquisa ex post facto.

Outra categorização recorrente na literatura remete à abordagem utilizada, sendo essa classificada entre quantitativa, qualitativa ou combinada.

Conforme sinalizado por Miguel et al. (2012), a distinção entre as abordagens quantitativas e qualitativas não ocorre pelo fato de mensurar ou não variáveis no processo de pesquisa, mas sim pela corrente filosófica ou paradigma que direciona a pesquisa. (e.g. Positivismo e Construtivismo).

- Abordagem Qualitativa: Baseia-se geralmente na corrente filosófica construtivista, e considera que há uma relação dinâmica entre o mundo real e o sujeito, isto é, um vínculo indissociável entre o mundo objetivo e a subjetividade do sujeito que não pode ser traduzido em números. A interpretação dos fenômenos e a atribuição de significados são básicas no processo de pesquisa qualitativa. É descritiva e os pesquisadores tendem a analisar seus dados indutivamente. $O$ processo e seu significado são os focos principais de abordagem.

Os métodos de pesquisa mais frequentes para a condução de pesquisas qualitativas na engenharia de produção é o estudo de caso e a pesquisa ação;

- Abordagem Quantitativa: Baseia-se no positivismo científico, considera o que pode ser quantificável, o que significa traduzir em números opiniões e informações para classificá-las e analisá-las. O relacionamento do pesquisador com o objeto de estudo é distante e imparcial, no qual prevalece a lógica dedutiva para o deste de hipóteses previamente estabelecidas. 
Requer o uso de recursos e de técnicas estatísticas (percentagem, média, moda, mediana, desvio-padrão, coeficiente de correlação, análise de regressão), e na área de engenharia de produção as metodologias mais frequentes são o levantamento tipo survey e modelagem/simulação.

- Abordagem Combinada: Caracteriza-se pela utilização concomitante de abordagens quantitativas e qualitativas dentro do mesmo estudo, no qual se assume o pressuposto de que a combinação das abordagens possibilita um entendimento melhor do problema de pesquisa frente a utilização isolada de uma delas. Está baseada no conceito de triangulação de dados, o qual objetiva mitigar possíveis vieses inerentes a cada um dos métodos. Tem como viés negativo a complexidade de operacionalização e a necessidade de maior alocação de recursos.

A ciência distingue-se do senso comum pela especialização e pelo controle disciplinado de seu processo. O termo especialização remete a necessidade do pesquisador ser um especialista num assunto ou tema de pesquisa, o e controle disciplinado remete à aplicação rigorosa do método de solução do problema, sendo esse o método científico (ALVES, 1981; MIGUEL et al., 2012).

Lakatos e Marconi (2003) apresentam a seguinte definição para método científico:

"Conjunto das atividades sistemáticas e racionais que, com maior segurança e economia, permite alcançar o objetivo - conhecimentos válidos e verdadeiros -, traçando o caminho a ser seguido, detectando erros e auxiliando as decisões do cientista”.

Devido a sua multidisciplinaridade, conforme discutido anteriormente, diversas alternativas de métodos científicos podem ser utilizadas em engenharia de produção. Miguel et al. (2012) apresenta as seguintes classificações:

- Levantamento tipo survey: uso de instrumento de coleta de dados único (em geral um questionário), aplicado a amostras de grande tamanho, com o uso de técnicas de amostragem e análise e inferência estatística;

- Estudo de caso: Análise aprofundada de um ou mais objetos (casos), com o uso de múltiplos instrumentos de coleta de dados e presença da interação entre pesquisador e objeto de pesquisa;

- Modelagem e Simulação: Uso de técnicas matemáticas para descrever o funcionamento de um sistema ou de parte de um sistema produtivo;

- Estudo de campo: Outros métodos de pesquisa (principalmente de abordagem qualitativa) ou presença de dados de campo, sem estruturação formal do método de pesquisa;

- Experimento: Estudo da relação causal entre duas variáveis de um sistema sob condições controladas pelo pesquisador;

- Teórico/conceitual: Discussões conceituais a partir da literatura, revisões bibliográficas e modelagens conceituais;

Os mesmos autores sinalizam que para uma mesma pergunta pesquisa pode haver diferentes métodos de pesquisa aplicáveis, e a sua escolha depende de um conjunto de fatores como 
disponibilidade de tempo e recursos, possibilidade de acesso a dados, natureza do problema de pesquisa e o perfil do pesquisador e/ou da equipe de pesquisa.

Dentre os métodos científicos apresentados, destaca-se para essa pesquisa a abordagem quantitativa de levantamento tipo survey por sua aptidão na obtenção de panoramas descritivos de um dado fenômeno conforme variáveis definidas ou extrair conclusões acerca da relação de causa e efeito entre variáveis (MIGUEL et al., 2012). O qual converge para o objetivo desse trabalho, sendo este a identificação das variáveis condicionantes e a intensidade de sua influência no sucesso de sistemas de Business Analytics.

Além do alinhamento mencionado anteriormente, outros dois fatores foram ponderados para a seleção do método survey, sendo eles tanto:

- A lacuna de pesquisas do tipo Survey na área de BI (JOURDAN et al., 2008);

- A restrita utilização na área de gestão de operações no Brasil (BERTO; NAKANO, 1999);

Dessa forma, para esse presente estudo será utilizada a metodologia de Levantamento tipo Survey tanto pelo seu alinhamento com os objetivos da pesquisa, como pela contribuição em suprir a lacuna da prática de estudos dessa natureza tanto na área de Business Intelligence, como na prática de pesquisas em gestão de operações no Brasil.

\subsection{Levantamento tipo Survey}

As investigações pautadas em Levantamento tipo survey, ou apenas survey, têm sido usadas para pesquisar fenômenos em diferentes áreas da engenharia de produção e gestão de operações. E tem como objetivo geral contribuir para o conhecimento em uma área particular de interesse por meio da coleta de dados/informações sobre indivíduos ou sobre os ambientes dos quais esses indivíduos fazem parte. Este levantamento permite obter um panorama sobre o fenômeno conforme variáveis definidas ou extrair conclusões, por exemplo, acerca da relação de causa e efeito entre tais variáveis (MIGUEL et al., 2012).

Filippini (1997) apresenta a seguinte definição para pesquisa survey:

"O termo survey é geralmente utilizado para o significado de conjunto/coleção de dados, informações e opiniões de um amplo grupo de unidades, referenciados como população. $O$ objeto de estudo pode ser indivíduos, grupos, plantas, companhias ou até projetos e sistemas. Surveys utilizam perguntas estruturadas e pré definidas e coletam dados através de amostras, as quais podem ser obtidas de distintas formas, como: questionários por correios, entrevistas presenciais estruturadas $e$ entrevistas ou questionários via telefone."

De acordo com Forza (2002), os levantamentos tipo survey podem ser classificados em três abordagens, sendo elas:

- Exploratório: Aplicada nos estágios iniciais do estudo de um fenômeno, seu objetivo principal está em obter conhecimentos iniciais (insights) que serão utilizados como ponto de partida para a estruturação de demais estudos. Geralmente não há modelos (frameworks) pré-definidos e os conceitos envolvidos precisam ser melhor entendidos. Surveys exploratórias podem 
auxiliar na determinação dos conceitos à serem medidos de acordo com o fenômeno de interesse, na melhora da forma de mensurá-los e na descoberta de novos aspectos do fenômeno estudado;

- Descritiva: Utilizada para compreender a relevância de um certo fenômeno e sua distribuição na população. Seu objetivo principal não é o desenvolvimento de teorias, apesar de sua análise fornecer possíveis insumos para tanto a construção como para o refinamento de teorias;

- Explanatória (ou Confirmatória): É empregada quando há um conhecimento teórico prévio sobre o fenômeno já articulado através de conceitos, modelos e proposições bem definidos. Nesta abordagem a coleta de dados é direcionada ao objetivo específico de teste da adequação dos conceitos e hipóteses relacionados ao fenômeno e também da validação dos limites/restrições do modelo;

De acordo com o objetivo desse trabalho o tipo mais adequado survey é o Explanatório, sendo esse caracterizado por testar a teoria e analisar a dependência, relacionamento e causalidade entre variáveis.

Segundo Miguel et al. (2012), as pesquisas tipo survey podem ser caracterizados de acordo com a interferência do pesquisador no objeto de estudo:

- Pesquisa Observacional: Envolvem coleta de informações de dados qualitativos e quantitativos de interesse, em indivíduos de um ou mais grupo, mas sem intervenção intencional do pesquisador. Sendo elas discriminadas em dois tipos de acordo com seu plano amostral: Levantamento Amostral e Levantamento Populacional;

- Pesquisa Experimental: Envolve a coleta de dados, de forma similar à pesquisa observacional, porém caracteriza-se pela intervenção do pesquisador, o qual manipular diretamente variáveis relacionadas com o objeto de estudo. Este tipo de pesquisa é empregado de forma recorrente na fase de desenvolvimento de novos produtos e são necessários grupos de controle para a avaliação dos resultados. Este tipo de pesquisa pode ser classificado de acordo com a aleatoriedade de alocação entre unidades experimentais: Alocação completamente aleatórias ou com restrição na alocação;

Este trabalho terá caráter observacional, e portanto, sem interferência do pesquisador no fenômeno analisado. 
Desta forma, a metodologia científica dessa dissertação pode ser classificada conforme a Tabela 17 apresentada abaixo:

Tabela 17- Classificação metodológica da dissertação

Fonte: Elaborado pelo autor

\begin{tabular}{ll}
\hline Critérios de classificação & Posicionamento \\
\hline Natureza da pesquisa & Aplicada \\
Objetivo & Explanatório \\
Abordagem & Quantitativa \\
Metodologia Científica & $\begin{array}{l}\text { Levantamento } \\
\text { tipo Survey }\end{array}$ \\
& Observacional \\
\hline
\end{tabular}

Conforme apontado por Forza (2002), pesquisas survey Explanatórias (testes de teoria) são processos longos compostos por distintas atividades, conforme Figura 16.

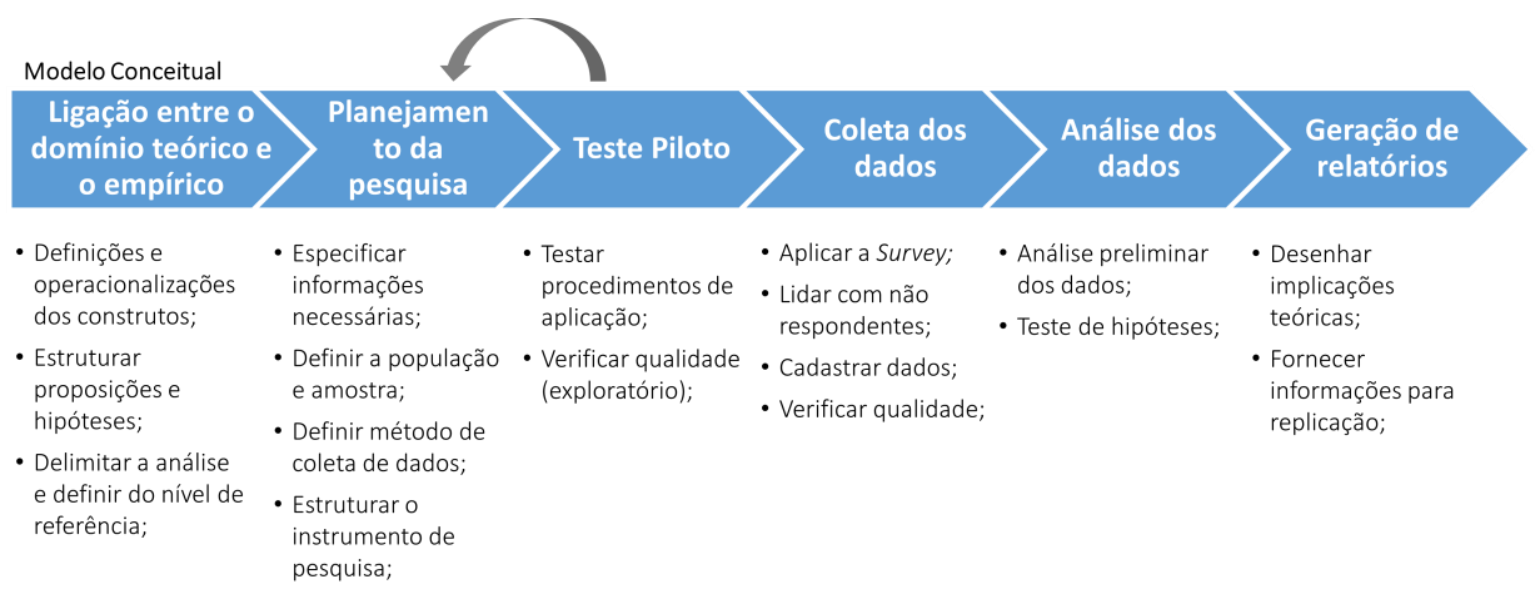

Figura 16 - Etapas de execução de um levantamento tipo survey explanatória

Fonte: Adaptado Forza (2002)

Inicialmente faz-se necessário a estruturação de um modelo conceitual (framework) para realizar a ligação entre o domínio teórico e o empírico, no qual são apresentados os construtos e as posições que direcionarão o estudo.

Posteriormente deve ocorrer o planejamento da pesquisa, no qual é mapeado as necessidades de informação, definido a população e a amostra utilizada e também definido o método e estruturada a ferramenta de coleta de dados.

A partir desse ponto é aconselhável a realização de um teste piloto para o refinamento tanto do instrumento como dos procedimentos de aplicação. E em seguida ocorre a coleta de dados, os quais serão analisados estatisticamente para a geração de relatórios e obtenção de conclusões. As etapas apresentadas no modelo serão mais exploradas nos tópicos a seguir. 


\subsection{Framework conceitual}

Miguel et al. (2012) sinalizam que o ser humano procura sempre a ordem, pois esta proporciona bem-estar e conforto à humanidade. Contudo, para notar a desordem é preciso ter uma referência da ordem, da organização. A ordem é representada em um modelo, sendo esse uma construção mental da ordem. O qual é constituído de conceitos que podem ser obtidos no conhecimento existente com conhecedores de modelos ou a partir da própria existência do pesquisador.

De forma convergente ao trabalho destes autores, Alves (1981) apresenta a seguinte definição para o conceito de modelos:

"São construções intelectuais, palpites, apostas baseados na crença de que existe uma relação de analogia entre aquilo que conhecemos e aquilo que desejamos conhecer."

Apesar do anseio para que o modelo seja uma cópia fiel da realidade, faz-se necessário ter em mente que se este for tão complexo que o pesquisador não consiga manipulá-lo, este perde sua utilidade na busca da solução do problema. Pois sua construção só faz sentido se for colocado à prova na elaboração de hipóteses para a desordem encontrada pelos pesquisadores (MIGUEL et al., 2012).

Para Sampieri et al. (2010), as hipóteses são tentativas de explicação do fenômeno pesquisado, sendo derivadas da teoria e estruturadas na forma de proposições.

Lakatos e Marconi (2003) argumentam que hipótese é uma resposta "suposta, provável e dprovisória" ao problema de pesquisa. Sendo essa estruturada pelo pesquisador com base no conhecimento científico existente, em observações realizadas de fatos, na comparação com outros estudos, em deduções lógicas ou casos discrepantes de uma teoria, experiências pessoas e analogias, dentre outros. Tanto os problemas quanto as hipóteses são enunciados de relações entre variáveis (fatos, fenômenos); sendo a diferença que o problema constitui uma sentença interrogativa e a hipótese, sentença afirmativa mais detalhada.

De forma similar, os autores Kauark et al, (2010) apresentam a seguinte definição de hipóteses:

"Hipótese é sinônimo de suposição. Neste sentido, hipótese é uma afirmação categórica (uma suposição) que tente responder ao problema levantado no tema escolhido para pesquisa. O trabalho de pesquisa, então, irá confirmar ou negar a hipótese (ou suposição) levantada.”

Nas hipóteses de problemas cujos modelos são matemáticos, as variáveis precisam ser bemdefinidas de forma a serem mensuradas com precisão. Isso depende da boa definição dos construtos (conceitos teóricos não observáveis) envolvidos e sua respectiva operacionalização (MIGUEL et al., 2012).

Conforme apontado por Forza (2002), pesquisas survey Explanatórias (testes de teoria) são processos longos dos quais pressupõe a pré-existência de um framework conceitual (Modelo). Sendo esse composto pelos seguintes sub processos:

- Definição dos construtos: Clara identificação e definição de todos os construtos considerados relevantes; 
- Hipóteses: Apresentação e discussão das correlações e indicação da natureza e direção do relacionamento dos construtos (e.g. independentes, dependentes e moderadores);

- Discussão: Clara explicação sobre o comportamento esperado com relação às relações entre os construtos em análise;

- Condições de contorno: Definição das condições sob as quais o pesquisador espera que essas relações ocorram e o nível de referência dos construtos (i.e. indivíduos, grupos, funções ou organizações);

Para a análise dos fatores críticos de sucesso de sistemas de Business Analytics, esta dissertação apresenta um framework conceitual que utiliza como variáveis de entrada (construtos independentes) os fatores críticos das 3 dimensões relacionadas ao Business Analytics mapeadas na revisão bibliográfica, e o sucesso do sistema de informação é analisado de forma multidimensional baseado no modelo apresentado por DeLone e McLean (1992). Conforme a discussão dos construtos e hipóteses apresentadas anteriormente em 2.2.6 Variáveis do modelo proposto.

Frequentemente os Frameworks conceituais são representados por diagramas por facilitarem sua visualização (FORZA, 2002). Dessa forma, a Figura 17 ilustra o relacionamento de causalidade entre os construtos e suas respectivas hipóteses. 


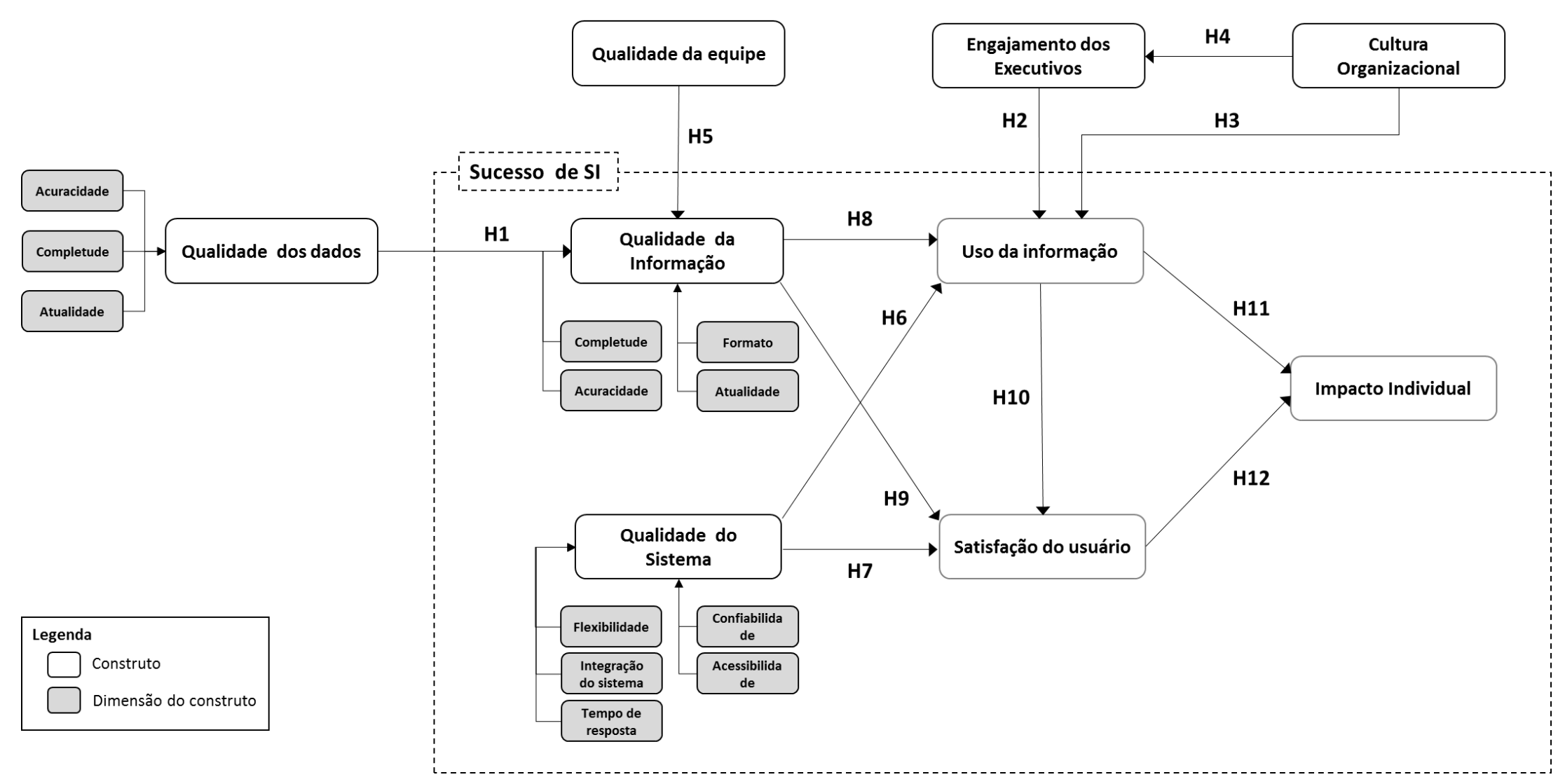

Figura 17 - Framework conceitual

Fonte: Elaborado pelo autor 


\subsubsection{Operacionalização dos construtos}

Segundo Forza (2002), o ato de operacionalizar um construto (torná-lo mensurável) apresenta diversos problemas, dentre eles: Alinhamento entre os conceitos teóricos e mensurações empíricas, grau de subjetividade das perguntas e a seleção de uma ou mais perguntas por construto. Essas dificuldades podem ser contornadas através da utilização de operacionalizações desenvolvidas, utilizadas e testadas previamente em outros trabalhos.

A seleção das variáveis para operacionalização dos construtos (dependente e independentes) para a análise do sucesso de sistemas de informação devem estar alinhadas com as características do SI, o ambiente no qual está inserido e os objetivos da análise (DELONE; MCLEAN, 1992) (DELONE et al., 2013).

Dessa forma, para esse trabalho a seleção das variáveis para operacionalização dos construtos foi realizada através de um levantamento bibliográfico de construtos operacionalizados com alta confiabilidade e que se adequem aos objetivos da pesquisa e características dos SI de Business Analytics.

\subsubsection{Modelo de sucesso de Sistemas de Informação}

Nessa seção serão discutidos os construtos relacionados ao sucesso de SI adotados nesse estudo.

\subsection{Qualidade do sistema}

Conforme apresentado anteriormente, Qualidade do sistema é um construto que considera as caraterísticas desejáveis do sistema, e é recorrentemente abordado na literatura como um construto multidimensional.

Com base na definição e nas dimensões estabelecidas sobre Qualidade do sistema para esse estudo apresentadas em 2.2.6 Variáveis do modelo proposto, este presente estudo utilizará a ferramenta desenvolvida e testada por Nelson et al. (2005) para a operacionalização do construto, conforme a Tabela 18.

Em seu trabalho, Nelson et al. (2005) operacionaliza o construto em uma ferramenta de pesquisa através de um questionário com escala Likert de 7 pontos que apresenta alpha de Cronbach superior à 0,78 para todas as dimensões do construto, sendo esses valores superiores ao índice de corte de 0.7 apontado por Fornell e Larcker (1981). 
Tabela 18 - Ferramenta de operacionalização da Qualidade do sistema Fonte: Adaptado Nelson et al. (2005)

\begin{tabular}{|c|c|c|c|}
\hline Construto & Dimensão & Pergunta & Código \\
\hline \multirow{18}{*}{$\begin{array}{l}\text { Qualidade } \\
\text { do sistema } \\
\text { (QS) }\end{array}$} & \multirow{3}{*}{$\begin{array}{c}\text { Confiabilidade } \\
\text { (QS_C) }\end{array}$} & O SI trabalha de forma confiável & QS_C1 \\
\hline & & O SI opera de forma confiável & QS_C2 \\
\hline & & A operação do sistema é estável & QS_C3 \\
\hline & \multirow{3}{*}{$\begin{array}{l}\text { Flexibilidade } \\
\text { (QS_F) }\end{array}$} & O sistema se adapta para atender às minhas necessidades & QS_F1 \\
\hline & & $\begin{array}{l}\text { O sistema pode se ajustar de forma flexível à novas condições e } \\
\text { demandas }\end{array}$ & QS_F2 \\
\hline & & $\begin{array}{l}\text { O sistema é versátil no atendimento de novas necessidades } \\
\text { conforme elas aparecem }\end{array}$ & QS_F3 \\
\hline & \multirow{3}{*}{$\begin{array}{l}\text { Integração } \\
\text { (QS_I) }\end{array}$} & $\begin{array}{l}\text { O sistema efetivamente integra dados de diferentes áreas da } \\
\text { empresa }\end{array}$ & QS_I1 \\
\hline & & $\begin{array}{l}\text { O sistema consolida informações que anteriormente eram providas } \\
\text { por diferentes áreas da empresa }\end{array}$ & QS_12 \\
\hline & & $\begin{array}{l}\text { O sistema efetivamente relaciona dados de diferentes áreas da } \\
\text { empresa }\end{array}$ & QS_13 \\
\hline & \multirow{3}{*}{$\begin{array}{l}\text { Acessibilidade } \\
\text { (QS_A) }\end{array}$} & O sistema viabiliza o pronto acesso as informações & QS_A1 \\
\hline & & O sistema torna as informações muito acessíveis & QS_A2 \\
\hline & & O sistema torna as informações de fácil acesso & QS_A3 \\
\hline & \multirow{3}{*}{$\begin{array}{c}\text { Tempo de } \\
\text { Resposta } \\
\text { (QS_TR) }\end{array}$} & O sistema leva muito tempo para responder às minhas solicitações & QS_TR1 \\
\hline & & O sistema disponibiliza informações prontamente & QS_TR2 \\
\hline & & O sistema retorna às minhas requisições de forma rápida & QS_TR3 \\
\hline & \multirow{3}{*}{$\begin{array}{l}\text { Qualidade do } \\
\text { sistema } \\
\text { (QS) }\end{array}$} & $\begin{array}{l}\text { Em termos de qualidade do sistema, o avalio com uma nota } \\
\text { elevada. }\end{array}$ & QS_1 \\
\hline & & De forma geral, o sistema apresenta alta qualidade. & QS_2 \\
\hline & & $\begin{array}{l}\text { De forma geral, posso avaliar a qualidade do sistema de forma } \\
\text { elevada }\end{array}$ & QS_3 \\
\hline
\end{tabular}

\subsection{Qualidade da informação}

Conforme apresentado anteriormente, Qualidade da informação é um construto definido por DeLone e McLean (1992) como "características desejáveis das informações disponibilizadas pelo sistema e é recorrentemente abordado na literatura como um construto multidimensional (ARISTIZABAL, 2016).

Rai et al. (2002) definem a Qualidade da informação como o grau em que a informação produzida atinge os requerimentos dos usuários com relação ao conteúdo, precisão e formato. E de forma similar Nelson et al. (2005) estrutura o construto em 4 dimensões (Acuracidade, Completude, Atualidade e Formato) e também apresentam sua operacionalização através de um questionário de escala tipo Likert de 7 pontos, o qual apresenta alpha de Cronbach superior a 0,83 para todas as suas dimensões, e será utilizado nesse estudo conforme a Tabela 19. 
Tabela 19 - Ferramenta de operacionalização do construto da Qualidade da informação Fonte: Adaptado Nelson et al. (2005)

\begin{tabular}{|c|c|c|c|}
\hline Construto & Dimensão & Pergunta & Código \\
\hline \multirow{15}{*}{$\begin{array}{l}\text { Qualidade } \\
\text { da } \\
\text { Informação } \\
\text { (QI) }\end{array}$} & \multirow{3}{*}{$\begin{array}{l}\text { Completude } \\
\text { (QI_C) }\end{array}$} & O SI fornece um conjunto completo de informações. & QI_C1 \\
\hline & & O SI produz informações abrangentes. & QI_C2 \\
\hline & & O SI prove todas as informações de que preciso. & QI_C3 \\
\hline & \multirow{3}{*}{$\begin{array}{l}\text { Acuracidade } \\
\text { (QI_AC) }\end{array}$} & O SI produz informações corretas. & QI_AC1 \\
\hline & & Existem poucos erros nas informações obtidas do sistema. & QI_AC2 \\
\hline & & A informação provida pelo SI é precisa. & QI_AC3 \\
\hline & \multirow{3}{*}{$\begin{array}{l}\text { Atualidade } \\
\text { (QI_AT) }\end{array}$} & O SI me oferece as informações mais recentes. & QI_AT1 \\
\hline & & O SI prove as mais atuais informações. & QI_AT2 \\
\hline & & A informação do SI está sempre atualizada. & QI_AT3 \\
\hline & \multirow{3}{*}{$\begin{array}{c}\text { Formato } \\
\text { (QI_F) }\end{array}$} & A informação disponibilizada pelo SI é bem formatada & QI_F1 \\
\hline & & A informação disponibilizada pelo SI apresenta bom lay-out & QI_F2 \\
\hline & & $\begin{array}{l}\text { A informação disponibilizada pelo SI é apresentada de forma clara } \\
\text { no monitor }\end{array}$ & QI_F3 \\
\hline & \multirow{3}{*}{$\begin{array}{l}\text { Qualidade da } \\
\text { Informação }\end{array}$} & De forma geral, posso avaliar o SI com uma boa nota. & QI_1 \\
\hline & & $\begin{array}{l}\text { De forma geral posso atribuir uma boa pontuação ao SI no quesito } \\
\text { qualidade da informação. }\end{array}$ & QI_2 \\
\hline & & No geral o SI me fornece informações de alta qualidade. & QI_3 \\
\hline
\end{tabular}

\subsection{Uso da informação}

Conforme apresentado anteriormente, o nível de uso dos sistemas de informação é uma das dimensões de sucesso de SI mais usadas na literatura por ser uma medida objetiva e fácil de quantificar. Porém, apenas a mensuração do tempo de utilização do SI não captura de forma adequada a relação entre a utilização e os resultados esperados, sendo também necessário considerar a natureza, extensão, qualidade e a adequação da utilização do sistema (DELONE et al. ,2013).

Popovič et al. (2012) define o uso da informação para DSS como "a aplicação de informações adquiridas e transmitidas para o processo organizacional de tomada de decisão" e apresenta uma ferramenta de pesquisa para sua mensuração, a qual foi adotada para esse estudo por apresentar visão holística do construto, boa confiabilidade (alpha de Cronbach superior a 0,87 ) e por ser estruturada para ferramentas com foco no suporte a tomada de decisão (Business Intelligence), conforme Tabela 20. 
Tabela 20 - Ferramenta de operacionalização do construto Uso da informação

Fonte: Adaptado Popovič et al. (2012)

\begin{tabular}{|c|c|c|}
\hline Construto & Pergunta & Código \\
\hline \multirow{9}{*}{$\begin{array}{l}\text { Uso da } \\
\text { informação } \\
\text { (UI) }\end{array}$} & $\begin{array}{l}\text { A informação disponibilizada pelo sistema expõe os atuais problemas dos } \\
\text { processos da empresa e dão visibilidade para todos os envolvidos. }\end{array}$ & UI_1 \\
\hline & $\begin{array}{l}\text { A informação disponibilizada pelo sistema fornece importantes inputs para } \\
\text { análises de desvio nos processos da empresa e para sua melhoria contínua. }\end{array}$ & UI_2 \\
\hline & $\begin{array}{l}\text { A informação disponibilizada pelo sistema estimula a inovação dos } \\
\text { processos internos e externos da empresa. }\end{array}$ & UI_3 \\
\hline & $\begin{array}{l}\text { A informação disponibilizada pelo sistema reduz incertezas no processo de } \\
\text { tomada de decisão, aumenta a confiança e melhora a efetividade do } \\
\text { processo operacional. }\end{array}$ & UI_4 \\
\hline & $\begin{array}{l}\text { A informação nos possibilita menor tempo de reação e pró-atividade na } \\
\text { realização do planejamento da empresa. }\end{array}$ & UI_5 \\
\hline & $\begin{array}{l}\text { A informação é utilizada para viabilizar mudanças estratégicas e planos, } \\
\text { modificar indicadores pré-existentes e mapear novos. }\end{array}$ & UI_6 \\
\hline & $\begin{array}{l}\text { Através da gestão da informação do sistema é possível agregar valor aos } \\
\text { clientes finais. }\end{array}$ & UI_7 \\
\hline & Através da gestão da informação do sistema é possível reduzir riscos. & UI_8 \\
\hline & $\begin{array}{l}\text { Através da gestão da informação do sistema é possível reduzir custos do } \\
\text { processo. }\end{array}$ & UI_9 \\
\hline
\end{tabular}

\subsection{Satisfação do usuário}

Conforme mencionado anteriormente, Satisfação do usuário é referente ao contentamento do usuário com o SI e apresenta interface com a utilização da informação do SI (DELONE; MCLEAN, 2003).

Para essa análise de satisfação com relação à sistemas de BA será adotado o construto proposto por Iivari (2005) por seu pragmatismo, confiabilidade (alpha de Cronbach superior a 0,92 ) e por atender os requisitos desse estudo, conforme Tabela 21.

Tabela 21 - Ferramenta de operacionalização do construto Satisfação do usuário Fonte: Adaptado (IIVARI, 2005)

\begin{tabular}{|c|c|c|c|c|}
\hline Construto & Pergunta & & & Código \\
\hline & Avalie o SI d & Analytics & & SU \\
\hline & Péssimo & ------- & Ótimo & SU_1 \\
\hline Satisfação do & Difícil & $-\ldots-\ldots--$ & Fácil & SU_2 \\
\hline usuário & Frustrante & $-\ldots-\ldots-\ldots$ & Satisfatório & SU_3 \\
\hline & Inadequado & $-\ldots-\ldots$ & Adequado & SU_4 \\
\hline & Monótono & ------- & Estimulante & SU_5 \\
\hline & Rígido & $-\ldots$ & Flexível & SU_6 \\
\hline
\end{tabular}

\subsection{Impacto individual}

Conforme apresentado anteriormente, o Impacto Individual se refere ao efeito causado pela informação fornecida pelo SI no comportamento do receptor (DELONE; MCLEAN, 1992). 
Para sistemas de BA, o impacto de maior relevância está no processo de tomada de decisão, e dessa forma será utilizada a ferramenta apresentada por Wixom e Watson (2001) em seu estudo sobre sistemas de Data Warehouse para a operacionalização do construto Percepção de benefício da utilização do sistema. A qual apresenta boa aderência para o objetivo do trabalho e bons níveis de confiança (alpha de Cronbach $=0,88$ ) e está descrita na Tabela 22.

Tabela 22 - Ferramenta de operacionalização do construto Impacto Individual Fonte: Adaptado Wixom e Watson (2001)

\begin{tabular}{|c|l|l|}
\hline Construto & Pergunta & \multicolumn{2}{c|}{ Código } \\
\hline \multirow{2}{*}{\begin{tabular}{c} 
Impacto $\begin{array}{c}\text { Individual } \\
\text { (II) }\end{array}$ \\
\cline { 2 - 3 }
\end{tabular}} & O SI alterou seu trabalho significativamente. & II_1 \\
\cline { 2 - 3 } & O SI reduziu o tempo necessário de análises para o suporte à decisão. & II_2 \\
\cline { 2 - 3 } & O SI reduziu o esforço necessário de análises para o suporte à decisão. & II_3 \\
\hline
\end{tabular}

\subsubsection{Construtos para Fatores críticos de sucesso de BA}

Nessa seção serão discutidos os construtos relacionados aos fatores críticos de sucesso de BA, sendo esses estruturados de acordo com as dimensões discutidas anteriormente em 2.2.1 Business Analytics.

\subsection{Qualidade dos dados}

Conforme descrito anteriormente na sessão 2.2.4 Sistemas de Informação, devido ao volume de dados e necessidade de processamento os sistemas são cruciais para o Business Analytics.

Dentre os pontos ressaltados pelos pesquisadores, destaca-se a qualidade de dados disponibilizada ao sistema por sua criticidade para o sucesso do SI (SAMMON; FINNEGAN, 2000; RUDRA; YEO, 2000; DAVENPORT et al., 2010).

Para esse estudo será utilizada uma adaptação da ferramenta apresentada por Nelson et al. (2005), a qual foi estruturada através de uma escala de 7 pontos e apresentou adequada confiabilidade (Alpha Cronbach 0,85). Conforme Tabela 23 apresentada abaixo: 
Tabela 23 - Ferramenta de operacionalização do construto da Qualidade dos dados

Fonte: Adaptado NELSON et al. (2005)

\begin{tabular}{|c|c|c|c|}
\hline Construto & Dimensão & Pergunta & Código \\
\hline \multirow{12}{*}{$\begin{array}{l}\text { Qualidade dos } \\
\text { dados }\end{array}$} & \multirow{3}{*}{ Acuracidade } & $\begin{array}{l}\text { Os dados disponibilizados por outros sistemas para a ferramenta } \\
\text { de Business Analytics estão corretos. }\end{array}$ & QD_AC1 \\
\hline & & $\begin{array}{l}\text { Existem poucos erros nos dados disponibilizados por outros } \\
\text { sistemas para a ferramenta de Business Analytics. }\end{array}$ & QD_AC2 \\
\hline & & $\begin{array}{l}\text { Os dados disponibilizados por outros sistemas para a ferramenta } \\
\text { de Business Analytics são assertivos. }\end{array}$ & QD_AC3 \\
\hline & \multirow{3}{*}{ Completude } & $\begin{array}{l}\text { O sistema de Business Analytics é provido de um conjunto } \\
\text { completo de dados necessários. }\end{array}$ & QD_C1 \\
\hline & & $\begin{array}{l}\text { O sistema de Business Analytics é abastecido com um conjunto de } \\
\text { dados abrangentes. }\end{array}$ & QD_C2 \\
\hline & & $\begin{array}{l}\text { O sistema de Business Analytics possui todos os dados necessários } \\
\text { para seu funcionamento. }\end{array}$ & QD_C3 \\
\hline & \multirow{3}{*}{ Atualidade } & $\begin{array}{l}\text { Os dados abastecidos ao sistema de Business Analytics são os mais } \\
\text { recentes. }\end{array}$ & QD_AT1 \\
\hline & & $\begin{array}{l}\text { Os dados providos ao sistema de Business Analytics são os mais } \\
\text { atuais. }\end{array}$ & QD_AT2 \\
\hline & & $\begin{array}{l}\text { Os dados disponibilizados ao sistema de Business Analytics estão } \\
\text { sempre atualizados. }\end{array}$ & QD_AT3 \\
\hline & \multirow{3}{*}{$\begin{array}{l}\text { Qualidade } \\
\text { dos Dados }\end{array}$} & $\begin{array}{l}\text { De forma geral, posso classificar os dados disponibilizados para o SI } \\
\text { com uma boa nota. }\end{array}$ & QD_1 \\
\hline & & $\begin{array}{l}\text { De forma geral posso atribuir uma boa pontuação ao SI no quesito } \\
\text { qualidade de dados. }\end{array}$ & QD_2 \\
\hline & & No geral o SI possui dados de alta qualidade. & QD_3 \\
\hline
\end{tabular}

\subsection{Engajamento dos executivos}

Conforme apresentado anteriormente, o engajamento dos executivos é definido por Croteau e Li (2003) como o grau de esforço empregado pelos executivos na implantação de sistemas de tecnologia da informação. Sendo especialmente importante em situações nas quais o redesenho de processos e papéis e responsabilidades tenham alta probabilidade de ocorrer.

Para esta dissertação será utilizado o conceito apresentado por Croteau e Li (2003) e, para a operacionalização do construto uma versão adaptada do trabalho de Dybå (2001), na qual o autor utilizou um questionário com de 5 pontos (sendo 1 Discordo totalmente e 5 Concordo totalmente) que apresentou boa confiabilidade (alpha de Cronbah de 0,87). Conforme Tabela 24 apresentada abaixo: 
Tabela 24 - Ferramenta de operacionalização do construto Engajamento dos executivos Fonte: Adaptado Dybå (2001)

\begin{tabular}{|c|c|c|}
\hline Construto & Pergunta & Código \\
\hline \multirow{5}{*}{$\begin{array}{c}\text { Engajamento } \\
\text { dos } \\
\text { executivos } \\
\text { (EE) }\end{array}$} & A equipe gerencial suporta ativamente as atividades relacionadas à BA? & EE_1 \\
\hline & A equipe gerencial aceita a responsabilidade sobre Business Analytics? & $\mathrm{EE} \_2$ \\
\hline & $\begin{array}{l}\text { A equipe gerencial considera BA uma forma de gerar vantagem } \\
\text { competitiva? }\end{array}$ & EE_3 \\
\hline & $\begin{array}{l}\text { A equipe gerencial participa ativamente das atividades relacionadas à } \\
\text { Business Analytics? }\end{array}$ & EE_4 \\
\hline & $\begin{array}{l}\text { Questões referentes a BA são frequentemente discutidas nas reuniões da } \\
\text { equipe gerencial? }\end{array}$ & EE_5 \\
\hline
\end{tabular}

\subsection{Cultura Organizacional de Gestão Baseada em Fatos}

De acordo com a discussão realizada anteriormente, além do desenvolvimento de sistemas e do compartilhamento de suas informações, as empresas devem estabelecer um ambiente de utilização proativa das informações no qual a tomada de decisão é realizada de forma racional e pautada em ampla análise das informações (POPOVIČ et al., 2012).

Para esse artigo será adotada a definição apresentada por Popovič et al. (2012) e operacionalização do construto (Tabela 25), com confiabilidade alpha de Cronbach 0,78 e utilizou uma escala sendo 1: Discordo totalmente e 7: Concordo totalmente.

Tabela 25 - Ferramenta de operacionalização do construto Cultura Organizacional Fonte: Adaptado Popovič et al. (2012)

\begin{tabular}{|c|c|c|}
\hline Construto & Pergunta & Código \\
\hline \multirow{3}{*}{$\begin{array}{c}\text { Cultura } \\
\text { Organizacional } \\
\text { (CO) }\end{array}$} & $\begin{array}{l}\text { O processo de tomada de decisão está bem estabelecido e é conhecido por } \\
\text { todos os interessados? }\end{array}$ & CO_1 \\
\hline & $\begin{array}{l}\text { Faz parte da política organizacional da empresa incorporar informações } \\
\text { disponíveis em todo processo de decisão? }\end{array}$ & $\mathrm{CO}_{2} 2$ \\
\hline & $\begin{array}{l}\text { Os gestores consideram as informações fornecidas indiferentemente do } \\
\text { tipo de decisão à ser tomada? }\end{array}$ & CO_3 \\
\hline
\end{tabular}

\subsection{Qualidade da equipe de BA}

De acordo com a discussão apresentada na sessão 2.2.6.3 Pessoas, Business Analytics é um conceito multidisciplinar e, desta forma, demanda conhecimentos e habilidades que transcendem a área de Tecnologia da informação.

Para esse artigo será adotada a definição apresentada por Wixom e Watson (2001) e sua operacionalização do construto, a qual apresenta boa confiabilidade pelo alpha de Cronbach 0,90 e utilizou uma escala sendo 1: Discordo totalmente e 7: Concordo totalmente. Conforme Tabela 26 apresentada abaixo: 
Tabela 26 - Ferramenta de operacionalização do construto Cultura Organizacional Fonte: Adaptado Wixom e Watson (2001)

\begin{tabular}{|c|c|c|}
\hline Construto & Pergunta & Código \\
\hline \multirow{2}{*}{$\begin{array}{l}\text { Qualificação da } \\
\text { Equipe } \\
\text { (QE) }\end{array}$} & $\begin{array}{l}\text { Os membros da equipe de BA têm os conhecimentos técnicos } \\
\text { corretos }\end{array}$ & QE_1 \\
\hline & $\begin{array}{l}\text { Os membros da equipe de BA possuem boas habilidades } \\
\text { interpessoais }\end{array}$ & QE_2 \\
\hline
\end{tabular}

\subsection{Planejamento da pesquisa}

Conforme apresentado anteriormente, um Levantamento tipo survey explanatório é um processo composto por uma série de atividades conectadas entre si. E um planejamento deste processo é crucial para prevenir possíveis problemas e garantir a qualidade da pesquisa (FORZA, 2002).

Dentre estas atividades destacam-se: Definição da população e amostra, definição do método de coleta de dados e a Estruturação do instrumento de pesquisa. Sendo estes pontos abordados neste capítulo.

\subsubsection{Definição da população e amostra}

Como apresentado anteriormente no tópico 3.1 Levantamento tipo Survey, esta pesquisa utilizará uma abordagem quantitativa e, consequente, empregará técnicas estatísticas para a análise dos dados. Desta forma será apresentado de forma sucinta as definições de alguns conceitos estatísticos recorrentes ao longo do debate deste trabalho:

- População objetivo (ou Alvo): É a totalidade de elementos que estão sob discussão e das quais se deseja informação A população pode ser formada por pessoas, domicílios, peças de produção, cobaias, ou qualquer outro elemento a ser investigado (GUIMARÃES, 2008).

- População referenciada: Conjunto de indivíduos da população que estão de fato acessíveis para serem amostrados;

- População Amostral: Conjunto total de amostras obtidas no trabalho de campo;

- Amostra: Parcela da população amostral utilizada para uma posterior análise de dados. A amostra fornece informações que podem ser utilizadas para estimar características de toda a população (GUIMARÃES, 2008);

- Unidade amostral: Unidade na qual são observadas e medidas as características quantitativas e qualitativas da população. A amostra é composta pelo conjunto de unidades amostrais. Cada unidade amostral gera uma única observação da variável de interesse.

- Plano Amostral: É a fase de planejamento estatístico, na qual consiste em definir as unidades amostrais, modo como a amostra será retirada (o tipo de amostragem), e o próprio tamanho da amostra (LINO, 2015); 
Miguel et al. (2012) ressalta que em levantamento tipo survey amostral além da clara definição dos objetivos, também faz-se necessário determinar a População Alvo, a População Amostrada (referenciada), a Unidade amostral e a Unidade de informação.

De acordo com o objetivo desse trabalho, sendo identificar os fatores condicionantes de sucesso de sistemas de Business Analytics, as seguintes definições foram adotadas:

- População referenciada: Profissionais que utilizam ferramentas de Business Analytics;

- População Objetivo: Desenvolvedores ou analistas de negócio que utilizem ferramentas de área de Business Analytics;

- Unidade amostral: Unidade amostral adotada neste caso é idêntica à unidade de informação, sendo essa o respondente da pesquisa.

Para o cálculo do tamanho mínimo da amostra foi utilizado o software livre G*Power (MAYR et al., 2007). Para este cálculo, o programa considera 3 parâmetros de entrada: O tipo de teste estatístico, o nível de confiança desejado e a maior quantidade de variáveis latentes relacionadas a um construto exógeno do modelo.

A técnica estatística selecionada para a análise dos dados coletados é a modelagem de equações estruturais (Structured Equation Model - SEM) baseada em Variância do Método de Mínimos Quadrados (Partial Least Squares - PLS-SEM), o nível de confiança foi fixado em 95\% e o construto com maior quantidade de variáveis é a Qualidade do Sistema com 7 variáveis latentes relacionadas. Resultando na amostra mínima de 153 unidades para o modelo proposto nesta pesquisa.

A Figura 18 apresenta o resultado apresentado pelo software GPower. 


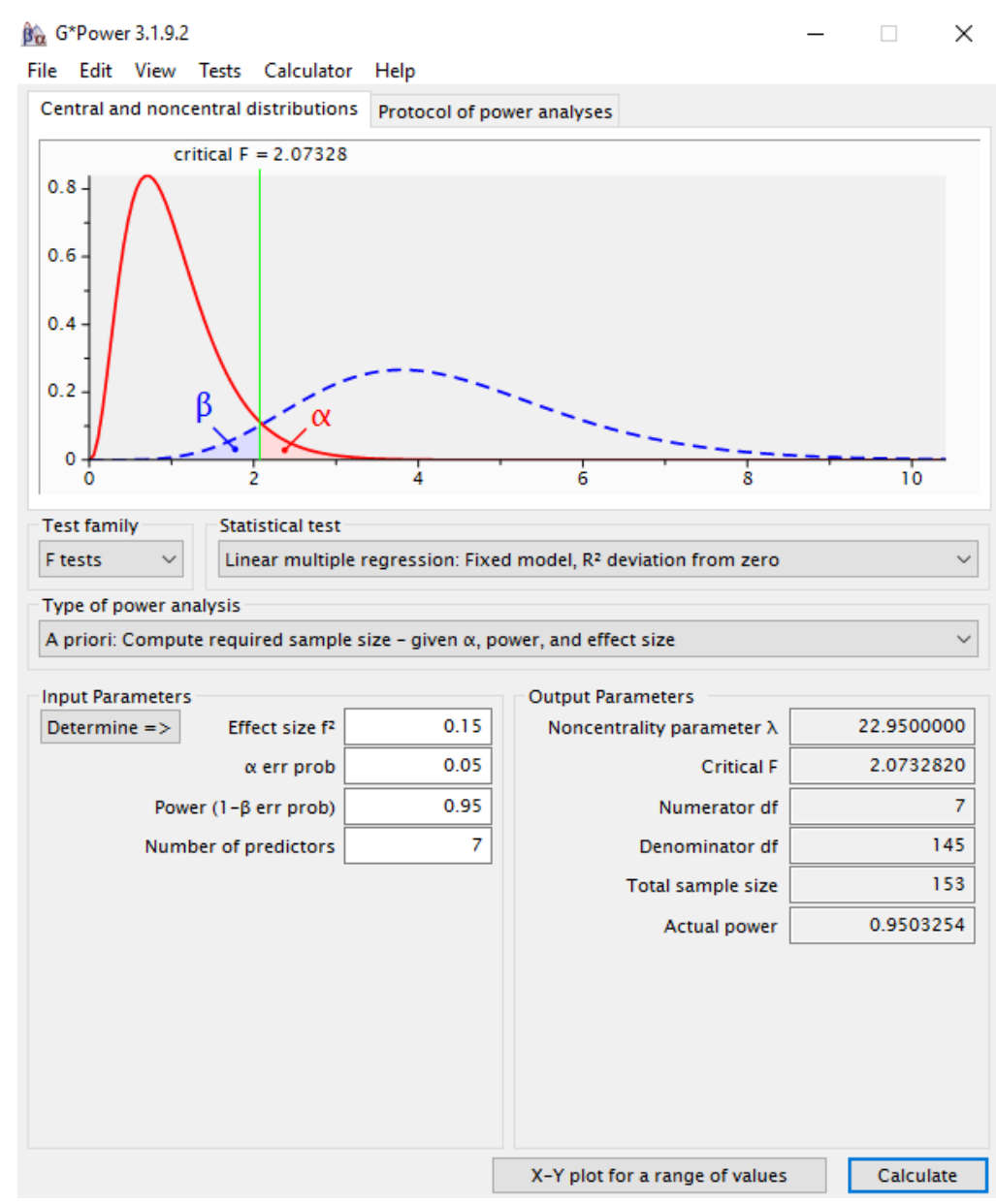

Figura 18 - Cálculo do tamanho da amostra no software G*Power Fonte: GPower

\subsubsection{Método de coleta de dados}

Para a condução desta survey, o instrumento de coleta de dados selecionado foi um questionário estruturado não disfarçado desenvolvido na plataforma web Survey Monkey.

Este tipo de questionário tem como característica o baixo uso de questões abertas e a ciência do respondente com relação aos objetivos da pesquisa.

A seleção da ferramenta SurveyMonkey ocorreu pela sua facilidade tanto na estruturação do questionário como no tratamento posterior dos dados, além de experiências positivas na sua utilização em trabalhos realizados anteriormente.

A prospecção de respondentes ocorreu através do envio de e-mails para ex-alunos do programa de pós-graduação em Gestão de Tecnologia da Informação do departamento de engenharia de produção da Universidade de São Paulo, bem como na divulgação do questionário em fóruns virtuais referentes à Business Analytics em redes sociais (e.g. Linkedin). 


\subsubsection{Instrumento de pesquisa}

O instrumento foi estruturado em três partes (Introdução, Caracterização do respondente e Questionário), e encontra-se disponível no capítulo Anexos.

A Introdução contempla uma contextualização sobre os objetivos da pesquisa, bem com uma sucinta explicação dos principais conceitos envolvidos (glossário) e instruções de preenchimento.

A Caracterização do respondente teve como objetivo capturar informações sobre o perfil do respondente para estratificações dos dados, análise da diversidade da amostra e mapeamento de possíveis tendências de comportamento.

As informações solicitadas abordaram os seguintes temas:

1. Informações pessoais: Nome e e-mail do respondente;

2. Gênero: Sexo do respondente; (Masculino ou Feminino)

3. Idade: Idade do respondente; (17 anos ou menos, 18 a 20 anos, 21 a 29 anos, 30 a 39 anos, 40 a 49 anos, 50 a 59 anos e 60 anos ou mais)

4. Localização geográfica: Estado brasileiro de residência; $(S P, R J, M G$, etc);

5. Grau de Escolaridade: Nível de escolaridade mais alto ou diploma do respondente (Menos do que o ensino médio, Ensino médio completo, Curso Técnico, Ensino superior incompleto, Ensino superior completo e Pós-graduação)

6. Área de atuação: Desenvolvedor de TI, Modelador matemático/estatístico e Usuário/Analista;

7. Cargo: Nível do seu cargo atual do respondente (Proprietário/Executivo/Nível de diretoria, Gerência, Coordenação, Analista e Outros)

8. Setor industrial: Segmento principal de atuação da empresa na qual o respondente exerce seu ofício;

(Serviços financeiros, Telecomunicações, Publicidade de Marketing, etc);

9. Porte da Industria: Classificação da empresa na qual o respondente exerce seu ofício de acordo com seu faturamento anual;

(Microempresa, Pequeno porte, Médio porte, Médio - Grande porte e Grande porte)

10. Funcionalidades do sistema: Funcionalidades presentes na ferramenta utilizada pelo usuário;

(Algoritmos de otimização, Análises Prescritivas, Análises Preditivas, OLAP, Análises estatísticas simples e Relatórios de dados)

A parte do questionário é constituída pela operacionalização dos construtos apresentados no tópico 3.2.1 Operacionalização dos construtos através de questões de múltipla escolha e de escala de intensidade. 


\subsection{Técnica Estatística}

A técnica estatística selecionada para esse estudo foi a análise multivariada de dados de modelagem de equações estruturais (Structured Equation Model - SEM). Além de sua adequação técnica para a interpretação do modelo proposto, Hair et al. (2017) destaca a relevância do método como um dos principais avanços na estatística aplicada a ciências sociais das últimas décadas e também sinalizar o exponencial crescimento de publicações envolvendo esse método nos últimos anos. Suas características e o critério para sua seleção serão apresentados no tópico abaixo.

\subsubsection{Análise multivariada de dados: SEM-PLS}

De acordo com HAIR et al. (2009), análise multivariada de dados pode ser definida como:

"Análise multivariada de dados se refere a todas as técnicas estatísticas que simultaneamente analisam múltiplas medidas sobre indivíduos ou objetos sob investigação. Assim qualquer análise simultânea de mais do que duas variáveis pode ser considerada, a princípio, como multivariada."

Os autores também ressaltam a variedade de técnicas estatísticas dessa natureza e apresentam um sumário sobre técnicas de análise de dependência de multivariada de dados, conforme Tabela 27.

Tabela 27 - Análises Multivariada de Dados

Fonte: Adaptado Hair et al. (2009)

\begin{tabular}{|c|c|c|c|}
\hline $\begin{array}{l}\text { Variáveis } \\
\text { Dependentes } \\
\text { (Quantidade) }\end{array}$ & $\begin{array}{l}\text { Variáveis } \\
\text { Independentes } \\
\text { (Quantidade) }\end{array}$ & $\begin{array}{l}\text { Variáveis } \\
\text { Dependentes } \\
\text { (Escala) }\end{array}$ & Técnica estatística \\
\hline \multirow[t]{4}{*}{ Única } & \multirow[t]{4}{*}{ Única } & Métrica & Regressão Múltipla \\
\hline & & Métrica & Análise conjunta \\
\hline & & Não-Métrica & Análise discriminante Múltipla \\
\hline & & Não-Métrica & Modelos Lineares de Probabilidade \\
\hline \multirow[t]{3}{*}{ Múltiplas } & \multirow[t]{3}{*}{ Única } & Métrica & Análise de correlação canônica \\
\hline & & Métrica & Análise multivariada de variância \\
\hline & & Não-Métrica & $\begin{array}{l}\text { Análise de correlação canônica com } \\
\text { variáveis dicotômicas }\end{array}$ \\
\hline Múltiplas & Múltiplas & $\begin{array}{l}\text { Métrica ou } \\
\text { Não-Métrica }\end{array}$ & Modelagem de Equações Estruturais \\
\hline
\end{tabular}

Para o contexto deste trabalho destaca-se a técnica de Modelagem de Equações Estruturais (SEM) por viabilizar a análise de múltiplas variáveis dependentes e independes, de forma a ser o método mais apropriado para a análise do modelo apresentado anteriormente na Figura 17.

A SEM é uma família de modelos estatísticos que buscam explicar as interações entre múltiplas variáveis através de uma estrutura de equações. Sendo que tais equações descrevem todas as relações entre construtos (variáveis dependentes e independentes) envolvidos na análise (HAIR et al., 2009). 
Para a condução deste método inicialmente o pesquisador baseia-se em análise prévia da teoria e experiências antecedentes para estruturar a proposta de relações entre as variáveis dependentes e independentes, sendo esse denominado de modelo estrutura (HAIR et al., 2009).

Outro diferencial da SEM está na habilidade de incorporar variáveis latentes na análise.

HAIR et al. (2009) apresentam a seguinte definição para este conceito:

"Um construto latente (também chamado de variável latente) é um conceito teorizado e não observado que pode ser representado por variáveis observáveis ou mensuráveis. Ele é medido indiretamente pelo exame de consistência entre múltiplas variáveis medidas, algumas vezes chamadas de variáveis manifestas, ou indicadores..."

PLS-SEM tem como objetivo maximizar a variância explicada (i.e. $\mathrm{R}^{2}$ ) das variáveis latentes endógenas do modelo estrutural (HAIR et al., 2017).

Os autores ainda apresentam uma classificação dos construtos de acordo com sua interação com seus respectivos indicadores.

- Construtos Exógenos: São equivalentes latentes a variáveis independentes, e são determinados por fatores externos ao modelo, ou seja, não são dependentes de qualquer outro construto do modelo.

- Construtos Endógenos: São equivalentes latentes a variáveis dependentes. Isto é, são teoricamente determinados por fatores internos do modelo (outros construtos).

Balasubraman et al. (2002) também apresentam outra classificação de acordo com a relação de causalidade entre o construto latente e seus respectivos indicadores:

- Construtos Reflexivos: A relação de causalidade ocorre na direção do construto latente para seus indicadores. Variações nas medições dos indicadores são consequência (reflexos) de variações da variável latente. Neste tipo de construto é esperada correlação (consistência interna) entre os indicadores, e a retirada por ventura de um deles não deve causar alterações significativas na concepção (significado) do construto.

- Construtos Formativos: A relação de causalidade ocorre na direção dos indicadores para o construto latente. Parte-se da hipótese que variações nas medições ocasionam variações nos construtos latentes. $\mathrm{O}$ conjunto de indicadores selecionados determinam o conceito e significado empírico do construto. Dessa forma, a retirada de um dos indicadores do construto pode impactar sua concepção e também não é esperada correlação entre os indicadores.

A Tabela 28 abaixo apresenta os construtos e sua classificação utilizadas neste trabalho. Os seus respectivos indicadores foram exibidos nas ferramentas de operacionalização apresentadas no capítulo 3.2.1 Operacionalização dos construtos.

Apesar da flexibilidade do método, vale ressaltar que a SEM é um método de análise confirmatória e a estruturação do modelo deve ser ditada por uma forte base teórica (ARISTIZABAL, 2016; CHIN, 1998). 


\subsubsection{Critérios de qualidade}

Nesta sessão será apresentado uma revisão bibliográfica sobre as análises de qualidade do modelo empregadas para a técnica estatística PLS-SEM.

\subsubsection{Modelo de mensuração}

A etapa de avaliação dos modelos de mensuração tem como objetivo analisar a confiabilidade e validade da ferramenta com relação a medição dos construtos.

Devido as características intrínsecas de cada tipo de construto, a os indicadores de qualidade do modelo de mensuração de construtos reflexivos e formativos são distintos, sendo eles:

\section{Reflexivos}

- Consistência interna (Alpha de Cronbach e Composite Reliability)

- Validação de convergência (Confiabilidade e AVE - Average Variance Extracted)

- Validação discriminatória (Cross-Loadings)

\section{Formativos}

- Validação de convergência

- Colinearidade entre indicadores

- Significância e relevância dos outer weights

Para este trabalho é pertinente a discussão restrita dos critérios de qualidade para indicadores reflexivos, pela ausência de indicadores formativos no modelo proposto.

\subsection{Consistência interna}

O Alpha de Cronbach é o indicador de consistência interna mais difundido na utilização da SEM, o qual apresenta uma estimativa de confiabilidade do construto com base na correlação entre seus indicadores (variância).

Seus valores variam entre 0 e 1 , sendo aceitáveis níveis superiores a 0,7 apontado por Fornell e Larcker (1981).

Vale ressaltar que o Alpha de Cronbach é sensível a quantidade de itens na escala de medição, não pondera os indicadores pelos seus distintos pesos (outer loadings) e tende a subestimar a consistência interna dos construtos.

Devido as suas limitações é aconselhável analisar de forma complementar o Composite Reliability, o qual também verifica a consistência interna do construto, porém com base nos Outer Loadigns e erro de medição de seus indicadores.

De forma similar ao Alpha de Cronbach o Composite Reliability também apresenta variação entre 0 e 1, sendo aceitável valores acima de 0,7 pesquisas não exploratórias.

Em contraste com o Alpha de Cronbach, o Composite Reliability tende a superestimar a consistência interna. No qual o real valor de consistência interna do construto deve estar estabelecido entre o valor dos dois indicadores. 


\subsection{Validação de convergência}

A validação de convergência refere-se à correlação entre as medições dos indicadores do mesmo construto.

Como premissa para a validade do modelo de mensuração, os construtos devem apresentar indicadores com valores de seus respectivos outer loadings (também referidos como confiabilidade do indicador) estatisticamente significantes, sendo esses geralmente considerados acima de 0,708 . O que sinaliza que mais de $50 \%$ da variação do indicador é causada pela variação do construto reflexivo.

Para indicadores com outer loadings entre 0,4 e 0,7, sua remoção deve ser realizada apenas se esta ação aumentar a consistência interna (ou o AVE - Average Variance Extracted). Caso contrário eles devem ser mantidos no modelo de mensuração. Já indicadores com outer loadings inferiores a 0,4 , sempre devem ser removidos do estudo.

Outro indicador importante de convergência é o Average Variance Extracted (AVE), o qual é calculado por construto através da média de seus outer loadings elevados ao quadrado e representa quanto da variação dos indicadores e representada pelo construto. De forma similar a confiabilidade do indicador, neste caso também é desejado valores superiores a 0,5.

\subsection{Validação discriminatória}

Validação discriminatória é o grau de distinção empírica dos construtos. Desta forma, o estabelecimento da validação discriminatória implica na unicidade dos construtos e sua respectiva captura única de fenômenos não representado por demais construtos do modelo.

A análise de cross-loadings é um procedimento típico de validação discriminatória, a qual verifica se a correlação (outer loadings) de cada indicador com seu construto é superior a uma possível correlação com os demais construtos do modelo.

O critério de Fornell-Larcker é uma maneira alternativa de analisar a validação discriminatória do modelo, sendo esta análise baseada no conceito de que o construto deve apresentar maior variância relacionada aos seus respectivos indicadores do que com qualquer outro construto.

Para a validação discriminatória pelo critério de Fornell-Larcker, o quadrado do AVE do construto deve ser superior a todas suas respectivas correlações com os demais construtos.

Como restrições dos modelos, a análise de cross-loadings pode falhar em sinalizar falta de validação discriminatória quando dois construtos são perfeitamente correlacionados. Já o critério de Fornell-Larcker apresenta baixa performance quando a carga dos indicadores referente aos construtos em análise apresenta baixa variação entre si.

Para contornar esses pontos, Henseler et al. (2015) propôs o Heterotrait-Monotrait Ratio (HTMT), o qual analisa a relação entre a correlação dos indicadores com seus construtos e com os demais construtos. Como parâmetro, valores acima de 0,85 sinalizam falta de validação discriminatória e para construtos conceitualmente similares utiliza-se 0,9.

Para uma análise de inferência estatística se utiliza a técnica de Bootstrapping para a estimativa do intervalo de confiança e validação do teste. Intervalos de confiança contendo o valor 1 representam ausência de validação de discriminação. 


\subsubsection{Modelo estrutural}

A análise do modelo estrutural permite determinar a capacidade do o modelo em prever os valores de um certo construto. Desta forma, a aderência dos modelos PLS-SEM são geralmente mensurados como os desvios entre os valores observados e previstos das variáveis dependentes do modelo.

Os principais indicadores de qualidade do modelo estrutural em PLS-SEM são: Análise de colinearidade, $\mathrm{R}^{2}$ (Explained variance), $\mathrm{f}^{2}$ (Effect size), $\mathrm{Q}^{2}$ (Predictive relevance) e o tamanho e relevância estatística dos coeficientes dos modelos estruturais.

\subsection{Análise de colinearidade}

A PLS-SEM é baseada na técnica de análise de regressão múltiplas, a qual pode apresentar resultados enviesados no caso da existência de elevado grau de colinearidade entre os construtos. Desta forma, faz-se necessário sua verificação para assegurar a qualidade do modelo.

Para essa análise é aplicada as medidas de tolerância (Tol) e o fator de inflação de variância (VIF - Variance Inflation Factor).

O indicador Tol representa a quantidade de variância de um construto exógeno que não é explicada por outro construto exógeno do mesmo grupo.

Sendo necessário examinar os conjuntos de construtos preditores de cada subparte do modelo estrutural para calcular a tolerância a partir do coeficiente de regressão, conforme equação abaixo:

$$
\operatorname{Tol}_{x_{1}}=1-R_{x_{1}}^{2}
$$

O VIF é uma medida correlata de colinearidade e representa o grau de aumento do erro padrão pelo efeito da colinearidade. E seu cálculo é realizado conforme equação (2) apresentada logo abaixo:

$$
V I F_{x_{1}}=1 / \text { Tol }_{X_{1}}
$$

Valores de Tol inferiores a 0,2 e VIF superiores de 5, são indicadores de problemas de colinearidade.

\subsection{Significância e Relevância das relações estruturais}

Os coeficientes de caminho do modelo estrutural apresentam valores padronizados entre -1 $\mathrm{e}+1$, valores próximos de 1 representam forte relacionamento positivo ou negativo entre as variáveis e coeficientes estimados perto de zero indicam fraca ou inexistente relações de causalidade entre os construtos.

A significância do relacionamento está atrelada ao erro padrão que é obtido por meio da técnica de bootstrapping, a qual permite a estimativa do $t$ student. Para análises bicaudais com nível de significância de 5\%, valores de t superiores a 1,96 apontam significância na relação causal em análise.

Outra forma recorrente de se apresentar a significância estatística dos coeficientes de caminho é através do valor $p$, o qual apresenta a probabilidade de erroneamente se rejeitar 
uma hipótese nula verdadeira. No contexto de PLS-SEM a probabilidade de se assumir de forma errônea a significância estatística de um coeficiente de caminho.

Após a verificação de significância das relações, faz-se necessário o entendimento de sua relevância. Tendo em vista que apesar de apresentar significância seu impacto na variável endógena pode ser pouco representativo e não apresenta relevância prática de gestão.

$\mathrm{Na}$ análise dos modelos estruturais é recorrente o interesse dos pesquisadores em analisar os efeitos diretos e indiretos das variáveis exógenas, sendo e esse conceito chamado de Efeito total (Total Effect).

\subsection{Avaliação do coeficiente de determinação $\left(\mathbf{R}^{2}\right)$}

$\mathrm{O} \mathrm{R}^{2}$ é um parâmetro frequentemente analisado na avaliação do modelo estrutural e representa quanto da variância de um construto endógeno é relacionado aos seus respectivos construtos exógenos.

Este coeficiente mede o poder de predição do modelo e é calculado pela correlação ao quadrado das variáveis preditivas do construto endógeno. E seus valores variam entre 0 e 1 , sendo que $0,75,0,50$ e 0,25 podem ser considerados como substancial, moderado e fraco, respectivamente para estudos de marketing Hair et al. (2017).

Vale ressaltar que o valor de $\mathrm{R}^{2}$ é influenciado pela quantidade de construtos exógenos, mesmo no caso em que exista baixa correlação entre os mesmos. Desta forma o $\mathrm{R}^{2}$ Ajustado pondera o valor pela quantidade de construtos endógenos de forma a mitigar este viés da análise.

\subsection{Avaliação do efeito do tamanho no coeficiente de determinação $\left(\mathrm{f}^{2}\right)$}

Adicionalmente a análise do valor de $\mathrm{R}^{2}$ do construto endógeno, é interessante o diagnóstico do impacto da omissão de cada construto endógeno no coeficiente de determinação. Sendo essa análise chamada de efeito do tamanho $\left(\mathrm{f}^{2}\right)$, conforme equação abaixo:

$$
f^{2}=\frac{R_{\text {incluido }}^{2}-R_{\text {excluide }}^{2}}{1-R_{\text {incluído }}^{2}}
$$

Os termos $\mathrm{R}^{2}$ incluído $\mathrm{R}^{2}$ excluído são referentes aos valores $\mathrm{R}^{2}$ da variável endógena com e sem a consideração da variável exógena no seu cálculo.

Como orientação pode-se utilizar os valores $0,02,0,15$ e 0,35 respectivamente como fraco, médio e forte efeito na variável endógena. Valores inferiores a 0,02 indicam a ausência de efeito no construto.

\subsection{Análise de relevância preditiva (Q2)}

De forma adicional a avaliação de magnitude dos valores de $\mathrm{R}^{2}$, pesquisadores recorrentemente examinam o valor de Stone-Geisser $\left(\mathrm{Q}^{2}\right)$ para construtos endógenos reflexivos.

Esta medida avalia o poder de predição do modelo para dados não contidos na amostra utilizada para a estimativa do modelo, e valores superiores a zero indicam relevância preditiva para o construto dependente. 
Os valores de $\mathrm{Q}^{2}$ são obtidos através do procedimento de Blindfolding, o qual omite sistematicamente dados da amostra em uma distância pré-definida (D). Sendo recomendável a utilização de valores entre os intervalos de 5 a 10, no qual a razão entre a quantidade de amostras e a distância (D) não pode ser um número inteiro.

\subsection{Estruturação do modelo em estudo}

A Tabela 28 apresenta um resumo sobre os códigos dos construtos e variáveis (indicadores) utilizados no modelo estrutural apresentado na Figura 19.

Tabela 28 - Código dos construtos

Fonte: Elaborado pelo autor

\begin{tabular}{|c|c|c|c|}
\hline Construto & Dimensão & Código & Classificacão \\
\hline \multirow{7}{*}{$\begin{array}{l}\text { Qualidade do } \\
\text { Sistema } \\
\text { (QS) }\end{array}$} & - & QS & Endógeno e Reflexivo \\
\hline & Flexibilidade & QS_F & Exógeno e Reflexivo \\
\hline & Integração do sistema & QS_IS & Exógeno e Reflexivo \\
\hline & Tempo de resposta & QS_T & Exógeno e Reflexivo \\
\hline & Recuperação do sistema & QS_R & Exógeno e Reflexivo \\
\hline & Comodidade no acesso & QS_C & Exógeno e Reflexivo \\
\hline & Interação com o usuário & QS_IU & Exógeno e Reflexivo \\
\hline \multirow{5}{*}{$\begin{array}{l}\text { Qualidade da } \\
\text { Informação } \\
\text { (QI) }\end{array}$} & - & QI & Endógeno e Reflexivo \\
\hline & Completude & QI_C & Exógeno e Refl exivo \\
\hline & Acuracidade & QI_AC & Exógeno e Reflexivo \\
\hline & Atualidade & QI_AT & Exógeno e Reflexivo \\
\hline & Formato & QI_F & Exógeno e Reflexivo \\
\hline \multicolumn{4}{|l|}{ Satisfação do } \\
\hline $\begin{array}{l}\text { Usuário } \\
\text { (SU) }\end{array}$ & - & su & Endógeno e Reflexivo \\
\hline $\begin{array}{l}\text { Uso da } \\
\text { Informação } \\
\text { (UI) }\end{array}$ & - & UI & Endógeno e Reflexivo \\
\hline $\begin{array}{l}\text { Impacto } \\
\text { Individual } \\
\text { (II) }\end{array}$ & - & II & Endógeno e Reflexivo \\
\hline
\end{tabular}

\begin{tabular}{|c|c|c|c|}
\hline Construto & Dimensão & Código & \\
\hline & - & QS & Endógeno e Reflexivo \\
\hline Qualidade dos & Acuracidade & QD_AC & Exógeno e Refl exivo \\
\hline dados & Completude & QD_C & Exógeno e Refl exivo \\
\hline & Atualidade & QD_AT & Exógeno e Refl exivo \\
\hline $\begin{array}{c}\text { Engajamento } \\
\text { dos Executivos } \\
\text { (EE) } \\
\end{array}$ & - & $\mathrm{EE}$ & Endógeno e Reflexivo \\
\hline $\begin{array}{c}\text { Cultura } \\
\text { Organizacional } \\
\text { (CO) }\end{array}$ & - & $\mathrm{CO}$ & Endógeno e Reflexivo \\
\hline Qualficação da & & & \\
\hline $\begin{array}{l}\text { Equipe } \\
\text { (QE) }\end{array}$ & - & $\mathrm{QE}$ & Endógeno e Reflexivo \\
\hline
\end{tabular}

Um modelo SEM completo (modelos de mensuração e estrutural) pode ser bastante complexo. E apesar de existirem muitas maneiras para especificar todas as relações matemáticas, muitos pesquisadores consideram mais conveniente retratar o modelo de forma visual, sendo esse conceito conhecido como Diagrama de caminhos (HAIR et al., 2009).

Esta notação visual (diagrama de caminhos) retrata os construtos, variáveis de medida (indicadores) e suas respectivas relações estipuladas no modelo. Por convenção, construtos são representados por elipses ou círculos, as variáveis medidas ou indicadores por retângulos e as relações por setas (ARISTIZABAL, 2016; HAIR et al., 2009).

Para a condução de análises SEM existem distintas abordagens estatísticas, nas quais destacam-se a Análise baseada em Covariância (Covariance-Based-CB-SEM), utilizada em softwares populares no mercado como LISREL e AMOS, e a análise Baseada em Variância do Método de Mínimos Quadrados (Partial Least Squares - PLS-SEM). O PLS-SEM tem se tornado cada vez mais popular e apresenta como principal vantagem sua robustez frente a problemas recorrentes nas ciências sociais como amostras pequenas, dados que não se distribuem normalmente ou a estimação de modelos complexos, ou seja, com muitos indicadores e muitas relações de causalidade (ARISTIZABAL, 2016; HAIR et al., 2009; HAIR et al., 2013). 
A Figura 19 apresenta o diagrama de caminhos referente ao modelo proposto neste trabalho. Para a sua estruturação foi utilizado o software Smartpls 3.0, o qual caracteriza-se por utilizar em seu algoritmo de análise a técnica PLS-SEM.

\subsection{Pré-teste}

Antes da coleta de dados foi realizado um pré-teste da ferramenta de pesquisa com o intuído de validar o entendimento por parte dos respondentes das questões elaboradas.

O pré-teste foi conduzido através da realização e análise do questionário por 5 pesquisadores da área de Tecnologia da Informação.

Todos os comentários apresentados pelos respondentes do pré-testes foram analisados e as 3alterações pertinentes foram realizadas.

O próximo capítulo apresenta a análise e discussão dos resultados. 


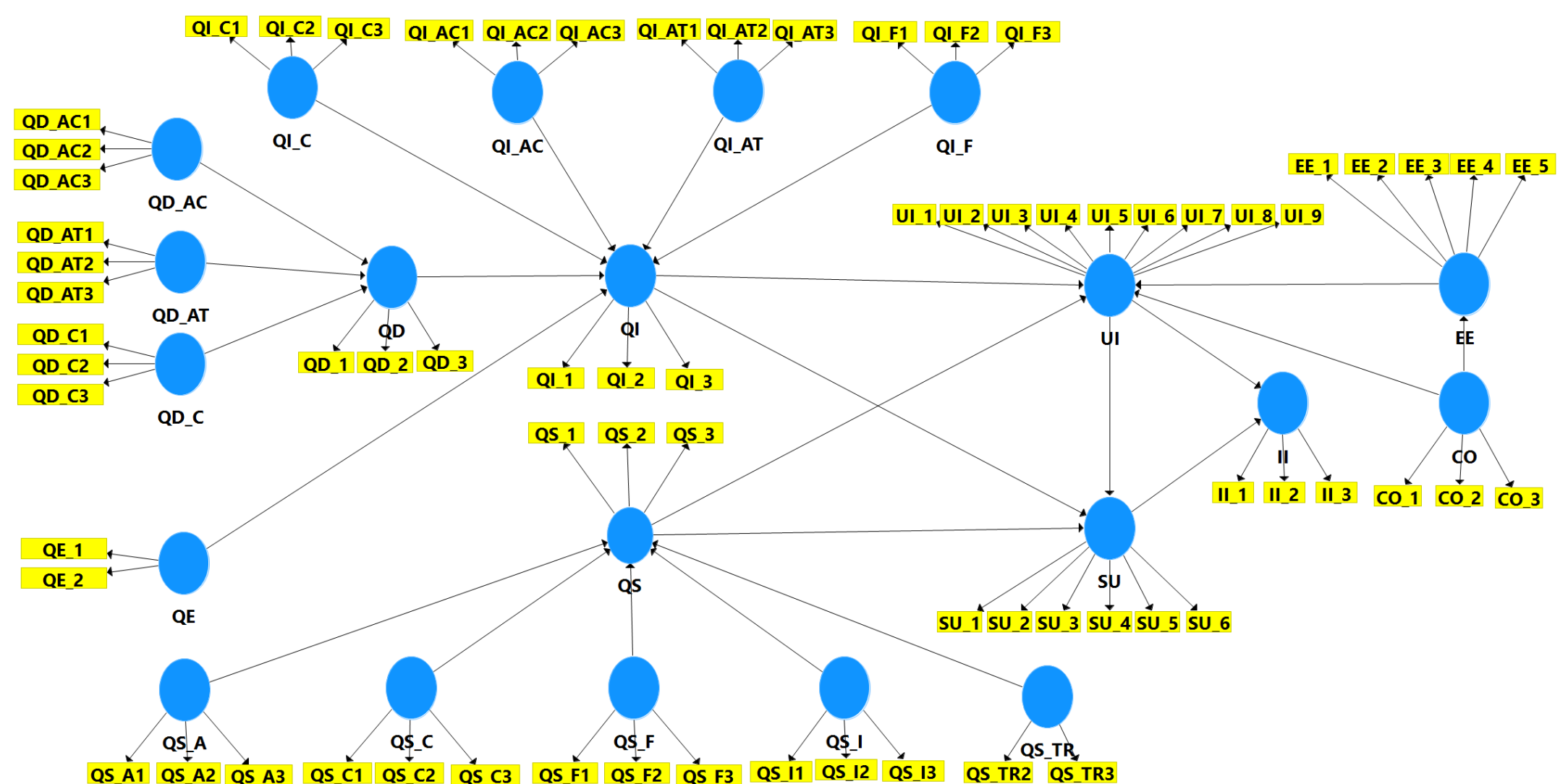

Figura 19 - Modelo estrutural

Fonte: Elaborado pelo autor em SmatPLS 


\section{Análise dos dados}

Este tópico apresenta uma analises de característica da amostra e seleção de respostas válidas, os resultados obtidos pela aplicação da técnica PLS-SEM e posteriormente uma análise de confirmação das hipóteses apresentadas anteriormente.

\subsection{Caracterização da amostra}

Neste tópico é analisado a taxa de resposta e, por fim, são apresentadas as principais características dos respondentes.

\subsubsection{Taxa de resposta}

A pesquisa foi conduzida durante o período dos meses de março e abril de 2017, no qual foram enviadas 3 ondas de solicitação de participação via e-mail para duas bases de potenciais participantes (i.e. ex-alunos do departamento de engenharia de produção e rede de contatos do Linkedin). Este e-mail de convite (disponível em 7.1 E-mail de solicitação de participação) apresentava uma breve apresentação do trabalho, do autor da pesquisa e ressaltava o sigilo e finalidade da utilização dos dados.

A Figura 20 apresenta e evolução de respostas e evidencia a redução das taxas de reposta e eficiência das ondas de solicitação, o que reduz a eficácia do envio de novas solicitações.

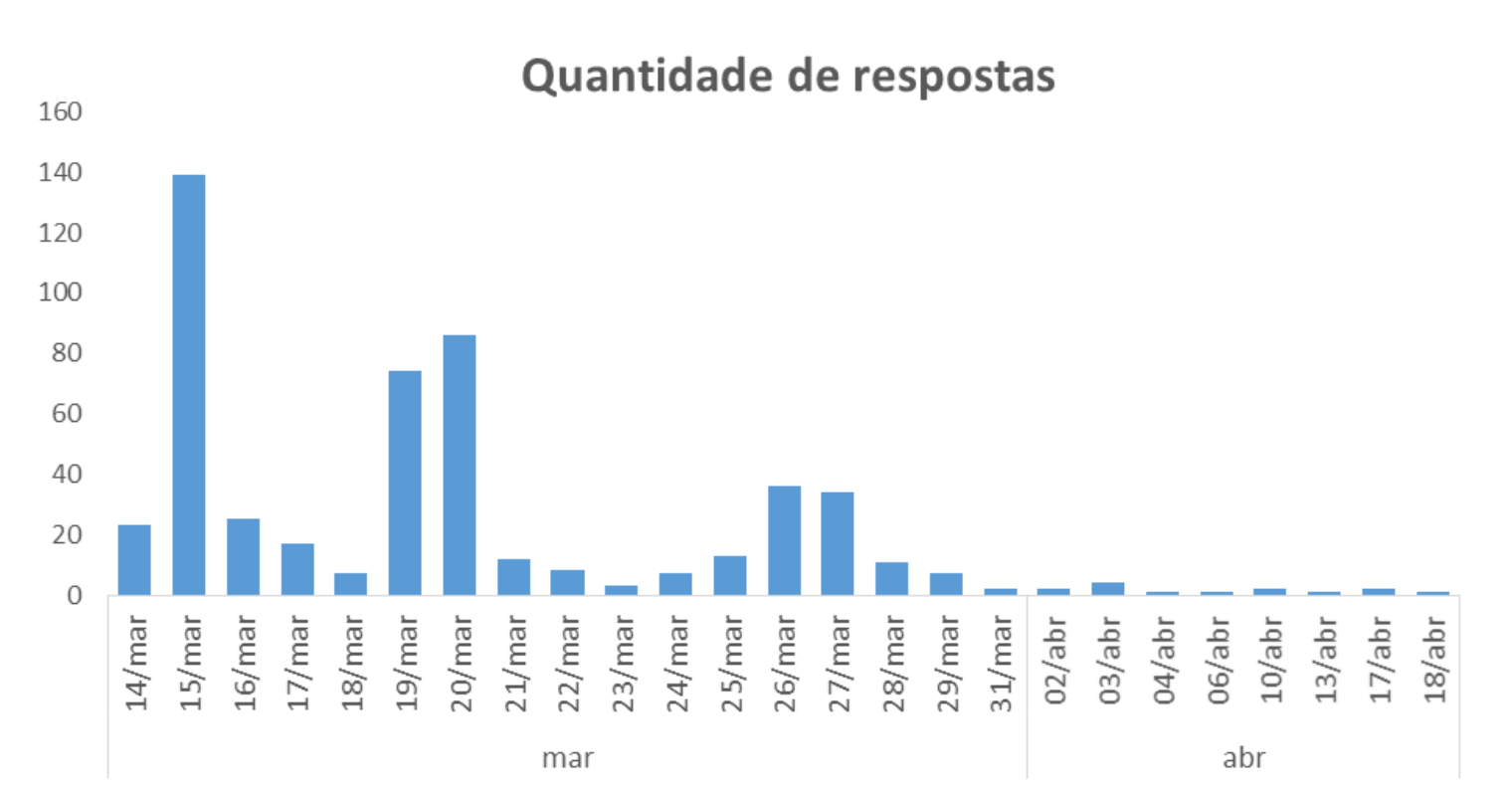

Figura 20 - Evolução das respostas

Fonte: Elaborado pelo autor

Ao total foram coletadas 519 respostas dos 10.778 potenciais participantes, o que resultou em uma taxa de respostas de 4,8\%, conforme Tabela 29. 
Tabela 29 - Taxa de resposta

Fonte: Elaborado pelo autor

\begin{tabular}{lccc} 
Base de dados & $\begin{array}{c}\text { Quantidade } \\
\text { de contatos }\end{array}$ & $\begin{array}{c}\text { Respostas } \\
\text { Coletadas }\end{array}$ & $\begin{array}{c}\text { Taxa de } \\
\text { Resposta }\end{array}$ \\
\hline Grupo de pesquisa & 6.475 & 138 & $2,1 \%$ \\
\hline Rede social Linkedin & 4.303 & 381 & $8,9 \%$ \\
\hline Total & $\mathbf{1 0 . 7 7 8}$ & $\mathbf{5 1 9}$ & $\mathbf{4 , 8 \%}$
\end{tabular}

Hair et al. (2017) apontam a relevância da avaliação de inconsistência nos dados antes da aplicação de técnicas estatísticas como: Questionários incompletos e Padrões suspeitos de resposta.

\subsubsection{Questionários incompletos}

Questionários incompletos são um problema recorrente nas ciências sociais e ocorrem quando o respondente de forma voluntária ou involuntária não responde uma ou mais questões. A remoção das observações com dados faltantes é uma opção para o tratamento desse problema, e deve ser aplicada para questionários com mais de $15 \%$ de respostas faltantes. Para a utilização desse método, os seguintes aspectos devem ser considerados: evitar a remoção sistemática de um certo grupo/perfil de respondente e o atingimento do tamanho mínimo da amostra. (HAIR et al., 2017).

Para esse estudo foi adotado um cenário mais conservador, no qual foi considerado questionários com até 5\% de respostas faltantes. Os quais foram tratados com a técnica de reposição pelo valor médio (Mean Value Replacement), a qual destaca-se pela facilidade de implementação e é indicada bases de dados com baixa taxa de respostas faltantes (até 5\%) (HAIR et al., 2017). A Tabela 30 apresenta um resumo da representatividade de cada grupo apresentado anteriormente, bem como a tratativa escolhida.

Tabela 30 - Questionários incompletos

Fonte: Elaborado pelo autor

\begin{tabular}{llccll}
\multicolumn{1}{c}{ Questionários } & $\begin{array}{c}\text { \% de questões } \\
\text { respondidas }\end{array}$ & Quantidade & $\%$ & \multicolumn{2}{c}{ Tratativa } \\
\hline Completos & $100 \%$ & 57 & $11 \%$ & - \\
Parcialmente Completos & $>=95 \%$ & 250 & $48 \%$ & Reposição pelo valor médio \\
Incompletos & $<95 \%$ & 212 & $41 \%$ & Exclusão & - \\
\multicolumn{1}{c}{ Total } & - & $\mathbf{5 1 9}$ & $\mathbf{1 0 0 \%}$ &
\end{tabular}

\subsubsection{Padrões suspeitos de resposta}

Padrões suspeitos de resposta são questionários que indiciem um provável preenchimento da pesquisa sem uma análise crítica por parte do respondente.

HAIR et al. (2017) apontam os seguintes exemplos de padrões suspeitos: Elevada proporção de respostas com o mesmo valor (straight lining), respostas em diagonal (diagonal lining) e alternância entre os polos (alternating extreme pole responses). Os mesmos autores também 
recomendam uma inspeção visual dos padrões de resposta e análises de estatística descritiva (e.g. média e desvio padrão).

$\mathrm{Na}$ base de respostas foram detectadas 22 respostas com padrões suspeitos, as quais foram excluídas da análise.

\subsubsection{Restrição de público alvo}

Perguntas de restrição de público alvo (Screening Questions) tem como objetivo garantir o alinhamento dos respondentes com o público alvo da pesquisa (HAIR et al., 2017).

Para esse estudo foi introduzido no questionário uma pergunta (questão 10) sobre a experiência prévia do usuário com sistemas de BA, BI ou Big Data. Questionários em que o respondente não apresenta experiência prévia com estes tipos de sistema também foram eliminados da base de respondentes.

\subsubsection{Respostas usáveis}

A Tabela 31 sumariza a quantidade de respostas excluídas da análise. Vale ressaltar que o volume restante é superior a população de amostra mínima (e.g. $\mathrm{N}=153$ ) apresentado anteriormente em 3.3.1 Definição da população e amostra.

Tabela 31 - Respostas usáveis

Fonte: Elaborado pelo autor

\begin{tabular}{|lcc|}
\hline Questionários & Quantidade & $\mathbf{\%}$ \\
\hline Total & $\mathbf{5 1 9}$ & $\mathbf{1 0 0 \%}$ \\
\hline (-) Respostas Incompletas & 212 & $41 \%$ \\
(-) Padrões suspeitos & 22 & $4 \%$ \\
(-) Restrição do público alvo & 54 & $10 \%$ \\
\hline Respostas usáveis & $\mathbf{2 3 1}$ & $\mathbf{4 5 \%}$ \\
\hline
\end{tabular}

\subsubsection{Caracterização dos respondentes}

Este tópico aborda uma análise estatística descritiva, considerando apenas das respostas usáveis, referente ao perfil dos respondentes de acordo com as perguntas do tópico 2. Informações gerais do respondente da ferramenta de pesquisa.

\subsubsection{Gênero}

Com relação ao gênero, destaca-se o volume de respondentes do gênero masculino (i.e. 76\%), conforme apresentado na Figura 22. Esta concentração pode ser justificada pela menor representatividade de pesquisadoras, estudantes e profissionais da área de TI do sexo feminino no Brasil.

\subsubsection{Dispersão geográfica}

As regiões Sul e Sudeste representaram 94\% dos respondentes (i.e. $15 \%$ e $79 \%$ respectivamente), dentre eles o estado de São Paulo destaca-se com 155 respondentes (67\%). Conforme apresentado na Figura 22. 
Esta centralização nas regiões Sul e Sudeste pode ser justificada devido a maior concentração de profissionais na área de TI nestas localidades.

\subsubsection{Faixa Etária}

Nas respostas usáveis $87 \%$ dos respondentes possuem entre 30 e 59 anos, conforme apresentado na Figura 22.

\subsubsection{Escolaridade}

$\mathrm{Na}$ amostra selecionada para o estudo $97 \%$ dos respondentes possuem curso superior, sendo 85\% pós-graduados, conforme Figura 22.

\subsubsection{Setor de atuação}

A maior concentração de respondentes atua profissionalmente em instituições dos setores de Tecnologia da Informação (28\%) e Educação (27\%), conforme Figura 23.

\subsubsection{Função}

Com relação ao cargo de atuação, a amostra apresentou abrangência entre os distintos níveis dentro da hierarquia organizacional, conforme Figura 23.

\subsubsection{Porte da empresa}

Com relação ao porte das empresa, $37 \%$ dos respondentes atuam em empresas de grande porte (i.e. faturamento anual superior a R \$ 90 milhões), conforme Figura 23.

\subsubsection{Interação com o sistema}

A Figura 24 apresenta o tipo de interação dos respondentes com o sistema, no qual $84 \%$ realizam atividades de estruturação de relatórios e análises, $43 \%$ apresentam atuação no desenvolvimento e suporte do sistema e $26 \%$ em atividades relacionadas a modelagem matemática e estatística da ferramenta.

Observando as intersecções entre os conjuntos apresentados na Figura 24, é possível observar um elevado número de respondentes que atuam apenas em atividades referentes a estruturação de relatórios e análises (47\%), porém a representatividade de profissionais especializados apenas no desenvolvimento/suporte ao sistema e modelagem matemática ainda apresentam pouca representatividade, sendo $12 \%$ e $3 \%$ respectivamente.

A distinção entre os perfis de profissionais especialistas em TI e modelagem matemática apresentados por Davenport e Harris (2007) não se apresentou de forma evidente na amostra, sendo observada maior polivalência entre os respondentes com atuação nessas atividades.

Esse menor grau de especialização pode ser decorrente do recente desenvolvimento da área de Business Analytics e da profissão de Cientista de dados no Brasil.

\subsubsection{Funcionalidades do sistema}

A Figura 21 apresenta um resumo das funcionalidades dos sistemas apontado pelos respondentes na questão 12. Na qual é possível observar uma menor representatividade gradativa das funcionalidades com maior grau de inteligência empregada nas análises e maior 
o valor gerado para as empresas, conforme modelo apresentado por Davenport e Harris (2007) na Figura 7.

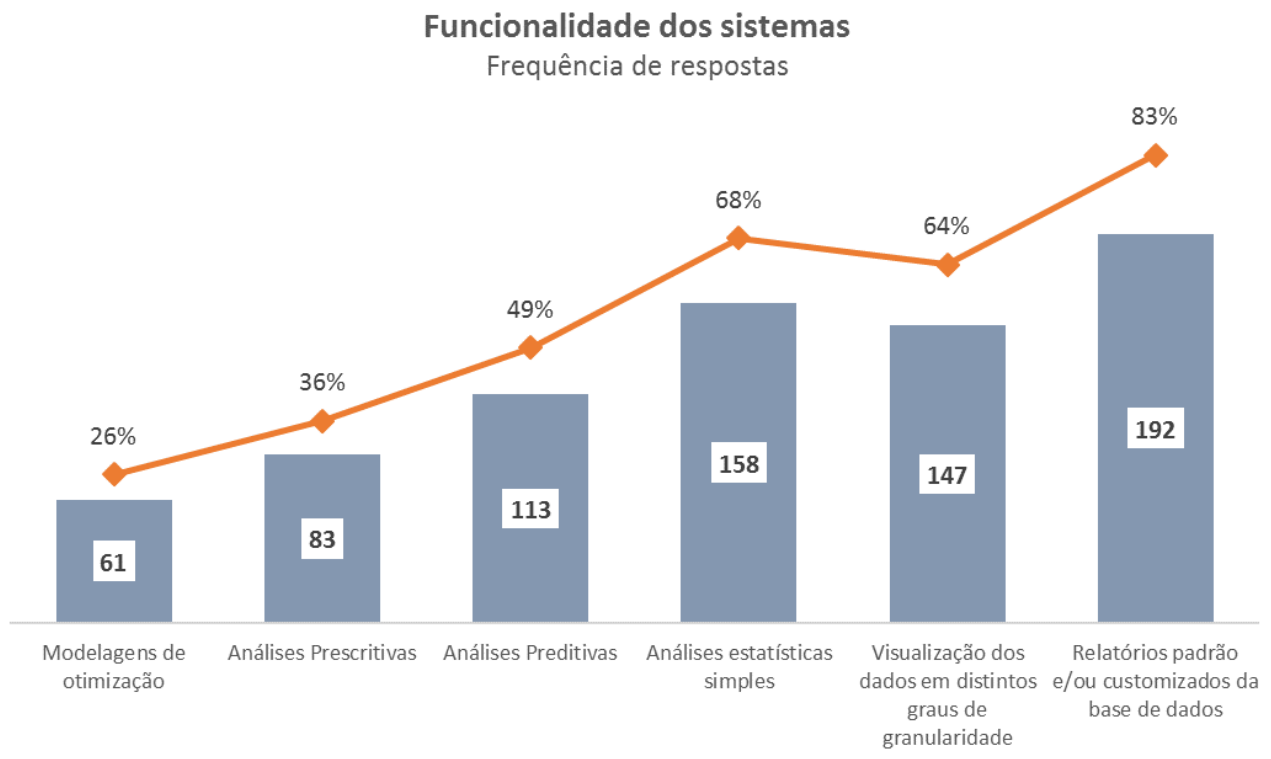

Figura 21 - Funcionalidades presentes no sistema

Fonte: Elaborado pelo autor 


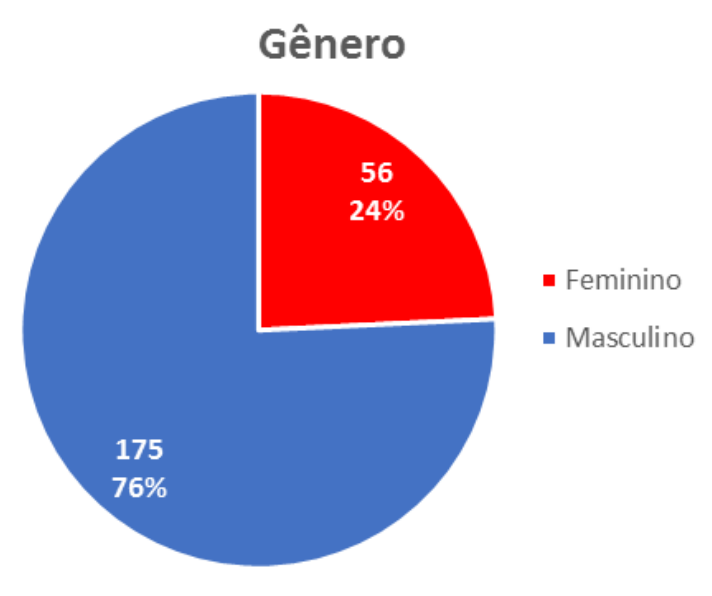

\section{Dispersão Geografica}

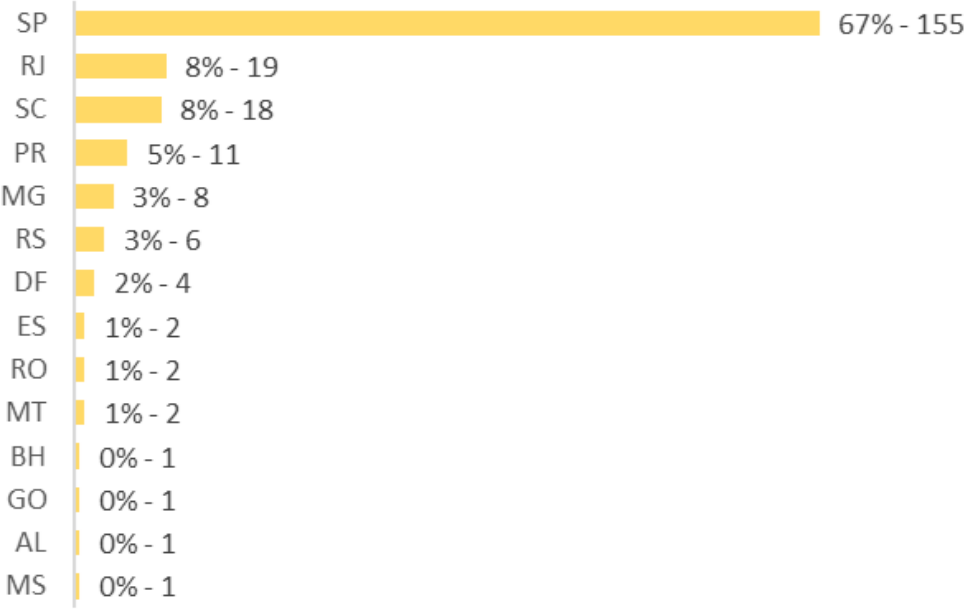

Faixa etária

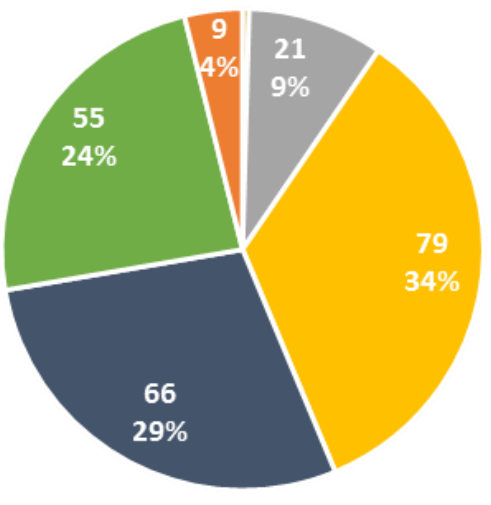

17 anos ou menos

- 18 a 20 anos

- 21 a 29 anos

量 30 a 39 anos

- 40 a 49 anos

드 50 a 59 anos

- 60 anos ou mais

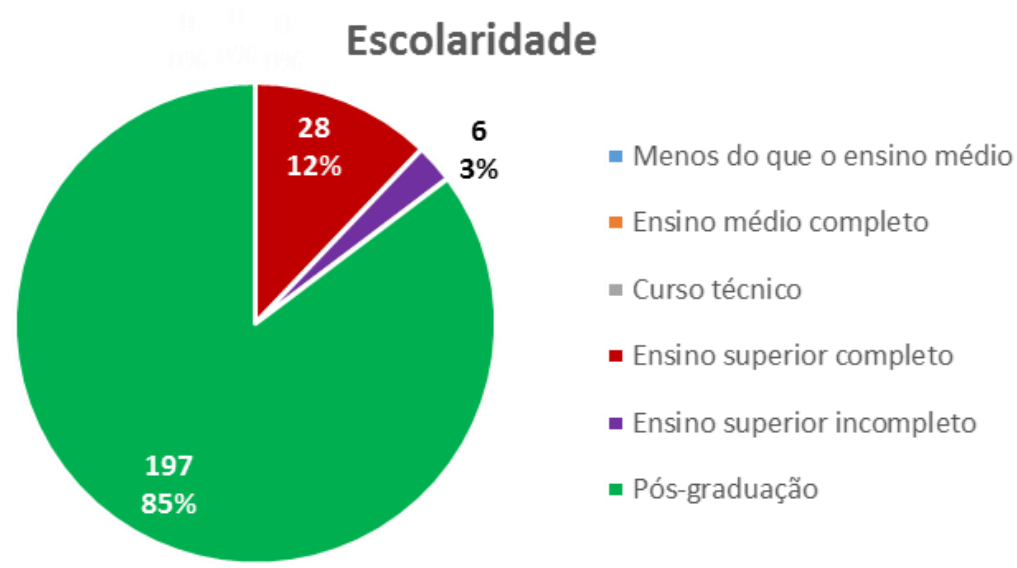

Figura 22- Características pessoais dos respondentes Fonte: Elaborado pelo autor 


\begin{tabular}{|c|c|}
\hline & Setor de atuação \\
\hline Tecnologia da informação & $28 \%-64$ \\
\hline Educação & $27 \%-62$ \\
\hline Industria de manufatura & $8 \%-19$ \\
\hline Serviços (Financeiros e Seguros) & $7 \%-17$ \\
\hline Serviços (Consultoria em gestão) & $5 \%-11$ \\
\hline Construção Civil & $4 \%-10$ \\
\hline Saúde e farmacêutico & $4 \%-10$ \\
\hline Varejo e bens duráveis de consumo & $4 \%-9$ \\
\hline Serviços (Publicidade e marketing) & $3 \%-8$ \\
\hline Governamental & $3 \%-7$ \\
\hline Outros & $3 \%-7$ \\
\hline Transporte e Logísticas & $2 \%-4$ \\
\hline Telecomunicações & $1 \%-3$ \\
\hline
\end{tabular}
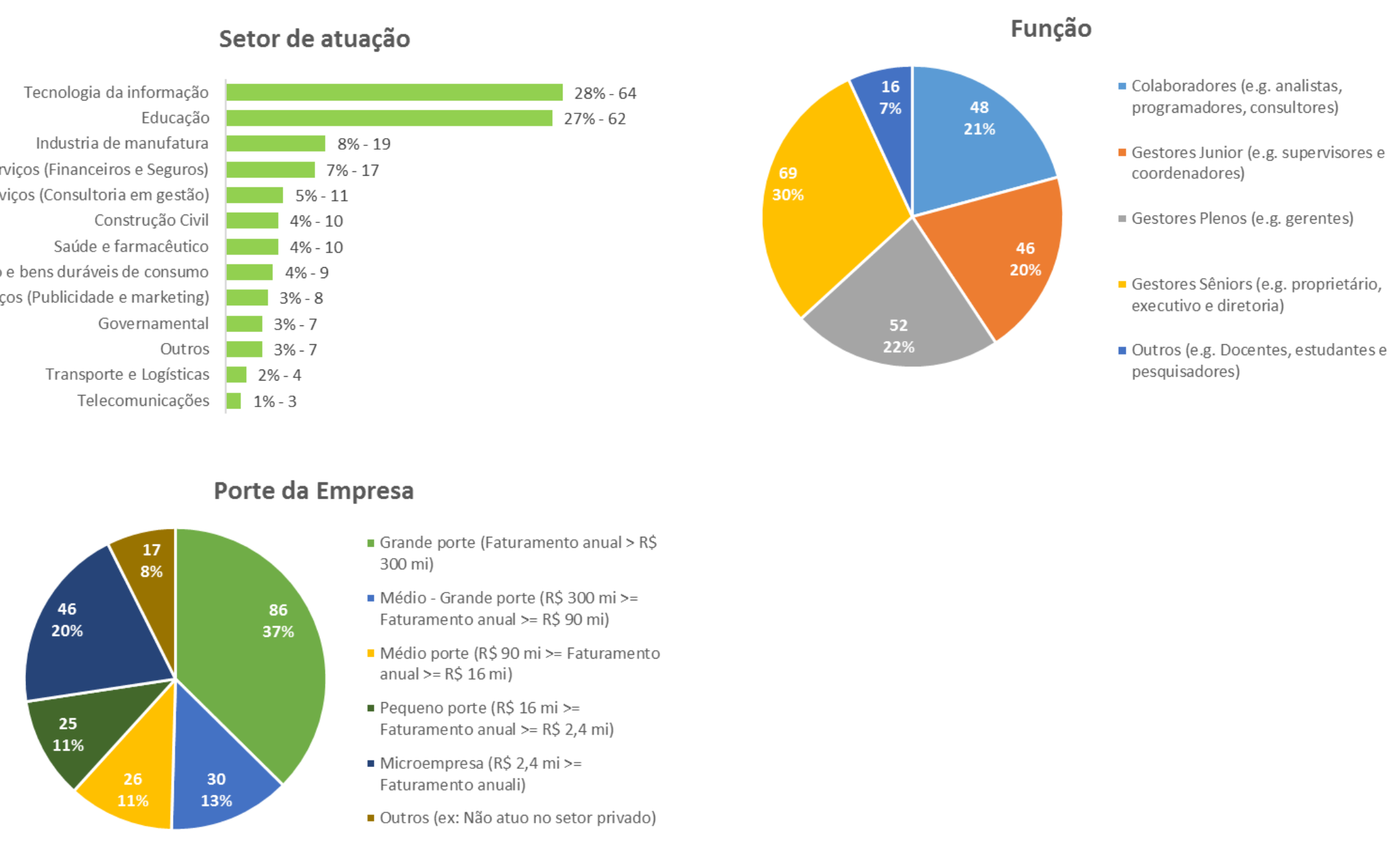

Figura 23 - Características profissionais dos respondentes Fonte: Elaborado pelo autor 


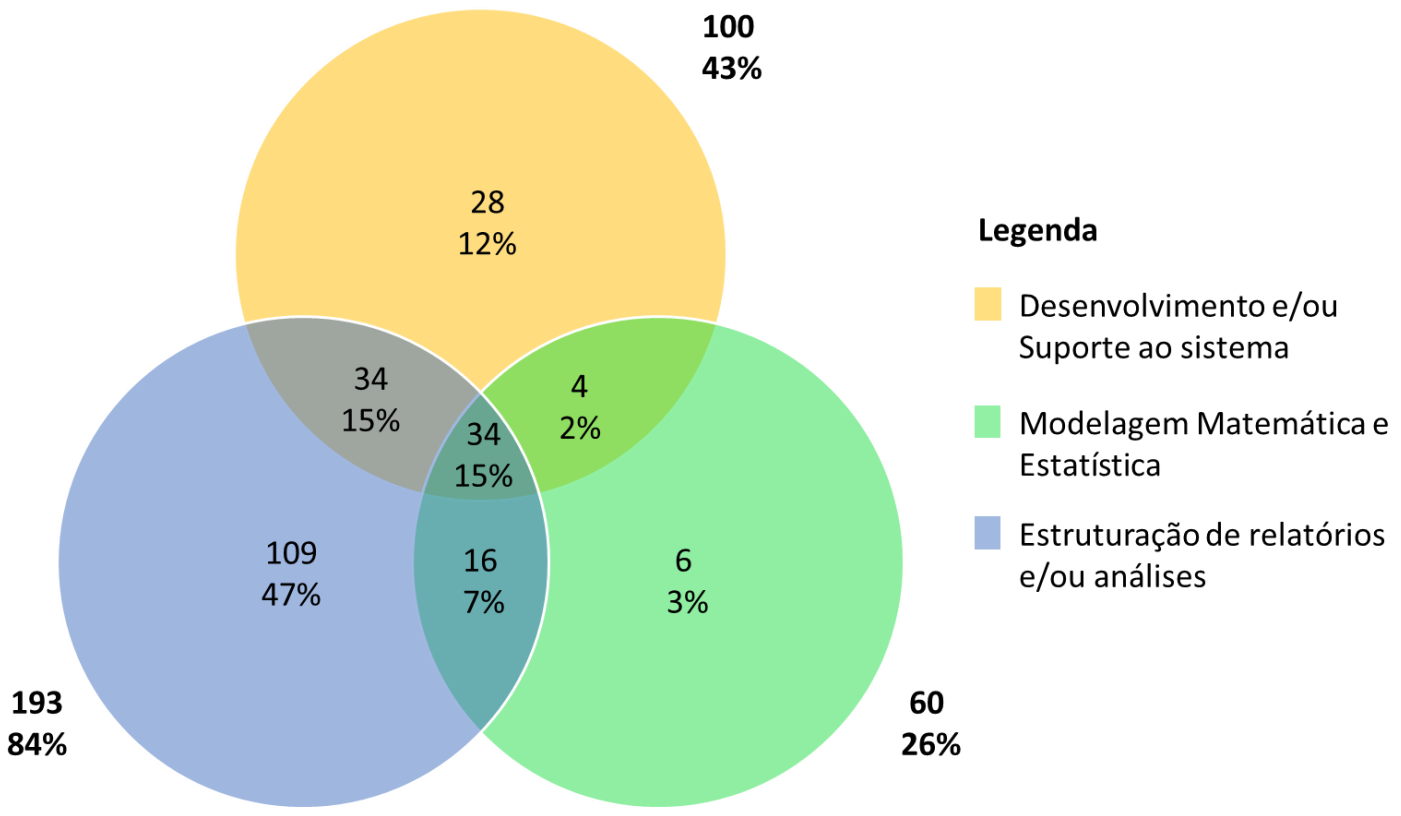

Figura 24 - Interação dos respondentes com o sistema

Fonte: Elaborado pelo autor

\subsection{Modelagem de Equações Estruturais}

Como parâmetros do sistema para o cálculo das equações estruturais, foi utilizado o valor inicial de 1, quantidade máxima de iterações de 300 e como gatilho de convergência variações de outer weights inferiores a 10E-7.

\subsubsection{Análise do modelo de mensuração}

A primeira rodada de análise do modelo apresentou 5 iterações até sua convergência, e seus resultados referentes ao critério de qualidade do modelo de mensuração estão expostos na Tabela 32.

Analisando a validação de convergência, todos os construtos apresentaram valores satisfatórios referentes ao AVE. Porém, com relação aos valores de outer loadings dois indicadores exibiram níveis inferiores ao desejado (i.e. 0,7): QS_TR1 $(-0,35)$ e SU_2 $(0,61)$.

Para QS_TR1 vale ressaltar que este indicador apresenta relação inversa com o construto, e acerca disso Weems e Orwuegbuzie (2001) destacam que o uso de escalas positivas e negativas misturadas reduzem a confiabilidade do instrumento. Dalmoro e Vieira (2013) apontam que os indicadores em sentido inverso podem gerar certa confusão nos respondentes. Hair et al. (2017) afirma que indicadores com outer loadings abaixo de 0,4 devem ser retirados do modelo, sendo necessário uma análise de impacto em seu significado (contente validity).

Desta forma este indicador foi retirado do modelo de mensuração por não ser considerado relevante o impacto na abrangência de seu significado tendo em vista a similaridade dos indicadores QS_TR1 e QS_TR3.

QS_TR1: O sistema leva muito tempo para responder às minhas solicitações 
QS_TR3: O sistema retorna às minhas requisições de forma rápida

Para indicadores com outer loadings entre 0,4 e 0,7, Hair et al. (2017) destacam que a retirada do indicador do modelo deve ser realizada apenas se a sua remoção eleve a Confiabilidade Composta para valores superiores ao desejado e não impacte a abrangência de significado do construto.

Por já apresentar valores adequados de confiabilidade composta e pelo impacto no escopo do construto ser considerado moderado tendo em vista ser o único indicador diretamente relacionado a facilidade de uso, optou-se pela manutenção do SU_2 no modelo.

SU_2: Avalie o SI de Business Analytics : Difícil _ _ _ _ _ Fácil

Com relação a validação discriminatória o único indicador a apresentar resultados de crossloadings não satisfatórios é o QS_TRl (Tabela 42). Este resultado corrobora com a decisão de retirada do indicador do modelo discutido anteriormente.

Com relação ao critério de Fornell-Lacker, todos os critérios foram atendidos conforme a Tabela 43.

$\mathrm{Na}$ análise de HTMT todos os construtos apresentaram valores inferiores a 0,85 (Tabela 44) com exceção ao QI_AC->QI $(0,853)$ e QS->QI $(0,879)$, porém pela semelhança conceitual os resultados são aceitáveis por serem inferiores a 0,9 . E a Tabela 45 evidência que todos os valores HTMT são significativamente diferentes de zero.

Sob a ótica da análise de consistência interna, todos os indicadores apresentaram valores de Alpha de Cronbach e Confiabilidade Composta superior ao limite de corte 0,7, conforme Tabela 32.

Após o ajuste proposto (i.e. retirada do construto QS_TR1), o modelo foi analisado novamente através do software SmartPls e todos os critérios de qualidade foram atingidos conforme a Tabela 33 que apresenta um resumo das análises. Seus resultados detalhados estão presentes na sessão 7 Anexos. 
Tabela 32 - Resultados modelo de mensuração (Rodada 1)

Fonte: Elaborado pelo autor

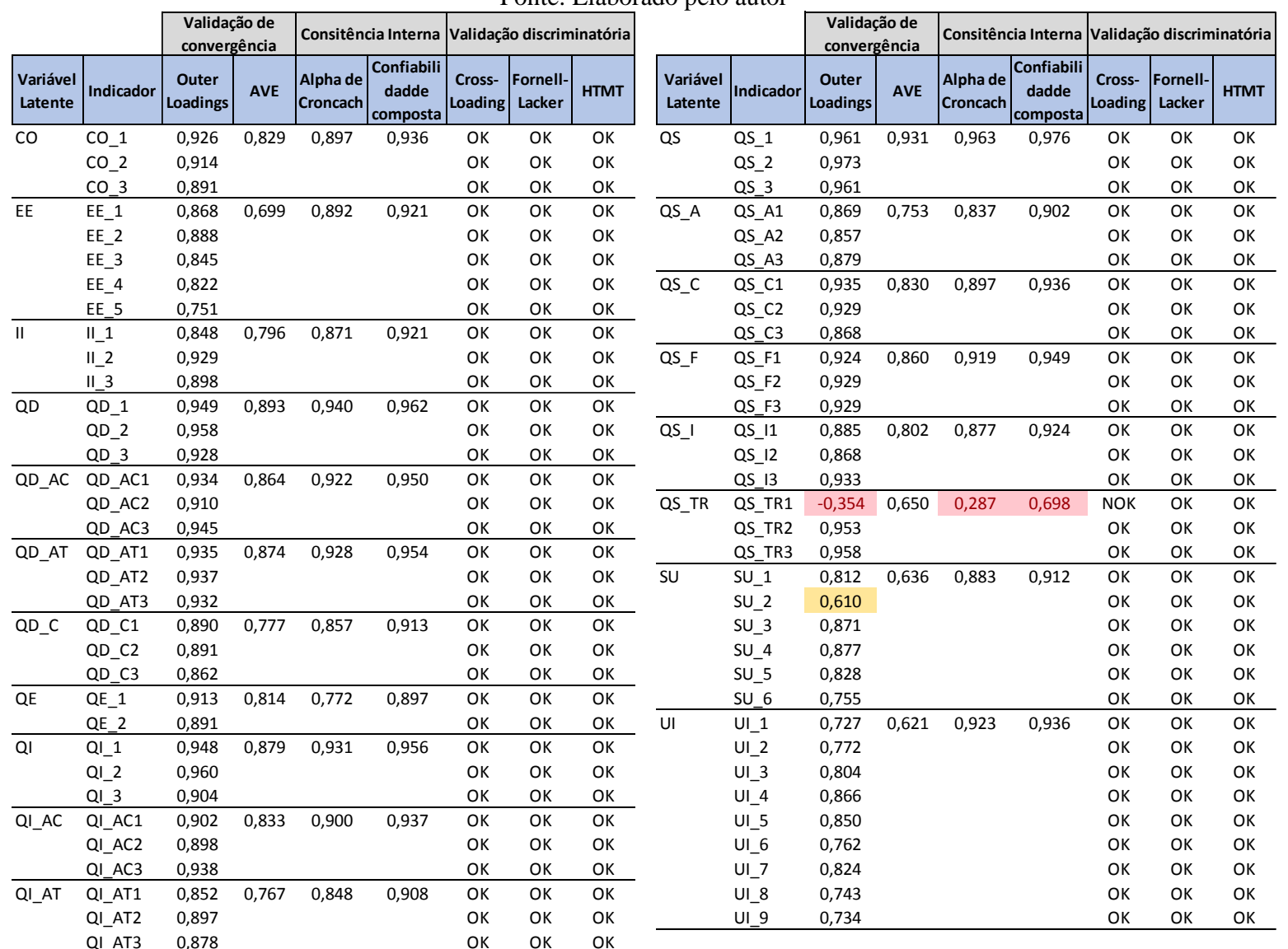


Tabela 33 - Resultados modelo de mensuração (Rodada 2)

Fonte: Elaborado pelo autor

\begin{tabular}{|c|c|c|c|c|c|c|c|c|c|c|c|c|c|c|c|c|c|}
\hline \multirow[b]{2}{*}{$\begin{array}{l}\text { Variáve } \\
\text { Latente }\end{array}$} & \multirow[b]{2}{*}{ Indicador } & \multicolumn{2}{|c|}{$\begin{array}{l}\begin{array}{l}\text { Validação de } \\
\text { convergência }\end{array} \\
\end{array}$} & \multicolumn{2}{|c|}{ Consitência Interna } & \multicolumn{3}{|c|}{ Validação discriminatória } & \multirow[b]{2}{*}{$\begin{array}{l}\text { Variáve } \\
\text { Latente }\end{array}$} & \multirow[b]{2}{*}{ Indicador } & \multicolumn{2}{|c|}{$\begin{array}{l}\text { Validação de } \\
\text { convergência }\end{array}$} & \multicolumn{2}{|c|}{ Consitência Interna } & \multicolumn{3}{|c|}{ Validação discriminatóri } \\
\hline & & $\left|\begin{array}{c}\text { Outer } \\
\text { Loadings }\end{array}\right|$ & AVE & $\begin{array}{l}\text { Alpha de } \\
\text { Croncach }\end{array}$ & $\begin{array}{c}\text { Confiabili } \\
\text { dadde } \\
\text { composta }\end{array}$ & $\begin{array}{c}\text { Cross- } \\
\text { Loading }\end{array}$ & $\begin{array}{c}\text { Fornell- } \\
\text { Lacker }\end{array}$ & НTMT & & & $\mid \begin{array}{c}\text { Outer } \\
\text { Loadings }\end{array}$ & AVE & $\begin{array}{l}\text { Alpha de } \\
\text { Croncach }\end{array}$ & $\begin{array}{c}\text { Confiabili } \\
\text { dadde } \\
\text { composta }\end{array}$ & $\begin{array}{l}\text { Cross- } \\
\text { Loading }\end{array}$ & $\begin{array}{c}\text { Fornell- } \\
\text { Lacker }\end{array}$ & HTMT \\
\hline \multirow[t]{3}{*}{$\mathrm{CO}$} & CO_1 & 0,926 & 0,829 & 0,897 & 0,936 & OK & OK & OK & QS & QS_1 & 0,961 & 0,931 & 0,963 & 0,976 & OK & OK & OK \\
\hline & $0 \mathrm{CO} \_2$ & 0,914 & & & & OK & OK & OK & & 0 QS_2 & 0,973 & & & & OK & OK & OK \\
\hline & $0 \mathrm{CO} \_3$ & 0,891 & & & & OK & OK & OK & & 0 QS_3 & 0,961 & & & & OK & OK & OK \\
\hline \multirow[t]{5}{*}{$\mathrm{EE}$} & EE_1 & 0,868 & 0,699 & 0,892 & 0,921 & OK & OK & OK & $\overline{Q S \_A}$ & QS_A1 & 0,869 & 0,753 & 0,837 & 0,902 & OK & OK & OK \\
\hline & 0 EE_2 & 0,888 & & & & OK & OK & OK & & 0 QS_A2 & 0,857 & & & & OK & OK & OK \\
\hline & 0 EE_3 & 0,845 & & & & OK & OK & OK & & 0 QS_A3 & 0,879 & & & & OK & OK & OK \\
\hline & 0 EE_4 & 0,822 & & & & OK & OK & OK & QS_C & QS_C1 & 0,935 & 0,830 & 0,897 & 0,936 & OK & OK & OK \\
\hline & 0 EE_5 & 0,751 & & & & OK & OK & OK & & 0 QS_C2 & 0,929 & & & & OK & OK & OK \\
\hline \multirow[t]{3}{*}{ II } & II_1 & 0,848 & 0,796 & 0,871 & 0,921 & OK & OK & OK & & 0 QS_C3 & 0,868 & & & & OK & OK & OK \\
\hline & 0 II_2 & 0,929 & & & & OK & OK & OK & QS_F & QS_F1 & 0,924 & 0,860 & 0,919 & 0,949 & OK & OK & OK \\
\hline & $0 \| 113$ & 0,898 & & & & OK & OK & OK & & 0 QS_F2 & 0,929 & & & & OK & OK & OK \\
\hline \multirow[t]{3}{*}{$\overline{Q D}$} & QD_1 & 0,949 & 0,893 & 0,940 & 0,962 & OK & OK & OK & & 0 QS_F3 & 0,929 & & & & OK & OK & OK \\
\hline & 0 QD_2 & 0,958 & & & & OK & OK & OK & QS_I & QS_I1 & 0,885 & 0,802 & 0,877 & 0,924 & OK & OK & OK \\
\hline & 0 QD_3 & 0,928 & & & & OK & OK & OK & & 0 QS_12 & 0,868 & & & & OK & OK & OK \\
\hline \multirow[t]{3}{*}{$\overline{Q D \_A C}$} & QD_AC1 & 0,934 & 0,864 & 0,922 & 0,950 & OK & OK & OK & & 0 QS_13 & 0,933 & & & & OK & OK & OK \\
\hline & 0 QD_AC2 & 0,910 & & & & OK & OK & OK & $\overline{Q S \_T R}$ & QS_TR1 & - & 0,922 & 0,916 & 0,960 & OK & OK & OK \\
\hline & 0 QD_AC3 & 0,945 & & & & OK & OK & OK & & 0 QS_TR2 & 0,956 & & & & OK & OK & OK \\
\hline \multirow[t]{3}{*}{$\overline{\text { QD_AT }}$} & QD_AT1 & 0,935 & 0,874 & 0,928 & 0,954 & OK & OK & OK & & 0 QS_TR3 & 0,965 & & & & OK & OK & OK \\
\hline & 0 QD_AT2 & 0,937 & & & & OK & OK & OK & SU & SU_1 & 0,812 & 0,636 & 0,883 & 0,912 & OK & OK & OK \\
\hline & 0 QD_AT3 & 0,932 & & & & OK & OK & OK & & $0 \mathrm{SU}_{-} 2$ & 0,610 & & & & OK & OK & OK \\
\hline \multirow{3}{*}{ QD_C } & QD_C1 & 0,890 & 0,777 & 0,857 & 0,913 & OK & OK & OK & & 0 SU_3 & 0,871 & & & & OK & OK & OK \\
\hline & 0 QD_C2 & 0,891 & & & & OK & OK & OK & & 0 SU_4 & 0,877 & & & & OK & OK & OK \\
\hline & 0 QD_C3 & 0,862 & & & & OK & OK & OK & & 0 SU_5 & 0,828 & & & & OK & OK & OK \\
\hline \multirow[t]{2}{*}{$\overline{\mathrm{QE}}$} & QE_1 & 0,913 & 0,814 & 0,772 & 0,897 & OK & OK & OK & & $0 \mathrm{SU} \_6$ & 0,755 & & & & OK & OK & OK \\
\hline & 0 QE_2 & 0,891 & & & & OK & OK & OK & $\overline{\mathrm{UI}}$ & UI_1 & 0,727 & 0,621 & 0,923 & 0,936 & OK & OK & OK \\
\hline \multirow[t]{3}{*}{$\overline{Q I}$} & QI_1 & 0,948 & 0,879 & 0,931 & 0,956 & OK & OK & OK & & 0 UI_2 & 0,772 & & & & OK & OK & OK \\
\hline & 0 QI_2 & 0,960 & & & & OK & OK & OK & & 0 UI_3 & 0,804 & & & & OK & OK & OK \\
\hline & 0 QI_3 & 0,904 & & & & OK & OK & OK & & 0 UI_4 & 0,866 & & & & OK & OK & OK \\
\hline QI_AC & QI_AC1 & 0,902 & 0,833 & 0,900 & 0,937 & OK & OK & OK & & 0 UI_5 & 0,850 & & & & OK & OK & OK \\
\hline & 0 QI_AC2 & 0,898 & & & & OK & OK & OK & & 0 UI_6 & 0,762 & & & & OK & OK & OK \\
\hline & 0 QI_AC3 & 0,938 & & & & OK & OK & OK & & 0 UI_7 & 0,824 & & & & OK & OK & OK \\
\hline QI_AT & QI_AT1 & 0,852 & 0,767 & 0,848 & 0,908 & OK & OK & OK & & 0 UI_8 & 0,743 & & & & OK & OK & OK \\
\hline & 0 QI_AT2 & 0,897 & & & & OK & OK & OK & & 0 UI_9 & 0,734 & & & & OK & OK & OK \\
\hline & 0 QI_AT3 & 0,878 & & & & OK & OK & OK & & & & & & & & & \\
\hline QI_C & QI_C1 & 0,929 & 0,817 & 0,888 & 0,931 & OK & OK & OK & & & & & & & & & \\
\hline & 0 QI_C2 & 0,916 & & & & OK & OK & OK & & & & & & & & & \\
\hline & 0 QI_C3 & 0,866 & & & & OK & OK & OK & & & & & & & & & \\
\hline QI_F & QI_F1 & 0,945 & 0,870 & 0,925 & 0,953 & OK & OK & OK & & & & & & & & & \\
\hline & 0 QI_F2 & 0,937 & & & & OK & OK & OK & & & & & & & & & \\
\hline & 0 QI_F3 & 0,916 & & & & OK & OK & OK & & & & & & & & & \\
\hline
\end{tabular}




\subsubsection{Análise do modelo estrutural}

De acordo com Hair et al. (2017) após validação de qualidade do modelo de mensuração, faz-se necessário a avaliação do modelo estrutural. Sendo este conduzido através das seguintes macro atividades:

a. Análise de colinearidade

b. Significância e Relevância dos coeficientes de caminho

c. Avaliação do coeficiente de determinação $\mathrm{R}^{2}$

d. Avaliação do efeito do tamanho f2

e. Análise de relevância preditiva Q2

Os próximos tópicos discorrem sobre a análise dos dados sob a ótica destas macro atividades.

\subsubsection{Análise de colinearidade}

Neste estudo foi analisado o VIF entre os construtos, sendo este uma medida correlata de colinearidade e representa o grau de aumento do erro padrão pelo efeito da colinearidade, em que valores superiores a 5 são indicadores de problemas de colinearidade.

A Tabela 50 apresenta o resultado da análise de colinearidade no modelo, e podemos observar a inexistência de valores superiores ao limite aceitável (i.e. 5).

\subsubsection{Significância e Relevância dos coeficientes de caminho}

Conforme apresentado anteriormente, após a validação de não colinearidade entre os construtos faz-se necessário analisar a significância e posteriormente a relevância das relações entre os construtos do modelo estrutural.

A Figura 25 apresenta os resultados dos coeficientes de caminho do modelo e sua respectiva significância calculada através da técnica de bootstrapping (3.000 amostras). Considerando análise bicaudal com nível de significância de 5\% temos todas as correlações estatisticamente significantes com exceção ao QI_AT -> QI, QD -> QI e QS -> SU. E na análise de relevância o construto QE apresentou baixa relevância para a qualidade da informação.

Conforme mencionado anteriormente, além da análise de relevância direta caracterizada pelo coeficiente de caminho também é relevante para o entendimento do modelo o efeito total dos construtos exógenos (efeitos diretos e indiretos via mediadores). Sendo essa análise apresentada na Tabela 51.

É possível observar que o construto Qualidade da Informação é pouco impactado pelo construto Qualidade de dados e suas respectivas variáveis endógenas.

Para Satisfação do usuário destaca-se o impacto dos construtos Qualidade do sistema e Qualidade da Informação e para o Uso da Informação, além dos dois construtos mencionados anteriormente (QS e QI) a Cultura Organizacional também é relevante para este construto.

No caso do Impacto individual a Satisfação do usuário e o Impacto individual são os de maior proeminência. 


\subsubsection{Avaliação do coeficiente de determinação $\left(R^{2}\right)$}

Conforme mencionado anteriormente, $\mathrm{R}^{2}$ é um parâmetro mais utilizado para a análise de modelos estruturais e representa quanto da variância de um construto endógeno é relacionado aos seus respectivos construtos exógenos. Isto é, o poder preditivo dos construtos endógenos do modelo. E seus valores variam entre 0 e 1 , sendo que 0,75, 0,50 e 0,25 podem ser considerados como substanciais, moderados e fracos, respectivamente para estudos de marketing Hair et al. (2017).

A Figura 25 apresenta o resultado da análise, na qual todos os construtos apresentaram relação moderada com exceção ao QI, pois obteve resultado superior a 0,75.

\begin{tabular}{|c|c|c|c|c|c|c|c|c|c|}
\hline \multirow[b]{2}{*}{ Construto } & \multicolumn{3}{|c|}{ Coeficiente de determinação } & \multicolumn{6}{|c|}{ Significância e Relevância } \\
\hline & $\mathbf{R}^{2}$ & $\mathbf{R}_{\text {Ajustado }}^{2}$ & Relação & $\begin{array}{l}\text { Construtos } \\
\text { Exógenos }\end{array}$ & $\begin{array}{l}\text { Coeficiente } \\
\text { de Caminho } \\
\text { (Original) }\end{array}$ & $\begin{array}{l}\text { Coeficiente } \\
\text { de Caminho } \\
\text { (Médio) }\end{array}$ & $\begin{array}{l}\text { Desvio } \\
\text { Padrão }\end{array}$ & $\begin{array}{l}\text { T Statistics } \\
(|\mathrm{O} / \mathrm{STDEV}|)\end{array}$ & $\begin{array}{l}\text { Relevância } \\
\text { Estatística } \\
\text { (tw o-tailed test - 5\% }\end{array}$ \\
\hline \multirow{4}{*}{ QD } & 0,686 & 0,682 & Moderado & - & - & - & - & - & - \\
\hline & & & & QD_AC -> QD & 0,283 & 0,281 & 0,086 & 3,283 & Sim \\
\hline & & & & QD_AT -> QD & 0,290 & 0,299 & 0,111 & 2,602 & Sim \\
\hline & & & & QD_C -> QD & 0,347 & 0,344 & 0,076 & 4,594 & Sim \\
\hline \multirow[t]{7}{*}{ QI } & 0,768 & 0,762 & Forte & - & - & - & - & - & - \\
\hline & & & & QI_AC -> QI & 0,388 & 0,386 & 0,072 & 5,363 & Sim \\
\hline & & & & QI_AT $>$ QI & $-0,027$ & $-0,027$ & 0,060 & 0,444 & Não \\
\hline & & & & QI_C -> QI & 0,226 & 0,228 & 0,064 & 3,523 & Sim \\
\hline & & & & QI_F -> QI & 0,300 & 0,296 & 0,060 & 5,018 & Sim \\
\hline & & & & QD $>$ QI & 0,088 & 0,094 & 0,058 & 1,503 & Não \\
\hline & & & & QE -> Q I & 0,091 & 0,089 & 0,045 & 2,006 & Sim \\
\hline \multirow[t]{6}{*}{ QS } & 0,733 & 0,727 & Moderado & - & - & - & - & - & - \\
\hline & & & & QS_A $>$ QS & 0,195 & 0,195 & 0,064 & 3,024 & Sim \\
\hline & & & & QS_C $>$ QS & 0,237 & 0,237 & 0,048 & 4,962 & Sim \\
\hline & & & & QS_F $>$ QS & 0,202 & 0,200 & 0,065 & 3,120 & Sim \\
\hline & & & & QS_I -> QS & 0,163 & 0,163 & 0,047 & 3,484 & Sim \\
\hline & & & & QS_TR $->$ QS & 0,298 & 0,299 & 0,060 & 4,928 & Sim \\
\hline \multirow[t]{5}{*}{\begin{tabular}{|l} 
UI \\
\end{tabular}} & 0,601 & 0,594 & Moderado & - & - & - & - & - & - \\
\hline & & & & QS -> UI & 0,420 & 0,420 & 0,088 & 4,781 & Sim \\
\hline & & & & QI -> UI & 0,206 & 0,207 & 0,093 & 2,203 & Sim \\
\hline & & & & CO $->\mathrm{UI}$ & 0,129 & 0,132 & 0,056 & 2,288 & Sim \\
\hline & & & & EE -> UI & 0,183 & 0,181 & 0,060 & 3,034 & Sim \\
\hline \multirow[t]{4}{*}{ SU } & 0,557 & 0,552 & Moderado & - & - & - & - & - & - \\
\hline & & & & QS -> SU & 0,151 & 0,152 & 0,100 & 1,508 & Não \\
\hline & & & & QI $>$ SU & 0,370 & 0,368 & 0,093 & 3,975 & Sim \\
\hline & & & & UI $->$ SU & 0,299 & 0,301 & 0,068 & 4,371 & Sim \\
\hline \multirow[t]{3}{*}{ II } & 0,555 & 0,551 & Moderado & - & - & - & - & - & - \\
\hline & & & & SU $->$ II & 0,434 & 0,435 & 0,072 & 6,050 & Sim \\
\hline & & & & UI $->$ II & 0,383 & 0,384 & 0,068 & 5,665 & Sim \\
\hline \multirow[t]{2}{*}{ EE } & 0,358 & 0,355 & Moderado & - & - & - & - & - & - \\
\hline & & & & CO $>$ EE & 0,598 & 0,599 & 0,051 & 11,632 & Sim \\
\hline
\end{tabular}

Figura 25 - Significância, Relevância e Coeficiente de determinação

Fonte: Elaborado pelo autor

\subsubsection{Avaliação do efeito do tamanho no coeficiente de determinação $\left(\mathbf{f}^{\mathbf{2}}\right)$}

Conforme mencionado anteriormente, $\mathrm{f}^{2}$ apresenta o efeito da retirada de um construto endógeno no $\mathrm{R}^{2}$ da variável dependente. Como orientação pode-se utilizar os valores 0,02 , 0,15 e 0,35 respectivamente como fraco, médio e forte efeito. E valores inferiores a 0,02 indicam a ausência de efeito no construto. 
A Tabela 52 apresenta a análise de $\mathrm{f}^{2}$, na qual destaca-se as relações QI_AT e QD não com o construto QI por apresentarem valores abaixo de 0,02, bem como de QS com SU.

\subsubsection{Análise de relevância preditiva $\left(Q^{2}\right)$}

Para a análise de relevância preditiva foi utilizada a técnica de Blindfolding com o parâmetro de distância (D) igual a 8, atendendo a diretriz apontada Hair et al. (2017) de utilização de valores entre 5 e 10 para esse termo.

A Tabela 34 apresenta o resultado da análise, na qual é possível observar que todos os construtos endógenos apresentaram relevância preditiva $\left(\mathrm{Q}^{2}\right)$ superior a 0 .

Tabela 34 - Relevância preditiva (Q2)

Fonte: Elaborado pelo autor

\begin{tabular}{|c|c|c|c|}
\hline \multirow[b]{2}{*}{ Construto } & \multirow[b]{2}{*}{$\begin{array}{l}\text { Construtos } \\
\text { Exógenos }\end{array}$} & \multicolumn{2}{|c|}{ Relevância preditiva } \\
\hline & & $\mathbf{Q}^{2}$ & Relevância \\
\hline \multirow{3}{*}{ QD } & QD_AC & \multirow{3}{*}{0,581} & \multirow{3}{*}{ Sim } \\
\hline & QD_AT & & \\
\hline & QD_C & & \\
\hline \multirow{6}{*}{ QI } & QI_AC & \multirow{6}{*}{0,638} & \multirow{6}{*}{ Sim } \\
\hline & QI_AT & & \\
\hline & QI_C & & \\
\hline & QI_F & & \\
\hline & QD & & \\
\hline & QE & & \\
\hline \multirow{5}{*}{ QS } & QS_A & \multirow{5}{*}{0,645} & \multirow{5}{*}{ Sim } \\
\hline & QS_C & & \\
\hline & QS_F & & \\
\hline & QS_I & & \\
\hline & QS_TR & & \\
\hline \multirow{4}{*}{ UI } & QS & \multirow{4}{*}{0,345} & \multirow{4}{*}{ Sim } \\
\hline & QI & & \\
\hline & EE & & \\
\hline & $\mathrm{CO}$ & & \\
\hline \multirow{3}{*}{ SU } & UI & \multirow{3}{*}{0,331} & \multirow{3}{*}{ Sim } \\
\hline & QS & & \\
\hline & QI & & \\
\hline \multirow{2}{*}{ II } & UI & \multirow{2}{*}{0,420} & Sim \\
\hline & SU & & Sim \\
\hline EE & CO & 0,235 & Sim \\
\hline
\end{tabular}

\subsubsection{Análise do framework conceitual proposto}

Este tópico apresenta uma discussão sobre os resultados do modelo de mensuração, modelo estrutural e das relações de causalidade materializadas nas hipóteses propostas. 
O Modelo de mensuração, sendo esse composto pela definição e operacionalização dos construtos propostos para o contexto de Business Analytics, apresentou critérios satisfatórios de convergência, consistência interna e validação discriminatória apresentados na Tabela 33.

Conforme apresentado em 4.2.1 Análise do modelo de mensuração, foi retirado o indicador QS_TR1 do construto endógeno reflexivo QS_TR por apresentar valor de outerloading inferior a 0,4 e não comprometer a abrangência (domínio) do construto.

A seguir será discutido os resultados do modelo estrutural obtidos para cada variável dependente, bem como suas relações com as hipóteses propostas.

\subsection{Qualidade dos dados}

Para este trabalho o construto Qualidade dos dados foi definido como grau de relevância, precisão, utilidade, contextualidade, compreensividade e atualidade dos dados. Sendo este estruturado através das dimensões: Acuracidade, Completude e Atualidade.

Todas as dimensões apresentaram significância estatística através da análise de bootstrapping, com valor de $p$ inferior a $1 \%$, sendo o coeficiente de caminho referente a Completude o de maior intensidade com 0,34. Desta forma as hipóteses $\mathrm{H}_{\mathrm{QD} 1}, \mathrm{H}_{\mathrm{QD} 2} \mathrm{e} \mathrm{H}_{\mathrm{QD} 3}$ foram confirmadas através da análise de bootstrapping do modelo.

Com relação a capacidade preditiva do construto, o mesmo apresentou resultados aceitáveis tanto para o coeficiente de determinação $\mathrm{R}^{2}$ (superior a 0,5 ), como para o valor de StoneGeisser $\mathrm{Q}^{2}$ (superior a 0).

A Tabela 35 expõe um resumo dos resultados obtidos da análise estrutural do construto Qualidade dos Dados.

Tabela 35 - Análise de significância e relevância (Qualidade dos dados)

Fonte: Elaborado pelo autor

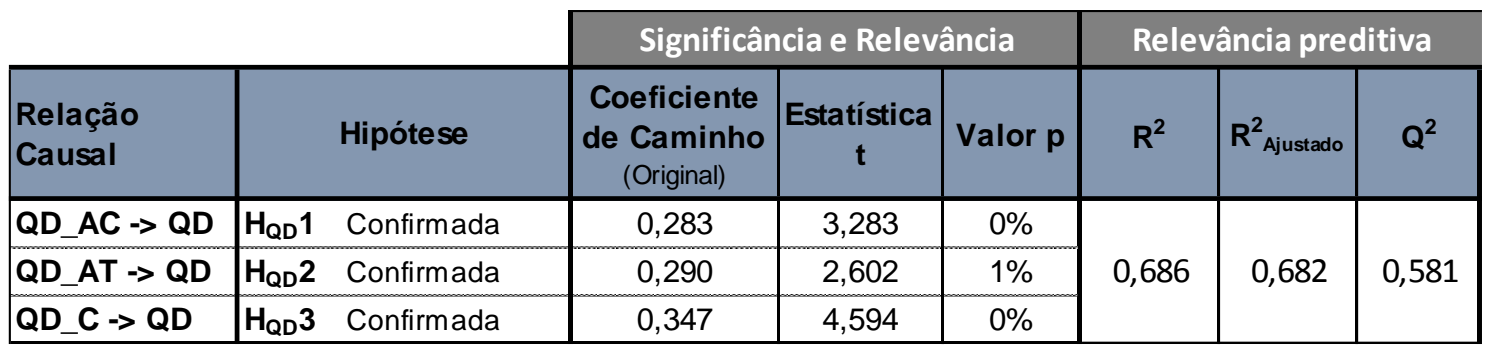

\subsection{Qualidade do sistema}

A Qualidade do sistema para o contexto de Business Analytics foi definida como características desejáveis de um sistema de informação e estruturada através das dimensões: Confiabilidade, Flexibilidade, Integração, Acessibilidade e Tempo de resposta.

De forma similar a Qualidade dos dados, todos os coeficientes de caminho das dimensões apresentaram significância estatística com valor de $p$ inferior a $1 \%$. Isto é, com probabilidade superior a $99 \%$ de existência da relação de causalidade entre cada construto exógeno (dimensão) e a Qualidade do sistema. Desta forma as hipóteses $\mathrm{H}_{\mathrm{QS} 1}, \mathrm{H}_{\mathrm{QS} 2}, \mathrm{H}_{\mathrm{QS} 3}, \mathrm{H}_{\mathrm{QS} 4} \mathrm{e} \mathrm{H}_{\mathrm{QS} 5}$ foram confirmadas através da análise de bootstrapping do modelo. 
Com relação a capacidade preditiva do construto, o mesmo apresentou resultados aceitáveis tanto para o coeficiente de determinação $\mathrm{R}^{2}$ (superior a 0,5 ), como para o valor de StoneGeisser $\mathrm{Q}^{2}$ (superior a 0).

A Tabela 36 expõe um resumo dos resultados obtidos da análise estrutural do construto Qualidade do Sistema.

Tabela 36- Análise de significância e relevância (Qualidade do Sistema)

Fonte: Elaborado pelo autor

\begin{tabular}{|c|c|c|c|c|c|c|c|c|}
\hline \multirow[b]{2}{*}{$\begin{array}{l}\text { Relação } \\
\text { Causal }\end{array}$} & \multirow{2}{*}{\multicolumn{2}{|c|}{ Hipótese }} & \multicolumn{3}{|c|}{ Significância e Relevância } & \multicolumn{3}{|c|}{ Relevância preditiva } \\
\hline & & & $\begin{array}{c}\text { Coeficiente } \\
\text { de Caminho } \\
\text { (Original) }\end{array}$ & $\begin{array}{c}\text { Estatística } \\
\mathbf{t}\end{array}$ & Valor $p$ & $\mathbf{R}^{2}$ & $R_{\text {Ajustado }}^{2}$ & $Q^{2}$ \\
\hline QS_A $>$ QS & $\mathrm{H}_{\mathrm{QS}} 1$ & Confirmada & 0,195 & 3,024 & $0 \%$ & \multirow{5}{*}{0,733} & \multirow{5}{*}{0,727} & \multirow{5}{*}{0,645} \\
\hline QS_C $\rightarrow$ QS & $\mathrm{H}_{\mathrm{QS}} 2$ & Confirmada & 0,237 & 4,962 & $0 \%$ & & & \\
\hline QS_F $->$ QS & $\mathrm{H}_{\mathrm{QS}} 3$ & Confirmada & 0,202 & 3,120 & $0 \%$ & & & \\
\hline QS_I -> QS & $\mathrm{H}_{\mathrm{QS}} 4$ & Confirmada & 0,163 & 3,484 & $0 \%$ & & & \\
\hline QS TR $->$ QS & $\mathrm{H}_{\mathrm{OD}} 5$ & Confirmada & 0,298 & 4,928 & $0 \%$ & & & \\
\hline
\end{tabular}

\subsection{Qualidade da Informação}

A Qualidade da informação neste trabalho foi definida como características desejáveis das informações disponibilizadas pelo sistema e estruturada através das dimensões: Completude, Acuracidade, Atualidade e Formato.

Com relação as dimensões atribuídas ao construto em sua operacionalização, a significância estatística do coeficiente de caminho foi constatada para Completude, Atualidade e Formato, confirmando as hipóteses $\mathrm{H}_{\mathrm{Q} 11}, \mathrm{H}_{\mathrm{Q} 12}$ e $\mathrm{H}_{\mathrm{QI}}$. Porém, neste conjunto amostral não foi averiguada significância estatística com relação a dimensão Atualidade, o que difere do resultado esperado conforme a hipóteses $\mathrm{H}_{\mathrm{Q} I 3}$.

Este efeito pode ser ocasionado para o contexto de Business Analytics por uma possível predominância na utilização de sistemas de BA em tomadas de decisão de horizontes maiores que aplicações convencionais de BI focadas na extração e visualização de relatórios em distintos graus de granularidade. Desta forma, a atualização de dados recentes (i.e. faturamento e estoques) podem ser menos relevante para o suporte a tomada de decisão.

Desta forma, a análise do horizonte de tomada de decisão como variável moderadora desta relação de causalidade pode ser abordado como uma oportunidade de pesquisa de desdobramento deste modelo proposto.

Outro ponto importante se refere ao elevado valor $p$ para a relação de causalidade de Qualidade de dados e Qualidade da Informação. O qual foi constato através da análise de bootstrapping a existência de $13 \%$ de probabilidade de se assumir erroneamente a relação de causalidade entre QD e QI. Dessa forma, para este estudo foi adotado como não confirmada a hipótese de relação entre estas duas variáveis dependente (e.g. QD e QI).

Apesar da diferenciação entre dados e informação ser amplamente divulgada nas áreas de gestão de conhecimento e ciências da informação (e.g. Modelo de hierarquia do conhecimento - Data, Information, Knowledge and Wisdom) (ROWLEY, 206) (MARTIM, 2017), a distinção entre esses dois conceitos pode não ser trivial para profissionais de outros 
campos de atuação. Desta forma, este resultado divergente da hipótese proposta pode ser decorrente de uma lacuna conceitual por parte dos respondentes tendo em vista seu perfil de interação com o sistema apresentado anteriormente em 4.1.2 Caracterização dos respondentes.

Isto posto, o entendimento do impacto na intensidade desta relação para distintos perfis de profissionais pode ser uma oportunidade de objeto de pesquisa para trabalhos futuros.

Com relação a Qualidade da Equipe (QE), foi identificação significância estatística em sua relação com a Qualidade da Informação, apresentado valor p de 4\%, confirmando a hipótese 5 .

A Tabela 37 expõe os resultados obtidos da análise de significância e relevância estatística do coeficiente de caminho das dimensões deste construto de segunda ordem.

Tabela 37 - Análise de significância e relevância (Qualidade da Informação)

Fonte: Elaborado pelo autor

\begin{tabular}{|c|c|c|c|c|c|c|c|c|}
\hline \multirow[b]{2}{*}{$\begin{array}{l}\text { Relação } \\
\text { Causal }\end{array}$} & \multirow{2}{*}{\multicolumn{2}{|c|}{ Hipótese }} & \multicolumn{3}{|c|}{ Significância e Relevância } & \multicolumn{3}{|c|}{ Relevância preditiva } \\
\hline & & & $\begin{array}{c}\text { Coeficiente } \\
\text { de Caminho } \\
\text { (Original) }\end{array}$ & $\begin{array}{c}\text { Estatística } \\
\mathrm{t}\end{array}$ & Valor $p$ & $\mathbf{R}^{2}$ & $\mathbf{R}_{\text {Ajustado }}^{2}$ & $Q^{2}$ \\
\hline QI_AC -> QI & $\mathrm{H}_{\mathrm{QI}} 1$ & Confirmada & 0,388 & 5,363 & $0 \%$ & \multirow{6}{*}{0,768} & \multirow{6}{*}{0,762} & \multirow{6}{*}{0,638} \\
\hline QI_AT $\rightarrow$ QI & $\mathrm{H}_{\mathrm{Q1}} 2$ & Não confirmada & $-0,027$ & 0,444 & $66 \%$ & & & \\
\hline QI_C -> QI & $\mathrm{H}_{\mathrm{Q} 1} 3$ & Confirmada & 0,226 & 3,523 & $0 \%$ & & & \\
\hline QI_F -> QI & $\mathrm{H}_{\mathrm{Q} 1} 4$ & Confirmada & 0,300 & 5,018 & $0 \%$ & & & \\
\hline QD -> Q I & $\mathrm{H} 1$ & Não confirmada & 0,088 & 1,503 & $13 \%$ & & & \\
\hline QE -> QI & H5 & Confirmada & 0,091 & 2,006 & $4 \%$ & & & \\
\hline
\end{tabular}




\subsection{Engajamento dos executivos}

O engajamento dos executivos é um dos fatores críticos de implementações de sistema de informação mais recorrentes na literatura (SHARMA; YETTON, 2003), o qual foi definido nesse estudo como o grau de esforço empregado pelos executivos na implantação de sistemas de tecnologia da informação.

No modelo proposto em análise, a cultura organizacional de gestão baseada em fatos foi considerada como variável dependente do engajamento dos executivos no contexto de Business Analytics. Sendo constatado na análise de equações estruturais uma relação causal positiva entre os construtos com elevada significância estatística.

A relevância preditiva do construto Engajamento dos executivos frente a Cultura Organizacional foi estabelecida de forma moderada. O que aponta a possível existência de outras variáveis dependentes nesta relação, corroborando com a visão de Davenport e Harris (2007) que além da cultura organizacional apontam a relevância do perfil dos executivos e familiaridade com técnicas estatísticas.

A Tabela 38 expõe os resultados obtidos da análise de significância e relevância estatística do coeficiente de caminho das dimensões deste construto de segunda ordem.

Tabela 38 - Análise de significância e relevância (Cultura Organizacional)

Fonte: Elaborado pelo autor

\begin{tabular}{|l|cc|c|c|c|c|c|c|}
\cline { 3 - 9 } \multicolumn{2}{c|}{} & \multicolumn{2}{|c|}{ Significância e Relevância } & \multicolumn{3}{|c|}{ Relevância preditiva } \\
\hline $\begin{array}{l}\text { Relação } \\
\text { Causal }\end{array}$ & Hipótese & $\begin{array}{c}\text { Coeficiente } \\
\text { de Caminho } \\
\text { (Original) }\end{array}$ & $\begin{array}{c}\text { Estatística } \\
\mathbf{t}\end{array}$ & Valor $\mathbf{p}$ & $\mathbf{R}^{2}$ & $\mathbf{R}_{\text {Ajustado }}^{2}$ & $\mathbf{Q}^{2}$ \\
\hline CO $>$ EE & H4 & Confirmada & 0,598 & 11,632 & $0 \%$ & 0,358 & 0,355 & 0,235 \\
\hline
\end{tabular}

\subsection{Uso da Informação}

Para este estudo o Uso da informação foi definido como a aplicação de informações adquiridas e transmitidas para o processo organizacional de tomada de decisão. No qual as hipóteses de dependência com os construtos Qualidade do Sistema, Qualidade da Informação, Cultura Organizacional e Engajamento do Executivos foram estabelecidas.

Todos os coeficientes de caminho das dimensões apresentaram significância estatística com valor $p$ inferior a 3\%, conforme exposto na Tabela 39 .

Entre os resultados, destaca-se a relevância dos coeficientes de caminho dos construtos QS e QI, o que valida estas relações apresentadas no modelo de sucesso de SI proposto por DeLone e McLean (1992) para o contexto de sistemas de BA.

A Cultura Organizacional de gestão baseada em fatos também exibiu elevada influência no Uso da informação, atuando com impacto direto e indireto através da variável mediadora Engajamento dos executivos.

A relevância destas relações podem ser observadas na análise de efeito total (Tabela 51), na qual a Cultura Organizacional apresenta o segundo maior impacto no Uso da Informação com intensidade inferior apenas a Qualidade do Sistema. 
Este resultado sinaliza que além de aumentar o engajamento dos executivos, uma cultura organizacional de gestão baseada em fatos influencia positivamente os demais colaboradores na utilização de BA nos processos decisórios da empresa.

Tabela 39 - Análise de significância e relevância (Uso da Informação)

Fonte: Elaborado pelo autor

\begin{tabular}{|c|c|c|c|c|c|c|c|c|}
\hline \multirow[b]{2}{*}{$\begin{array}{l}\text { Relação } \\
\text { Causal }\end{array}$} & \multirow{2}{*}{\multicolumn{2}{|c|}{ Hipótese }} & \multicolumn{3}{|c|}{ Significância e Relevância } & \multicolumn{3}{|c|}{ Relevância preditiva } \\
\hline & & & $\begin{array}{c}\text { Coeficiente } \\
\text { de Caminho } \\
\text { (Original) }\end{array}$ & $\begin{array}{c}\text { Estatística } \\
\mathrm{t}\end{array}$ & Valor $p$ & $R^{2}$ & $R_{\text {Ajustado }}^{2}$ & $\mathbf{Q}^{2}$ \\
\hline QS -> UI & $\mathrm{H} 6$ & Confirmada & 0,420 & 4,78 & $0 \%$ & \multirow{4}{*}{0,601} & \multirow{4}{*}{0,594} & \multirow{4}{*}{0,345} \\
\hline QI -> UI & $\mathrm{H} 8$ & Confirmada & 0,206 & 2,203 & $3 \%$ & & & \\
\hline EE $->$ UI & $\mathrm{H} 2$ & Confirmada & 0,129 & 2,288 & $2 \%$ & & & \\
\hline CO -> UI & H3 & Confirmada & 0,183 & 3,034 & $0 \%$ & & & \\
\hline
\end{tabular}

\subsection{Satisfação do usuário}

Com relação ao nível de satisfação do usuário com o sistema, 3 variáveis dependentes foram definidas de acordo com o modelo de sucesso de SI proposto por DeLone e McLean (1992).

As relações causais relacionadas a Qualidade da Informação e Uso da Informação apresentam significância estatística com valor de $p$ inferiores a $1 \%$.

Para a Qualidade do sistema foi constato através da análise de bootstrapping a existência de $13 \%$ de probabilidade de se assumir erroneamente a significância estatística desta relação causal. Dessa forma, para este estudo foi adotado como não confirmada a hipótese de relação entre estes dois construtos.

Vale ressaltar que apesar do baixo valor de $p$ do coeficiente de caminho, o construto apresentou elevado impacto indireto exposto na análise de efeito total exposto na Tabela 51. Sendo possível constatar a relevância deste construto para o modelo proposto por DeLone e McLean (1992) no contexto de BA.

A Tabela 40 expõe os resultados obtidos na análise do modelo estrutural referente a este construto.

Tabela 40 - Análise de significância e relevância (Satisfação do usuário)

Fonte: Elaborado pelo autor

\begin{tabular}{|c|c|c|c|c|c|c|c|c|}
\hline \multirow[b]{2}{*}{$\begin{array}{l}\text { Relação } \\
\text { Causal }\end{array}$} & \multirow{2}{*}{\multicolumn{2}{|c|}{ Hipótese }} & \multicolumn{3}{|c|}{ Significância e Relevância } & \multicolumn{3}{|c|}{ Relevância preditiva } \\
\hline & & & $\begin{array}{c}\text { Coeficiente } \\
\text { de Caminho } \\
\text { (Original) }\end{array}$ & $\begin{array}{c}\text { Estatística } \\
\mathbf{t}\end{array}$ & Valor $p$ & $\mathbf{R}^{2}$ & $\mathbf{R}_{\text {Ajustado }}^{2}$ & $\mathbf{Q}^{2}$ \\
\hline QS -> SU & $\mathrm{H} 7$ & Não confirmada & 0,151 & 1,508 & $13 \%$ & \multirow{3}{*}{0,557} & \multirow{3}{*}{0,552} & \multirow{3}{*}{0,331} \\
\hline QI -> SU & H9 & Confirmada & 0,370 & 3,975 & $0 \%$ & & & \\
\hline UI $->$ SU & $\mathrm{H} 10$ & Confirmada & 0,299 & 4,371 & $0 \%$ & & & \\
\hline
\end{tabular}




\subsection{Impacto individual}

Para este trabalho o construto Impacto Individual foi definido como o efeito causado pela informação fornecida pelo SI no comportamento do receptor, e as variáveis dependentes Uso da Informação e Satisfação do Usuário foram definidas de acordo com o modelo de sucesso de SI proposto por DeLone e McLean (1992).

Ambas variáveis apresentaram significância estatística através da análise de bootstrapping, com valor de $p$ inferior a $1 \%$, e resultados aceitáveis referentes a capacidade preditiva do construto tanto para o coeficiente de determinação $\mathrm{R}^{2}$ (superior a 0,5 ), como para o valor de Stone-Geisser $\mathrm{Q}^{2}$ (superior a 0 ).

A Tabela 41 expõe um resumo dos resultados obtidos da análise estrutural do construto Impacto Individual.

Através da análise de efeito total é possível observar que os construtos de maior relevância são: Uso da Informação, Satisfação do usuário, Qualidade do sistema e Qualidade da informação. Reforçando a aderência do modelo proposto por DeLone e McLean (1992) para o contexto de Business Analytics.

Tabela 41 - Análise de significância e relevância (Impacto Individual)

Fonte: Elaborado pelo autor

\begin{tabular}{|l|cc|c|c|c|c|c|c|}
\cline { 3 - 9 } \multicolumn{2}{c|}{} & \multicolumn{2}{c|}{ Significância e Relevância } & \multicolumn{2}{c|}{ Relevância preditiva } \\
\hline $\begin{array}{l}\text { Relação } \\
\text { Causal }\end{array}$ & Hipótese & $\begin{array}{c}\text { Coeficiente } \\
\text { de Caminho } \\
\text { (Original) }\end{array}$ & $\begin{array}{c}\text { Estatística } \\
\mathbf{t}\end{array}$ & Valor $\mathbf{p}$ & $\mathbf{R}^{2}$ & $\mathbf{R}_{\text {Ajustado }}$ & $\mathbf{Q}^{2}$ \\
\hline UI $>$ II & H11 & Confirmada & 0,383 & 5,665 & $0 \%$ & 0,555 & 0,551 & 0,420 \\
\hline SU $>$ II & H12 & Confirmada & 0,434 & 6,050 & $0 \%$ & \\
\hline
\end{tabular}

A Figura 26 abaixo apresenta o modelo proposto anteriormente e uma ilustração gráfica das hipóteses confirmadas através da análise estatística. 

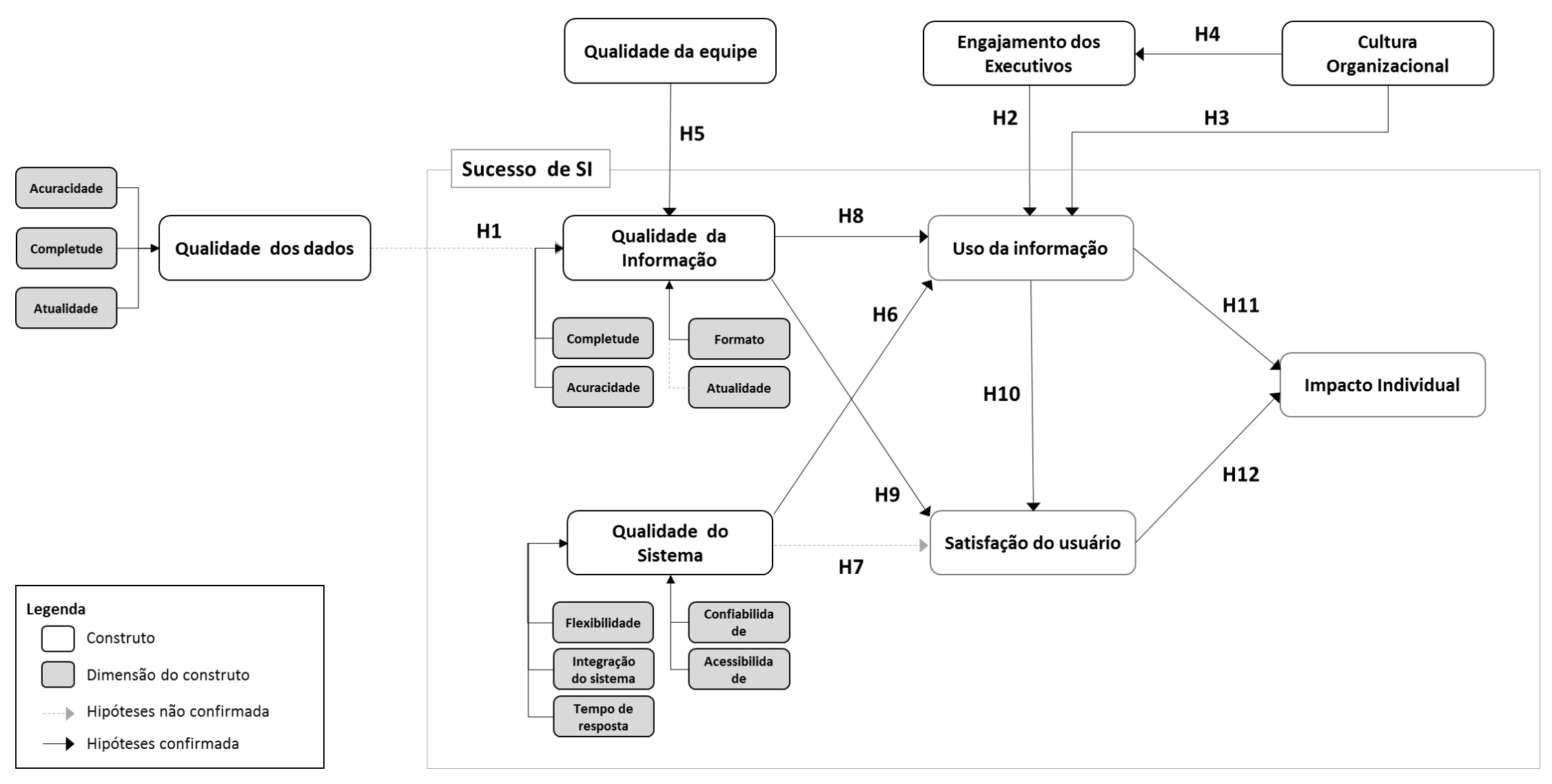

Figura 26 - Framework conceitual (Confirmação de hipóteses)

Fonte: Elaborado pelo autor 


\section{Conclusão}

Este presente trabalho teve como objetivo analisar os fatores críticos de sucesso de sistemas de Business Analytics, e também apresenta como contribuição a estruturação de uma ferramenta de mensuração de sucesso de SI de BA baseado no modelo apresentado por Delone e McLean (1992).

Para a condução do trabalho foi utilizada a metodologia de pesquisa científica de Levantamento tipo Survey e a técnica estatística de Modelagem de Equações Estruturais.

Devido à falta de consenso sobre a definição de Business Analytics, conforme apontado por Mortenson et al. (2015), inicialmente foi necessário estruturar uma proposta de posicionamento frente a termos correlatos da literatura de sistema de informação e apoio a decisão como: Business Inteligência, Big Data e Inteligência Competitiva.

Com base na revisão bibliográfica realizada, o termo Business Intelligence foi adotado de forma mais ampla que Business Analytics e Big Data. No qual BA é um subconjunto de sistemas de BI caracterizados pela aplicação de técnicas de modelagem matemática e estatística, e Big Data está correlacionado a complexidade e volume de dados processados pelos sistemas para a estruturação das informações. A Figura 10 apresenta de forma gráfica o relacionamento entre estes conceitos.

Já o termo Inteligência Competitiva está relacionado ao monitoramento do mercado para o auxílio na definição estratégica das empresas e posicionamento de mercado, a qual pode utilizar de ferramentas de Business Intelligence na operacionalização deste monitoramento.

Após a delimitação do conceito de BA, foi discutido os fatores críticos de sucesso (FCS) de BA presentes na literatura e suas particularidades frente a sistemas transacionais (e.g. Enterprise Resource Planning). Os quais foram estruturados em 3 dimensões e 4 construtos: Tecnologia (Qualidade dos dados), Cultura organizacional (Gestão Baseada em Fatos e Engajamento dos executivos) e Pessoas (Qualidade da Equipe).

Para a elaboração da ferramenta de pesquisa, os construtos referentes aos FCS das 3 dimensões e ao modelo apresentado por Delone e McLean (1992) foram operacionalizados para o contexto de Business Analytics.

O Levantamento tipo Survey foi conduzido através da plataforma online Survey Monkey, no qual foi obtido uma taxa de resposta de 4,8\% e 231 respostas usáveis. A qual foi submetida a análise multivariada de dados de modelagem de equações estruturais (Structured Equation Model-SEM).

O Modelo de mensuração apresentou critérios satisfatórios de convergência, consistência interna e validação discriminatória. O qual foi ajustado através da retirada do indicador QS_TR1 do construto endógeno reflexivo QS_TR por apresentar valor de outerloading inferior a 0,7 e não comprometer a abrangência (domínio) do construto.

Atendendo os objetivos específicos de estruturar um instrumento para mensuração de sucesso de sistemas de Business Analytics, bem como a operacionalização de seus respectivos construtos para este contexto de aplicação. 
Após a validação do modelo de mensuração, foi conduzida a análise do modelo estrutural exposto pela técnica PLS-SEM.

O modelo exposto por Delone e McLean (1992) apresentou boa aderência para o contexto de sistemas de BA, com expressiva relevância e significância estatística dos coeficientes de caminho.

Como uma possível particularidade para este tipo de sistema, foi observada baixa significância estatística do impacto da Qualidade do sistema na Satisfação do usuário (Valor de p: 13\%), porém com elevado impacto indireto exposto na análise de efeito total (Tabela 51). No qual o Uso da Informação atua como variável mediadora da interação destes dois construtos.

Com relação aos FCS foi possível observar através da análise de efeito total (Tabela 51) que a Cultura Organizacional apresentou a maior relevância no sucesso de SI (i.e. Uso da Informação e Impacto Individual) dentre as 3 dimensões. Como alta representatividade tanto do engajamento dos executivos, como da Cultura organizacional de gestão baseada em fatos.

Apesar da relevância da COGB no sucesso de sistemas de BA ter sido constatada neste estudo e estar alinhada com a visão exposta por pesquisadores desta área como Davenport e Harris (2007), Mcafee e Brynjolfsson (2012) e Holsapple et al. (2014), este ponto não foi sinalizado por autores de FCS de sistemas ERP.

Esta particularidade pode ser interpretada pelo fato de sistemas de apoio a decisão não apresentarem sua utilização obrigatória por parte do usuário, e uma cultura organizacional que não favoreça sua aplicação pode resultar em seu desuso.

Outro ponto relevante observado na análise foi o impacto indireto de COGB no Uso da Informação através da variável mediadora Engajamento dos executivos, o que acentua sua relevância para esse contexto.

A relevância preditiva do construto Engajamento dos executivos frente a Cultura Organizacional de gestão baseada em fatos foi estabelecida de forma moderada, o que sinaliza a possível existência de outras variáveis dependentes nesta relação como perfil dos executivos e familiaridade com técnicas estatísticas, conforme apontado por autores como Davenport e Harris (2007).

Desta forma, a existência de impactos diretos e indiretos da COGB no sucesso de SI (i.e. Uso da Informação e Impacto Individual) sinaliza seu papel tanto de catalizador do Engajamento dos executivos, como de influencia positivamente aos demais colaboradores na utilização de BA nos processos decisórios da empresa.

\subsection{Limitações e oportunidades de pesquisa}

Apesar da amostra ser consideravelmente superior (i.e. 50\%) ao tamanho mínimo necessário para a aplicação da técnica estatística PLS-SEM, existe uma elevada concentração de respondentes que classificaram sua interação com o sistema restrita a estruturação de relatórios e análises.

Uma comparação entre a percepção de FCS de profissionais com distintas interações com o sistema (.i.e. estruturação de relatórios e análises, desenvolvimento/suporte ao sistema e modelagem matemática) pode favorecer ao maior entendimento do tema de pesquisa. 
Outro possível desdobramento deste trabalho está na análise do perfil dos executivos como variável moderadora em seu engajamento em projetos de Business Analytics.

\subsection{Considerações finais}

Esta pesquisa buscou identificar os fatores de sucesso de sistemas de BA e avaliar empiricamente suas relações de causalidade. A análise estatística de equações estruturais permitiu concluir a alta relevância de uma cultura organizacional de gestão baseada em fatos neste contexto, contribuindo como evidência empírica sobre discussões teóricas apresentadas anteriormente por pesquisadores deste tema.

Além de contribuir com a expansão do conhecimento relacionado a área de Business Analytics, esta dissertação apresentou uma discussão e proposta de delimitação do conceito de BA frente demais termos relacionados a literatura de sistemas de suporte a decisão (i.e. BI, Big Data e Inteligência Competitiva) e a estruturação de uma ferramenta de mensuração de sucesso de SI de BA baseado no modelo apresentado por Delone e McLean (1992). 


\section{Referência bibliográfica}

AKKERMANS, H.; VAN HELDEN, K. Vicious and virtuous cycles in ERP implementation: a case study of interrelations between critical success factors. European Journal of Information Systems, v. 11, n. 1, p. 35-46, 2002.

ALVES, R. Filosofia da ciência: introdução ao jogo e sua regras. São Paulo: Brasilense, 1981.

AMBERG, M.; FISCHL, F.; WIENER, M. Background of critical success factor research. Evolution, v. 17, n. 2, p. 12, 2005.

ARAÚJO, C. A. Bibliometria : evolução histórica e questões atuais. em questão, p. 11-32, 2006.

ARISTIZABAL, C. R. Dimensões de sucesso para sistemas de business intelligence. Universidade de São Paulo, São Paulo, 2014.

ARISTIZABAL, C. R. Sucesso de sistemas de business intelligence: uma abordagem multidimensiona. Universidade de São Paulo, São Paulo, 2016.

BAILEY, J. E.; PEARSON, S. W. Development of a Tool for Measuring and Analyzing Computer User Satisfaction. Management Science, v. 29, n. 5, p. 530-545, 1983.

BALASUBRAMAN, S.; PETERSON, R. a.; JARVENPAA, S. L. Exploring the Implications of M-Commerce for Markets and Marketing. Journal of the Academy of Marketing Science, v. 30, n. 4, p. 348-361, 2002.

BARTLETT, R. A practitioner's guide to business analytics: using data analysis tools to improve your organization's decision making and strategy. McGraw-Hill, 2013.

BERTO, R. M. V. S.; NAKANO, D. N. A produção científica nos anais do encontro nacional de engenharia de produção: um levantamento de métodos e tipos de pesquisa. Produção, v. 9, n. 2, p. 65-75, 1999.

BOOTE, D. N.; BEILE, P. Scholars Before Researchers: On the Centrality of the Dissertation Literature Review in Research Preparation. Educational Researcher, v. 34, n. 6, p. 3-15, 2005.

BOSE, R. Advanced analytics : opportunities and challenges. Industrial Management \& Data Systems, v. 109, n. 2, p.155-172, 2009

CABRAL NETTO, O. V. Uma visão holística da inteligência competitiva para a construção de uma teoria. Universidade de São Paulo, São Paulo, 2011.

CAPUANO, E. A.; CASAES, J.; COSTA, J. R. Da; JESUS, M. S. De; MACHADO, M. A. Inteligência competitiva e suas conexões epistemológicas com gestão da informação e do conhecimento. Ciência da Informação, v. 38, n. 2, p. 19-34, 2009.

CHEN, C. The CiteSpace Manual. n. 2014, p. 1-59, 2014. Disponível em: $<$ http://cluster.ischool.drexel.edu/ cchen/citespace/CiteSpaceManual.pdf $>$. Acessado em: 18 jun. 2016.

CHEN, H.; CHEN, G. Business Intelligence and Analytics: Research Directions. ACM Trans. Manage. Inf. Syst, v. 3, n. 4, p. 1-10, 2013.

CHEN, H.; STOREY, V. C.; CHIANG, R. H. L. Business intelligence and analytics : from 
big data to big impact. MIS Quarterly. v. 36, n. 4, p. 1-24, 2012.

CHIANG, R. H. L.; GOES, P.; STOHR, E. A. Business Intelligence and Analytics Education , and Program Development: A Unique Opportunity for the Information. ACM Trans. Manage. Inf. Syst, v. 3, n. 3, p. 1-13, 2012.

CHIN, W. W. Commentary: Issues and Opinion on Structural Equation Modeling. MIS Quarterly, v. 22, n. 1, p. 1, 1998.

CORNELL, U. In Memorian - Gerard Salton. Cornell University, 2017. Disponível em: <http://www.cs.cornell.edu/Info/Department/Annual96/Beginning/salton.html>. Acessado em 17 jul. 2017.

CROTEAU, A.-M.; LI, P. Critical Success Factors of CRM Technological Initiatives. Canadian Journal of Administrative Sciences, v. 20, n. 1, p. 21-34, 2003.

DALMORO, M.; VIEIRA, K.M. Dilemas na construção de escalas tipo likert: o número de itens e a disposição influenciam nos resultados?, Revista Gestão Organizacional, v. 6, 2013.

DAMIANI, W. B. Gestão de dados: um levantamento de seu estado-da-arte. FGV Pesquisas, São Paulo, 2004.

DAVENPORT, T. H. Competing on Analytics. Harvard Business Review, v. 84, n. 1, p. 98-107, 2006.

DAVENPORT, T. H. Big data no trabalho: derrubando mitos e descobrindo oportunidades. $1^{\circ}$. ed. Elsevier Ltd, 2014.

DAVENPORT, T. H.; HARRIS, J. G. Competing on analytics: the new science of winning. Harvard Business School Press, $2^{\circ}$. ed. 2009.

DAVENPORT, T. H.; HARRIS, J. G.; MORISON, R. Analytics at work: smarter decisions, better results. Harvard Business School Press, $1^{\circ}$. ed. 2010.

DELONE, W. H.; MCLEAN, E. The DeLone and McLean model of information systems success: A ten-year updated. Journal of Management Information Systems, v. 19, n. 4, p. 9-30, 2003.

DELONE, W. H.; MCLEAN, E. R. Information systems success: The quest for the dependent variable. Information Systems Research, v. 3, n. 1, p. 60-95, 1992.

DEMIRKAN, H.; DELEN, D. Leveraging the capabilities of service-oriented decision support systems: Putting analytics and big data in cloud. Decision Support Systems, v. 55, n. 1, p. 412-421, 2013.

DUBNER, S. J.; STEVEN, L. Hal Varian Answers Your Questions, 2008 Disponível em: <http://freakonomics.com/2008/02/25/hal-varian-answers-your-questions/>. Acesso em: 10 jul. 2015.

DYBÅ, T. An Instrument for Measuring the Key Factors of Success in Software Process Improvement. Empirical Software Engineering, v. 5, p. 357-390, 2001.

FARBEY, B.; LAND, F. F.; TARGETT, D. A taxonomy of information systems applications: the benefits' evaluation ladder. European Journal of Information Systems, v. 4, n. 1, p. 41-50, 1995. 
FILIPPINI, R. Operations management research: Some reflections on evolution, models and empirical studies in OM. International Journal of Operations and Production Management, v. 17, n. 7, p. 655-670, 1997.

FORNELL, C.; LARCKER, D. Evaluating structural equation models with unobservable variables and measurement error. Journal of Marketing Research, v. 18, n. 4, p. 456-464, 1981.

FORZA, C. Survey research in operations management: a process-based perspective. International Journal of Operations \& Production Management, v. 22, n. 2, p. 152-194, 2002.

GUIMARÃES, P. R. B. Métodos Quantitativos Estatísticos. IESDE Brasil S.A., 2008.

HAIR, J. F. J.; BLACK, W. C.; BABIN, B. J.; ANDERSON, R. E.; TATHAM, R. L. Análise multivariada de dados. $6^{\circ}$ ed. Bookman, 2009.

HAIR, J. F. J.; HULT, G. T. M.; RINGLE, C. M.; SARSTEDT, M. A prime on partial least squares structural equation modeling (pls-sem). $2^{\circ}$ ed. SAGE, 2017.

HAWKING, P. Factors Critical To The Succ ess of Business Intelligence Systems. College of business - Victoria University, 2013.

HAWKING, P.; SELLITTO, C. Critical Success Factors of Business Intelligence ( BI) in an ERP Systems Environment. Institute for Logistics and Supply Chain Management Victoria University, 2009.

SAMPIERI, R. H.; COLLADO, C. F.; LUCIO, M. B. Definición del alcance de la investigación a realizar: exploratoria, descriptiva, correlacional o explicativa. $5^{\circ}$ ed. McGrawHill, 2010.

HEUDECKER, N.; KART, L. Survey Analysis: Big Data Investment Grows but Deployments Remain Scarce in 2014. Gartner, 2014. Disponível em: <http://www.gartner.com/newsroom/id/2848718>. Acesso em: 10 jun. 2015.

HILL, T. Completing the value chain: data, insight, action. Tech page one - Dell UK. 2014 Disponível em: <http://www.techpageone.co.uk/en/technology/completing-the-value-chaindata-insight-action/\#.Vav7NvlViko>. Acesso em: 19 jul. 2015.

HOLLAND, C. P.; LIGHT, B. A Critical Success Factors Model For Enterprise Resource Planning Implementation Critical Success Factors For ERP Implementation. Manchester Business School, 1999.

HOLSAPPLE, C.; LEE-POST, A.; PAKATH, R. A unified foundation for business analytics. Decision Support Systems, v. 64, p. 130-141, 2014.

HONG, K.; KIM, Y. The critical success factors for ERP implementation : an organizational perspective. Information and Management, v. 40, 2002.

HOWARD, C.; PLUMMER, D.; MANN, C. The Nexus of Forces: Social, Mobile, Cloud and Information. Gartner, 2012.

IBICT - INSTITUTO BRASILEIRO DE INFORMAÇÃO EM CIÊNCIA E TECNOLOGIA. Inteligência, informação e conhecimento. IBICT, p. 456, 2006.

IIVARI, J. An Empirical Test of the Model of Information System Success. The DATA BASE for Advances in Information Systems, v. 36, n. 2, p. 8-27, 2005. 
ILLINOIS, U. Steve LaValle information. Disponível em: <https://cs.illinois.edu/directory/profile/lavalle>. Acessado em: 18 jul. 2017

MANYIKA, J.; CHUI, M.; BROWN, B.; BUGHIN, J.; DOBBS, R.; ROXBURGH, C.; A. H. B. Big data: The next frontier for innovation, competition, and productivity. McKinsey Global Institute, n. June, p. 156, 2011.

JOURDAN, Z.; RAINER, R. K.; MARSHALL, T. E. Business intelligence: An analysis of the literature. Information Systems Management, v. 25, n. 2, p. 121-131, 2008.

KAHANER, L. Competitive intelligence: how to gather analyze and use information to move your business to the top. Simon and Schuster, 1997.

KAISER, K. M.; SRINIVASAN, A. The Relationship of User Attitude Toward Design Criteria and Information System Success. Proceedings of the 12th AIDS Annual Meeting, v.1, 1980.

KAUARK, F. da S.; MANHÃES, F. C.; MEDEIROS, C. H. Metodologia da Pesquisa: Um guia prático. Itabuna - Via Litterarum, 2010.

KIM, K. K. User satisfaction: A synthesis of three different perspectives. Journal of Information Systems, v. 4, n. 1, p. 1-12, 1989.

LAKATOS, E.; MARCONI, M. Fundamentos de metodologia científica. $5^{\circ}$. ed. Editora Atlas S.A., 2003.

LAVALLE, S.; LESSER, E.; SHOCKLEY, R.; HOPKINS, M. S.; KRUSCHWITZ, N. Big Data, Analytics and the Path From Insights to Value. MIT Sloan Management Review, v. 52, n. 2, p. 21-32, 2011.

LAWRENCE, S. G.; COURTNEY, J. F. A field study of organizational factors influencing DSS success. MIS quarterly, n. March, p. 77-90, 1985.

LIANG, T. P. Critical success factors of decision support systems. Data Base Winter, 1986.

LINO, M. M. R. M. D. O. Estatística para Administradores. Santa Catarina: Universidade Federal de Santa Catarina - Departamento de Informática e Estatística, 2009

LOVEJOY, W. S. Integrated operations: A proposal for operations management teaching and research. Production and Operations Management, v. 7, n. 2, p. 106-124, 1998.

MACIAS-CHAPULA, C. a. O papel da informetria e da cienciometria e sua perspectiva nacional e internacional. Ciência da Informação, v. 27, n. 2, p. nd-nd, 1998.

MARCIAL, E. C. Utilização do modelo multivariado para identificação dos elementos-chave que compõem sistemas de inteligência competitiva. Dissertação (Mestrado em Ciência da Informação) - Universidade de Brasília, 2007.

MARTIM, F. The Knowledge Pyramid: A Critique of the DIKW Hierarchy. Journal of Information Science, 2008 
MAYR, S.; BUCHNER, A.; ERDFELDER, E.; FAUL, F. A short tutorial of GPower. Tutorials in Quantitative Methods for Psychology, v. 3, n. 2, p. 51-59, 2007.

MCAFEE, A.; BRYNJOLFSSON, E. Big Data. The management revolution. Harvard Buiness Review, v. 90, n. 10, p. 61-68, 2012.

MIGUEL, P. A. C. Estudo de caso na engenharia de produção: estruturação e recomendações para sua condução. Produção, v. 17, n. 1, p. 216-229, 2007.

MIGUEL, P. A. C.; FLEURY, A. C. C.; MELLO, C. H. P.; NAKANO, D. N.; TURRIONI, J. B.; HO, L. L. Metodologia de pesquisa em engenharia de produção e gestão de operações. $2^{\circ}$ ed. ABEPRO, 2012.

MORTENSON, M. J.; DOHERTY, N. F.; ROBINSON, S. Operational research from Taylorism to Terabytes: A research agenda for the analytics age. European Journal of Operational Research, v. 241, n. 3, p. 583-595, 2015.

NELSON, R. R.; TODD, P. a; WIXOM, B. H. Antecedents of information and system quality: An empirical examination within the context of data warehousing. Journal of Management Information Systems, v. 21, n. 4, p. 199-235, 2005.

NEVES, S. M.; SILVA, A. F.; MELO, J. E. C. Bibliometria - uma abordagem prática. Bauru: UNESP, 2011.

O’HAIR, A.; BERTSIMAS, D. The Analytics Edge. MIT - edx, 2015.

OLSZAK, C. M.; ZIEMBA, E. Critical Success Factors for Implementing Business Intelligence Systems in Small and Medium Enterprises on the Example of Upper Silesia, Poland. Interdisciplinary Journal of Information, Knowledge, and Management. v. 7, 2012.

PETTER, S.; DELONE, W.; MCLEAN, E. R. Information systems success: The quest for the independent variables. Journal of Management Information Systems, v. 29, n. 4, p. 762, 2013.

POPOVIČ, A.; HACKNEY, R.; COELHO, P. S.; JAKLIČ, J. Towards business intelligence systems success: Effects of maturity and culture on analytical decision making. Decision Support Systems, v. 54, n. 1, p. 729-739, 2012.

RAI, A.; LANG, S. S.; WELKER, R. B. Assessing the Validity of IS Success Models: An Empirical Test and Theoretical Analysis. Information Systems Research. v. 13, n. 1, p. 5069, 2002.

RANDOLPH, J. J. A Guide to Writing the Dissertation Literature Review. Practical Assessment, Research \& Evaluation, v. 14, n. 13, p. 1-13, 2009.

REUTERS, T. Pesquisando no campo Tópico. Disponível em: <http://images.webofknowledge.com/WOKRS5132R4.2/help/pt_BR/WOK/hs_topic.html>. Acessado em: 18 jul. 2017.

ROCKART, J. F. Chief executives define their own data needs. Harvard business review, v. 57, n. 2, p. 81-93, jan. 1979.

ROWLEY, J. The Wisdom hierachy representations of the DIKW hierarchy. Journal of Information Science, 2007

RUDRA, A.; YEO, E. Issues in User Perceptions of Data Quality and Satisfaction in Using 
a Data Warehouse - An Australian Experience. IEEE - Proceedings of the $33^{\text {rd }}$ Hawaii International Conference on System Sciences, p. 1-7, 2000.

SAMMON, D.; FINNEGAN, P. The ten commandments of data warehousing. ACM SIGMIS Database, v. 31, n. 4, p. 81-91, 2000.

SANTOS, C. P. Estudo dos fatores influenciadores da intenção de uso da informação dos sistemas de business intelligence em empresas brasileiras. Universidade de São Paulo, São Paulo, 2014.

SHARMA, R.; YETTON, P. The Contingent Effects of Management Support and Task Interdependence on Successful Information Systems Implementation. MIS Quarterly, v. 27, n. 4, p. 533-556, 2003.

SMITHSON, S.; HIRSCHHEIM, R. Analysing information systems evaluation: another look at an old problem. European Journal of Information Systems, v. 7, n. 3, p. 158-174, 14 out. 1998.

SOMERS, T. M.; NELSON, K. The impact of critical success factors across the stages of enterprise resource planning implementations. Proceedings of the 34th Annual Hawaii International Conference on System Sciences, v. 00, n. c, p. 1-10, 2001.

SUTTON, R. I.; STAW, B. M. What Theory is Not What Theory is. Adminisrtative Science Quaterly, v. 40, n. 3, p. 371-384, 2007.

TRKMAN, P.; MCCORMACK, K.; DE OLIVEIRA, M. P. V.; LADEIRA, M. B. The impact of business analytics on supply chain performance. Decision Support Systems, v. 49, n. 3, p. 318-327, 2010.

TURRIONI, J. B.; MELLO, C. H. P. Metodologia de pesquisa em engenharia de produção. Universidade Federal de Itajubá - UNIFEI, p. 191, 2012.

UMBLE, E. J.; HAFT, R. R.; UMBLE, M. M. Enterprise resource planning: Implementation procedures and critical success factors. European Journal of Operational Research, v. 146, n. 2, p. 241-257, 2003.

VIAENE, S.; BUNDER, A. Van Den. The secrets to managing business analytics projects. MIT Sloan Management Review, v. 53, n. 1, p. 64-70, 2011.

VRIENS, D. Information and communication technology for competitive intelligence. United States of America - IRM Press, 2004.

WEEMS, G. H.; ONWUEGBUZIE, A. J. The impact of midpoint responses and reverse coding on survey data. Measurement and Evaluation in Counseling and Development, 2001

WIXOM, B. H.; WATSON, H. J. An Empirical Investigation of the Factors Affecting Data Warehousing Success. Management Information Systems Quarterly, 2001. 


\section{Anexos}

\subsection{E-mail de solicitação de participação}

\section{Dissertação de mestrado - Universidade de São Paulo (POLI - USP)}

Olá,

Meu nome é Cezar Sayão, sou aluno do programa de mestrado em Gestão de Tecnologia da Informação da Universidade de São Paulo (USP) - Departamento de Engenharia de produção da Escola Politécnica.

Minha tese aborda o tema de Fatores Críticos de Sucesso de sistemas de Business Analytics, e para a etapa de estudo de campo gostaria convidá-lo a participar desta pesquisa on-line.

A pesquisa tem duração aproximada de $15 \mathrm{~min}$, e todas as informações serão utilizadas unicamente para fins acadêmicos. Também vale ressaltar que todos participantes que responderem o questionário receberão um sumário dos resultados, além de poder consultar o trabalho final da dissertação no site: http://hunw.teses.usp.br.

Muito obrigado!

Cezar Sayão

Aluno de Mestrado - Departamento de Engenharia de Produção - USP cezar.sayao@gmail.com

Renato de Oliveira Moraes

Professor e Orientador - Departamento de Engenharia de Produção - USP

Iniciar questionário

\subsection{Ferramenta de pesquisa}

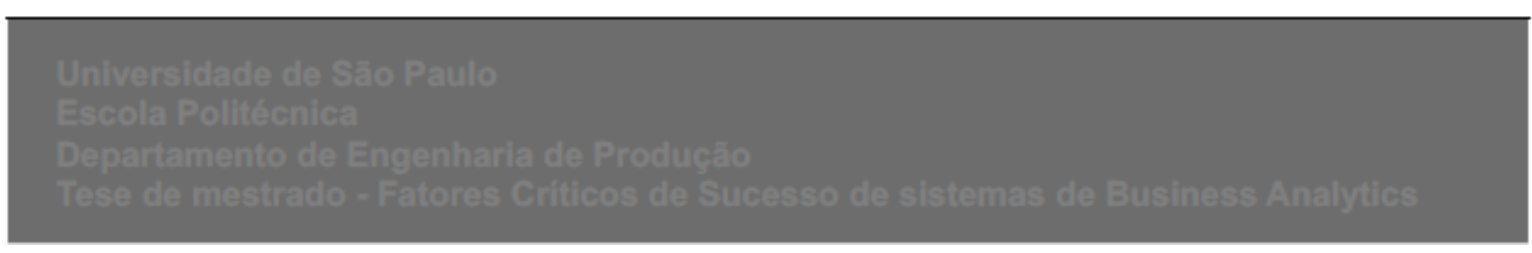




\section{Introdução}

Olá,

Esta pesquisa faz parte do estudo de campo sobre Fatores Criticos de Sucesso de sistemas de Business Analytics do programa de pós graduaçăo em Gestão da Tecnologia da Informação da Universidade de São Paulo (USP) - Departamento de Engenharia de produção da escola politécnica.

Através da revisão bibliográfica e da pesquisa com profissionais da área, este trabalho tem como objetivo identificar variáveis (e suas respectivas intensidades) que influenciam no sucesso de sistemas de Business Analytics. Além de contribuir com a estruturação de uma ferramenta de mensuração de sucesso deste tipo de Sistema de Informação.

Este instrumento de pesquisa foi estruturado em três partes: Introdução, Informações gerais do respondente e Questionário;

As informaçōes gerais do respondente têm como objetivo analisar possiveis tendências de resposta de acordo com o perfil do respondente (ex: Setor de atuaçāo, Idade e Grau de instrução) e análise da diversidade da amostra.

Vale ressaltar que todas as informaçōes serāo utilizadas unicamente para fins acadêmicos, e todos participantes que responderem o questionário receberão um sumário dos resultados. Além de poder consultar o trabalho final da dissertação no site: http:/hww.teses.usp.br.

A pesquisa tem duração aproximada de 15 min.

É importante ressaltar que questionários incompletos infelizmente nāo podem ser considerados no estudo, por isso reforço a necessidade da finalização da pesquisa.

Obrigado pela participaçăo, e qualquer dúvida estou à disposição!

Cezar Sayão

Aluno de Mestrado - Departamento de Engenharia de Produçăo - USP

cezar.sayao@gmail.com

Renato de Oliveira Moraes

Professor e Orientador - Departamento de Engenharia de Produção - USP

Curriculo Lattes 


\section{Informaçōes Gerais do respondente}

1. Nome (opcional)

2. E-mail para contato

Campo necessario para o envio do resultado da pesquisa

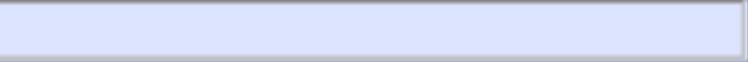

3. Gênero

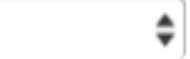

4. Em que estado brasileiro você mora?

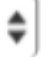

5. Qual é a sua idade?

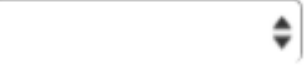

6. Qual o nível de escolaridade mais alto que você concluiu ou o diploma mais alto que recebeu?

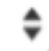

7. Qual das seguintes opções melhor descreve o setor principal da sua empresa?

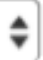

8. Qual das seguintes opçőes melhor descreve o nível do seu cargo atual?

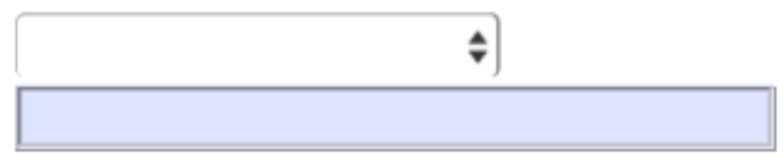

9. Qual classificação melhor representa o porte da empresa em que você atua? 
10. Você já teve interação com sistemas de Business Analytics (BA), Business Intelligence (BI) ou Big Data?

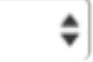

11. Quais atividades melhor caracterizam sua interação com este(s) sistema(s)?

Desenvolvimento e/ou suporte do sistema (ex: Integraçăo de sistemas, gestão de banco de dados, desenvolvimento de interfaces com usuários, etc)

Desenvolvimento de modelagens matemáticas e estatisticas

Estruturação de relatórios e análises com base nas informaçōes disponibilizadas pelo sistema

12. Quais funcionalidades estão presentes nesta(s) ferramenta(s)?

1. Modelagens de otimizaçāo

(Uso de dados, algoritmos matemáticos e estatisticos para encontrar boas soluçōes de problemas complexos - ex: Sequenciamento de produção, Desenho de malhas logisticas, etc)

Análises Prescritivas

(Uso de dados, algoritmos estatísticos e técnicas de computação para gerar recomendaçōes de ações para o usuário - ex: Alteraçāo de um preço de venda, Sugestão de produtos à serem ofertados para um cliente, Sugestäo de um medicamento para um paciente, etc)

Análises Preditivas

(Uso de dados, algoritmos estatísticos e técnicas de computação para identificar a probabilidade de resultados futuros com base em dados históricos. Ex: Previsāo de demanda, Crescimento populacional, etc)

Análises estatísticas simples

(ex: Indicadores de Média, Moda e desvio padrão)

Visualizaçăo dos dados em distintos graus de granularidade (Drill up e Drill Down)

(ex: Faturamento por pais, por estado e por cidades)

Relatórios padrão e/ou customizados da base de dados 


\section{Sucesso de Sistemas de Informação}

\section{Qualidade do Sistema}

Aspectos técnicos da ferramenta de Business Analytics, tais como confiabilidade, flexibilidade, integração, tempo de resposta e acessibilidade.

13. Avalie a qualidade do sistema

$\begin{gathered}\text { Discordo } \\ \text { plenamente }\end{gathered}$
$\begin{aligned} & \text { O SI trabalha de forma } \\ & \text { confiável }\end{aligned}$
$\begin{aligned} & \text { O SI opera de forma } \\ & \text { confiável }\end{aligned}$
$\begin{aligned} & \text { A operação do sistema é } \\ & \text { estável }\end{aligned}$
$\begin{aligned} & \text { O sistema se adapta } \\ & \text { para atender às minhas } \\ & \text { necessidades }\end{aligned}$

O sistema pode se ajustar de forma flexível à novas condiçōes $\mathrm{e}$ demandas

O sistema é versátil no atendimento de novas necessidades conforme elas aparecem

O sistema efetivamente integra dados de diferentes áreas da empresa

O sistema consolida informaçōes que anteriormente eram providas por diferentes áreas da empresa

O sistema efetivamente relaciona dados de diferentes áreas da empresa 


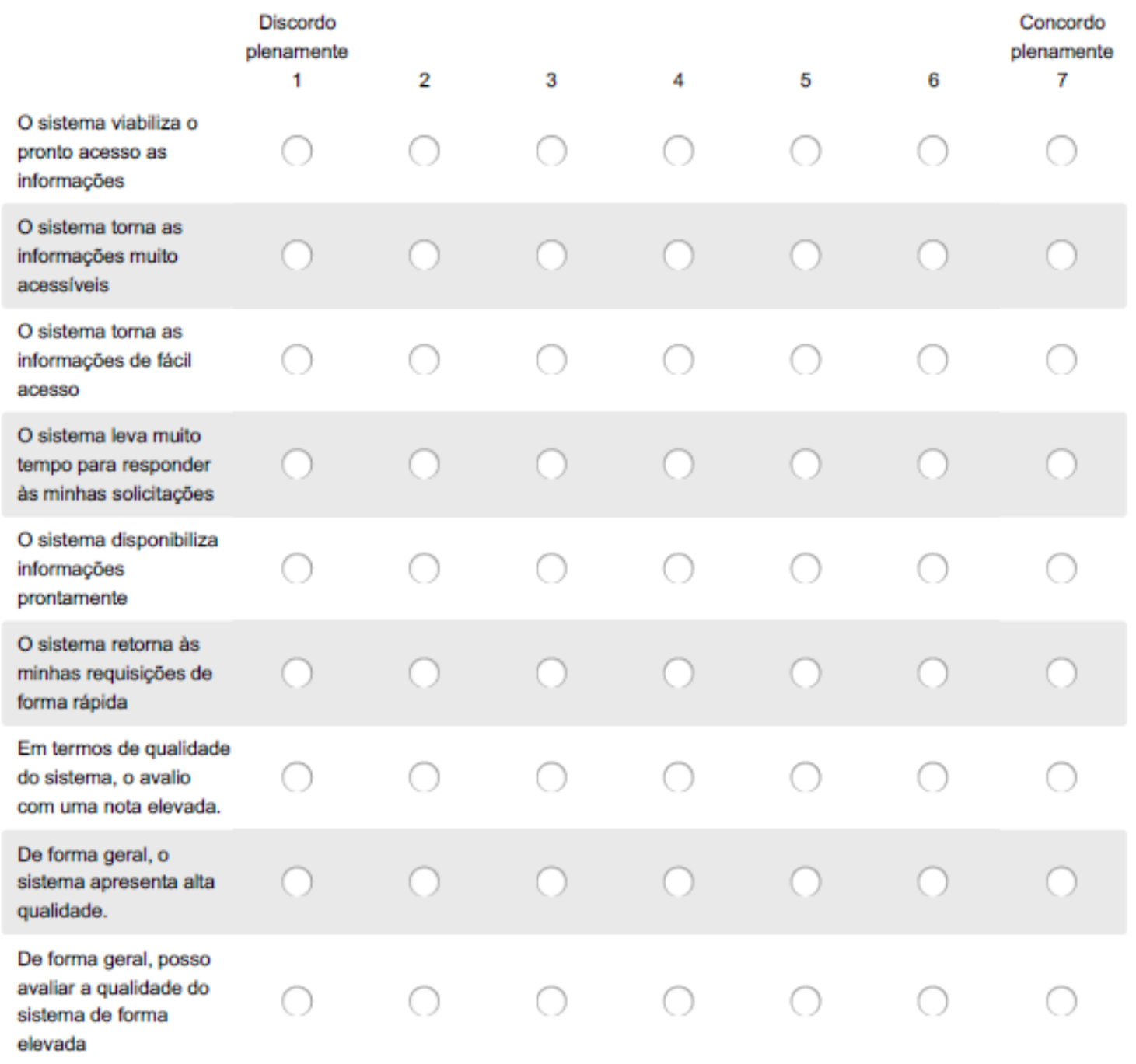




\section{Sucesso de Sistema de Informação}

\section{Qualidade da Informação}

Aspectos referentes a qualidade das informações geradas pelo sistema como acuracidade, completude, formato e grau de atualidade das informações

14. Avalie o sistema sobre a qualidade da informação

\begin{tabular}{|c|c|c|c|c|c|c|c|}
\hline & $\begin{array}{c}\text { Discordo } \\
\text { plenamente } \\
1\end{array}$ & 2 & 3 & 4 & 5 & 6 & $\begin{array}{c}\text { Concordo } \\
\text { plenamente } \\
7\end{array}$ \\
\hline $\begin{array}{l}\text { O SI fornece um } \\
\text { conjunto completo de } \\
\text { informaçōes. }\end{array}$ & & & & & & & \\
\hline $\begin{array}{l}\text { O SI produz } \\
\text { informaçōes } \\
\text { abrangentes. }\end{array}$ & & & & & & & \\
\hline $\begin{array}{l}\text { O SI prove todas as } \\
\text { informaçōes de que } \\
\text { preciso. }\end{array}$ & & & & & & & \\
\hline $\begin{array}{l}\text { O SI produz } \\
\text { informaçōes corretas. }\end{array}$ & & & & & & & \\
\hline $\begin{array}{l}\text { Existem poucos erros } \\
\text { nas informaçōes obtidas } \\
\text { do sistema. }\end{array}$ & & & & & & & \\
\hline $\begin{array}{l}\text { A informação provida } \\
\text { pelo SI é precisa. }\end{array}$ & & & & & & & \\
\hline $\begin{array}{l}\text { O SI me oferece as } \\
\text { informaçōes mais } \\
\text { recentes. }\end{array}$ & & & & & & & \\
\hline $\begin{array}{l}\text { O SI provê as mais } \\
\text { atuais informaçōes. }\end{array}$ & & & & & & & \\
\hline $\begin{array}{l}\text { A informação do SI está } \\
\text { sempre atualizada. }\end{array}$ & & & & & & & \\
\hline $\begin{array}{l}\text { A informação } \\
\text { disponibilizada pelo SI } \\
\text { é bem formatada. }\end{array}$ & & & & & & & \\
\hline $\begin{array}{l}\text { A informação } \\
\text { disponibilizada pelo SI } \\
\text { apresenta bom lay-out. }\end{array}$ & & & & & & & \\
\hline
\end{tabular}


Discordo

plenamente

A informação

disponibilizada pelo SI

é apresentada de forma clara no monitor.

De forma geral, posso avaliar o SI com uma boa nota.

De forma geral posso atribuir uma boa pontuação ao SI no quesito qualidade da informação.

No geral o SI me

fornece informaçōes de alta qualidade.

\section{C}

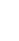

1

23

4

5

6

Concordo

plenamente

7

O O

()

()

()

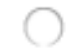

O

()

()

O

O

O

()

(2)

O

\begin{abstract}
()
\end{abstract}
O

()

()

()

000000




\section{Sucesso de Sistemas de Informação}

\section{Uso da informação}

Aplicação de informações adquiridas e transmitidas pelo sistema no processo organizacional de tomada de decisão

15. Avalie o sistema sobre o uso da Informação

\section{Discordo \\ plenamente}

1

2

A informação

disponibilizada pelo

sistema expōe os atuais

problemas dos

processos da empresa

e dão visibilidade para

todos os envolvidos.

A informação

disponibilizada pelo

sistema fornece

importantes inputs para

análises de desvio nos

processos da empresa

e para sua melhoria

continua.

A informação

disponibilizada pelo

sistema estimula a

inovaçăo dos processos

internos e externos da

empresa.

A informação

disponibilizada pelo

sistema reduz

incertezas no processo

de tomada de decisão,

aumenta a confiança $e$

melhora a efetividade

do processo

operacional.

A informação nos

possibilita menor tempo

de reação e pró-

atividade na realização

do planejamento da

empresa.

Concordo

plenamente

7

6 
A informação é utilizada para viabilizar

mudanças estratégicas e planos, modificar

indicadores pré-

existentes e mapear novos.

Através da gestão da informação do sistema é possivel agregar valor aos clientes finais.

Através da gestão da informação do sistema é possivel reduzir riscos.

Através da gestão da informação do sistema é possivel reduzir custos do processo. 


\section{Sucesso de Sistemas de Informação}

\section{Satisfação do usuário}

Grau de contentamento do usuário com relação ao sistema, o qual influencia a intenção de uso do mesmo.

16. Avalie o Sistema de informação de Business Analytics, sendo:

\begin{tabular}{|c|c|c|c|c|c|c|c|}
\hline & $\begin{array}{c}\text { Discordo } \\
\text { Plenamente } \\
1\end{array}$ & 2 & 3 & 4 & 5 & 6 & $\begin{array}{c}\text { Concordo Plenamente } \\
7\end{array}$ \\
\hline $\begin{array}{l}1=\text { Péssimo e } 7= \\
\text { Ótimo }\end{array}$ & & 2 & 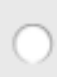 & $C$ & O & & O \\
\hline $1=$ Dificil e $7=$ Fácil & O & D & ( ) & O & ( ) & & O \\
\hline $\begin{array}{l}1=\text { Frustrante e } 7= \\
\text { Satisfatório }\end{array}$ & 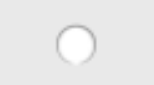 & & O & $\cap$ & 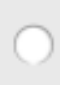 & & \\
\hline $\begin{array}{l}1=\text { Inadequado e } 7= \\
\text { Adequado }\end{array}$ & 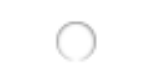 & & & $\bigcirc$ & O & & $C$ \\
\hline $\begin{array}{l}1=\text { Monótono e } 7 \\
=\text { Estimulante }\end{array}$ & $\cap$ & $\cap$ & $\Omega$ & O & 0 & $\cap$ & 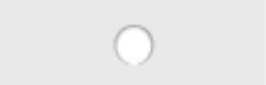 \\
\hline $\begin{array}{l}1=\text { Rigido e } 7 \\
=\text { Flexível }\end{array}$ & & 0 & () & O & O & & O \\
\hline
\end{tabular}

\section{Impacto individual}

Efeito causado pela informação fornecida pelo sistema no comportamento do usuário(receptor)

17. Avalie o sistema sobre o Impacto Individual

\begin{tabular}{|c|c|c|c|c|c|c|c|}
\hline & $\begin{array}{c}\text { Discordo } \\
\text { plenamente } \\
1\end{array}$ & 2 & 3 & 4 & 5 & 6 & $\begin{array}{c}\text { Concordo } \\
\text { plenamente } \\
7\end{array}$ \\
\hline $\begin{array}{l}\text { O SI alterou seu } \\
\text { trabalho } \\
\text { significativamente. }\end{array}$ & & & & & & & \\
\hline $\begin{array}{l}\text { O SI reduziu o tempo } \\
\text { necessário de analise } \\
\text { para o suporte à } \\
\text { decisäo. }\end{array}$ & & & & & & & \\
\hline $\begin{array}{l}\text { O SI reduziu o esforço } \\
\text { necessário de análises } \\
\text { para o suporte à } \\
\text { decisão. }\end{array}$ & & & & & & & \\
\hline
\end{tabular}




\section{Fatores Críticos de Sucesso Business Analytics}

\section{Qualidade dos dados}

Característica dos dados de entrada (Inputs) do sistema de Business Analytics

18. Avalie a qualidade dos dados de entrada do sistema de Business Analytics

$\begin{gathered}\text { Discordo } \\ \text { plenamente }\end{gathered}$
$\begin{aligned} & 1 \\ & \text { Os dados }\end{aligned}$

Existem poucos erros

nos dados

disponibilizados por outros sistemas para a ferramenta de Business Analytics.

Os dados disponibilizados por outros sistemas para a ferramenta de Business Analytics são assertivos.

O sistema de Business Analytics é provido de um conjunto completo de dados necessários.

O sistema de Business Analytics é abastecido com um conjunto de dados abrangentes.

O sistema de Business Analytics possui todos os dados necessários para seu

funcionamento.

Os dados abastecidos ao sistema de Business Analytics são os mais recentes. 


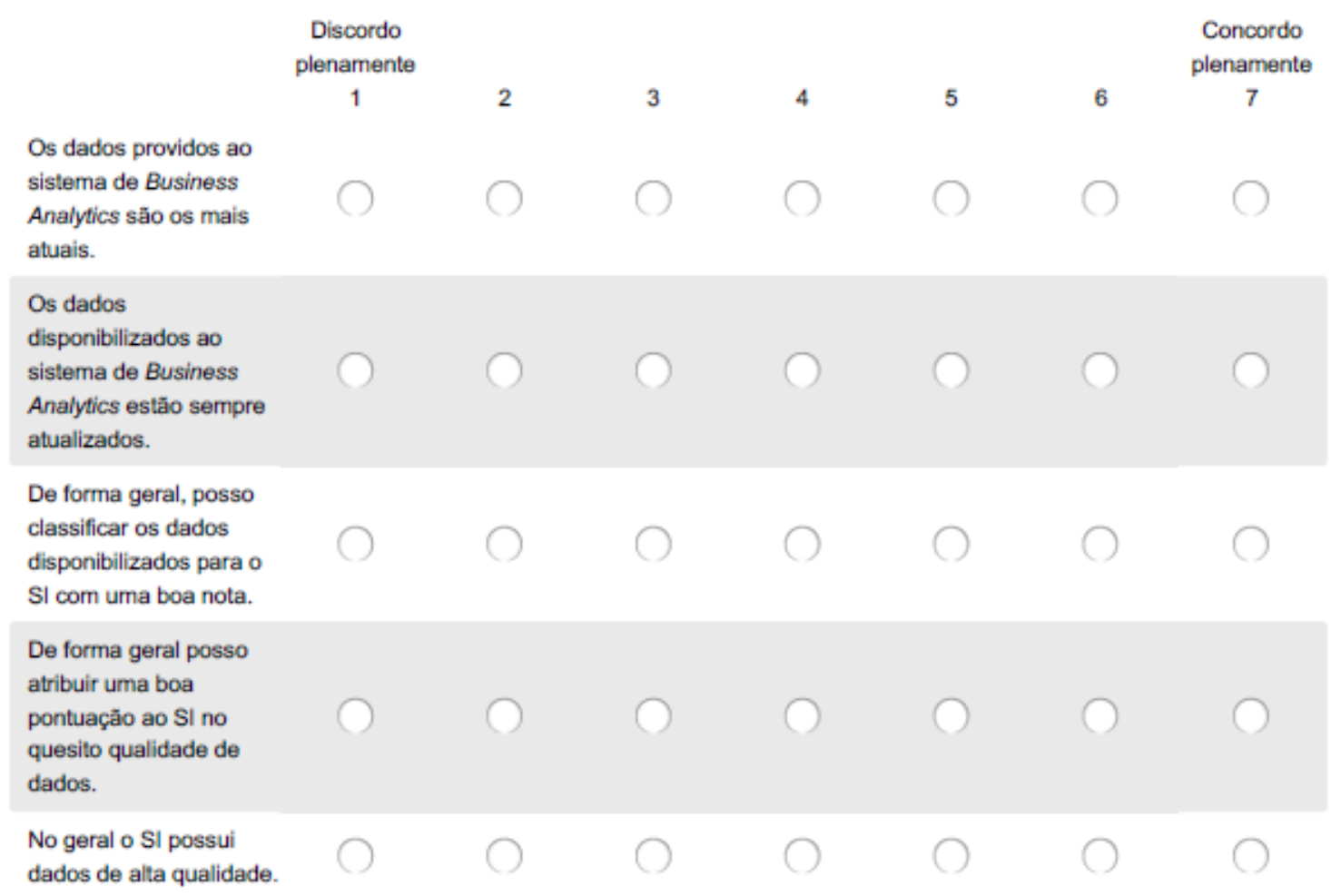




\section{Engajamento dos executivos}

Grau de relevância no tema e esforço empregado pelos executivos na implantação do sistema de Business Analytics.

19. Avalie o sistema de acordo com o engajamento dos executivos

Discordo

plenamente

1

A equipe gerencial suporta ativamente as atividades relacionadas à Business Analytics.

A equipe gerencial aceita a

responsabilidade sobre

Business Analytics.

A equipe gerencial considera Business Analytics uma forma de gerar vantagem competitiva.

A equipe gerencial participa ativamente das atividades relacionadas à Business Analytics.

Questōes referentes a Business Analytics são frequentemente discutidas nas reuniōes da equipe gerencial.

Concordo plenamente

5

4

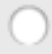

O O

()

O

O

()

()

O

()

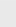

de

0

()

()

O

()

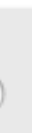

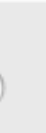




\section{Cultura organizacional de gestão baseada em fatos}

Ambiente de utilização proativa das informações no qual a tomada de decisão é realizada de forma racional e pautada em ampla análise das informações

20. Avalie a o grau de gestão baseada em fatos de sua organização

O processo de tomada
de decisäo está bem
estabelecido é é
conhecido por todos os
interessados.
Faz parte da politica
organizacional da
empresa incorporar
informaçōes disponiveis
em todo processo de
decisão.
Os gestores consideram
as informaçōes
fornecidas
indiferentemente do tipo
de decisäo à ser
tomada.

\section{Qualidade da equipe de Business Analytics}

Grau de conhecimento técnico e habilidades interpesssoais (ex: comunicação) da equipe de projeto do BA

21. Avalie a qualidade da equipe de Business Analytics do projeto

$\begin{gathered}\text { Discordo } \\ \text { plenamente }\end{gathered}$
$\begin{aligned} & \text { Os membros da equipe } \\ & \text { de BA têm os } \\ & \text { conhecimentos técnicos } \\ & \text { corretos. }\end{aligned}$
$\begin{aligned} & \text { Os membros da equipe } \\ & \text { de BA possuem boas } \\ & \text { habilidades } \\ & \text { interpessoais. }\end{aligned}$




\subsection{Análise dos dados}

Tabela 42 - Análise de Cross-Loadings (Rodada 1)

Fonte: Elaborado pelo autor

\begin{tabular}{|c|c|c|c|c|c|c|c|c|c|c|c|c|c|c|c|c|c|c|c|c|c|}
\hline & & & & & & & & & & & & & & & & & & & & & \\
\hline 1 & 926 & & & & 436 & 500 & 0,497 & 443 & 0,367 & 226 & 73 & 0,415 & 0,423 & 0,375 & 313 & & 61 & 0,240 & 03 & 438 & 483 \\
\hline $0 \_2$ & 14 & 40 & & & & & & & & & & & & & & & & & & & \\
\hline & & & & & & & & & & & & & & & & & & & & & \\
\hline$E_{1}$ 1 & & & & & & & & & & & & & & & & & & & & & \\
\hline 2 & & & & & & 47 & & & & & & & & & & & & & & & \\
\hline E_3 & 0,484 & & 43 & & & & 18 & & & 304 & & 351 & 294 & & 245 & 0 & & & & 0,40 & \\
\hline 4 & & & & & & 55 & & & & & & & & & & & & & & & \\
\hline 5 & 47. & & 48 & & & 386 & 376 & & & 262 & 292 & 376 & 296 & 0,295 & 251 & 26 & & 150 & 0,26 & & \\
\hline & & & & & & & & & & & & & & & & & & & & & \\
\hline & 0,409 & & & & 0,363 & 0,463 & 19 & & & 24 & 32 & 68 & 480 & 08 & 79 & 26 & 199 & 13 & 485 & 668 & 515 \\
\hline 3 & & & & & & \begin{tabular}{|l|}
0,413 \\
\end{tabular} & & & & & 396 & & & & & & & & & & \\
\hline$D_{-}$ & 2) & & 2 & & \begin{tabular}{|c|}
0,675 \\
\end{tabular} & 696 & 30 & 85 & & 53 & 996 & 93 & 144 & 16 & 39 & 33 & 00 & 45 & 470 & 996 & 539 \\
\hline D_2 & & & (1) & & & & & & & & & & & & & & & & & & \\
\hline D_3 & 0,426 & & 06 & & 89 & 667 & 18 & 40 & & 41 & 97 & 576 & 50 & 0,533 & 75 & 67 & & & 415 & & \\
\hline D_AC & 0,374 & & & & 34 & & 50 & & & 544 & 871 & & & 419 & & & & & 24 & 0,39 & \\
\hline & & & & & & & & & & & 155 & & & & & & & & & & \\
\hline $\bar{D}$ & 375 & & & & 945 & 637 & 37 & 376 & & 0.552 & 476 & 476 & 42 & 150 & 396 & & 3 & & & & 384 \\
\hline $\overrightarrow{A A}$ & & & & & & & & & & & & & & & & & & & & & \\
\hline 2D_AT2 & 0,474 & 58 & 14 & & 623 & ,937 & 687 & 136 & & 0,501 & 646 & 419 & 456 & 0,515 & 489 & 361 & 391 & 0,391 & \begin{tabular}{|l|}
0,386 \\
\end{tabular} &, 42 & 427 \\
\hline QD_AT3 & & & & & & & & & & & & & & & & & & & & & \\
\hline QD_C & 72 & & & & 0,728 & 613 & 990 & 554 & & 511 & 506 & 40 & & 501 & 889 & 449 & & 0,326 & 400 &, 47 & 43 \\
\hline C & & & & & & & & & & & & & & & & & & & & & \\
\hline D_C3 & 144 & 97 & 23 & & 0,609 & 675 & 62 & 80 & & 001 & 453 & 175 & 407 & 0,515 & 473 & 93 & 374 & 0,343 & 386 & 452 & 413 \\
\hline E_1 & & & & & & & & & & & & & & & & & & & & & \\
\hline E_2 & 0,423 & & t & & & 97 & & & & & 49 & & & & 02 & 307 & & & 325 & 430 & 377 \\
\hline & & & & & & & & & & & & & & & & & & & & & \\
\hline 12 & & & & & 0 & I0 & $1 / 5$ & & & & 302 & & & & & & & & & & \\
\hline 13 & & & & & 471 & 502 & 5 & 20 & & 0,699 & \begin{tabular}{l|l|}
778 \\
\end{tabular} & & 0 & & 574 & & 0 & & 0,54 & & 578 \\
\hline QI_AC & & & & & & 20 & 58 & & & 902 & 226 & & & & & & & & & & \\
\hline IIA & 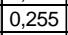 & & & & 0,522 & 0,464 & 30 & 55 & & 0,898 & 597 & 221 & , & , & 488 & & & & 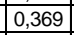 & & 114 \\
\hline 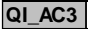 & & & & & & & 68 & & & & & & & & & & & & & & \\
\hline IA & 30 & 68 & 26 & & 324 & ,484 & 881 & 54 & & 0,527 & 852 & 422 & 0,471 & 0,492 & 479 & 0 & 10 & 364 & ,379 & 361 & 371 \\
\hline$\hat{n}$ & & & & & & & & & & & & & & & & & & & & & \\
\hline AT & 157 & & & & 24 & 691 & 25 & & & 98 & 计 & 548 & 341 & 0,581 & 66 & & & & 3 & & \\
\hline & & & & & & & & & & & & & & & & & & & & & \\
\hline $\mathrm{C} 2$ & & & & & & & 11 & & & 59 & 55 & 9 & & & 50 & & & & 40 & & \\
\hline$=$ & & & & & & 0 & 20 & & & 0,561 & 3 & & & 0,599 & & & & & & & \\
\hline QIF1 & & & & & & & & & & 05 & 4 & & & & & & & & & & \\
\hline F2 & & & & & & 423 & & & & 0,500 & & & & 0, & & & & & & & \\
\hline F3 & & & & & & & & & & 857 & 70 & & 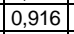 & 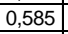 & 622 & & & & t & & \\
\hline 1 & & & & & & 645 & & 84 & & & 575 & & & & 712 & & & & & & \\
\hline & & & & & & & & & & & & & & & & & & & & & \\
\hline S_3 & & & & & & & & & & & & & & & & & & & & & \\
\hline & & & & & & & & & & & & & & & & & & & & & \\
\hline A & & & & & & & & & & & & & & & & & & & 80 & & 455 \\
\hline & & & & & & & & & & & & & & & & & & & & & \\
\hline & & & & & & & & & & & & & & & & & & & & & \\
\hline & & & & & & & & & & & & & & & & & & & & & \\
\hline & & & & & & & & & & & & & & & & & & & & & \\
\hline & & & & & & & & & & & & & & & & & & & & & \\
\hline & & & & & & & & & & & & & & & & & & & & & \\
\hline & & & & & & & & & & & & & & & & & & & & & \\
\hline & & & & & & & & & & & & & & & & & & & & & \\
\hline$s_{1}$ & & & & & & & & & & & & & & & & & & & & & \\
\hline & & & & & & & & & & & & & & & & & & & & & \\
\hline & & & & & & & & & & & & & & & & & & & & & \\
\hline & & & & & & & & & & & & & & & & & & & & & \\
\hline & & & & & & & & & & & & & & & & & & & & & \\
\hline & & & & & & & & & & & & & & & & & & & & & \\
\hline & & & & & & & & & & & & & & & & & & & & & \\
\hline & & & & & & & & & & & & & & & & & & & & & \\
\hline & & & & & & 12 & & & & 87 & & & & 0, & 515 & 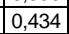 & 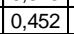 & 426 &, 37 & & 572 \\
\hline & & & & & & & & & & & & & & & & & & & & & \\
\hline & & & & & & 23 & 54 & & & 44 & & & & & & T & J & 405 & 384 & f & 540 \\
\hline & & & & & & & & & & & & & & & & & & & & & \\
\hline & & & & & & & & & & & & & & & & & & 4 & & & \\
\hline & & & & & & & & & & & & & & & & & & & & & \\
\hline & & & & & & & & & & & & & & & & & & & & & \\
\hline & & & & & & & & & & & & & & & & & & & & & \\
\hline & & & & & & & & & & & & & & & & & & & & & \\
\hline & & & & & & & & & & & & & & 33 & & 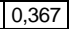 & 440 & 344 & 0,3 &, 5 & 824 \\
\hline & & & & & & & & & & & & & & & & & & 5 & & & \\
\hline & 301 & 14 & 90 & 104 & 280 & 301 & 14 & 315 & $40 /$ & 368 & 293 & 39 & $\overline{34}$ & 46 & 316 & 31 & 0,553 & 0,393 & 265 & , 42 &,$/ 3$ \\
\hline
\end{tabular}


Tabela 43 - Análise de Fornell-Lacker (Rodada 1)

Fonte: Elaborado pelo autor

\begin{tabular}{|c|c|c|c|c|c|c|c|c|c|c|c|c|c|c|c|c|c|c|c|c|c|}
\hline & $\mathrm{CO}$ & EE & II & QD & QD_AC & QD_AT & QD_C & QE & QI & QI_AC & QI_AT & QI_C & QI_F & QS & QS_A & QS_C & QS_F & QS_I & QS_TR & SU & UI \\
\hline $\mathrm{CO}$ & 0,911 & & & & & & & & & & & & & & & & & & & & \\
\hline EE & 0,598 & 0,836 & & & & & & & & & & & & & & & & & & & \\
\hline II & 0,389 & 0,452 & \begin{tabular}{l|l|}
0,892 \\
\end{tabular} & & & & & & & & & & & & & & & & & & \\
\hline QD & 0,430 & 0,446 & 0,579 & 0,945 & & & & & & & & & & & & & & & & & \\
\hline QD_AC & 0,390 & 0,285 & 0,378 & 0,732 & 0,930 & & & & & & & & & & & & & & & & \\
\hline QD_AT & 0,505 & 0,418 & 0,446 & 0,735 & 0,672 & 0,935 & & & & & & & & & & & & & & & \\
\hline QD_C & 0,455 & 0,433 & 0,528 & 0,767 & 0,734 & 0,734 & 0,881 & & & & & & & & & & & & & & \\
\hline QE & 0,466 & 0,461 & 0,366 & 0,488 & 0,368 & 0,491 & 0,421 & 0,902 & & & & & & & & & & & & & \\
\hline QI & 0,361 & 0,426 & 0,627 & 0,665 & 0,518 & 0,548 & 0,605 & 0,472 & 0,938 & & & & & & & & & & & & \\
\hline QI_AC & 0,313 & 0,335 & 0,545 & 0,676 & 0,574 & 0,538 & 0,606 & 0,346 & 0,785 & 0,913 & & & & & & & & & & & \\
\hline QI_AT & 0,443 & 0,393 & 0,425 & 0,534 & 0,503 & 0,664 & 0,543 & 0,390 & 0,625 & 0,670 & 0,876 & & & & & & & & & & \\
\hline QI_C & 0,369 & 0,417 & 0,586 & 0,623 & 0,463 & 0,471 & 0,570 & 0,367 & 0,715 & 0,637 & 0,575 & \begin{tabular}{|l|}
0,904 \\
\end{tabular} & & & & & & & & & \\
\hline QI_F & 0,373 & 0,352 & 0,450 & 0,482 & 0,431 & 0,487 & 0,489 & 0,441 & 0,727 & 0,603 & 0,598 & 0,566 & 0,933 & & & & & & & & \\
\hline QS & 0,390 & 0,433 & 0,655 & 0,609 & 0,441 & 0,562 & 0,586 & 0,493 & 0,835 & 0,654 & 0,615 & 0,673 & 0,650 & 0,965 & & & & & & & \\
\hline QS_A & 0,334 & 0,379 & 0,581 & 0,540 & 0,432 & 0,535 & 0,550 & 0,444 & 0,681 & 0,611 & 0,581 & 0,516 & 0,659 & 0,713 & \begin{tabular}{|l|}
0,868 \\
\end{tabular} & & & & & & \\
\hline QS_C & 0,254 & 0,329 & 0,566 & 0,528 & 0,483 & 0,411 & 0,486 & 0,390 & 0,658 & 0,619 & 0,447 & 0,553 & 0,518 & 0,667 & 0,550 & 0,911 & & & & & \\
\hline QS_F & 0,338 & 0,392 & 0,506 & 0,568 & 0,340 & 0,435 & 0,455 & 0,361 & 0,625 & 0,463 & 0,459 & 0,634 & 0,531 & 0,647 & 0,483 & 0,495 & 0,928 & & & & \\
\hline QS_I & 0,267 & 0,277 & 0,465 & 0,407 & 0,244 & 0,398 & 0,401 & 0,429 & 0,514 & 0,390 & 0,411 & 0,475 & 0,427 & 0,577 & 0,497 & 0,431 & 0,561 & 0,896 & & & \\
\hline QS_TR & \begin{tabular}{l|l}
0,312 \\
\end{tabular} & 0,355 & 0,482 & 0,460 & 0,361 & 0,429 & 0,443 & \begin{tabular}{|l|}
0,427 \\
\end{tabular} & 0,641 & 0,528 & 0,507 & 0,473 & 0,600 & 0,702 & 0,699 & 0,510 & 0,468 & 0,327 & 0,806 & & \\
\hline SU & 0,446 & 0,419 & 0,687 & 0,625 & 0,396 & 0,491 & 0,532 & 0,478 & 0,699 & 0,560 & 0,489 & 0,600 & 0,579 & 0,675 & 0,600 & 0,571 & 0,628 & 0,477 & 0,516 & 0,797 & \\
\hline UI & 0,476 & 0,529 & 0,669 & 0,551 & 0,362 & 0,456 & 0,492 & 0,471 & 0,681 & 0,516 & 0,470 & 0,612 & 0,559 & 0,721 & 0,530 & 0,497 & 0,639 & 0,490 & \begin{tabular}{|l|}
0,442 \\
\end{tabular} & 0,659 & 0,788 \\
\hline
\end{tabular}


Tabela 44 - Análise de HTMT

Fonte: Elaborado pelo autor

\begin{tabular}{|c|c|c|c|c|c|c|c|c|c|c|c|c|c|c|c|c|c|c|c|c|c|}
\hline & $\mathrm{CO}$ & EE & II & QD & QD_AC & QD_AT & QD_C & QE & QI & QI_AC & QI_AT & QI_C & QI_F & QS & QS_A & QS_C & QS_F & QS_I & QS_TR & SU & UI \\
\hline \multicolumn{22}{|l|}{$\mathrm{CO}$} \\
\hline EE & 0,666 & & & & & & & & & & & & & & & & & & & & \\
\hline II & 0,435 & 0,505 & & & & & & & & & & & & & & & & & & & \\
\hline QD & 0,466 & 0,487 & 0,639 & & & & & & & & & & & & & & & & & & \\
\hline QD_AC & 0,423 & 0,313 & 0,417 & 0,781 & & & & & & & & & & & & & & & & & \\
\hline QD_AT & 0,551 & 0,458 & 0,492 & 0,783 & 0,725 & & & & & & & & & & & & & & & & \\
\hline QD_C & 0,518 & 0,498 & 0,608 & 0,850 & 0,819 & 0,824 & & & & & & & & & & & & & & & \\
\hline QE & 0,560 & 0,550 & \begin{tabular}{l|l}
0,442 \\
\end{tabular} & 0,575 & 0,440 & 0,583 & 0,522 & & & & & & & & & & & & & & \\
\hline QI & 0,396 & 0,463 & 0,694 & 0,710 & 0,555 & 0,589 & 0,675 & 0,555 & & & & & & & & & & & & & \\
\hline QI_AC & 0,345 & 0,370 & 0,612 & 0,734 & 0,629 & 0,586 & 0,683 & 0,412 & 0,853 & & & & & & & & & & & & \\
\hline QI_AT & 0,501 & 0,443 & 0,490 & 0,594 & 0,561 & 0,741 & 0,629 & 0,476 & 0,700 & 0,764 & & & & & & & & & & & \\
\hline QI_C & 0,411 & 0,469 & 0,664 & 0,681 & 0,507 & 0,519 & 0,652 & 0,439 & 0,786 & 0,710 & 0,658 & & & & & & & & & & \\
\hline QI_F & 0,407 & 0,385 & \begin{tabular}{|l|}
0,498 \\
\end{tabular} & 0,515 & 0,463 & 0,523 & 0,545 & 0,519 & 0,779 & 0,655 & 0,671 & 0,622 & & & & & & & & & \\
\hline QS & 0,419 & 0,461 & 0,714 & 0,640 & 0,465 & 0,594 & 0,646 & 0,567 & 0,879 & 0,697 & 0,678 & 0,728 & 0,685 & & & & & & & & \\
\hline QS_A & 0,384 & 0,432 & 0,678 & 0,606 & 0,487 & 0,603 & 0,648 & 0,550 & 0,768 & 0,697 & 0,686 & 0,593 & 0,744 & 0,792 & & & & & & & \\
\hline QS_C & 0,282 & 0,365 & 0,641 & 0,575 & 0,530 & 0,448 & 0,552 & 0,465 & 0,720 & 0,684 & 0,510 & 0,618 & 0,564 & 0,716 & 0,632 & & & & & & \\
\hline QS_F & 0,370 & 0,432 & 0,561 & 0,608 & 0,361 & 0,468 & 0,509 & 0,427 & 0,672 & 0,504 & 0,517 & 0,701 & 0,573 & 0,685 & 0,545 & 0,540 & & & & & \\
\hline QS_I & 0,299 & 0,306 & 0,534 & 0,447 & 0,265 & 0,440 & 0,463 & 0,517 & 0,566 & 0,438 & 0,476 & 0,535 & 0,473 & 0,624 & 0,581 & 0,484 & 0,619 & & & & \\
\hline QS_TR & 0,349 & 0,398 & 0,557 & 0,489 & 0,402 & 0,466 & 0,504 & 0,516 & 0,706 & 0,589 & 0,594 & 0,531 & 0,645 & 0,765 & 0,830 & 0,579 & 0,501 & 0,376 & & & \\
\hline SU & 0,503 & 0,473 & 0,772 & 0,683 & 0,438 & 0,543 & 0,616 & 0,583 & 0,763 & 0,626 & 0,566 & 0,676 & 0,645 & 0,724 & 0,696 & 0,640 & 0,699 & 0,538 & 0,577 & & \\
\hline UI & 0,516 & 0,572 & 0,744 & 0,587 & 0,381 & 0,484 & 0,545 & 0,550 & 0,722 & 0,557 & 0,521 & 0,673 & 0,597 & 0,756 & 0,593 & 0,537 & 0,694 & 0,539 & \begin{tabular}{|l|}
0,482 \\
\end{tabular} & 0,713 & \\
\hline
\end{tabular}


Tabela 45 - Análise de significância HTMT (Rodada 1)

\begin{tabular}{|c|c|c|c|c|}
\hline & $\begin{array}{l}\text { Original } \\
\text { Sample }\end{array}$ & $\begin{array}{c}\text { Sample } \\
\text { Mean }\end{array}$ & $2.5 \%$ & $97.5 \%$ \\
\hline $\mathrm{EE}>\mathrm{CO}$ & 0,666 & 0,666 & 0,552 & 0,759 \\
\hline$\| I \rightarrow C O$ & 0,435 & 0,440 & 0,275 & 0,593 \\
\hline $\mathrm{II} \rightarrow \mathrm{EE}$ & 0,505 & 0,508 & 0,376 & 0,628 \\
\hline$Q D \rightarrow C O$ & 0,466 & 0,471 & 0,323 & 0,606 \\
\hline$Q D \rightarrow E E$ & 0,487 & 0,490 & 0,356 & 0,613 \\
\hline$Q D \rightarrow I I$ & 0,639 & 0,636 & 0,495 & 0,750 \\
\hline QD_AC $>$ CO & 0,423 & 0,425 & 0,261 & 0,572 \\
\hline QD_AC $\rightarrow$ EE & 0,313 & 0,316 & 0,166 & 0,470 \\
\hline QD_AC $\rightarrow$ II & 0,417 & 0,416 & 0,248 & 0,570 \\
\hline QD_AC $>Q D$ & 0,781 & 0,782 & 0,707 & 0,851 \\
\hline QD_AT $>$ CO & 0,551 & 0,553 & 0,429 & 0,663 \\
\hline QD_AT $>$ EE & 0,458 & 0,461 & 0,322 & 0,591 \\
\hline QD_AT $>$ II & 0,492 & 0,491 & 0,330 & 0,634 \\
\hline QD_AT $>$ QD & 0,783 & 0,788 & 0,627 & 0,903 \\
\hline QD_AT $>$ QD_AC & 0,725 & 0,724 & 0,632 & 0,804 \\
\hline QD_C $\rightarrow C O$ & 0,518 & 0,521 & 0,383 & 0,644 \\
\hline QD_C $>$ EE & 0,498 & 0,501 & 0,350 & 0,641 \\
\hline QD_C $>$ II & 0,608 & 0,606 & 0,476 & 0,718 \\
\hline QD_C $>$ QD & 0,850 & 0,852 & 0,753 & 0,930 \\
\hline QD_C $>$ QD_AC & 0,819 & 0,819 & 0,735 & 0,887 \\
\hline QD_C $>$ QD_AT & 0,824 & 0,825 & 0,744 & 0,894 \\
\hline$Q E>C O$ & 0,560 & 0,563 & 0,399 & 0,710 \\
\hline QE $>$ EE & 0,550 & 0,552 & 0,412 & 0,684 \\
\hline QE $>$ II & 0,442 & 0,445 & 0,288 & 0,599 \\
\hline$Q E$ $>$ QD & 0,575 & 0,579 & 0,429 & 0,719 \\
\hline QE $>$ > QD_AC & 0,440 & 0,441 & 0,294 & 0,579 \\
\hline QE $>$ > QD_AT & 0,583 & 0,585 & 0,467 & 0,695 \\
\hline$Q E->$ QD_C & 0,522 & 0,525 & 0,386 & 0,656 \\
\hline $\mathrm{QI} \rightarrow \mathrm{CO}$ & 0,396 & 0,399 & 0,259 & 0,539 \\
\hline QI $\rightarrow$ EE & 0,463 & 0,466 & 0,343 & 0,587 \\
\hline QI $>$ II & 0,694 & 0,693 & 0,585 & 0,788 \\
\hline $\mathrm{QI} \rightarrow \mathrm{QD}$ & 0,710 & 0,710 & 0,612 & 0,799 \\
\hline QI $\rightarrow$ QD_AC & 0,555 & 0,554 & 0,424 & 0,673 \\
\hline QI $\rightarrow$ QD_AT & 0,589 & 0,589 & 0,458 & 0,703 \\
\hline$Q I \Rightarrow Q D \_C$ & 0,675 & 0,674 & 0,574 & 0,763 \\
\hline $\mathrm{QI} \rightarrow \mathrm{QE}$ & 0,555 & 0,558 & 0,421 & 0,681 \\
\hline QI_AC $>$ CO & 0,345 & 0,348 & 0,203 & 0,487 \\
\hline QI_AC $>$ EE & 0,370 & 0,372 & 0,225 & 0,514 \\
\hline QI_AC $>>$ II & 0,612 & 0,610 & 0,481 & 0,725 \\
\hline QI_AC $>$ QD & 0,734 & 0,733 & 0,651 & 0,804 \\
\hline QI_AC $\rightarrow$ QD_AC & 0,629 & 0,628 & 0,497 & 0,744 \\
\hline QI_AC $>$ QD_AT & 0,586 & 0,585 & 0,452 & 0,705 \\
\hline QI_AC $\rightarrow$ QD_C & 0,683 & 0,681 & 0,582 & 0,767 \\
\hline QI_AC $>$ QE & 0,412 & 0,415 & 0,272 & 0,553 \\
\hline Ql_AC $>$ Q Q & 0,853 & 0,853 & 0,771 & 0,918 \\
\hline Ql_AT $\rightarrow$ CO & 0,501 & 0,502 & 0,382 & 0,616 \\
\hline QI_AT $>$ EE & 0,443 & 0,446 & 0,307 & 0,580 \\
\hline QI_AT $>>$ II & 0,490 & 0,491 & 0,340 & 0,627 \\
\hline QI_AT -> QD & 0,594 & 0,600 & 0,445 & 0,732 \\
\hline QI_AT $>$ QD_AC & 0,561 & 0,562 & 0,442 & 0,669 \\
\hline QI_AT $\rightarrow$ QD_AT & 0,741 & 0,742 & 0,643 & 0,831 \\
\hline QI_AT $>$ QD_C & 0,629 & 0,631 & 0,516 & 0,732 \\
\hline QI_AT $>$ QE & 0,476 & 0,479 & 0,329 & 0,628 \\
\hline QI_AT $>$ QI & 0,700 & 0,703 & 0,599 & 0,791 \\
\hline QI_AT $>$ Q QI_AC & 0,764 & 0,768 & 0,673 & 0,857 \\
\hline QI_C $>$ CO & 0,411 & 0,416 & 0,265 & 0,558 \\
\hline QI_C $>$ EE & 0,469 & 0,471 & 0,321 & 0,609 \\
\hline QI_C $>$ II & 0,664 & 0,663 & 0,544 & 0,767 \\
\hline QI_C $>$ QD & 0,681 & 0,679 & 0,559 & 0,781 \\
\hline QI_C $>$ QD_AC & 0,507 & 0,505 & 0,366 & 0,630 \\
\hline QI_C $>$ QD_AT & 0,519 & 0,522 & 0,367 & 0,666 \\
\hline QI_C $>$ QD_C & 0,652 & 0,652 & 0,532 & 0,762 \\
\hline QI_C $>$ QE & 0,439 & 0,444 & 0,293 & 0,593 \\
\hline QI_C $>$ Q Q & 0,786 & 0,787 & 0,699 & 0,870 \\
\hline QI_C $>$ QI_AC & 0,710 & 0,709 & 0,602 & 0,807 \\
\hline QI_C $>$ QI_AT & 0,658 & 0,661 & 0,519 & 0,782 \\
\hline QI_F $>$ CO & 0,407 & 0,408 & 0,284 & 0,519 \\
\hline QI_F $\rightarrow$ EE & 0,385 & 0,386 & 0,240 & 0,526 \\
\hline QI_F $>$ II & 0,498 & 0,500 & 0,369 & 0,612 \\
\hline QI_F $\rightarrow$ QD & 0,515 & 0,518 & 0,362 & 0,649 \\
\hline
\end{tabular}

\begin{tabular}{|c|c|c|c|c|}
\hline & \begin{tabular}{|l|} 
Original \\
Sample \\
\end{tabular} & \begin{tabular}{|c|} 
Sample \\
Mean
\end{tabular} & $2.5 \%$ & $97.5 \%$ \\
\hline QI_F $>$ QD_AC & 0,463 & 0,464 & 0,340 & 0,579 \\
\hline QI_F $>$ QD_AT & 0,523 & 0,523 & 0,404 & 0,634 \\
\hline QI_F $>$ QD_C & 0,545 & 0,545 & 0,429 & 0,654 \\
\hline QI_F $>$ QE & 0,519 & 0,518 & 0,370 & 0,656 \\
\hline QI_F $>>$ QI & 0,779 & 0,780 & 0,707 & 0,844 \\
\hline QI_F $>$ QI_AC & 0,655 & 0,656 & 0,557 & 0,750 \\
\hline QI_F $>$ QI_AT & 0,671 & 0,671 & 0,562 & 0,768 \\
\hline QI_F $>$ Ql_C & 0,622 & 0,625 & 0,487 & 0,746 \\
\hline QS $>$ CO & 0,419 & 0,422 & 0,280 & 0,557 \\
\hline$Q S$ > EE & 0,461 & 0,463 & 0,326 & 0,591 \\
\hline QS $\rightarrow$ II & 0,714 & 0,714 & 0,595 & 0,809 \\
\hline$Q S \rightarrow Q D$ & 0,640 & 0,642 & 0,479 & 0,775 \\
\hline QS $>$ PD_AC & 0,465 & 0,463 & 0,328 & 0,588 \\
\hline QS $>$ > QD_AT & 0,594 & 0,594 & 0,462 & 0,705 \\
\hline QS $>$ QD_C & 0,646 & 0,645 & 0,537 & 0,733 \\
\hline$Q S \rightarrow Q E$ & 0,567 & 0,570 & 0,433 & 0,687 \\
\hline QS $\rightarrow$ QI & 0,879 & 0,879 & 0,833 & 0,920 \\
\hline QS $>$ Q QI_AC & 0,697 & 0,697 & 0,584 & 0,798 \\
\hline QS $\rightarrow$ Ql_AT & 0,678 & 0,679 & 0,576 & 0,769 \\
\hline QS $\rightarrow$ QI_C & 0,728 & 0,730 & 0,594 & 0,838 \\
\hline QS $>$ Q QI_F & 0,685 & 0,685 & 0,600 & 0,761 \\
\hline QS_A $\rightarrow$ CO & 0,384 & 0,387 & 0,230 & 0,529 \\
\hline QS_A $>$ EE & 0,432 & 0,433 & 0,277 & 0,583 \\
\hline QS_A $\rightarrow$ II & 0,678 & 0,676 & 0,551 & 0,777 \\
\hline QS_A $\rightarrow$ QD & 0,606 & 0,608 & 0,443 & 0,742 \\
\hline QS_A $\rightarrow$ QD_AC & 0,487 & 0,487 & 0,338 & 0,620 \\
\hline QS_A $\rightarrow$ QD_AT & 0,603 & 0,603 & 0,471 & 0,725 \\
\hline QS_A $\rightarrow$ QD_C & 0,648 & 0,646 & 0,539 & 0,745 \\
\hline QS_A $>$ QE & 0,550 & 0,552 & 0,396 & 0,686 \\
\hline QS_A $\rightarrow$ QI & 0,768 & 0,767 & 0,680 & 0,843 \\
\hline QS_A $\rightarrow$ QI_AC & 0,697 & 0,697 & 0,586 & 0,793 \\
\hline QS_A $\rightarrow$ QI_AT & 0,686 & 0,688 & 0,578 & 0,789 \\
\hline QS_A $\rightarrow$ QI_C & 0,593 & 0,595 & 0,449 & 0,727 \\
\hline QS_A $\rightarrow$ QI_F & 0,744 & 0,746 & 0,662 & 0,818 \\
\hline QS_A $\rightarrow$ QS & 0,792 & 0,792 & 0,690 & 0,876 \\
\hline QS_C $>C O$ & 0,282 & 0,286 & 0,126 & 0,445 \\
\hline QS_C $\rightarrow$ EE & 0,365 & 0,367 & 0,224 & 0,505 \\
\hline QS_C $>$ II & 0,641 & 0,639 & 0,513 & 0,745 \\
\hline QS_C $>$ QD & 0,575 & 0,573 & 0,448 & 0,682 \\
\hline QS_C $\rightarrow$ QD_AC & 0,530 & 0,529 & 0,387 & 0,654 \\
\hline QS_C $\rightarrow$ QD_AT & 0,448 & 0,448 & 0,292 & 0,583 \\
\hline QS_C $\rightarrow$ QD_C & 0,552 & 0,550 & 0,427 & 0,662 \\
\hline QS_C $\rightarrow$ QE & 0,465 & 0,467 & 0,331 & 0,589 \\
\hline QS_C $>$ QI & 0,720 & 0,718 & 0,619 & 0,809 \\
\hline QS_C $>$ > QI_AC & 0,684 & 0,683 & 0,576 & 0,778 \\
\hline QS_C $>>$ QI_AT & 0,510 & 0,513 & 0,382 & 0,636 \\
\hline QS_C $\rightarrow$ QI_C & 0,618 & 0,617 & 0,486 & 0,737 \\
\hline QS_C $\rightarrow$ QI_F & 0,564 & 0,565 & 0,460 & 0,666 \\
\hline QS_C $>$ QS & 0,716 & 0,714 & 0,612 & 0,805 \\
\hline QS_C $\rightarrow$ QS_A & 0,632 & 0,630 & 0,502 & 0,744 \\
\hline QS_F $\rightarrow$ CO & 0,370 & 0,372 & 0,219 & 0,519 \\
\hline QS_F $>$ EE & 0,432 & 0,434 & 0,301 & 0,561 \\
\hline QS_F $>$ II & 0,561 & 0,559 & 0,449 & 0,664 \\
\hline$Q S \_F \rightarrow Q D$ & 0,608 & 0,606 & 0,495 & 0,703 \\
\hline QS_F $>$ QD_AC & 0,361 & 0,361 & 0,206 & 0,502 \\
\hline QS_F $>$ Q QD_AT & 0,468 & 0,469 & 0,308 & 0,611 \\
\hline QS_F $>$ QD_C & 0,509 & 0,510 & 0,385 & 0,622 \\
\hline QS_F $>$ QE & 0,427 & 0,429 & 0,274 & 0,575 \\
\hline QS_F $>$ QI & 0,672 & 0,671 & 0,586 & 0,749 \\
\hline QS_F $>$ QI_AC & 0,504 & 0,502 & 0,376 & 0,620 \\
\hline QS_F $>$ QI_AT & 0,517 & 0,517 & 0,379 & 0,648 \\
\hline QS_F $>$ Ql_C & 0,701 & 0,701 & 0,593 & 0,790 \\
\hline QS_F $>$ QI_F & 0,573 & 0,573 & 0,454 & 0,677 \\
\hline QS_F $\rightarrow$ QS & 0,685 & 0,683 & 0,582 & 0,771 \\
\hline QS_F $>$ QS_A & 0,545 & 0,547 & 0,417 & 0,662 \\
\hline QS_F $>$ QS_C & 0,540 & 0,540 & 0,409 & 0,651 \\
\hline QS_I $>$ CO & 0,299 & 0,304 & 0,143 & 0,466 \\
\hline QS_I $>$ EE & 0,306 & 0,312 & 0,150 & 0,471 \\
\hline QS_I > II & 0,534 & 0,534 & 0,380 & 0,671 \\
\hline QS_I $>$ QD & 0,447 & 0,451 & 0,282 & 0,614 \\
\hline
\end{tabular}

\begin{tabular}{|c|c|c|c|c|}
\hline & \begin{tabular}{|l|} 
Original \\
Sample
\end{tabular} & \begin{tabular}{|c|} 
Sample \\
Mean
\end{tabular} & $2.5 \%$ & $97.5 \%$ \\
\hline QS_I $>$ QD_AC & 0,265 & 0,269 & 0,114 & 0,419 \\
\hline QS_I $>$ QD_AT & 0,440 & 0,443 & 0,288 & 0,589 \\
\hline QS_I $>$ QD_C & 0,463 & 0,466 & 0,304 & 0,609 \\
\hline$Q S \_I>Q E$ & 0,517 & 0,518 & 0,365 & 0,671 \\
\hline QS_I $>$ QI & 0,566 & 0,568 & 0,424 & 0,689 \\
\hline QS_I $>$ QI_AC & 0,438 & 0,439 & 0,295 & 0,578 \\
\hline QS_I $>$ QI_AT & 0,476 & 0,480 & 0,325 & 0,630 \\
\hline QS_I $>$ QI_C & 0,535 & 0,539 & 0,363 & 0,698 \\
\hline QS_I $>$ QI_F & 0,473 & 0,474 & 0,311 & 0,621 \\
\hline$Q S \_I>Q S$ & 0,624 & 0,626 & 0,487 & 0,739 \\
\hline$Q S \_I \rightarrow$ QS_A & 0,581 & 0,583 & 0,419 & 0,724 \\
\hline$Q S \_I>Q S \_C$ & 0,484 & 0,485 & 0,324 & 0,636 \\
\hline$Q S \_I->Q S \_F$ & 0,619 & 0,622 & 0,488 & 0,740 \\
\hline QS_TR $\rightarrow$ CO & 0,349 & 0,368 & 0,230 & 0,521 \\
\hline QS_TR $\rightarrow$ EE & 0,398 & 0,415 & 0,260 & 0,582 \\
\hline QS_TR $\rightarrow$ II & 0,557 & 0,566 & 0,424 & 0,699 \\
\hline QS_TR $\rightarrow$ QD & 0,489 & 0,511 & 0,335 & 0,678 \\
\hline QS_TR $\rightarrow$ QD_AC & 0,402 & 0,419 & 0,274 & 0,572 \\
\hline QS_TR $\rightarrow$ QD_AT & 0,466 & 0,479 & 0,320 & 0,632 \\
\hline QS_TR $\rightarrow$ QD_C & 0,504 & 0,520 & 0,380 & 0,654 \\
\hline QS_TR $\rightarrow$ QE & 0,516 & 0,522 & 0,371 & 0,674 \\
\hline QS_TR $>$ QI & 0,706 & 0,712 & 0,606 & 0,817 \\
\hline QS_TR $\rightarrow$ QI_AC & 0,589 & 0,598 & 0,459 & 0,729 \\
\hline QS_TR $\rightarrow$ QI_AT & 0,594 & 0,602 & 0,469 & 0,737 \\
\hline QS_TR $\rightarrow$ QI_C & 0,531 & 0,553 & 0,390 & 0,730 \\
\hline QS_TR $\rightarrow$ QI_F & 0,645 & 0,660 & 0,548 & 0,780 \\
\hline QS_TR $\rightarrow$ QS & 0,765 & 0,770 & 0,653 & 0,877 \\
\hline QS_TR $\rightarrow$ QS_A & 0,830 & 0,836 & 0,726 & 0,938 \\
\hline QS_TR $\rightarrow$ QS_C & 0,579 & 0,583 & 0,450 & 0,712 \\
\hline QS_TR $\rightarrow$ QS_F & 0,501 & 0,520 & 0,375 & 0,673 \\
\hline QS_TR $\rightarrow$ QS_I & 0,376 & 0,398 & 0,237 & 0,563 \\
\hline $\mathrm{SU} \rightarrow \mathrm{CO}$ & 0,503 & 0,505 & 0,369 & 0,630 \\
\hline$S U \rightarrow E E$ & 0,473 & 0,474 & 0,339 & 0,595 \\
\hline SU $>$ II & 0,772 & 0,771 & 0,682 & 0,848 \\
\hline$S U \rightarrow Q D$ & 0,683 & 0,681 & 0,585 & 0,768 \\
\hline SU $\rightarrow$ QD_AC & 0,438 & 0,436 & 0,296 & 0,567 \\
\hline SU $>$ QD_AT & 0,543 & 0,543 & 0,421 & 0,661 \\
\hline$S U \rightarrow$ QD_C & 0,616 & 0,615 & 0,493 & 0,725 \\
\hline $\mathrm{SU} \rightarrow \mathrm{QE}$ & 0,583 & 0,585 & 0,443 & 0,713 \\
\hline SU $>$ QI & 0,763 & 0,761 & 0,668 & 0,843 \\
\hline SU $>$ Q QI_AC & 0,626 & 0,624 & 0,521 & 0,719 \\
\hline SU $>$ Q QI_AT & 0,566 & 0,568 & 0,448 & 0,680 \\
\hline SU $>$ Q Ql_C & 0,676 & 0,677 & 0,565 & 0,774 \\
\hline SU $>$ Q QI_F & 0,645 & 0,645 & 0,542 & 0,740 \\
\hline$S U \rightarrow Q S$ & 0,724 & 0,723 & 0,628 & 0,808 \\
\hline SU $\rightarrow$ QS_A & 0,696 & 0,695 & 0,597 & 0,786 \\
\hline SU $\rightarrow$ QS_C & 0,640 & 0,636 & 0,520 & 0,740 \\
\hline SU $\rightarrow$ QS_F & 0,699 & 0,699 & 0,604 & 0,784 \\
\hline SU $>$ QS_I & 0,538 & 0,540 & 0,403 & 0,666 \\
\hline SU $>$ QS_TR & 0,577 & 0,591 & 0,457 & 0,728 \\
\hline $\mathrm{UI} \rightarrow \mathrm{CO}$ & 0,516 & 0,518 & 0,387 & 0,638 \\
\hline$U I \rightarrow E E$ & 0,572 & 0,573 & 0,456 & 0,677 \\
\hline $\mathrm{UI} \rightarrow \mathrm{II}$ & 0,744 & 0,745 & 0,663 & 0,819 \\
\hline$U I \rightarrow Q D$ & 0,587 & 0,586 & 0,453 & 0,697 \\
\hline UI $\rightarrow$ QD_AC & 0,381 & 0,379 & 0,217 & 0,526 \\
\hline UI $\rightarrow$ QD_AT & 0,484 & 0,483 & 0,335 & 0,615 \\
\hline$U I$ $>$ QD_C & 0,545 & 0,544 & 0,413 & 0,657 \\
\hline $\mathrm{UI} \rightarrow \mathrm{QE}$ & 0,550 & 0,550 & 0,413 & 0,671 \\
\hline UI $\rightarrow$ Q I & 0,722 & 0,722 & 0,639 & 0,793 \\
\hline UI $\rightarrow$ QI_AC & 0,557 & 0,556 & 0,417 & 0,679 \\
\hline UI $\rightarrow$ QI_AT & 0,521 & 0,522 & 0,386 & 0,650 \\
\hline UI $\rightarrow$ QI_C & 0,673 & 0,674 & 0,573 & 0,759 \\
\hline UI $\rightarrow$ QI_F & $\begin{array}{ll}0,597 \\
\end{array}$ & 0,597 & 0,485 & 0,703 \\
\hline $\mathrm{UI} \rightarrow \mathrm{QS}$ & 0,756 & 0,756 & 0,678 & 0,820 \\
\hline$U I \rightarrow$ QS_A & 0,593 & 0,592 & 0,457 & 0,716 \\
\hline$U I \rightarrow$ QS_C & 0,537 & 0,537 & 0,412 & 0,648 \\
\hline$U I \rightarrow$ QS_F & 0,694 & 0,692 & 0,606 & 0,773 \\
\hline UI $\rightarrow$ QS_I & 0,539 & 0,541 & 0,388 & 0,674 \\
\hline UI $\rightarrow$ QS_TR & 0,482 & 0,499 & 0,367 & 0,642 \\
\hline $\mathrm{UI} \rightarrow \mathrm{SU}$ & 0,713 & 0,713 & 0,618 & 0,791 \\
\hline
\end{tabular}


Tabela 46 - Análise de Cross-Loadings (Rodada 2)

Fonte: Elaborado pelo autor

\begin{tabular}{|c|c|c|c|c|c|c|c|c|c|c|c|c|c|c|c|c|c|c|c|c|c|}
\hline & Co & $\mathrm{EE}$ & II & $\overline{Q D}$ & DAC & QD_AT & QD_C & $\overline{Q E}$ & QI & QI_AC & QI_AT & QI_C & QI_F & QS & QS_A & QS_C & QS_F & QS_I & QS_TR & su & UI \\
\hline $0 \_1$ & 0,926 & 0,579 & 0,404 & \begin{tabular}{|l|}
0,469 \\
\end{tabular} & 0,436 & 0,500 & 0,497 & 0,443 & 0,367 & 0,326 & 0,473 & 0,415 & 0,423 & 0,375 & \begin{tabular}{|l|}
0,313 \\
\end{tabular} & \begin{tabular}{|l|}
0,273 \\
\end{tabular} & \begin{tabular}{|l|}
0,361 \\
\end{tabular} & 0,240 & 0,318 & 0,438 & 0,483 \\
\hline CO_2 & \begin{tabular}{|l|l|}
0,914 \\
\end{tabular} & \begin{tabular}{|l|l|}
0,540 \\
\end{tabular} & 0,345 & 0,328 & 0,288 & 0,436 & 0,331 & 0,398 & 0,284 & 232 & \begin{tabular}{|l|l|}
0,341 \\
\end{tabular} & \begin{tabular}{|c|}
0,276 \\
\end{tabular} & \begin{tabular}{|l|}
0,286 \\
\end{tabular} & \begin{tabular}{|l|l|}
0,335 \\
\end{tabular} & \begin{tabular}{|l|}
0,266 \\
\end{tabular} & \begin{tabular}{|l|l|}
0,199 \\
\end{tabular} & \begin{tabular}{|l|}
0,265 \\
\end{tabular} & 0,211 & 0,279 & \begin{tabular}{|l|}
0,384 \\
\end{tabular} & 0,411 \\
\hline O_3 & \begin{tabular}{|l|}
0,891 \\
\end{tabular} & 111 & 07 & 871 & 332 & 441 & 407 & 32 & 331 & 293 & 388 & 308 & 301 & 354 & 334 & 217 & \begin{tabular}{|l|}
0,292 \\
\end{tabular} & $\begin{array}{ll}0,280 \\
\end{array}$ & 0,296 & 0,392 & 401 \\
\hline $\mathrm{E}$-1 & \begin{tabular}{|l|l}
0,533 \\
\end{tabular} & 868 & 421 & 0,414 & 0,271 & 0,385 & 0,425 & 0,493 & 0,395 & 0,315 & \begin{tabular}{|l|l}
0,377 \\
\end{tabular} & 0,368 & 0,336 & \begin{tabular}{|c|}
0,449 \\
\end{tabular} & \begin{tabular}{|c|}
0,379 \\
\end{tabular} & \begin{tabular}{|l|}
0,305 \\
\end{tabular} & \begin{tabular}{|l|}
0,343 \\
\end{tabular} & 0,305 & 0,353 & \begin{tabular}{|l|}
0,390 \\
\end{tabular} & 0,492 \\
\hline$E 2$ & \begin{tabular}{|l|l|}
0,543 \\
\end{tabular} & \begin{tabular}{|l|l}
0,888 \\
\end{tabular} & \begin{tabular}{|l|l|}
0,395 \\
\end{tabular} & \begin{tabular}{|l|l|}
0,342 \\
\end{tabular} & \begin{tabular}{|l|l|}
0,206 \\
\end{tabular} & \begin{tabular}{|l|l|}
0,347 \\
\end{tabular} & \begin{tabular}{|l|l}
0,368 \\
\end{tabular} & 0,369 & 375 & 302 & \begin{tabular}{|l|l|}
0,381 \\
\end{tabular} & 0,358 & \begin{tabular}{|c|}
0,306 \\
\end{tabular} & 0,377 & 0,332 & \begin{tabular}{|l|l|}
0,313 \\
\end{tabular} & \begin{tabular}{|l|l|}
0,338 \\
\end{tabular} & 0,246 & 0,312 & \begin{tabular}{|l|}
0,382 \\
\end{tabular} & 0,466 \\
\hline E_3 & \begin{tabular}{|l|l}
0,484 \\
\end{tabular} & \begin{tabular}{|l|l|} 
\\
\end{tabular} & 443 & 387 & 0,208 & 0,277 & 0,318 & 0,384 & 0,413 & 304 & 315 & 0,351 & 0,294 & 0,405 & 0,345 & 0,274 & 0,325 & 0,263 & \begin{tabular}{|l|l}
0,314 \\
\end{tabular} & \begin{tabular}{|l}
0,405 \\
\end{tabular} & 0,480 \\
\hline E-4 & 0,460 & \begin{tabular}{|l|l|}
0,822 \\
\end{tabular} & \begin{tabular}{|l}
0,263 \\
\end{tabular} & \begin{tabular}{|l}
0,346 \\
\end{tabular} & \begin{tabular}{|l|l|}
0,267 \\
\end{tabular} & 0,355 & \begin{tabular}{|l}
0,316 \\
\end{tabular} & \begin{tabular}{|l|}
0,342 \\
\end{tabular} & \begin{tabular}{|l}
0,256 \\
\end{tabular} & 0,202 & \begin{tabular}{|l|}
0,263 \\
\end{tabular} & 0,285 & 0,230 & \begin{tabular}{|l|}
0,256 \\
\end{tabular} & \begin{tabular}{|l|}
0,261 \\
\end{tabular} & \begin{tabular}{|l|}
0,207 \\
\end{tabular} & \begin{tabular}{|l|}
0,317 \\
\end{tabular} & 0,177 & \begin{tabular}{|l|l|}
0,255 \\
\end{tabular} & \begin{tabular}{|l|l|}
0,274 \\
\end{tabular} & 0,346 \\
\hline E5 & \begin{tabular}{|l|l}
0,473 \\
\end{tabular} & \begin{tabular}{|l}
0,751 \\
\end{tabular} & 0,348 & 0,373 & 0,245 & 0,386 & 0,376 & 0,325 & 0,321 & 262 & 0,292 & \begin{tabular}{|c|}
0,376 \\
\end{tabular} & 296 & \begin{tabular}{|l|}
0,295 \\
\end{tabular} & 0,251 & 0,264 & \begin{tabular}{|l|l|}
0,315 \\
\end{tabular} & \begin{tabular}{|c|}
0,150 \\
\end{tabular} & 0,278 & \begin{tabular}{|l|}
0,282 \\
\end{tabular} & 0,410 \\
\hline 1 & \begin{tabular}{|l|l|}
0,355 \\
\end{tabular} & \begin{tabular}{|l|l|}
0,416 \\
\end{tabular} & 0,848 & 0,445 & 0,296 & 0,313 & 0,402 & 0,325 & 0,519 & 0,425 & \begin{tabular}{|l|l|}
0,307 \\
\end{tabular} & 0,472 & \begin{tabular}{|c|}
0,289 \\
\end{tabular} & 0,573 & \begin{tabular}{|l|l|}
0,436 \\
\end{tabular} & \begin{tabular}{|l|l|}
0,446 \\
\end{tabular} & \begin{tabular}{|l|l|}
0,427 \\
\end{tabular} & 0,425 & \begin{tabular}{|l|l}
0,404 \\
\end{tabular} & \begin{tabular}{|l|}
0,561 \\
\end{tabular} & 0,630 \\
\hline 2 & \begin{tabular}{|l}
0,409 \\
\end{tabular} & 458 & \begin{tabular}{|l|l}
0,929 \\
\end{tabular} & \begin{tabular}{|l|l}
0,568 \\
\end{tabular} & 0,363 & \begin{tabular}{|l}
0,463 \\
\end{tabular} & 0,519 & 346 & 598 & 524 & \begin{tabular}{|l|l}
0,432 \\
\end{tabular} & 0,568 & 0,480 & \begin{tabular}{|l|}
0,608 \\
\end{tabular} & \begin{tabular}{|l|}
0,579 \\
\end{tabular} & \begin{tabular}{|l|}
0,526 \\
\end{tabular} & \begin{tabular}{|l|}
0,499 \\
\end{tabular} & 0,413 & 0,490 & \begin{tabular}{|l|}
0,668 \\
\end{tabular} & 0,619 \\
\hline 3 & \begin{tabular}{|l}
0,270 \\
\end{tabular} & 331 & 0,898 & 0,535 & 0,353 & \begin{tabular}{|l}
0,413 \\
\end{tabular} & \begin{tabular}{|l|l}
0,489 \\
\end{tabular} & 0,308 & 0,560 & 0,508 & \begin{tabular}{|l|}
0,396 \\
\end{tabular} & 0,524 & 0,432 & \begin{tabular}{|c|}
0,571 \\
\end{tabular} & \begin{tabular}{|l|}
0,536 \\
\end{tabular} & \begin{tabular}{|l|}
0,543 \\
\end{tabular} & \begin{tabular}{|l|l}
0,424 \\
\end{tabular} & 0,408 & \begin{tabular}{|l|l}
0,414 \\
\end{tabular} & \begin{tabular}{|c|}
0,606 \\
\end{tabular} & \begin{tabular}{|c|}
0,541 \\
\end{tabular} \\
\hline QD_1 & \begin{tabular}{|l|l|}
0,382 \\
\end{tabular} & \begin{tabular}{|l|l|}
0,423 \\
\end{tabular} & 0,592 & \begin{tabular}{|l|l|}
0,949 \\
\end{tabular} & 0,675 & 0,696 & 0,730 & \begin{tabular}{|l|l|}
0,485 \\
\end{tabular} & 0,641 & 0,653 & \begin{tabular}{|l|}
0,496 \\
\end{tabular} & 0,593 & \begin{tabular}{|c|}
0,444 \\
\end{tabular} & \begin{tabular}{|l|}
0,616 \\
\end{tabular} & \begin{tabular}{|l|}
0,539 \\
\end{tabular} & 0,537 & \begin{tabular}{|l|l|}
0,553 \\
\end{tabular} & 0,445 & 0,477 & \begin{tabular}{|l|}
0,596 \\
\end{tabular} & 0,539 \\
\hline QD_2 & \begin{tabular}{|l|}
0,413 \\
\end{tabular} & \begin{tabular}{|l|l}
0,426 \\
\end{tabular} & \begin{tabular}{|l|}
0,544 \\
\end{tabular} & \begin{tabular}{|l|l}
0,958 \\
\end{tabular} & \begin{tabular}{|l|l}
0,713 \\
\end{tabular} & \begin{tabular}{|l|l}
0,719 \\
\end{tabular} & \begin{tabular}{|l|l}
0,728 \\
\end{tabular} & \begin{tabular}{|l|l}
0,458 \\
\end{tabular} & \begin{tabular}{|l}
0,622 \\
\end{tabular} & 0,623 & \begin{tabular}{|l|l}
0,520 \\
\end{tabular} & 0,596 & 0,472 & \begin{tabular}{|l|}
0,579 \\
\end{tabular} & \begin{tabular}{|l|}
0,516 \\
\end{tabular} & \begin{tabular}{|l|}
0,491 \\
\end{tabular} & \begin{tabular}{|l}
0,545 \\
\end{tabular} & 0,405 & \begin{tabular}{|l|l}
0,430 \\
\end{tabular} & \begin{tabular}{|l|}
0,587 \\
\end{tabular} & 0,522 \\
\hline QD_3 & \begin{tabular}{|l|}
0,426 \\
\end{tabular} & \begin{tabular}{|l|l|}
0,415 \\
\end{tabular} & \begin{tabular}{|l|}
0,506 \\
\end{tabular} & \begin{tabular}{|l}
0,928 \\
\end{tabular} & 0,689 & 0,667 & \begin{tabular}{|l}
0,718 \\
\end{tabular} & \begin{tabular}{|l}
0,440 \\
\end{tabular} & \begin{tabular}{|l}
0,622 \\
\end{tabular} & 0,641 & \begin{tabular}{|l|}
0,497 \\
\end{tabular} & 0,576 & 0,450 & \begin{tabular}{|l|}
0,533 \\
\end{tabular} & \begin{tabular}{|l|}
0,475 \\
\end{tabular} & \begin{tabular}{|l|}
0,467 \\
\end{tabular} & \begin{tabular}{|l|}
0,512 \\
\end{tabular} & \begin{tabular}{|c|}
0,303 \\
\end{tabular} & \begin{tabular}{|l|l|}
0,428 \\
\end{tabular} & \begin{tabular}{|l|}
0,587 \\
\end{tabular} & 0,501 \\
\hline D_AC1 & \begin{tabular}{|l}
0,374 \\
\end{tabular} & 245 & \begin{tabular}{|l|l}
0,349 \\
\end{tabular} & \begin{tabular}{|l|l}
0,707 \\
\end{tabular} & 0,934 & 0,633 & 0,650 & 0,322 & 0,506 & 544 & \begin{tabular}{|l|l}
0,471 \\
\end{tabular} & 0,455 & 0,410 & & \begin{tabular}{|l|}
0,439 \\
\end{tabular} & \begin{tabular}{|l|}
0,445 \\
\end{tabular} & \begin{tabular}{|l|l}
0,335 \\
\end{tabular} & 0,235 & 0,366 & \begin{tabular}{|l|}
0,394 \\
\end{tabular} & \\
\hline D_AC2 & 333 & 230 & 286 & 0,591 & 0,910 & 0,604 & 657 & 0,327 & 0,417 & 0,502 & \begin{tabular}{|l|}
0,455 \\
\end{tabular} & 0,346 & 0,368 & 0,353 & 0,365 & \begin{tabular}{|l|l|}
0,413 \\
\end{tabular} & \begin{tabular}{|l|l|}
0,223 \\
\end{tabular} & \begin{tabular}{|c|}
0,158 \\
\end{tabular} & 0,312 & \begin{tabular}{|l|}
0,315 \\
\end{tabular} & 0,237 \\
\hline QD_AC3 & \begin{tabular}{|l|l|}
0,375 \\
\end{tabular} & \begin{tabular}{|l|}
0,313 \\
\end{tabular} & \begin{tabular}{|l|l|}
0,409 \\
\end{tabular} & \begin{tabular}{|l|}
0,731 \\
\end{tabular} & 0,945 & 0,637 & 0,737 & 0,376 & 0,513 & 0,552 & \begin{tabular}{|l|}
0,476 \\
\end{tabular} & 0,476 & 0,421 & 0,450 & \begin{tabular}{|l|}
0,396 \\
\end{tabular} & \begin{tabular}{|l|l|}
0,485 \\
\end{tabular} & \begin{tabular}{|l|}
0,373 \\
\end{tabular} & 0,275 & 0,372 & \begin{tabular}{|l|}
0,387 \\
\end{tabular} & 0,384 \\
\hline DD_AT1 & 446 & \begin{tabular}{|l|}
0,369 \\
\end{tabular} & \begin{tabular}{|l|l|}
0,374 \\
\end{tabular} & \begin{tabular}{|l|}
0,657 \\
\end{tabular} & 0,601 & \begin{tabular}{|l|}
0,935 \\
\end{tabular} & 0,650 & 0,468 & 0,500 & 0,465 & \begin{tabular}{|l|}
0,579 \\
\end{tabular} & 0,412 & \begin{tabular}{|l|}
0,431 \\
\end{tabular} & \begin{tabular}{|l|}
0,525 \\
\end{tabular} & \begin{tabular}{|l|}
0,484 \\
\end{tabular} & \begin{tabular}{|l|}
0,374 \\
\end{tabular} & \begin{tabular}{|l|}
0,390 \\
\end{tabular} & 0,344 & \begin{tabular}{|l|}
0,397 \\
\end{tabular} & \begin{tabular}{|l|}
0,433 \\
\end{tabular} & 0,414 \\
\hline D_AT2 & \begin{tabular}{|l|}
0,474 \\
\end{tabular} & 358 & \begin{tabular}{|l|}
0,414 \\
\end{tabular} & \begin{tabular}{|l|}
0,656 \\
\end{tabular} & 0,623 & \begin{tabular}{|l|}
0,937 \\
\end{tabular} & 0,687 & 0,436 & \begin{tabular}{|l|}
0,504 \\
\end{tabular} & 0,501 & \begin{tabular}{|l|}
0,646 \\
\end{tabular} & 0,419 & \begin{tabular}{|l|}
0,456 \\
\end{tabular} & \begin{tabular}{|l|}
0,515 \\
\end{tabular} & \begin{tabular}{|l|}
0,489 \\
\end{tabular} & \begin{tabular}{|l|}
0,361 \\
\end{tabular} & \begin{tabular}{|l|}
0,391 \\
\end{tabular} & 0,391 & 0,397 & \begin{tabular}{|l|}
0,428 \\
\end{tabular} & \begin{tabular}{|l|l|}
0,427 \\
\end{tabular} \\
\hline QD_AT3 & 495 & 49 & \begin{tabular}{|l|}
0,457 \\
\end{tabular} & \begin{tabular}{|l|}
0,740 \\
\end{tabular} & 0,659 & \begin{tabular}{|l|}
0,932 \\
\end{tabular} & 0,718 & & 0,531 & 0,538 & \begin{tabular}{|l|}
0,636 \\
\end{tabular} & 0,484 & & & \begin{tabular}{|l|}
0,523 \\
\end{tabular} & \begin{tabular}{|l|}
0,415 \\
\end{tabular} & \begin{tabular}{|l|}
0,435 \\
\end{tabular} & 0,380 & \begin{tabular}{|l|}
0,427 \\
\end{tabular} & \begin{tabular}{|l|}
0,510 \\
\end{tabular} & \\
\hline D_C1 & \begin{tabular}{|l|}
0,372 \\
\end{tabular} & 335 & \begin{tabular}{|l|}
0,494 \\
\end{tabular} & \begin{tabular}{|l|}
0,747 \\
\end{tabular} & \begin{tabular}{|l|}
0,728 \\
\end{tabular} & 0,613 & \begin{tabular}{|l|}
0,890 \\
\end{tabular} & 0,354 & \begin{tabular}{|l|}
0,562 \\
\end{tabular} & 0,611 & \begin{tabular}{|l|}
0,506 \\
\end{tabular} & 0,540 & \begin{tabular}{|l|}
0,458 \\
\end{tabular} & \begin{tabular}{|l|}
0,501 \\
\end{tabular} & \begin{tabular}{|l|}
0,489 \\
\end{tabular} & \begin{tabular}{|l|}
0,449 \\
\end{tabular} & \begin{tabular}{|l|}
0,425 \\
\end{tabular} & 0,326 & \begin{tabular}{|l|l|}
0,412 \\
\end{tabular} & \begin{tabular}{|l|}
0,473 \\
\end{tabular} & 0,432 \\
\hline D_C2 & \begin{tabular}{|l|}
0,394 \\
\end{tabular} & 422 & \begin{tabular}{|l|}
0,473 \\
\end{tabular} & \begin{tabular}{|l|}
0,644 \\
\end{tabular} & 0,591 & \begin{tabular}{|l|}
0,660 \\
\end{tabular} & 0,891 & 0,382 & 0,554 & 0,476 & \begin{tabular}{|l|}
0,472 \\
\end{tabular} & \begin{tabular}{l|}
0,487 \\
\end{tabular} & \begin{tabular}{|l|}
0,425 \\
\end{tabular} & \begin{tabular}{|l|}
0,536 \\
\end{tabular} & \begin{tabular}{|l|}
0,492 \\
\end{tabular} & \begin{tabular}{|l|}
0,439 \\
\end{tabular} & \begin{tabular}{|l|}
0,401 \\
\end{tabular} & \begin{tabular}{|l|}
0,395 \\
\end{tabular} & \begin{tabular}{|l|}
0,383 \\
\end{tabular} & \begin{tabular}{|l|}
0,482 \\
\end{tabular} & 0,455 \\
\hline D_C3 & \begin{tabular}{|l|l|}
0,444 \\
\end{tabular} & 997 & 0,423 & 626 & 609 & 0,675 & 62 & 80 & 478 & 501 & \begin{tabular}{|l|}
0,453 \\
\end{tabular} & 0,475 & \begin{tabular}{|c|}
0,407 \\
\end{tabular} & 05 & \begin{tabular}{|l|l|}
0,473 \\
\end{tabular} & \begin{tabular}{|l|}
0,393 \\
\end{tabular} & \begin{tabular}{|l|l|}
0,374 \\
\end{tabular} & 0,343 & 0,393 & \begin{tabular}{|l|}
0,452 \\
\end{tabular} & 0,413 \\
\hline QE_1 & \begin{tabular}{|l|}
0,420 \\
\end{tabular} & \begin{tabular}{|l|l|}
0,445 \\
\end{tabular} & \begin{tabular}{|l|l|}
0,383 \\
\end{tabular} & \begin{tabular}{|l|l|}
0,417 \\
\end{tabular} & \begin{tabular}{|l|}
0,275 \\
\end{tabular} & \begin{tabular}{|l|}
0,395 \\
\end{tabular} & 0,345 & 0,913 & 0,449 & 0,315 & \begin{tabular}{|l|}
0,354 \\
\end{tabular} & 0,394 & \begin{tabular}{|l|}
0,418 \\
\end{tabular} & \begin{tabular}{|l|l|}
0,496 \\
\end{tabular} & \begin{tabular}{|l|}
0,399 \\
\end{tabular} & \begin{tabular}{|l|}
0,393 \\
\end{tabular} & \begin{tabular}{|l|l|}
0,332 \\
\end{tabular} & \begin{tabular}{|l|}
0,439 \\
\end{tabular} & \begin{tabular}{|l|l|}
0,447 \\
\end{tabular} & \begin{tabular}{|l|}
0,433 \\
\end{tabular} & 0,469 \\
\hline QE_2 & \begin{tabular}{|l|}
0,423 \\
\end{tabular} & 384 & 272 & \begin{tabular}{|l|}
0,467 \\
\end{tabular} & 0,397 & 0,497 &, 419 & 391 & 402 & 310 & \begin{tabular}{|l|}
0,349 \\
\end{tabular} & 0,261 & 0,377 & \begin{tabular}{|l|}
0,387 \\
\end{tabular} & \begin{tabular}{|l|}
0,402 \\
\end{tabular} & \begin{tabular}{|l|}
0,307 \\
\end{tabular} & \begin{tabular}{|l|}
0,320 \\
\end{tabular} & 0,330 & \begin{tabular}{|l|l|}
0,325 \\
\end{tabular} & \begin{tabular}{|l|}
0,430 \\
\end{tabular} & \begin{tabular}{|l|l}
0,377 \\
\end{tabular} \\
\hline QI_1 & \begin{tabular}{|l|}
0,311 \\
\end{tabular} & $\mid 0,377$ & \begin{tabular}{|l|}
0,603 \\
\end{tabular} & \begin{tabular}{|l|}
0,612 \\
\end{tabular} & 0,486 & \begin{tabular}{|l|}
0,524 \\
\end{tabular} & 0,575 & 0,469 & \begin{tabular}{|l|}
0,948 \\
\end{tabular} & 0,716 & \begin{tabular}{|l|}
0,579 \\
\end{tabular} & \begin{tabular}{|l|}
0,645 \\
\end{tabular} & \begin{tabular}{|l|}
0,732 \\
\end{tabular} & \begin{tabular}{|l|}
0,834 \\
\end{tabular} & \begin{tabular}{|l|}
0,687 \\
\end{tabular} & \begin{tabular}{|l|}
0,632 \\
\end{tabular} & \begin{tabular}{|l|}
0,606 \\
\end{tabular} & \begin{tabular}{l|}
0,555 \\
\end{tabular} & \begin{tabular}{|l|}
0,662 \\
\end{tabular} & \begin{tabular}{|l|}
0,704 \\
\end{tabular} & 0,671 \\
\hline Q1_2 & \begin{tabular}{|l|}
0,327 \\
\end{tabular} & 113 & 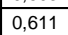 & \begin{tabular}{|l|}
0,655 \\
\end{tabular} & 0,502 & 0,515 & 0,575 & 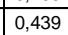 & 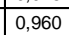 & 792 & \begin{tabular}{|l|}
0,602 \\
\end{tabular} & 0,719 & \begin{tabular}{|l|}
0,702 \\
\end{tabular} & \begin{tabular}{|l|}
0,792 \\
\end{tabular} & \begin{tabular}{|l|}
0,649 \\
\end{tabular} & \begin{tabular}{|l|}
0,615 \\
\end{tabular} & \begin{tabular}{|l|}
0,580 \\
\end{tabular} & 0 & \begin{tabular}{|l|l|}
0,610 \\
\end{tabular} & \begin{tabular}{|l|}
0,672 \\
\end{tabular} & 0,661 \\
\hline 21_3 & \begin{tabular}{|l|}
0,384 \\
\end{tabular} & 410 & 546 & \begin{tabular}{|l|}
0,602 \\
\end{tabular} & 0,471 & \begin{tabular}{|l|}
0,502 \\
\end{tabular} & 0,553 & 0,420 & \begin{tabular}{|l|}
0,904 \\
\end{tabular} & 0,699 & \begin{tabular}{|l|}
0,578 \\
\end{tabular} & $\begin{array}{ll}0,647 \\
\end{array}$ & 0,605 & \begin{tabular}{|l|}
0,717 \\
\end{tabular} & \begin{tabular}{|l|}
0,574 \\
\end{tabular} & \begin{tabular}{|l|}
0,606 \\
\end{tabular} & \begin{tabular}{|l|}
0,573 \\
\end{tabular} & 0,420 & \begin{tabular}{|l|}
0,551 \\
\end{tabular} & \begin{tabular}{|l|}
0,585 \\
\end{tabular} & 0,578 \\
\hline IAC1 & \begin{tabular}{|l|}
0,298 \\
\end{tabular} & 303 & 0,499 & \begin{tabular}{|l|}
0,570 \\
\end{tabular} & 0,527 & 0,520 & 0,558 & 0,335 & 0,743 & 0,902 & \begin{tabular}{|l|}
0,626 \\
\end{tabular} & 0,579 & $\begin{array}{l}0,606 \\
\end{array}$ & \begin{tabular}{|l|}
0,650 \\
\end{tabular} & \begin{tabular}{|l|}
0,593 \\
\end{tabular} & \begin{tabular}{|l|}
0,604 \\
\end{tabular} & \begin{tabular}{|l|}
0,457 \\
\end{tabular} & 0,383 & \begin{tabular}{|l|l|}
0,535 \\
\end{tabular} & \begin{tabular}{|l|}
0,516 \\
\end{tabular} & 0,500 \\
\hline IAC2 & \begin{tabular}{|l|l|}
0255 \\
\end{tabular} & 301 & 452 & 0,599 & 522 & 0,464 &, 530 & 255 & 0,642 & 898 & \begin{tabular}{|l|}
0,597 \\
\end{tabular} & 0,521 & 0.483 & \begin{tabular}{|l|}
0,497 \\
\end{tabular} & \begin{tabular}{|l|}
0,488 \\
\end{tabular} & \begin{tabular}{|l|}
0,486 \\
\end{tabular} & \begin{tabular}{|l|}
0,366 \\
\end{tabular} & 0,308 & 0,377 & \begin{tabular}{|l|}
0,482 \\
\end{tabular} & 0.414 \\
\hline I_AC3 & \begin{tabular}{|l|}
0,300 \\
\end{tabular} & 313 & 535 & \begin{tabular}{|l|}
0,680 \\
\end{tabular} & 0,524 & 0,487 & 0,568 & 0,350 & 0,755 & 938 & 0,612 & 0,637 & 0,553 & \begin{tabular}{|l|}
0,631 \\
\end{tabular} & \begin{tabular}{|l|}
0,583 \\
\end{tabular} & \begin{tabular}{|l|}
0,594 \\
\end{tabular} & \begin{tabular}{|l|}
0,438 \\
\end{tabular} & 0,371 & 0,535 & \begin{tabular}{|l|}
0,533 \\
\end{tabular} & 0,491 \\
\hline QI_AT1 & \begin{tabular}{|l|}
0,330 \\
\end{tabular} & 268 & 326 & \begin{tabular}{|l|}
0,398 \\
\end{tabular} & 0,324 & 0,484 & 81 & 54 & 495 & 527 & \begin{tabular}{|l|}
0,852 \\
\end{tabular} & 0,422 & 0,471 & \begin{tabular}{|l|}
0,492 \\
\end{tabular} & \begin{tabular}{|l|}
0,479 \\
\end{tabular} & \begin{tabular}{|l|}
0,360 \\
\end{tabular} & \begin{tabular}{|l|}
0,367 \\
\end{tabular} & 0,364 & \begin{tabular}{|l|}
0,385 \\
\end{tabular} & \begin{tabular}{|l|}
0,361 \\
\end{tabular} & \begin{tabular}{|l|l|}
0,371 \\
\end{tabular} \\
\hline IIAT2 & \begin{tabular}{|l|l}
0,368 \\
\end{tabular} & 0,360 & 0,365 & \begin{tabular}{|l}
0,492 \\
\end{tabular} & 0,457 & \begin{tabular}{|l|l}
0,555 \\
\end{tabular} & \begin{tabular}{|l|l}
0,509 \\
\end{tabular} & 0,368 & 0,551 & 631 & \begin{tabular}{|l|}
0,897 \\
\end{tabular} & 0,531 & $\begin{array}{ll}0,555 \\
\end{array}$ & \begin{tabular}{|c|}
0,537 \\
\end{tabular} & \begin{tabular}{|l|}
0,540 \\
\end{tabular} & \begin{tabular}{|l|}
0,401 \\
\end{tabular} & \begin{tabular}{|l|}
0,405 \\
\end{tabular} & 0,336 & \begin{tabular}{|c|}
0,461 \\
\end{tabular} & \begin{tabular}{|l|}
0,446 \\
\end{tabular} & 0,436 \\
\hline QI_AT3 & \begin{tabular}{|l|}
0,457 \\
\end{tabular} & 395 & 419 & \begin{tabular}{|l|}
0,504 \\
\end{tabular} & 0,524 & 0,691 & 0,525 & 0,391 & 0,588 & 598 & \begin{tabular}{|l|}
0,878 \\
\end{tabular} & 0,548 & 0,541 & \begin{tabular}{|l|}
0,581 \\
\end{tabular} & \begin{tabular}{|l|}
0,506 \\
\end{tabular} & \begin{tabular}{|l|}
0,410 \\
\end{tabular} & \begin{tabular}{|l|}
0,430 \\
\end{tabular} & 0,381 & \begin{tabular}{|l|}
0,489 \\
\end{tabular} & \begin{tabular}{|l|}
0,469 \\
\end{tabular} & 0,424 \\
\hline I_C1 & \begin{tabular}{|l|l}
0,283 \\
\end{tabular} & 334 & 0,564 & \begin{tabular}{|l|l}
0,569 \\
\end{tabular} & 0,427 & \begin{tabular}{|l|l|}
0,389 \\
\end{tabular} & 0,511 & $\overline{0,}$ & 0,669 & 0,578 & \begin{tabular}{|l|}
0,515 \\
\end{tabular} & 0,929 & \begin{tabular}{|l|}
0,526 \\
\end{tabular} & \begin{tabular}{|l|l|}
0,611 \\
\end{tabular} & \begin{tabular}{|l|l|}
0,477 \\
\end{tabular} & \begin{tabular}{|l|l|}
0,523 \\
\end{tabular} & \begin{tabular}{|l|l|}
0,574 \\
\end{tabular} & 0,444 & \begin{tabular}{|l|l}
0,472 \\
\end{tabular} & \begin{tabular}{|l|}
0,568 \\
\end{tabular} & 0,548 \\
\hline IC2 & \begin{tabular}{|l|}
0,349 \\
\end{tabular} & 420 & 527 & \begin{tabular}{|l|l|}
0,580 \\
\end{tabular} & 0,399 & 0,424 & 0,517 & 0,357 & 655 & 0,590 & \begin{tabular}{|l|}
0,551 \\
\end{tabular} & 0,916 & 0,532 & \begin{tabular}{|l|}
0,616 \\
\end{tabular} & \begin{tabular}{|l|}
0,502 \\
\end{tabular} & \begin{tabular}{|l|}
0,552 \\
\end{tabular} & \begin{tabular}{|l|}
0,627 \\
\end{tabular} & 0,468 & \begin{tabular}{|l|l}
0,421 \\
\end{tabular} & \begin{tabular}{|l|}
0,579 \\
\end{tabular} & \begin{tabular}{|l}
0,598 \\
\end{tabular} \\
\hline QI_C3 & \begin{tabular}{|l}
0,373 \\
\end{tabular} & 0 & 495 & 40 & 0,431 & \begin{tabular}{|l|l}
0,470 \\
\end{tabular} & 20 & & 114 & 561 & \begin{tabular}{|l|}
0,493 \\
\end{tabular} & 0,866 & 0,475 & \begin{tabular}{|l|l|}
0,599 \\
\end{tabular} & \begin{tabular}{|l|l|}
0,417 \\
\end{tabular} & \begin{tabular}{|l|}
0,418 \\
\end{tabular} & \begin{tabular}{|l|}
0,517 \\
\end{tabular} & 0,375 & 0,450 & \begin{tabular}{|l|}
0,478 \\
\end{tabular} & 0,513 \\
\hline QI_F1 & \begin{tabular}{|l}
0,321 \\
\end{tabular} & 0,344 & 0,431 & 482 & 0,438 & 0,471 & 0,506 & - & 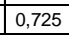 & 605 & 0,591 & 0,553 & 0,945 & \begin{tabular}{|l|l|}
0,670 \\
\end{tabular} & \begin{tabular}{|l|}
0,677 \\
\end{tabular} & \begin{tabular}{|l|}
0,528 \\
\end{tabular} & \begin{tabular}{|l}
0,543 \\
\end{tabular} & 0,429 & \begin{tabular}{|c|}
0,634 \\
\end{tabular} & \begin{tabular}{|l|}
0,566 \\
\end{tabular} & 0,547 \\
\hline Q1_F2 & \begin{tabular}{|l}
0,373 \\
\end{tabular} & 316 & 357 & 393 & 0,369 & 0,423 & 395 & 380 & 335 & 500 & 0,509 & 0,486 & 0,937 & \begin{tabular}{|c|}
0,556 \\
\end{tabular} & \begin{tabular}{|l|}
0,538 \\
\end{tabular} & \begin{tabular}{|l|}
0,428 \\
\end{tabular} & \begin{tabular}{|l}
0,475 \\
\end{tabular} & 0,360 & 0,527 & \begin{tabular}{|l|}
0,504 \\
\end{tabular} & 0,519 \\
\hline QI_F3 & \begin{tabular}{|l}
0,354 \\
\end{tabular} & 325 & 0,468 & 468 & 0,395 & \begin{tabular}{|l}
0,466 \\
\end{tabular} & 0,461 & 0,406 & 670 & 574 & \begin{tabular}{|l|}
0,570 \\
\end{tabular} & 0,540 & 0,916 & \begin{tabular}{|l|}
0,585 \\
\end{tabular} & \begin{tabular}{|c|}
0,622 \\
\end{tabular} & \begin{tabular}{|l|}
0,486 \\
\end{tabular} & \begin{tabular}{|l|}
0,465 \\
\end{tabular} & 0,402 & \begin{tabular}{|l|}
0,545 \\
\end{tabular} & \begin{tabular}{|l|}
0,547 \\
\end{tabular} & 0,498 \\
\hline QS_1 & \begin{tabular}{|l|}
0,397 \\
\end{tabular} & 114 & 664 & .594 & 0,452 & 0,545 & 0,589 & 0,484 & 0,811 & 643 & 0,575 & 0,657 & 0,644 & 0,961 & \begin{tabular}{|l|}
0,712 \\
\end{tabular} & \begin{tabular}{|l|}
0,675 \\
\end{tabular} & \begin{tabular}{|c|}
0,634 \\
\end{tabular} & 0,575 & \begin{tabular}{|l}
0,727 \\
\end{tabular} & \begin{tabular}{|l|}
0,664 \\
\end{tabular} & 0,690 \\
\hline QS_2 & & 0 & & 0,592 & 0,4 & \begin{tabular}{|l|l|}
0,539 \\
\end{tabular} & 0,5 & & & & \begin{tabular}{|l|}
0,607 \\
\end{tabular} & 0,661 & & & \begin{tabular}{|l|}
0,688 \\
\end{tabular} & \begin{tabular}{|l|}
0,651 \\
\end{tabular} & \begin{tabular}{|l|}
0,650 \\
\end{tabular} & 0,575 & \begin{tabular}{|l|l}
0,676 \\
\end{tabular} & \begin{tabular}{|l|}
0,676 \\
\end{tabular} & \\
\hline QS_3 & \begin{tabular}{|l}
0,362 \\
\end{tabular} & 421 & $\overline{516}$ & 578 & 413 & 0,543 & 0,554 & 0,448 & 0,784 & 618 & \begin{tabular}{|l|}
0,597 \\
\end{tabular} & 0,629 & 0,609 & 0,961 & \begin{tabular}{|l|}
0,662 \\
\end{tabular} & \begin{tabular}{|l|}
0,603 \\
\end{tabular} & \begin{tabular}{|l}
0,588 \\
\end{tabular} & 0,520 & \begin{tabular}{|l|l|}
0,649 \\
\end{tabular} & \begin{tabular}{|l|}
0,613 \\
\end{tabular} & \begin{tabular}{|l|}
0,702 \\
\end{tabular} \\
\hline S_A1 & \begin{tabular}{|l|}
0,330 \\
\end{tabular} & T & 0,53 & 529 & 29 & 0,517 & 0,511 & 431 & 629 & 583 & \begin{tabular}{|l|}
0,549 \\
\end{tabular} & 0,551 & 615 & \begin{tabular}{|l|}
0,657 \\
\end{tabular} & \begin{tabular}{|l|}
0,869 \\
\end{tabular} & 0,531 & \begin{tabular}{|l|}
0,485 \\
\end{tabular} & 0,509 & 0,653 & 0,554 & 0,493 \\
\hline S_A2 & \begin{tabular}{|l}
0,270 \\
\end{tabular} & 87 & 0,507 & 420 & 319 & 0,419 & 0,439 & 0,358 & 0.547 & 477 & 480 & 0,401 & 556 & \begin{tabular}{|l|}
0,589 \\
\end{tabular} & \begin{tabular}{|l|}
0,857 \\
\end{tabular} & \begin{tabular}{|l|}
0,435 \\
\end{tabular} & \begin{tabular}{|l|}
0,356 \\
\end{tabular} & 0,366 & 0,591 & \begin{tabular}{|l|}
0,483 \\
\end{tabular} & 0,455 \\
\hline QS_A3 & \begin{tabular}{|l}
0,265 \\
\end{tabular} & 302 & 0,465 & 451 & 370 & 0,451 & 0,479 & 362 & 593 & 524 & ,479 & 0,381 & 542 & \begin{tabular}{|l|}
0,608 \\
\end{tabular} & \begin{tabular}{|l|}
0,879 \\
\end{tabular} & \begin{tabular}{|l|}
0,460 \\
\end{tabular} & \begin{tabular}{|l|}
0,411 \\
\end{tabular} & 0,410 & 0,583 & \begin{tabular}{|l|}
0,523 \\
\end{tabular} & 0,431 \\
\hline QS_C1 & \begin{tabular}{|l}
0,238 \\
\end{tabular} & 329 & 0 & 502 & 0,4 & \begin{tabular}{|l}
0,360 \\
\end{tabular} & 0,426 & & & 84 & \begin{tabular}{|l|}
0,399 \\
\end{tabular} & 0,518 & 0,412 & \begin{tabular}{|l|}
0,574 \\
\end{tabular} & \begin{tabular}{|l|}
0,471 \\
\end{tabular} & \begin{tabular}{|l|}
0,935 \\
\end{tabular} & \begin{tabular}{|l|}
0,430 \\
\end{tabular} & 0,348 & \begin{tabular}{|l|}
0,458 \\
\end{tabular} & \begin{tabular}{|l|}
0,532 \\
\end{tabular} & \begin{tabular}{|l|l|}
0,431 \\
\end{tabular} \\
\hline QS_C2 & \begin{tabular}{|l|}
0,216 \\
\end{tabular} & 303 & 515 & 491 & 0,432 & \begin{tabular}{|l|l}
0,383 \\
\end{tabular} & 0,432 & 356 & 0,620 & 583 & 412 & 0,512 & 480 & \begin{tabular}{|l|}
0,635 \\
\end{tabular} & \begin{tabular}{|l|}
0,511 \\
\end{tabular} & \begin{tabular}{|c|}
0,929 \\
\end{tabular} & \begin{tabular}{|l|}
0,462 \\
\end{tabular} & 0,376 & \begin{tabular}{|l}
0,467 \\
\end{tabular} & \begin{tabular}{|l|}
0,532 \\
\end{tabular} & 0,484 \\
\hline & \begin{tabular}{|l|l}
0,241 \\
\end{tabular} & 0 & 0,4 & 0,448 & 0,434 & 0,3 & 0, & & & & 0,409 & 0,479 & & & & \begin{tabular}{|l|}
0,868 \\
\end{tabular} & \begin{tabular}{|l|}
0,458 \\
\end{tabular} & 0,451 & \begin{tabular}{|l|}
0,479 \\
\end{tabular} & \begin{tabular}{|l|}
0,494 \\
\end{tabular} & 0,440 \\
\hline QS_F1 & $\begin{array}{l} \\
0,\end{array}$ & 0 & 0 & 572 & 35 & 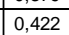 & \begin{tabular}{|l|l|}
0,456 \\
\end{tabular} & & & 472 & 438 & $\begin{array}{l}0,599 \\
\end{array}$ & - & - & \begin{tabular}{|l|}
0,489 \\
\end{tabular} & \begin{tabular}{|l|}
0,524 \\
\end{tabular} & \begin{tabular}{|l|}
0,924 \\
\end{tabular} & 0,556 & \begin{tabular}{|l|}
0,463 \\
\end{tabular} & \begin{tabular}{|l|}
0,613 \\
\end{tabular} & \begin{tabular}{|l|l|}
0,597 \\
\end{tabular} \\
\hline QS_F2 & \begin{tabular}{|l|}
0,298 \\
\end{tabular} & 327 & 423 & 0,476 & 0,277 & 0,366 & 0,398 & 0,299 & 0,533 & 398 & 0,416 & 0,560 & 0,500 & \begin{tabular}{|l|}
0,565 \\
\end{tabular} & \begin{tabular}{|l|}
0,403 \\
\end{tabular} & \begin{tabular}{|l|}
0,402 \\
\end{tabular} & \begin{tabular}{|l}
0,929 \\
\end{tabular} & 0,489 & 0,406 & \begin{tabular}{|l|}
0,557 \\
\end{tabular} & 0,580 \\
\hline S_F3 & \begin{tabular}{|l|}
0,332 \\
\end{tabular} & & 555 & . & 0329 & 0 & 0707 & & 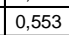 & 112 & (20, & 605 & 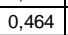 & \begin{tabular}{|c|}
0,579 \\
\end{tabular} & \begin{tabular}{|l}
0,447 \\
\end{tabular} & \begin{tabular}{|l|}
0,441 \\
\end{tabular} & \begin{tabular}{|c|}
0,929 \\
\end{tabular} & 0,511 & 0,461 & \begin{tabular}{|l|}
0,573 \\
\end{tabular} & 0509 \\
\hline QS_11 & \begin{tabular}{|l}
0,284 \\
\end{tabular} & 299 & 0,396 & 364 & 0,228 & 0,352 & 363 & 392 & 462 & 328 & 380 & 465 & 375 & \begin{tabular}{|l|}
0,563 \\
\end{tabular} & \begin{tabular}{|l|}
0,368 \\
\end{tabular} & \begin{tabular}{|l|}
0,405 \\
\end{tabular} & \begin{tabular}{|l}
0,567 \\
\end{tabular} & 0,885 & 0,318 & \begin{tabular}{|l|l|}
0,411 \\
\end{tabular} & 0,495 \\
\hline 12 & 0 & 0 & & \begin{tabular}{|l}
0,347 \\
\end{tabular} & 0,186 & 0,3 & 0,337 & & & 46 & 59 & 0,395 & 0,367 & 0, & \begin{tabular}{|l|}
0,480 \\
\end{tabular} & \begin{tabular}{|l|}
0,392 \\
\end{tabular} & \begin{tabular}{|l|}
0,481 \\
\end{tabular} & 0,868 & \begin{tabular}{|c|}
0,294 \\
\end{tabular} & \begin{tabular}{|l|}
0,421 \\
\end{tabular} & 0,387 \\
\hline QS_13 & 0 & 0 & & 381 & 38 & 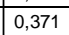 & 375 & & & 77 & 64 & 0,409 & - & - & ,497 & \begin{tabular}{|l|}
0,358 \\
\end{tabular} & \begin{tabular}{|l|}
0,450 \\
\end{tabular} & 0,933 & \begin{tabular}{|l|}
0,309 \\
\end{tabular} & \begin{tabular}{|l|}
0,451 \\
\end{tabular} & 0,424 \\
\hline QS_TR & 284 & 316 & 0,4 & 0,441 & 0,361 & 0,412 & 0, & & 0, & 503 & 0,516 & 0,472 & 0,598 & 0,638 & 0,673 & 0,463 & 0,435 & 0,331 & 0,956 & \begin{tabular}{|l|}
0,482 \\
\end{tabular} & 0,390 \\
\hline QS_TR & & & & & & & & & & 20 & & & & $\mid$ & 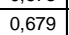 & 5020 & 50 & 0,330 & 0 & \begin{tabular}{|l|}
0,525 \\
\end{tabular} & 0,482 \\
\hline SU_1 & \begin{tabular}{|l|l|}
0,404 \\
\end{tabular} & 400 & \begin{tabular}{|l}
0,632 \\
\end{tabular} & \begin{tabular}{|l|l|}
0,594 \\
\end{tabular} & 0,359 & 0,414 & 0,426 & 44 & 0,63 & 500 & 404 & 0,567 & 0,464 & \begin{tabular}{|l|}
0,634 \\
\end{tabular} & \begin{tabular}{|l|}
0,513 \\
\end{tabular} & \begin{tabular}{|l|}
0,547 \\
\end{tabular} & \begin{tabular}{|l|}
0,517 \\
\end{tabular} & 0,419 & \begin{tabular}{|l|}
0,487 \\
\end{tabular} & \begin{tabular}{|l|l|}
0,812 \\
\end{tabular} & 0,636 \\
\hline U_2 & & 0 & & & \begin{tabular}{|l}
0,336 \\
\end{tabular} & 0,3 & & & & & & & & 0,3 & \begin{tabular}{|l|}
0,427 \\
\end{tabular} & \begin{tabular}{|l|}
0,395 \\
\end{tabular} & $\begin{array}{l}0,391 \\
\end{array}$ & 0,268 & 0,403 & 610 & \\
\hline U_3 & 0 & 0 & & 554 & 397 & 0,475 & 39 & & & 548 & 164 & 0,525 &, 527 & \begin{tabular}{|l|l|}
0,613 \\
\end{tabular} & \begin{tabular}{|l|}
0,590 \\
\end{tabular} & \begin{tabular}{|l|}
0,536 \\
\end{tabular} & \begin{tabular}{|l|}
0,513 \\
\end{tabular} & 0,422 & 0,497 & 871 & 532 \\
\hline J_4 & 0 & 312 & 604 & 520 & 329 & 0,412 & 0,444 & & & 487 & 382 & \begin{tabular}{|c|}
0,468 \\
\end{tabular} & 464 & \begin{tabular}{|l|l|}
0,560 \\
\end{tabular} & \begin{tabular}{|l|}
0,515 \\
\end{tabular} & \begin{tabular}{|l|l|}
0,434 \\
\end{tabular} & \begin{tabular}{|l|l|}
0,452 \\
\end{tabular} & \begin{tabular}{|c|}
0,426 \\
\end{tabular} & 0,386 & \begin{tabular}{|l|}
0,877 \\
\end{tabular} & 572 \\
\hline SU_5 & \begin{tabular}{|l}
0,306 \\
\end{tabular} & 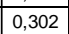 & 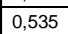 & 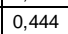 & 257 & 0838 & & & & 78 & 350 & 0,445 & 0416 & 2 & 414 & \begin{tabular}{|l|}
0,421 \\
\end{tabular} & \begin{tabular}{|l}
0,475 \\
\end{tabular} & 0,315 & 0,353 & \begin{tabular}{|l|}
0,828 \\
\end{tabular} & 0,508 \\
\hline SU_6 & 0,301 & 331 & 0,490 & ,433 & 0,215 & 0,323 & 0,354 & 0,366 & 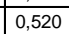 & 344 & 0,357 & 0,449 & 0,475 & 0,497 & 0,397 & 0,377 & 0,660 & 0,405 & 0,387 & 0,755 & 0,540 \\
\hline$=$ & & & & & & & & & & & & & & & & s. & 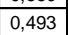 & 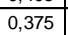 & 0,279 & | & \\
\hline UI_2 & \begin{tabular}{|l|l|}
0,315 \\
\end{tabular} & 310 & 0 & 402 & 0,252 & 0,288 & 0,343 & 0, & y & 0,334 & \begin{tabular}{|l|}
0,312 \\
\end{tabular} & 0,456 & ,401 & \begin{tabular}{|l|l|}
0,518 \\
\end{tabular} & \begin{tabular}{|l|l|}
0,369 \\
\end{tabular} & 0,364 & \begin{tabular}{|l|l}
0,498 \\
\end{tabular} & 0,354 & 0,271 & \begin{tabular}{|l|}
0,539 \\
\end{tabular} & 0,772 \\
\hline 13 & 397 & 429 & 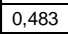 & 434 & 0,292 & 0,412 & 0,381 & 0, & & 372 & 353 & 0,465 & 424 & \begin{tabular}{|c|}
0,556 \\
\end{tabular} & \begin{tabular}{|c|}
0,366 \\
\end{tabular} & \begin{tabular}{|l|}
0,384 \\
\end{tabular} & \begin{tabular}{|l}
0,529 \\
\end{tabular} & 0,386 & 0,339 & \begin{tabular}{|l|}
0,537 \\
\end{tabular} & \begin{tabular}{|l}
0,804 \\
\end{tabular} \\
\hline UI_4 & \begin{tabular}{|l}
0,404 \\
\end{tabular} & 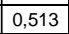 & 587 & 523 & 0,380 & 0,466 & 512 & & & 515 & 474 & 0,571 & 572 & 733 & 565 & \begin{tabular}{|l|}
0,517 \\
\end{tabular} & \begin{tabular}{|l|}
0,572 \\
\end{tabular} & 0,492 & 0,513 & \begin{tabular}{|l|}
0,608 \\
\end{tabular} & 866 \\
\hline 15 & 477 & 0,498 & .566 & 0,547 & 0,384 & 0,516 & 0,510 & 0,4 & 0,6 & 0,515 & 534 & 0,571 & 580 & \begin{tabular}{|l|}
0,714 \\
\end{tabular} & 0,553 & \begin{tabular}{|l|}
0,509 \\
\end{tabular} & \begin{tabular}{|l|}
0,557 \\
\end{tabular} & 0,436 & 0,506 & \begin{tabular}{|l|}
0,615 \\
\end{tabular} & 850 \\
\hline UI_6 & & & & & & & & & & & & & & & 367 & 0,332 & . & 0,314 & 0,354 & (1) & \\
\hline \begin{tabular}{|l} 
\\
UI_7
\end{tabular} & $0,0,409$ & 493 & 594 & , 397 & 0,234 & 0,312 & 0,367 & 0,352 & 0,515 & 0,402 & \begin{tabular}{|l|}
0,322 \\
\end{tabular} & 0,445 & 0,412 & \begin{tabular}{|c|}
0,533 \\
\end{tabular} & \begin{tabular}{|l|}
0,402 \\
\end{tabular} & \begin{tabular}{|c|}
0,367 \\
\end{tabular} & \begin{tabular}{|l|}
0,440 \\
\end{tabular} & 0,344 & 0,320 & \begin{tabular}{|l|}
0,546 \\
\end{tabular} & 0,824 \\
\hline II8 & 0, & 0,35 & 54 & 0,412 & 0,254 & 0,243 & 0,317 & & 0,482 & 381 & 0,277 & 0,496 & , 356 & \begin{tabular}{|l|}
0,490 \\
\end{tabular} &, $38 \varepsilon$ & 0,354 & 0,446 & 0,365 & 0,306 & \begin{tabular}{|l|}
0,459 \\
\end{tabular} & 743 \\
\hline$\sqrt{1} 9$ & \begin{tabular}{|l}
0,331 \\
\end{tabular} & 0,414 & 0,490 & 404 & 0,280 & 0,301 & 0,314 & 0,315 & 0,407 & 0,368 & \begin{tabular}{|l|l|}
0,293 \\
\end{tabular} & 0,398 & 0,348 & 0,464 & 0,316 & 0,317 & \begin{tabular}{|l}
0,553 \\
\end{tabular} & 0,393 & \begin{tabular}{|l|}
0,284 \\
\end{tabular} & \begin{tabular}{|l|}
0,427 \\
\end{tabular} & 0,734 \\
\hline
\end{tabular}


Tabela 47 - Análise de Fornell-Lacker (Rodada 2)

Fonte: Elaborado pelo autor

\begin{tabular}{|c|c|c|c|c|c|c|c|c|c|c|c|c|c|c|c|c|c|c|c|c|c|}
\hline & $\mathrm{CO}$ & EE & II & QD & QD_AC & QD_AT & QD_C & QE & QI & QI_AC & QI_AT & QI_C & QI_F & QS & QS_A & QS_C & QS_F & QS_I & QS_TR & SU & UI \\
\hline $\mathrm{CO}$ & 0,911 & & & & & & & & & & & & & & & & & & & & \\
\hline EE & 0,598 & 0,836 & & & & & & & & & & & & & & & & & & & \\
\hline II & 0,389 & 0,452 & 0,892 & & & & & & & & & & & & & & & & & & \\
\hline QD & 0,430 & 0,446 & 0,579 & 0,945 & & & & & & & & & & & & & & & & & \\
\hline QD_AC & 0,390 & 0,285 & 0,378 & 0,732 & 0,930 & & & & & & & & & & & & & & & & \\
\hline QD_AT & 0,505 & 0,418 & 0,446 & 0,735 & 0,672 & 0,935 & & & & & & & & & & & & & & & \\
\hline QD_C & 0,455 & 0,433 & 0,528 & 0,767 & 0,734 & 0,734 & 0,881 & & & & & & & & & & & & & & \\
\hline QE & 0,466 & 0,461 & 0,366 & 0,488 & 0,368 & 0,491 & 0,421 & 0,902 & & & & & & & & & & & & & \\
\hline QI & 0,361 & 0,426 & 0,627 & 0,665 & 0,518 & 0,548 & 0,605 & 0,472 & 0,938 & & & & & & & & & & & & \\
\hline QI_AC & 0,313 & 0,335 & 0,545 & 0,676 & 0,574 & 0,538 & 0,606 & 0,346 & 0,785 & 0,913 & & & & & & & & & & & \\
\hline QI_AT & 0,443 & 0,393 & 0,425 & 0,534 & 0,503 & 0,664 & 0,543 & 0,390 & 0,625 & 0,670 & 0,876 & & & & & & & & & & \\
\hline QI_C & 0,369 & 0,417 & 0,586 & 0,623 & 0,463 & 0,471 & 0,570 & 0,367 & 0,715 & 0,637 & 0,575 & 0,904 & & & & & & & & & \\
\hline QI_F & 0,373 & 0,352 & 0,450 & 0,482 & 0,431 & 0,487 & 0,489 & 0,441 & 0,727 & 0,603 & 0,598 & 0,566 & 0,933 & & & & & & & & \\
\hline QS & 0,390 & 0,433 & 0,655 & 0,609 & 0,441 & 0,562 & 0,586 & 0,493 & 0,835 & 0,654 & 0,615 & 0,673 & 0,650 & 0,965 & & & & & & & \\
\hline QS_A & 0,334 & 0,379 & 0,581 & 0,540 & 0,432 & 0,535 & 0,550 & 0,444 & 0,681 & 0,611 & 0,581 & 0,516 & 0,659 & 0,713 & 0,868 & & & & & & \\
\hline QS_C & 0,254 & 0,329 & 0,566 & 0,528 & 0,483 & 0,411 & 0,486 & 0,390 & 0,658 & 0,619 & \begin{tabular}{|l|}
0,447 \\
\end{tabular} & 0,553 & 0,518 & 0,667 & 0,550 & 0,911 & & & & & \\
\hline QS_F & 0,338 & 0,392 & 0,506 & 0,568 & 0,340 & 0,435 & 0,455 & 0,361 & 0,625 & 0,463 & \begin{tabular}{|l|}
0,459 \\
\end{tabular} & 0,634 & 0,531 & 0,647 & 0,483 & 0,495 & 0,928 & & & & \\
\hline QS_I & 0,267 & 0,277 & 0,465 & 0,407 & 0,244 & 0,398 & 0,401 & 0,429 & 0,514 & 0,390 & 0,411 & 0,475 & 0,427 & 0,577 & 0,497 & 0,431 & 0,561 & 0,896 & & & \\
\hline QS_TR & 0,327 & 0,364 & 0,490 & 0,471 & 0,379 & 0,436 & 0,450 & 0,431 & 0,650 & 0,534 & 0,511 & 0,495 & 0,612 & 0,710 & 0,704 & 0,514 & 0,479 & 0,344 & 0,960 & & \\
\hline SU & 0,446 & 0,419 & 0,687 & 0,625 & 0,396 & 0,491 & 0,532 & 0,478 & 0,699 & 0,560 & \begin{tabular}{|l|}
0,489 \\
\end{tabular} & 0,600 & 0,579 & 0,675 & 0,600 & 0,571 & 0,628 & 0,477 & 0,526 & 0,797 & \\
\hline UI & 0,476 & 0,529 & 0,669 & 0,551 & 0,362 & 0,456 & 0,492 & 0,471 & 0,681 & 0,516 & \begin{tabular}{|l|}
0,470 \\
\end{tabular} & 0,612 & 0,559 & 0,721 & 0,530 & 0,497 & 0,639 & 0,490 & 0,457 & 0,659 & 0,788 \\
\hline
\end{tabular}


Tabela 48- Análise de HTMT

Fonte: Elaborado pelo autor

\begin{tabular}{|c|c|c|c|c|c|c|c|c|c|c|c|c|c|c|c|c|c|c|c|c|c|}
\hline & $\mathrm{CO}$ & $\mathrm{EE}$ & II & QD & QD_AC & QD_AT & QD_C & QE & QI & QI_AC & QI_AT & QI_C & QI_F & QS & QS_A & QS_C & QS_F & QS_I & QS_TR & SU & UI \\
\hline \multicolumn{22}{|l|}{$\mathrm{CO}$} \\
\hline $\mathrm{EE}$ & 0,666 & & & & & & & & & & & & & & & & & & & & \\
\hline II & 0,435 & 0,505 & & & & & & & & & & & & & & & & & & & \\
\hline QD & 0,466 & 0,487 & 0,639 & & & & & & & & & & & & & & & & & & \\
\hline QD_AC & 0,423 & 0,313 & 0,417 & 0,781 & & & & & & & & & & & & & & & & & \\
\hline QD_AT & 0,551 & 0,458 & 0,492 & 0,783 & 0,725 & & & & & & & & & & & & & & & & \\
\hline QD_C & 0,518 & 0,498 & 0,608 & 0,850 & 0,819 & 0,824 & & & & & & & & & & & & & & & \\
\hline QE & 0,560 & 0,550 & 0,442 & 0,575 & 0,440 & 0,583 & 0,522 & & & & & & & & & & & & & & \\
\hline Q I & 0,396 & 0,463 & 0,694 & 0,710 & 0,555 & 0,589 & 0,675 & 0,555 & & & & & & & & & & & & & \\
\hline QI_AC & 0,345 & 0,370 & 0,612 & 0,734 & 0,629 & 0,586 & 0,683 & 0,412 & 0,853 & & & & & & & & & & & & \\
\hline QI_AT & 0,501 & 0,443 & 0,490 & 0,594 & 0,561 & 0,741 & 0,629 & 0,476 & 0,700 & 0,764 & & & & & & & & & & & \\
\hline QI_C & 0,411 & 0,469 & 0,664 & 0,681 & 0,507 & 0,519 & 0,652 & 0,439 & 0,786 & \begin{tabular}{|l|}
0,710 \\
\end{tabular} & \begin{tabular}{|l|}
0,658 \\
\end{tabular} & & & & & & & & & & \\
\hline QI_F & 0,407 & 0,385 & 0,498 & 0,515 & 0,463 & 0,523 & 0,545 & 0,519 & 0,779 & 0,655 & 0,671 & 0,622 & & & & & & & & & \\
\hline QS & 0,419 & 0,461 & 0,714 & 0,640 & 0,465 & 0,594 & 0,646 & 0,567 & 0,879 & 0,697 & 0,678 & 0,728 & 0,685 & & & & & & & & \\
\hline QS_A & 0,384 & 0,432 & 0,678 & 0,606 & 0,487 & 0,603 & 0,648 & 0,550 & 0,768 & 0,697 & 0,686 & 0,593 & 0,744 & 0,792 & & & & & & & \\
\hline QS_C & 0,282 & 0,365 & 0,641 & 0,575 & 0,530 & 0,448 & 0,552 & 0,465 & 0,720 & 0,684 & 0,510 & 0,618 & 0,564 & 0,716 & 0,632 & & & & & & \\
\hline QS_F & 0,370 & 0,432 & 0,561 & 0,608 & 0,361 & 0,468 & 0,509 & 0,427 & 0,672 & 0,504 & 0,517 & 0,701 & 0,573 & 0,685 & 0,545 & 0,540 & & & & & \\
\hline QS_I & 0,299 & 0,306 & 0,534 & 0,447 & 0,265 & 0,440 & 0,463 & 0,517 & 0,566 & 0,438 & 0,476 & 0,535 & 0,473 & 0,624 & \begin{tabular}{|l|}
0,581 \\
\end{tabular} & \begin{tabular}{|l|}
0,484 \\
\end{tabular} & 0,619 & & & & \\
\hline QS_TR & 0,358 & 0,398 & 0,545 & 0,507 & 0,410 & 0,472 & 0,506 & 0,507 & 0,701 & 0,581 & 0,578 & 0,549 & 0,663 & 0,752 & 0,802 & 0,565 & 0,519 & 0,383 & & & \\
\hline SU & 0,503 & 0,473 & 0,772 & 0,683 & 0,438 & 0,543 & 0,616 & 0,583 & 0,763 & 0,626 & 0,566 & 0,676 & 0,645 & 0,724 & 0,696 & 0,640 & \begin{tabular}{|l|}
0,699 \\
\end{tabular} & 0,538 & 0,586 & & \\
\hline UI & 0,516 & 0,572 & 0,744 & 0,587 & 0,381 & 0,484 & 0,545 & 0,550 & 0,722 & 0,557 & 0,521 & 0,673 & 0,597 & 0,756 & 0,593 & \begin{tabular}{|l|}
0,537 \\
\end{tabular} & 0,694 & 0,539 & \begin{tabular}{|l|}
0,484 \\
\end{tabular} & 0,713 & \\
\hline
\end{tabular}


Tabela 49 - Análise de significância HTMT (Rodada 2)

Fonte: Elaborado pelo autor

\begin{tabular}{|c|c|c|c|c|}
\hline & \begin{tabular}{|l|} 
Original \\
Sample
\end{tabular} & $\begin{array}{c}\text { Sample } \\
\text { Mean }\end{array}$ & $2.5 \%$ & $97.5 \%$ \\
\hline $\mathrm{EE} \rightarrow \mathrm{CO}$ & 0,666 & 0,664 & 0,548 & 0,761 \\
\hline III $\rightarrow \mathrm{CO}$ & 0,435 & 0,435 & 0,266 & 0,588 \\
\hline$\| I I \rightarrow E E$ & 0,505 & 0,504 & 0,375 & 0,623 \\
\hline$Q D \rightarrow C O$ & 0,466 & 0,467 & 0,322 & 0,605 \\
\hline $\mathrm{QD}>\mathrm{EE}$ & 0,487 & 0,486 & 0,355 & 0,611 \\
\hline QD $>$ II & 0,639 & 0,638 & 0,508 & 0,752 \\
\hline$Q D \_A C \rightarrow C O$ & 0,423 & 0,422 & 0,273 & 0,565 \\
\hline QD_AC $>$ EE & 0,313 & 0,314 & 0,159 & 0,461 \\
\hline QD_AC $>$ II & 0,417 & 0,419 & 0,255 & 0,573 \\
\hline QD_AC $>$ QD & 0,781 & 0,782 & 0,706 & 0,848 \\
\hline QD_AT $>$ CO & 0,551 & 0,549 & 0,431 & 0,654 \\
\hline QD_AT $>$ EE & 0,458 & 0,458 &, 318 &, 589 \\
\hline QD_AT $>$ II & 0,492 & 0,494 & 336 & 6,632 \\
\hline QD_AT $>$ QD & 0,783 & 0,788 & 0,620 & ,900 \\
\hline QD_AT $\rightarrow$ QD_AC & 0,725 & 0,723 & 0,633 & 802 \\
\hline QD_C $>C O$ & 0,518 & 0,519 & 0,379 & 0,638 \\
\hline QD_C $>$ EE & 0,498 & 0,496 & 0,348 &, 633 \\
\hline QD_C $>$ II & 0,608 & 0,608 & 0,481 & 0,724 \\
\hline QD_C $>$ QD & 0,850 & 851 & 0,748 & 0,928 \\
\hline QD_C $>$ QD_AC & 0,819 & 0,819 & 0,737 & 8,888 \\
\hline QD_C $>$ QD_AT & 0,824 & 0,824 & 0,743 & 0,893 \\
\hline$Q E \rightarrow C O$ & 0,560 & 0,560 & 0,395 & 0,710 \\
\hline$Q E \rightarrow E E$ & 0,550 & 0,551 & 0,412 & 681 \\
\hline QE $>$ II & 0,442 & 0,444 & 276 & 602 \\
\hline$Q E \rightarrow Q D$ & 0,575 & 0,577 & 431 &, 715 \\
\hline$Q E \rightarrow$ QD_AC & 0,440 & 0,440 & 0,294 & 0,579 \\
\hline QE $>$ PD_AT & 0,583 & 0,583 & 0,471 & 0,693 \\
\hline QE $\rightarrow$ QD_C & 0,522 & 0,521 & 0,379 & 0,659 \\
\hline $\mathrm{QI}>\mathrm{CO}$ & 0,396 & 0,395 & 0,247 & 530 \\
\hline $\mathrm{Ql}->\mathrm{EE}$ & 0,463 & 0,463 & 0,336 & 0,584 \\
\hline QI $\rightarrow$ II & 0,694 & 0,694 & 0,586 & 0,789 \\
\hline $\mathrm{QI} \rightarrow \mathrm{QD}$ & 0,710 & 0,711 & 0,614 & 0,800 \\
\hline QI $\rightarrow$ QD_AC & 0,555 & 0,554 & 0,422 & 0,674 \\
\hline QI $\rightarrow$ QD_AT & 0,589 & 0,589 & 457 & ,,702 \\
\hline$Q I \Rightarrow Q D \_C$ & 0,675 & 0,673 & 573 & ,761 \\
\hline $\mathrm{QI} \rightarrow \mathrm{QE}$ & 0,555 & 0,557 & 0,418 & 0,682 \\
\hline QI_AC $>$ CO & 0,345 & 0,345 & 0,195 & 0,488 \\
\hline QI_AC $>$ EE & 0,370 & 0,370 & 0,227 & 0,510 \\
\hline QI_AC $>>$ II & 0,612 & 0,612 & 0,480 & 0,728 \\
\hline QI_AC $>$ QD & 0,734 & 0,734 & 647 & 810 \\
\hline QI_AC $>$ QD_AC & 0,629 & 0,629 & 0,499 & 0,748 \\
\hline QI_AC $>$ QD_AT & 0,586 & 587 & 0,453 & 0,711 \\
\hline QI_AC $>$ QD_C & 0,683 & 0,681 & 0,581 & 0,771 \\
\hline QI_AC $>$ QE & 0,412 & 0,414 & 0,269 & 0,546 \\
\hline Ql_AC $>$ QI & 0,853 & 853 & 0,772 & , ,920 \\
\hline QI_AT -> CO & 0,501 & 0,500 & 378 & 614 \\
\hline QI_AT $>$ EE & 0,443 & 0,444 & 0,303 & 0,574 \\
\hline QI_AT $>$ III & 0,490 & 0,493 & 0,341 & 0,633 \\
\hline QI_AT $>$ QD & 0,594 &, 597 & 0,439 & 0,727 \\
\hline QI_AT $>$ QD_AC & 0,561 &, 561 & 0,441 & 0,666 \\
\hline QI_AT -> QD_AT & 0,741 &, 742 & 644 &, 828 \\
\hline QI_AT $>$ Q QD_C & 629 & 629 & 516 &, 730 \\
\hline QI_AT $>$ QE &, 476 & 0,476 & 0,325 & 0,619 \\
\hline QI_AT $>$ Q & 0,700 & 0,702 & 0,602 & 0,792 \\
\hline QI_AT $>>$ QI_AC & 0,764 & 0,767 & 0,667 & 0,859 \\
\hline QI_C $>$ CO & 0,411 & 413 & 0,258 & 0,560 \\
\hline QI_C $>$ EE & 0,469 & 0,467 & 0,324 & 0,605 \\
\hline QI_C $\rightarrow$ II & 0,664 & , 664 & 0,549 & 0,765 \\
\hline QI_C $>$ QD & 681 & ,679 & 0,558 & 0,781 \\
\hline QI_C $\rightarrow$ QD_AC & 0,507 & 0,505 & 0,371 & 0,626 \\
\hline QI_C $\rightarrow$ QD_AT & 0,519 & 0,520 & 0,366 & 0,656 \\
\hline QI_C $>$ QD_C & 0,652 & 0,652 & 0,531 & 0,754 \\
\hline QI_C $>$ QE & 0,439 & 0,441 & 0,286 & 0,590 \\
\hline QI_C $>$ Q Q & 0,786 & 0,785 & 0,694 & 0,866 \\
\hline QI_C $>$ QI_AC & 0,710 & 0,708 & 0,602 & 0,806 \\
\hline QI_C $\rightarrow$ QI_AT & 0,658 & 0,659 & 0,520 & 0,780 \\
\hline QI_F $>C O$ & 0,407 & 0,407 & 0,285 & 0,518 \\
\hline QI_F $>$ EE & 0,385 & 0,383 & 0,234 & 0,525 \\
\hline QI_F $>$ II & 0,498 & 0,501 & 0,371 & 0,618 \\
\hline QI_ &, 515 & 0,517 & 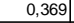 & 0,00 \\
\hline
\end{tabular}

\begin{tabular}{|c|c|c|c|c|}
\hline & \begin{tabular}{c|} 
Original \\
Sample
\end{tabular} & $\begin{array}{c}\begin{array}{c}\text { Sample } \\
\text { Mean }\end{array} \\
\end{array}$ & $2.5 \%$ & $97.5 \%$ \\
\hline QI_F $>$ QD_AC & 0,463 & 0,463 & 0,337 & 0,584 \\
\hline QI_F $>$ QD_AT & 0,523 & 0,524 & 0,404 & 0,634 \\
\hline QI_F $\rightarrow$ QD_C & 0,545 & 0,545 & 0,422 & 0,652 \\
\hline QI_F $>$ QE & 0,519 & 0,517 & 0,368 & 0,652 \\
\hline QI_F $\rightarrow$ QI & 0,779 & 0,780 & 0,708 & 0,845 \\
\hline QI_F $>$ QI_AC & 0,655 & 0,655 & 0,549 & 0,753 \\
\hline QI_F $>$ Q QI_AT & 0,671 & 0,670 & 0,557 & 0,774 \\
\hline QI_F $>$ QI_C & 0,622 & 0,623 & 0,489 & 0,743 \\
\hline$Q S \rightarrow C O$ & 0,419 & 0,417 & 0,267 & 0,555 \\
\hline$Q S \rightarrow E E$ & 0,461 & 0,459 & 0,326 & 0,583 \\
\hline QS $>$ II & 0,714 & 0,715 & 0,598 & 0,812 \\
\hline$Q S \rightarrow Q D$ & 0,640 & 0,642 & 0,481 & 0,769 \\
\hline QS $>$ QD_AC & 0,465 & 0,464 & 0,325 & 0,589 \\
\hline QS $>$ Q QD_AT & 0,594 & 0,594 & 0,462 & 0,704 \\
\hline$Q S \rightarrow Q D \_C$ & 0,646 & 0,644 & 0,534 & 0,734 \\
\hline$Q S \rightarrow Q E$ & 0,567 & 0,569 & 0,436 & 0,688 \\
\hline QS $\rightarrow$ Q I & 0,879 & 0,880 & 0,833 & 0,921 \\
\hline QS $\rightarrow$ QI_AC & 0,697 & 0,698 & 0,575 & 0,796 \\
\hline QS $>$ P QI_AT & 0,678 & 0,678 & 0,574 & 0,766 \\
\hline QS $\rightarrow$ Q I_C & 0,728 & 0,729 & 0,600 & 0,831 \\
\hline QS $>$ Q QI_F & 0,685 & 0,687 & 0,600 & 0,767 \\
\hline QS_A $\rightarrow$ CO & 0,384 & 0,383 & 0,220 & 0,522 \\
\hline$Q S \_A>E E$ & 0,432 & 0,429 & 0,262 & 0,579 \\
\hline QS_A $>$ II & 0,678 & 0,678 & 0,563 & 0,785 \\
\hline QS_A $>$ QD & 0,606 & 0,607 & 0,444 & 0,749 \\
\hline$Q S \_A \rightarrow Q D \_A C$ & 0,487 & 0,487 & 0,335 & 0,624 \\
\hline QS_A $\rightarrow$ QD_AT & 0,603 & 0,604 & 0,470 & 0,720 \\
\hline QS_A $\rightarrow$ QD_C & 0,648 & 0,646 & 0,535 & 0,748 \\
\hline$Q S \_A \rightarrow Q E$ & 0,550 & 0,549 & 0,398 & 0,685 \\
\hline QS_A $\rightarrow$ QI & 0,768 & 0,768 & 0,680 & 0,846 \\
\hline QS_A $\rightarrow$ QI_AC & 0,697 & 0,698 & 0,587 & 0,795 \\
\hline QS_A $\rightarrow$ Q QI_AT & 0,686 & 0,689 & 0,577 & 0,792 \\
\hline QS_A $\rightarrow$ QI_C & 0,593 & 0,595 & 0,442 & 0,727 \\
\hline QS_A $\rightarrow$ QI_F & 0,744 & 0,745 & 0,656 & 0,819 \\
\hline QS_A $\gg$ QS & 0,792 & 0,793 & 0,687 & 0,879 \\
\hline QS_C $>$ CO & 0,282 & 0,281 & 0,122 & 0,436 \\
\hline QS_C $>$ EE & 0,365 & 0,363 & 0,220 & 0,504 \\
\hline QS_C $>$ II & 0,641 & 0,641 & 0,513 & 0,746 \\
\hline$Q S \_C \rightarrow Q D$ & 0,575 & 0,573 & 0,454 & 0,685 \\
\hline QS_C $\rightarrow$ QD_AC & 0,530 & 0,528 & 0,394 & 0,646 \\
\hline QS_C $\rightarrow$ QD_AT & 0,448 & 0,447 & 0,294 & 0,581 \\
\hline QS_C $\rightarrow$ QD_C & 0,552 & 0,549 & 0,423 & 0,664 \\
\hline QS_C $>$ QE & 0,465 & 0,466 & 0,333 & 0,591 \\
\hline QS_C $\rightarrow$ QI & 0,720 & 0,719 & 0,617 & 0,808 \\
\hline QS_C $\rightarrow$ QI_AC & 0,684 & 0,684 & 0,572 & 0,776 \\
\hline QS_C $>>$ QI_AT & 0,510 & 0,511 & 0,376 & 0,633 \\
\hline QS_C $>>$ QI_C & 0,618 & 0,617 & 0,490 & 0,734 \\
\hline QS_C $>$ QI_F & 0,564 & 0,566 & 0,466 & 0,667 \\
\hline QS_C $>$ QS & 0,716 & 0,715 & 0,608 & 0,807 \\
\hline QS_C $>$ QS_A & 0,632 & 0,631 & 0,504 & 0,744 \\
\hline QS_F $\rightarrow C O$ & 0,370 & 0,369 & 0,213 & 0,508 \\
\hline QS_F $>$ EE & 0,432 & 0,430 & 0,300 & 0,553 \\
\hline QS_F $\rightarrow$ II & 0,561 & 0,559 & 0,446 & 0,664 \\
\hline$Q S \_F \rightarrow Q D$ & 0,608 & 0,606 & 0,490 & 0,705 \\
\hline QS_F $\rightarrow$ QD_AC & 0,361 & 0,360 & 0,209 & 0,500 \\
\hline QS_F $\rightarrow$ QD_AT & 0,468 & 0,468 & 0,313 & 0,610 \\
\hline QS_F $>$ QD_C & 0,509 & 0,507 & 0,382 & 0,622 \\
\hline QS_F $>>$ QE & 0,427 & 0,427 & 0,273 & 0,567 \\
\hline QS_F $\rightarrow$ Q & 0,672 & 0,671 & 0,585 & 0,747 \\
\hline QS_F $>$ Q QI_AC & 0,504 & 0,502 & 0,377 & 0,620 \\
\hline QS_F $>$ Q QI_AT & 0,517 & 0,515 & 0,379 & 0,647 \\
\hline QS_F $\rightarrow$ QI_C & 0,701 & 0,700 & 0,593 & 0,791 \\
\hline QS_F $>$ QI_F & 0,573 & 0,574 & 0,460 & 0,678 \\
\hline$Q S \_F>Q S$ & 0,685 & 0,684 & 0,581 & 0,770 \\
\hline QS_F $\rightarrow$ QS_A & 0,545 & 0,545 & 0,423 & 0,663 \\
\hline QS_F $\rightarrow$ QS_C & 0,540 & 0,539 & 0,409 & 0,651 \\
\hline QS_I $>$ CO & 0,299 & 0,297 & 0,134 & 0,458 \\
\hline QS_I $>$ EE & 0,306 & 0,305 & 0,145 & 0,463 \\
\hline QS_I $>$ II & 0,534 & 0,533 & 0,385 & 0,675 \\
\hline QS_I $>$ QD & 0,447 & 0,447 & 0,280 & 0,603 \\
\hline
\end{tabular}

\begin{tabular}{|c|c|c|c|c|}
\hline & \begin{tabular}{|l|} 
Original \\
Sample \\
\end{tabular} & \begin{tabular}{|c|}
$\begin{array}{c}\text { Sample } \\
\text { Mean }\end{array}$ \\
\end{tabular} & $2.5 \%$ & $97.5 \%$ \\
\hline QS_I I > QD_AC & 0,265 & 0,265 & 0,118 & 0,411 \\
\hline QS_I $>$ Q QD_AT & 0,440 & 0,442 & 0,290 & 0,579 \\
\hline QS_I $>$ QD_C & 0,463 & 0,462 & 0,304 & 0,602 \\
\hline$Q S \_I>Q E$ & 0,517 & 0,515 & 0,355 & 0,660 \\
\hline QS_I $>$ QI & 0,566 & 0,566 & 0,419 & 0,696 \\
\hline QS_I $>$ Q QI_AC & 0,438 & 0,439 & 0,292 & 0,578 \\
\hline QS_I $>$ Q QI_AT & 0,476 & 0,478 & 0,322 & 0,621 \\
\hline QS_I $>$ QI_C & 0,535 & 0,536 & 0,359 & 0,698 \\
\hline QS_I $>$ QI_F & 0,473 & 0,473 & 0,314 & 0,623 \\
\hline$Q S \_I \rightarrow Q S$ & 0,624 & 0,623 & 0,474 & 0,742 \\
\hline QS_I $\rightarrow$ QS_A & 0,581 & 0,580 & 0,412 & 0,727 \\
\hline QS_I $>$ QS_C & 0,484 & 0,483 & 0,324 & 0,629 \\
\hline QS_I $>$ QS_F & 0,619 & 0,619 & 0,484 & 0,740 \\
\hline QS_TR $>$ CO & 0,358 & 0,356 & 0,202 & 0,497 \\
\hline QS_TR $>$ EE & 0,398 & 0,397 & 0,235 & 0,548 \\
\hline QS_TR $\rightarrow$ II & 0,545 & 0,546 & 0,412 & 0,665 \\
\hline QS_TR $\rightarrow$ QD & 0,507 & 0,508 & 0,343 & 0,661 \\
\hline QS_TR $\rightarrow$ QD_AC & 0,410 & 0,409 & 0,261 & 0,548 \\
\hline QS_TR $\rightarrow$ QD_AT & 0,472 & 0,471 & 0,323 & 0,603 \\
\hline QS_TR $\rightarrow$ QD_C & 0,506 & 0,504 & 0,361 & 0,631 \\
\hline QS_TR $>$ QE & 0,507 & 0,506 & 0,368 & 0,630 \\
\hline QS_TR $\rightarrow$ QI & 0,701 & 0,701 & 0,607 & 0,784 \\
\hline QS_TR $\rightarrow$ QI_AC & 0,581 & 0,582 & 0,455 & 0,695 \\
\hline QS_TR $\rightarrow$ QI_AT & 0,578 & 0,577 & 0,449 & 0,695 \\
\hline QS_TR $\rightarrow$ QI_C & 0,549 & 0,549 & 0,385 & 0,696 \\
\hline QS_TR $\rightarrow$ QI_F & 0,663 & 0,662 & 0,562 & 0,744 \\
\hline QS_TR $\rightarrow$ QS & 0,752 & 0,753 & 0,651 & 0,834 \\
\hline QS_TR $\rightarrow$ QS_A & 0,802 & 0,803 & 0,717 & 0,880 \\
\hline QS_TR $>$ PS_C & 0,565 & 0,566 & 0,446 & 0,673 \\
\hline QS_TR $\rightarrow$ QS_F & 0,519 & 0,518 & 0,386 & 0,641 \\
\hline QS_TR $\rightarrow$ QS_I & 0,383 & 0,381 & 0,201 & 0,546 \\
\hline $\mathrm{SU} \rightarrow>\mathrm{CO}$ & 0,503 & 0,501 & 0,360 & 0,626 \\
\hline$S U>E E$ & 0,473 & 0,472 & 0,335 & 0,596 \\
\hline SU $>$ II & 0,772 & 0,772 & 0,685 & 0,850 \\
\hline$S U \rightarrow Q D$ & 0,683 & 0,683 & 0,584 & 0,775 \\
\hline SU $\rightarrow$ QD_AC & 0,438 & 0,437 & 0,301 & 0,570 \\
\hline SU $>$ P QD_AT & 0,543 & 0,543 & 0,417 & 0,658 \\
\hline$S U \rightarrow$ QD_C & 0,616 & 0,615 & 0,499 & 0,728 \\
\hline$S U \rightarrow Q E$ & 0,583 & 0,584 & 0,440 & 0,713 \\
\hline SU $\rightarrow$ QI & 0,763 & 0,763 & 0,662 & 0,849 \\
\hline SU $\rightarrow$ QI_AC & 0,626 & 0,625 & 0,520 & 0,722 \\
\hline SU $\rightarrow$ Q Q _AT & 0,566 & 0,566 & 0,442 & 0,680 \\
\hline SU $\rightarrow$ Ql_C & 0,676 & 0,676 & 0,569 & 0,778 \\
\hline$S U \rightarrow$ QI_F & 0,645 & 0,646 & 0,538 & 0,747 \\
\hline$S U \rightarrow Q S$ & 0,724 & 0,725 & 0,626 & 0,811 \\
\hline SU $\rightarrow$ QS_A & 0,696 & 0,695 & 0,593 & 0,785 \\
\hline SU $>$ QS_C & 0,640 & 0,639 & 0,526 & 0,742 \\
\hline SU $>>$ QS_F & 0,699 & 0,700 & 0,598 & 0,784 \\
\hline$S U \rightarrow Q S \_I$ & 0,538 & 0,538 & 0,390 & 0,661 \\
\hline SU $\rightarrow$ QS_TR & 0,586 & 0,585 & 0,466 & 0,696 \\
\hline $\mathrm{UI} \rightarrow \mathrm{CO}$ & 0,516 & 0,516 & 0,392 & 0,636 \\
\hline $\mathrm{UI}$-> EE & 0,572 & 0,571 & 0,460 & 0,674 \\
\hline UI $\rightarrow$ II & 0,744 & 0,744 & 0,665 & 0,820 \\
\hline$U I \rightarrow Q D$ & 0,587 & 0,587 & 0,460 & 0,697 \\
\hline$U I \rightarrow$ QD_AC & 0,381 & 0,381 & 0,223 & 0,529 \\
\hline UI $\rightarrow$ QD_AT & 0,484 & 0,484 & 0,336 & 0,618 \\
\hline$U I \rightarrow$ QD_C & 0,545 & 0,544 & 0,423 & 0,658 \\
\hline $\mathrm{UI} \rightarrow \mathrm{QE}$ & 0,550 & 0,552 & 0,419 & 0,678 \\
\hline $\mathrm{UI} \rightarrow \mathrm{QI}$ & 0,722 & 0,722 & 0,641 & 0,797 \\
\hline UI $\rightarrow$ QI_AC & 0,557 & 0,556 & 0,415 & 0,680 \\
\hline UI $>$ Q QI_AT & 0,521 & 0,521 & 0,389 & 0,643 \\
\hline UI $\rightarrow$ QI_C & 0,673 & 0,673 & 0,578 & 0,761 \\
\hline UI $>$ Q QI_F & 0,597 & 0,597 & 0,487 & 0,702 \\
\hline UI $\rightarrow$ QS & 0,756 & 0,756 & 0,681 & 0,820 \\
\hline UI $\rightarrow$ QS_A & 0,593 & 0,593 & 0,463 & 0,711 \\
\hline$U I \rightarrow$ QS_C & 0,537 & 0,537 & 0,416 & 0,650 \\
\hline UI $\rightarrow$ QS_F & 0,694 & 0,693 & 0,603 & 0,772 \\
\hline UI $\rightarrow$ QS_I & 0,539 & 0,537 & 0,385 & 0,677 \\
\hline UI $\rightarrow$ QS_TR & 0,484 & 0,483 & 0,352 & 0,606 \\
\hline 0 & 0,713 & $0,7 / 3 \mid$ & $0,0<2$ & $0,1 y^{2}$ \\
\hline
\end{tabular}


Tabela 50 - Análise de colinearidade

Fonte: Elaborado pelo autor

\begin{tabular}{|c|c|c|c|c|c|c|c|c|c|c|c|c|c|c|c|c|c|c|c|c|c|}
\hline & $\mathrm{CO}$ & $\mathrm{EE}$ & II & QD & QD_AC & QD_AT & QD_C & $\mathrm{QE}$ & QI & QI_AC & QI_AT & QI_C & QI_F & QS & QS_A & QS_C & QS_F & QS_I & QS_TR & SU & UI \\
\hline $\mathrm{CO}$ & & 1,000 & & & & & & & & & & & & & & & & & & & 1,610 \\
\hline EE & & & & & & & & & & & & & & & & & & & & & 1,700 \\
\hline \multicolumn{22}{|l|}{ II } \\
\hline QD & & & & & & & & & 2,333 & & & & & & & & & & & & \\
\hline QD_AC & & & & 2,368 & & & & & & & & & & & & & & & & & \\
\hline QD_AT & & & & 2,367 & & & & & & & & & & & & & & & & & \\
\hline QD_C & & & & 2,813 & & & & & & & & & & & & & & & & & \\
\hline QE & & & & & & & & & 1,447 & & & & & & & & & & & & \\
\hline QI_AC & & & & & & & & & 2,761 & & & & & & & & & & & & \\
\hline QI_AT & & & & & & & & & 2,135 & & & & & & & & & & & & \\
\hline QI_C & & & & & & & & & 2,099 & & & & & & & & & & & & \\
\hline QI_F & & & & & & & & & 1,972 & & & & & & & & & & & & \\
\hline QS & & & & & & & & & & & & & & & & & & & & 3,854 & 3,421 \\
\hline QS_A & & & & & & & & & & & & & & 2,431 & & & & & & & \\
\hline QS_C & & & & & & & & & & & & & & 1,653 & & & & & & & \\
\hline QS_F & & & & & & & & & & & & & & 1,770 & & & & & & & \\
\hline QS_TR & & & & & & & & & & & & & & 2,176 & & & & & & & \\
\hline SU & & & 1,769 & & & & & & & & & & & & & & & & & & \\
\hline UI & & & 1,769 & & & & & & & & & & & & & & & & & 2,177 & \\
\hline
\end{tabular}


Tabela 51 - Análise de efeito total

Fonte: Elaborado pelo autor

\begin{tabular}{|c|c|c|c|c|c|c|c|c|c|c|c|c|c|c|c|c|c|c|c|c|c|}
\hline & $\mathrm{CO}$ & $\mathrm{EE}$ & II & QD & QD_AC & QD_AT & QD_C & QE & QI & QI_AC & QI_AT & QI_C & QI_F & QS & QS_A & QS_C & QS_F & QS_I & QS_TR & SU & UI \\
\hline $\mathrm{CO}$ & & 0,598 & 0,122 & & & & & & & & & & & & & & & & & 0,071 & 0,238 \\
\hline EE & & & 0,094 & & & & & & & & & & & & & & & & & 0,055 & 0,183 \\
\hline \multicolumn{22}{|l|}{ II } \\
\hline QD & & & 0,023 & & & & & & 0,088 & & & & & & & & & & & 0,038 & 0,018 \\
\hline QD_AC & & & 0,007 & 0,283 & & & & & 0,025 & & & & & & & & & & & 0,011 & 0,005 \\
\hline QD_AT & & & 0,007 & 0,290 & & & & & 0,025 & & & & & & & & & & & 0,011 & 0,005 \\
\hline QD_C & & & 0,008 & 0,347 & & & & & 0,030 & & & & & & & & & & & 0,013 & 0,006 \\
\hline $\mathrm{QE}$ & & & 0,024 & & & & & & 0,091 & & & & & & & & & & & 0,039 & 0,019 \\
\hline QI & & & 0,266 & & & & & & & & & & & & & & & & & 0,431 & 0,206 \\
\hline QI_AC & & & 0,103 & & & & & & 0,388 & & & & & & & & & & & 0,167 & 0,080 \\
\hline QI_AT & & & $-0,007$ & & & & & & $-0,027$ & & & & & & & & & & & $-0,012$ & $-0,005$ \\
\hline QI_C & & & 0,060 & & & & & & 0,226 & & & & & & & & & & & 0,097 & 0,046 \\
\hline QI_F & & & 0,080 & & & & & & 0,300 & & & & & & & & & & & 0,129 & 0,062 \\
\hline QS & & & 0,281 & & & & & & & & & & & & & & & & & 0,277 & 0,420 \\
\hline QS_A & & & 0,055 & & & & & & & & & & & 0,195 & & & & & & 0,054 & 0,082 \\
\hline QS_C & & & 0,067 & & & & & & & & & & & 0,237 & & & & & & 0,065 & 0,100 \\
\hline QS_F & & & 0,057 & & & & & & & & & & & 0,202 & & & & & & 0,056 & 0,085 \\
\hline QS_I & & & 0,046 & & & & & & & & & & & 0,163 & & & & & & 0,045 & 0,068 \\
\hline QS_TR & & & 0,084 & & & & & & & & & & & 0,298 & & & & & & 0,082 & 0,125 \\
\hline su & & & 0,434 & & & & & & & & & & & & & & & & & & \\
\hline UI & & & 0,513 & & & & & & & & & & & & & & & & & 0,299 & \\
\hline
\end{tabular}


Tabela 52- Análise f2

Fonte: Elaborado pelo autor

\begin{tabular}{|c|c|c|c|c|c|c|c|c|c|c|c|c|c|c|c|c|c|c|c|c|c|}
\hline & Co & $\mathrm{EE}$ & II & QD & QD_AC & QD_AT & QD_C & QE & QI & QI_AC & QI_AT & QI_C & QI_F & QS & QS_A & QS_C & QS_F & QS_I & QS_TR & SU & UI \\
\hline $\mathrm{CO}$ & & 0,56 & & & & & & & & & & & & & & & & & & & 0,03 \\
\hline EE & & & & & & & & & & & & & & & & & & & & & 0,05 \\
\hline \multicolumn{22}{|l|}{ II } \\
\hline QD & & & & & & & & & 0,01 & & & & & & & & & & & & \\
\hline QD_AC & & & & 0,11 & & & & & & & & & & & & & & & & & \\
\hline QD_AT & & & & 0,11 & & & & & & & & & & & & & & & & & \\
\hline QD_C & & & & 0,14 & & & & & & & & & & & & & & & & & \\
\hline QE & & & & & & & & & 0,02 & & & & & & & & & & & & \\
\hline QI & & & & & & & & & & & & & & & & & & & & 0,09 & 0,03 \\
\hline QI_AC & & & & & & & & & 0,24 & & & & & & & & & & & & \\
\hline QI_AT & & & & & & & & & 0,00 & & & & & & & & & & & & \\
\hline QI_C & & & & & & & & & 0,10 & & & & & & & & & & & & \\
\hline QI_F & & & & & & & & & 0,20 & & & & & & & & & & & & \\
\hline QS & & & & & & & & & & & & & & & & & & & & 0,01 & 0,13 \\
\hline QS_A & & & & & & & & & & & & & & 0,06 & & & & & & & \\
\hline QS_C & & & & & & & & & & & & & & 0,13 & & & & & & & \\
\hline QS_F & & & & & & & & & & & & & & 0,09 & & & & & & & \\
\hline QS_I & & & & & & & & & & & & & & 0,06 & & & & & & & \\
\hline QS_TR & & & & & & & & & & & & & & 0,15 & & & & & & & \\
\hline SU & & & 0,24 & & & & & & & & & & & & & & & & & & \\
\hline UI & & & 0,19 & & & & & & & & & & & & & & & & & 0,09 & \\
\hline
\end{tabular}

Legenda

$\square$ Forte $\square$ Médio $\square$ Fraco $\square$ Inexistente 